\author{
Marcelo Pires Prado
}

\title{
Estudo comparativo, prospectivo e randomizado do resultado de duas formas de tratamento clínico das lesões ligamentares primárias agudas e graves do tornozelo
}

Tese apresentada à Faculdade de Medicina da Universidade de São Paulo para obtenção do título de Doutor em Ciências

Programa de Ortopedia e Traumatologia

Orientador: Dr. Tulio Diniz Fernandes 


\section{Marcelo Pires Prado}

\section{Estudo comparativo, prospectivo e randomizado do resultado de duas formas de tratamento clínico das lesões ligamentares primárias agudas e graves do tornozelo}

Tese apresentada à Faculdade de Medicina da Universidade de São Paulo para obtenção do título de Doutor em Ciências

Programa de Ortopedia e Traumatologia

Orientador: Dr. Tulio Diniz Fernandes 


\section{Dados Internacionais de Catalogação na Publicação (CIP)}

Preparada pela Biblioteca da

Faculdade de Medicina da Universidade de São Paulo

\section{Creprodução autorizada pelo autor}

Prado, Marcelo Pires

Estudo comparativo, prospectivo e randomizado do resultado de duas formas de tratamento clínico das lesões ligamentares primárias agudas e graves do tornozelo / Marcelo Pires Prado. -- São Paulo, 2013.

Tese(doutorado)--Faculdade de Medicina da Universidade de São Paulo.

Programa de Ortopedia e Traumatologia. Orientador: Túlio Diniz Fernandes.

Descritores: 1.Articulaçôes do tornozelo 2.Ligamentos laterais do tornozelo/lesões 3.Tratamento 4.Tratamento clínico.

USP/FM/DBD-007/13 


\section{DEDICATÓRIA}

Dedico esta tese, como tudo o que faço na minha vida á minha querida esposa e melhor amiga, Ana Paula, e ás minhas filhas Laura e Júlia, as pessoas mais fantásticas que conheço.

Sem a sua companhia nada teria graça. 


\section{AGRADECIMENTOS}

Agradeço pela amizade e companheirismo, apoio e dedicação ao meu amigo, Dr. Alberto Abussamra Moreira Mendes, o melhor sócio que alguém poderia ter.

Ao Dr. Daniel Tassetto Amodio, pela ajuda inestimável na avaliação exaustiva dos ângulos e distâncias realizados por horas a fio nos computadores do HCor e HIAE.

Ao Prof. Dr. Gilberto Luiz Camanho pelo apoio durante o processo de aceitação deste trabalho pela pós graduação do IOT HC FMUSP, pelas orientações constantes, e pelas várias oportunidades oferecidas na minha vida profissional.

Ao Dr. Túlio Diniz Fernandes, pelos ensinamentos nos primórdios da minha carreira como cirurgião de Pé e Tornozelo, e pela orientação neste trabalho, desde seu início.

Ao Sr. Henry Dan Kiymoto, pela análise estatístida dos dados deste trabalho, e pelas orientações tão importantes para que este trabalho tenha chegado ao final.

Aos Drs. Carlos Henrique Longo e Hamilton Picolo Guidorizzi, pelo auxílio na descrição da técnica das imagens radiográficas e de ressonância magnética. 
Esta tese está de acordo com as seguintes normas, em vigor no momento desta publicação:

Referências: adaptado de International Committee of Medical Journals Editors (Vancouver).

Universidade de São Paulo. Faculdade de Medicina. Divisão de Biblioteca e Documentação. Guia de apresentação de dissertações, teses e monografias. Elaborado por Anneliese Carneiro da Cunha, Maria Julia de A. L. Freddi, Maria F. Crestana, Marinalva de Souza Aragão, Suely Campos Cardoso, Valéria Vilhena. 3a ed. São Paulo: Divisão de Biblioteca e Documentação; 2011.

Abreviaturas dos títulos dos periódicos de acordo com List of Journals Indexed in Index Medicus, 1997.

"Nômina Antatômica" - $5^{\mathrm{a}}$ Edição, aprovada no $11^{\circ}$ Congresso Internacional de Anatomia na Cidade do México, 1980. Traduzuda sob supervisão da Comissão de Nomenclatura da Sociedade Brasileira de Anatomia. 


\section{SUMÁRIO}

Lista de abreviaturas

Lista de tabelas

Resumo

Summary

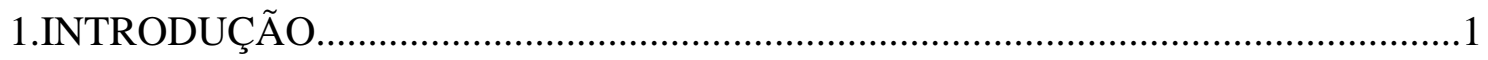

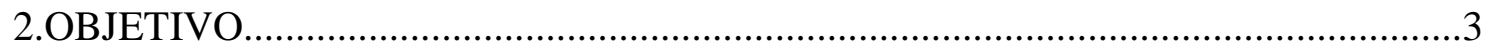

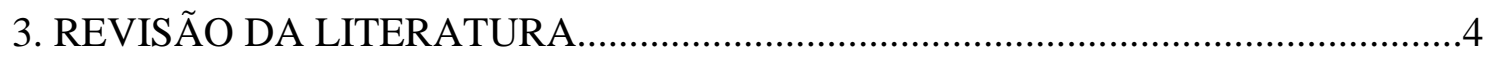

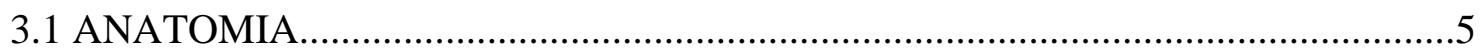

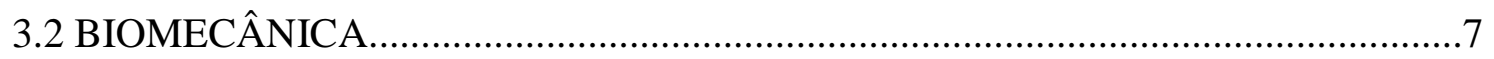

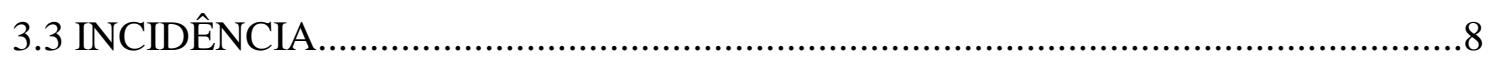

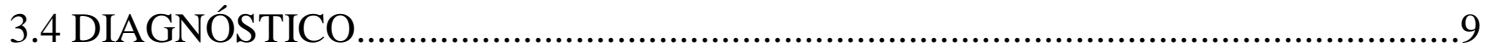

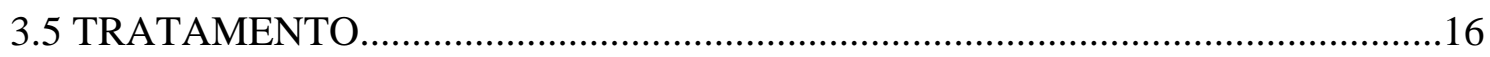

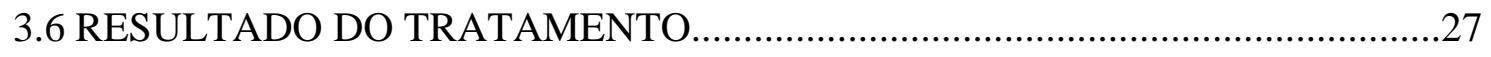

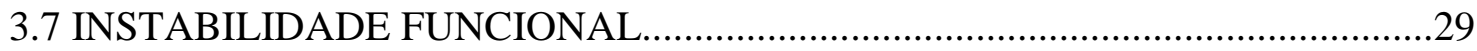

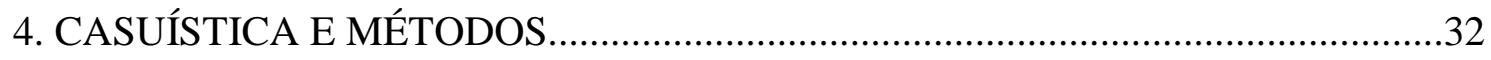

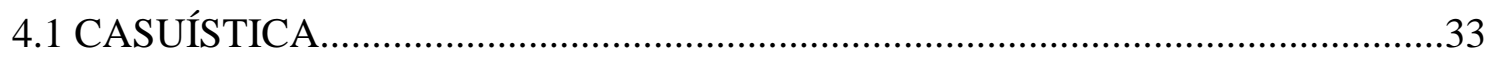

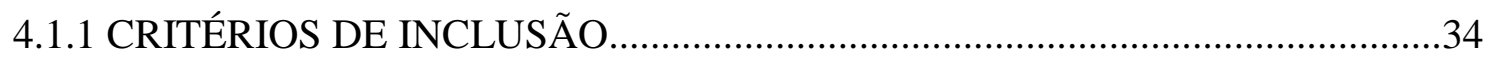

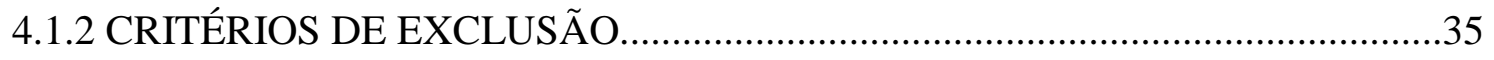

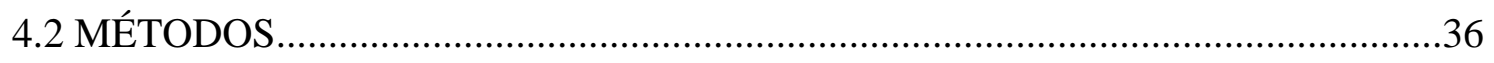

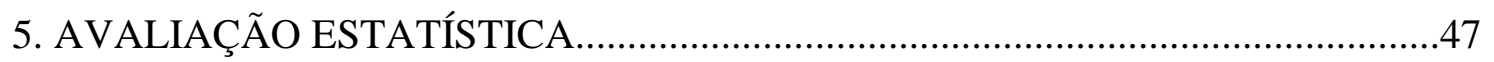

6. ANÁLISE DA CASUÍSTICA E RESULTADOS ...................................................

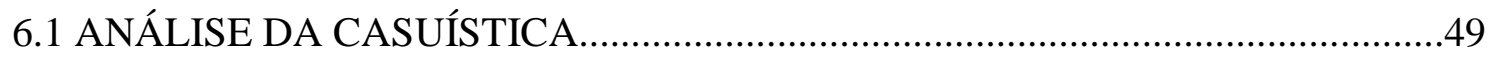

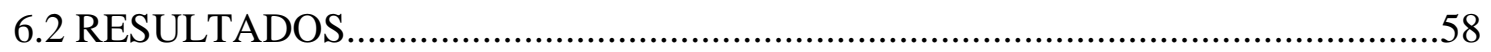

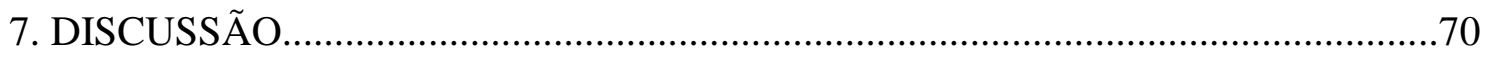

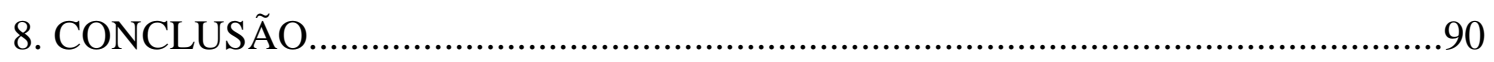

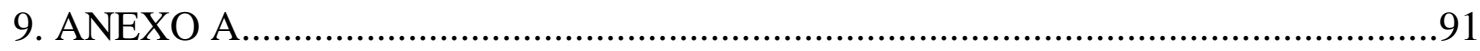

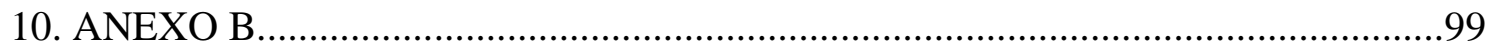

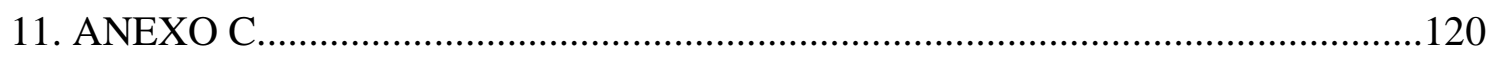

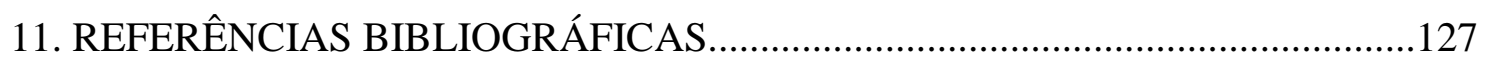




\section{RESUMO}

PRADO,M.P.: Estudo comparativo, prospectivo e randomizado do resultado de duas formas de tratamento clínico das lesões ligamentares primárias agudas e graves do tornozelo, 2013. P. Tese (Doutorado) - Faculdade de Medicina, Universidade de São Paulo.

Objetivo: Este trabalho tem como objetivo a avaliação dos resultados funcionais, e da incidência da instabilidade articular mecânica, resultantes do tratamento clínico das lesões ligamentares primárias, agudas e graves do tornozelo (associada a instabilidade articular). Esta lesão é extremamente frequente e acomete indivíduos jovens, economicamente e fisicamente ativos, causando prejuízos pessoais e econômicos importantes. Existe dificuldade no adequado diagnóstico e heterogeneidade na escolha da melhor forma de tratamento.

Materiais e métodos: Foram incluídos neste estudo 186 pacientes portadores de lesão ligamentar aguda grave do tornozelo. A amostra foi randomizada em dois grupos de tratamento clínico.

Os pacientes incluídos no grupo A foram tratados com uso de imobilização suro podálica imediata (Robofoot $\left.{ }^{\circledR}\right)$, carga permitida conforme tolerado, analgesia, gelo, elevação e mobilização leve da articulação do tornozelo por três semanas. Em seguida foram imobilizados com órtese curta funcional (Aircast ${ }^{\circledR}$ esportivo) por mais três semanas, e encaminhado para programa de reabilitação fisioterápico.

No grupo B os pacientes foram imobilizados no primeiro atendimento com órtese curta funcional (Aircast ${ }^{\circledR}$ esportivo), a carga foi permitida conforme tolerado, analgesia, gelo, elevação e mobilização leve da articulação realizadas por três semanas, e em seguida foram encaminhados para programa de tratamento fisioterápico, como no grupo A.

Os pacientes são avaliados clínica e radiograficamente para determinar a limitação funcional nas diversas fases do processo cicatricial, e a presença de instabilidade residual nos tornozelos.

Resultados: Não encontramos diferença significativa com relação à evolução para instabilidade mecânica entre os grupos. Da mesma forma não houve diferença na incidência 
de dor, mas a avaliação através do método de pontuação da Associação Americana dos Cirurgiões de pé e tornozelo (AOFAS) mostrou melhores resultados nos pacientes submetidos ao tratamento com órtese funcional (grupo B).

Conclusões: O tratamento das lesões ligamentares graves através do uso de órtese funcional tem melhores resultados do que o tratamento com órtese rígida. A incidência de instabilidade crônica foi muito pequena nos dois grupos. 


\section{SUMMARY}

PRADO,M.P.: Comparative, prospective and randomized study of the results after two conservative treatment options for lateral severe first episode of ankle ligament lesions, 2013. P. Tese (Doutorado) - Faculdade de Medicina, Universidade de São Paulo.

Objective: The objective of this study is to investigate functional results and the incidence of mechanical ankle instability, following conservative treatment of the first episode involving severe lateral ankle ligamentar lesions (with articular instability). This common lesion most often affects young, professional and physically active patients, causing serious personal and economic consequences. Adequate diagnosis is challenging and treatment alternatives for these lesions vary considerably.

Methods and cases: 186 patients with severe lateral ankle ligamentar lesions were included in this study. Patients were randomized in two conservative treatment option groups.

In group A, patients were treated with long ankle orthosis (Robofoot $\left.{ }^{\circledR}\right)$, comfortable weight bearing allowed, pain management, ice and elevation with restricted joint mobilization for three weeks. After this, they were placed in a short, functional orthosis (Aircast ${ }^{\circledR}$ ) for an additional three weeks period, with rehabilitation program commencing.

In group $B$, patients were initially immobilized using a functional orthosis (sportive Aircast $\left.{ }^{\circledR}\right)$, and followed the above mentioned sequences for patients in group A.

Patients were clinically and radiographically evaluated to determine the functional deficit in each phase, and the presence of ankle residual instability.

Results: No significant differences were found in relation to the residual mechanical ankle instability between both groups. Additionally no differences were found in pain intensity, however, the functional evaluation using the American Orthopaedic Foot and Ankle Society (AOFAS) ankle and hind foot score system showed better results in the functional orthosis treatment group (group B).

Conclusions: The treatment of severe lateral ankle ligamentar lesions, using functional orthosis, has shown better results over those treated with a rigid orthosis, and both methods presented a very low incidence of residual chronic instability. 



\section{INTRODUÇÃO}

As lesões ligamentares do tornozelo estão entre os motivos mais comuns de atendimento médico nos serviços de emergência e consultórios ortopédicos. Estas lesões se associam aos traumas torcionais desta articulação.

Nos Estados Unidos, ocorre uma entorse para cada 10.000 pessoas ao dia (Baumhauer et al., 1995), resultando em 27.000 ocorrências, o que, totaliza dois milhões de atendimentos nos departamentos de emergência anualmente.

Acomete, com maior frequência, indivíduos jovens, profissionalmente ativos, e envolvidos na prática de atividades físicas regulares, com graves consequências pessoais e econômicas.

O tratamento tem como objetivos, a normalização das funções articulares (mobilidade normal e estabilidade articular) e o retorno mais precoce possível às atividades da vida diária, atividades profissionais e atividades físicas realizadas previamente à ocorrência da lesão.

As lesões ligamentares são classificadas de acordo com sua gravidade em grau I, correspondendo apenas ao estiramento do ligamento acometido, lesões grau II, correspondendo às lesões parciais, sem instabilidade articular, e as lesões completas, classificadas como grau III, quando ocorre prejuízo da estabilidade articular (Mack, 1982). Os casos de lesões ligamentares parciais são de tratamento clínico, com retorno precoce às atividades prévias à lesão. As lesões ligamentares agudas com instabilidade articular (grau III) são o foco do presente estudo, pois a incidência de sintomas residuais e de sensação de instabilidade articular após este tipo de lesão é alta, na literatura. Este fato ainda motiva discussões a respeito da melhor forma de tratamento.

A insuficiência das estruturas ligamentares e o processo de cicatrização destas lesões não têm sido cuidadosamente investigados ou relatados na maioria dos estudos (Hubbard, 2008). A falta de tratamento adequado em metade dos pacientes com instabilidade ligamentar aguda do tornozelo, e o rápido retorno às atividades, podem interferir no processo cicatricial, com consequente maior chance de evolução para instabilidade mecânica crônica, situação na qual a mobilidade articular é anormalmente grande (Smith e Reischl, 1986). 
Apesar da adequada descrição do mecanismo de lesão, exame físico e critérios para o diagnóstico, recente trabalho nacional (Belangero et al., 2010) mostra que os ortopedistas e residentes tem dificuldades no adequado diagnóstico e classificação da lesão ligamentar aguda do tornozelo (apenas 59\% classificam esta lesão com segurança) e que não há consenso quanto ao tratamento ideal, apesar de metanálise de 2007 realizada por Kerkhoffs e colaboradores mostrar resultados mais favoráveis com o tratamento conservador funcional.

Este estudo compara os resultados de duas formas de tratamento clínico das lesões ligamentares agudas graves do tornozelo, através do uso de imobilizador rígido (Robofoot ${ }^{\circledR}$ ) e de imobilizador dinâmico ou funcional (Aircast ${ }^{\circledR}$ esportivo), usando como critérios de comparação a intensidade da dor, limitações funcionais, tempo de afastamento das atividades laborais e evolução para instabilidade articular mecânica crônica.

O objetivo é avaliar a possibilidade do uso da imobilização funcional (que permite mobilidade articular fisiológica) nas fases iniciais do tratamento.

As órteses que são utilizadas com calçados convencionais podem permitir aos pacientes uma melhor função, acelerando o retorno dos pacientes às suas atividades da vida diária e atividades profissionais, o que minora o prejuízo causado por esta lesão extremamente comum.

A uniformização dos métodos de tratamento, com a utilização de órteses comercialmente acessíveis, permite que se realize a comparação dos seus resultados. Na literatura este tópico é falho, visto que existem inúmeros métodos de tratamento para as lesões ligamentares do tornozelo que não são facilmente reprodutíveis.

A expectativa é que os resultados das duas formas de tratamento sejam equivalentes. 


\section{OBJETIVO}

O presente trabalho tem como objetivo comparar os resultados clínicos, funcionais, o tempo de retorno às atividades profissionais, e a instabilidade articular residual após o uso de dois métodos de tratamento clínico das lesões ligamentares agudas graves do tornozelo, em pacientes sem antecedentes de traumas nesta articulação. 
3. REVISÃO DA LITERATURA 


\subsection{ANATOMIA}

Krips (2006) considera a articulação do tornozelo como uma dobradiça simples. É a mais congruente do corpo humano e sua estabilidade é provida pela configuração óssea da pinça maleolar e do domus talar e pelos ligamentos do tornozelo, que se localizam na sua face medial, lateral, e na sindesmose tibiofibuar distal.

O ligamento talofibular anterior (LTFA) é um espessamento da cápsula anterior e lateral da articulação do tornozelo, tem origem na borda anterior da fíbula distal, $1 \mathrm{~cm}$ proximal à extremidade do maléolo lateral, junto à sua cartilagem articular. Sua inserção no tálus começa distalmente à cartilagem articular e seu centro fica a $18 \mathrm{~mm}$ da articulação subtalar. Com o tornozelo em posição neutra forma um ângulo de 75 graus com o solo. Em alguns indivíduos existe uma pequena banda inferior acessória (RASMUSSEN, 1985).

O ligamento calcâneo fibular (LCF) tem origem na borda anterior da fíbula distal, a $8,5 \mathrm{~mm}$ da ponta do maléolo lateral, logo abaixo da origem do LTFA. Dirige-se medialmente, posteriormente e inferiormente para sua inserção no calcâneo, que começa $13 \mathrm{~mm}$ distal à articulação subtalar, cruzando-a perpendicularmente. É um ligamento extra-articular e forma o assoalho da bainha dos tendões fibulares. Mede 20 a $25 \mathrm{~mm}$ de comprimento e seis a oito mm de diâmetro. É maior e mais resistente do que o LTFA. Com o tornozelo na posição neutra forma ângulo de 113 a 150 graus em relação à fíbula (GOLANO ET AL., 2006).

O ligamento tibiofibular posterior (LTFP) é o mais resistente do complexo ligamentar lateral, e tem origem na borda medial do maléolo lateral e cruza medialmente, em posição horizontal para inserir na porção não articular posterior do tálus e sulco para o tendão do músculo flexor longo do hálux, confluindo com a cápsula articular (BURKS E MORGAN, 1994).

Mann, em 1992, define as alterações posturais do pé, que foram levadas em consideração na avaliação clínica dos pacientes deste trabalho. O pé é considerado cavo quando apresenta arco longitudinal elevado, que não sofre aplanamento durante a carga. 
O retropé em varo é definido durante a observação do paciente em posição ortostáica, quando o calcâneo é orientado medialmente, além da posição neutra levando-se em consideração o alinhamento do tendão calcaneano com relação à perna. 


\subsection{BIOMECÂNICA}

Ferkel et al., 1991, afirmam que os ligamentos laterais do tornozelo são os mais comumente afetados na entorse, mormente os LTFA e LCF. Os autores consideram a ressonância magnética, o método de escolha na avaliação das patologias que acometem as partes moles do tornozelo.

A instabilidade do tornozelo ocorre nas lesões isoladas do LTFA e nas lesões associadas deste com o LCF. Em estudo com tornozelos de cadáveres e pacientes com lesão ligamentar observam que a radiografia em perfil do tornozelo com estresse em gaveta anterior evidencia a lesão do LTFA (GLASGOW ET AL., 1980).

Estudos biomecânicos em cadáveres mostra que os LTFA e LCF agem sinergicamente na estabilização do tornozelo. Enquanto o primeiro é isométrico em posição neutra e em flexão plantar do tornozelo, o segundo é solicitado em flexão dorsal (RENSTROM ET AL., 1988).

Jahss, em 1991, afirma que a inversão de um pé supinado causa tensão de todos os ligamentos laterais, e a flexão plantar tensiona o LTFA.

A função das estruturas ligamentares em primatas mostra que, durante os movimentos habituais, os ligamentos não são responsáveis pela estabilização das articulações, não sendo solicitados dentro de amplitudes de movimentos funcionais. A imobilização provoca significativa diminuição da resistência da unidade ligamentar, que não se recupera mesmo após 20 semanas de reabilitação (NOYES ET AL., 1974).

A carga axial no tornozelo aumenta o contato entre as superfícies articulares, aumentando muito a estabilidade rotacional (CAWLEY E FRANCE, 1991). 


\subsection{INCIDÊNCIA}

As lesões do tornozelo e do pé são as lesões mais comuns (25\%) associadas à prática esportiva (das 19 modalidades mais praticadas) e às atividades recreacionais. As entorses correspondem a 75\% destes traumas (GARRICK, 1977).

Em 180 jogadores de futebol avaliados por um ano, 29\% de todas as lesões que acometem a extremidade inferior destes atletas são entorses do tornozelo. Esta lesão também é a mais comum na dança moderna e no balé clássico, e corresponde a 54\% das lesões no basquete (EKSTRAND, 1983).

A trauma em inversão do tornozelo é a lesão traumática mais comum nos dançarinos (KADEL, 2006).

As únicas alterações relacionadas a uma maior incidência de entorses do tornozelo são: o pé cavo varo, arco longitudinal medial elevado, aumento da largura do pé e maior amplitude de eversão do calcâneo (nas mulheres) (MORRISON E KAMINSKI,2007).

Neste trabalho com voluntários em laboratório de biomecânica os autores identificam a presença de relação entre o uso de salto alto e a maior chance de ocorrer entorse em inversão do tornozelo (FOSTER ET AL., 2012).

Rosner, 2010 e Triola, 2011 descrevem os testes estatísticos utilizados na avaliação dos resultados deste trabalho. 


\subsection{DIAGNÓSTICO}

A história clínica e o exame físico cuidadoso permitem a adequada avaliação e diagnóstico das entorses do tornozelo. A incidência de lesões da cartilagem do domus talar nos pacientes com lesão ligamentar aguda é de 66,7\% (VAN DIJK ET AL., 1996 a).

O diagnóstico das lesões ligamentares do tornozelo é eminentemente clínico, baseado na história e no exame físico, e seu tratamento inicialmente é conservador (WATSON, 2007).

O exame físico, realizado por cirurgião experiente, permite a adequada avaliação clínica da estabilidade do tornozelo, mesmo quando o exame é realizado próximo ao momento do trauma (KLENERMAN, 1998).

Em 15 pacientes com sinais de lesão ligamentar aguda do tornozelo grau II e III há correlação de $100 \%$ entre o exame físico e a presença de lesões tipo III, que cursam com instabilidade articular (FREY ET AL., 1996).

As alterações no exame físico permitem o diagnóstico de aproximadamente dois terços $(68,2 \%)$ das lesões ligamentares agudas do tornozelo (RAATIKAINEN ET AL., 1992).

A dor nas primeiras horas após a lesão ligamentar do tornozelo é localizada, mas logo se torna difusa, e depois de alguns dias, o exame físico volta a ser mais específico. $52 \%$ dos pacientes com dor sobre o LTFA tem acometimento deste, e $72 \%$ dos pacientes com dor na topografia da inserção do LCF tem ruptura deste (FUNDER ET AL., 1982).

O exame clínico, com localização da área de maior dor e o teste da gaveta anterior, permite a avaliação da estabilidade da articulação do tornozelo mesmo quando realizado logo após o trauma. É realizado com o joelho fletido 90 graus e o tornozelo em posição neutra, uma mão é posicionada na tíbia distal e a palma da outra no calcanhar. Aplica-se pressão em direções opostas. O deslocamento anterior do tálus pode ser visualizado, sentido e palpado pelo examinador (TREVINO ET AL., 1994). 
O teste de gaveta anterior do tornozelo é normalmente realizado com uma mão estabilizando a tíbia distal e a outra mão puxando o pé anteriormente. A presença de dor, percepção de subluxação e o sinal da sucção (depressão da pele na face anterolateral do tornozelo no momento do teste) são descritos como achados positivos (CLANTON E McGARVEY, 2007).

A avaliação manual da gaveta anterior após 48hs do trauma, em 160 pacientes, permite um diagnóstico adequado da gravidade da lesão, com especificidade e sensibilidade de $84 \%$ e $96 \%$, respectivamente. O teste da gaveta anterior é realizado com o paciente sentado relaxadamente com o joelho fletido a 90 graus e tornozelo com flexão plantar de 10 a 15 graus (VAN DIJK ET AL., 1996 b).

Os testes de estresse manual não são sensíveis o suficiente na determinação dos ligamentos envolvidos na instabilidade da articulação do tornozelo, porém permitem identificar a instabilidade (FUJII ET AL., 2000).

O teste da gaveta anterior manual é útil para a avaliação da estabilidade mecânica da articulação do tornozelo e, portanto para a indicação do tratamento específico (KERKHOFFS ET AL., 2007).

Em 159 indivíduos portadores de instabilidade crônica do tornozelo $42 \%$ tinham teste da gaveta anterior positivo. A instabilidade mecânica do tornozelo se relaciona com o aumento da mobilidade desta articulação (TROPP ET ALL., 1985).

Estudo prospectivo, com 145 atletas, mostra correlação da entorse do tornozelo com alteração do equilíbrio muscular e com aumento da relação de força entre inversores e eversores e diminuição da relação entre flexores dorsais e flexores plantares. O teste da gaveta anterior em estresse é preditivo para instabilidade mecânica do tornozelo (BAUMHAUER ET AL., 1995).

Johannsen, em 1978, observa 244 pacientes e afirma que o teste da gaveta anterior e o teste da inclinação talar são úteis para o diagnóstico da lesão ligamentar, porém um não 
substitui o outro, sendo, portanto, complementares no diagnóstico, porém não permitem afirmar se a lesão é isolada do LTFA, ou associada com lesão do LCF.

A classificação anatômica divide as lesões ligamentares do tornozelo em: grau I corresponde a lesões leves, sem lesão ligamentar completa, apenas estiramento; o grau II, moderado, corresponde à lesão do LTFA, com LCF íntegro; o grau III, grave, apresenta lesões dos dois ligamentos e clinicamente apresentam maior dor, edema e equimose, normalmente com dificuldade em apoiar o peso no pé acometido (HAMILTON, 1982).

As entorses do tornozelo correspondem a $25 \%$ de todas as lesões relacionadas a atividades esportivas de salto e corrida. As manobras de mudança de direção e de drible envolvem deslocamento lateral, que resulta em solicitação das estruturas laterais do tornozelo. Uma vez que a inversão tem início, o tornozelo perde relativamente sua estabilidade óssea, maior lateralmente, e o maléolo medial age como um fulcro aumentando o momento de inversão. A presença de dor intensa, incapacidade para o apoio, e sensação de estalido indicam possibilidade de lesão mais grave. A lesão grau I é pouco importante, parcial, com a articulação estável; a lesão grau II, lesão intermediária, com a articulação ainda estável; a lesão grau III corresponde à lesão acompanhada de instabilidade mecânica da articulação. O imobilizador ajustável com coxim de ar é o ideal para a imobilização do tornozelo lesado, pois pode ser retensionado de acordo com o edema, e ser usado com calçado convencional, permitindo marcha quase normal, com retorno mais rápido às atividades da vida diária e esportivas. (MACK, 1982).

A classificação clínica das lesões ligamentares agudas do tornozelo é importante. As radiografias em estresse e ultra sonografias não são necessárias para o diagnóstico. O tratamento funcional é suficiente, não se relacionando a aumento da incidência de instabilidade objetiva ou subjetiva, e nem a um maior número de recidivas. Apesar de não haver estudos controlados sobre o tratamento destas lesões nos atletas não há razão para tratá-los de forma diferente (TILING ET AL., 1994).

A escala visual analógica (EVA) de dor varia de zero (nenhuma dor) até 10 (pior dor possível), e permite que a quantificação da intensidade da dor seja realizada pelo próprio paciente (PRICE ET AL., 1983). 
Gatchel et al., em 2010, discorrem a respeito da menor diferença necessária para se conferir variações clínicas na avaliação da dor, através da escala visual analógica de dor, e concluem que apenas diferenças acima de dois significam uma diferente percepção da dor pelos pacientes.

A Associação Americana de Cirurgiões de Pé e Tornozelo (AOFAS) propõe uma escala de pontuação (dor e função) para avaliação do resultado de tratamento para o retropé e tornozelo, médio pé, hálux e dedos laterais (KITAOKA ET AL., 1994).

A escala AOFAS para avaliação clínica é instrumento comprovadamente útil na formulação de conclusões válidas com relação às questões relacionadas à qualidade de vida associadas às patologias do pé e do tornozelo (IBRAHIM ET AL., 2006).

A presença de frouxidão ligamentar generalizada deve ser pesquisada através dos seguintes sinais: extensão passiva dos dedos das mãos além de $90^{\circ}$, aposição do polegar à face flexora do respectivo antebraço, hiperextensão dos cotovelos além de $10^{\circ}$, hiperextensão dos joelhos além de $10^{\circ}$ e flexão do tronco com os joelhos completamente estendidos de modo que as palmas das mãos repousem no solo (BEINGHTON E HORAN, 1969).

Neste trabalho com 106 indivíduos portadores de lesão ligamentar grave do tornozelo Black et al, em 1978, mostram que as lesões do LTFA são de diagnóstico clínico, e que as radiografias com estresse podem auxiliar na identificação da instabilidade anterior.

As lesões que mais frequentemente permanecem sem diagnóstico inicial nos casos de entorses do pé e tornozelo são as fraturas osteocondrais do domus talar, as fraturas do processo lateral do tálus, fraturas do tubérculo medial ou lateral do processo posterior do tálus, fraturas da tuberosidade anterior do calcâneo e lesões do ligamento bifurcado. O exame físico cuidadoso no momento do trauma pode auxiliar no diagnóstico destas patologias traumáticas, fato importante, pois, em alguns casos, o tratamento específico é necessário (JUDD E KIM, 2002). 
As regras que devem ser seguidas para se determinar a necessidade de investigação radiográfica dos traumas agudos do tornozelo são conhecidas como regras de Ottawa. A presença de dor à palpação dos maléolos, na base do quinto osso metatarsal, dor à palpação do navicular, acompanhados de incapacidade para o apoio imediatamente ou pouco após a lesão (incapacidade de caminhar quatro passos) indicam a necessidade de investigação radiográfica. Quando indicada, deve-se realizar as incidências de antero posterior, lateral e oblíqua com rotação interna de 15 graus do tornozelo. A radiografia com estresse não é indicada, pois não muda o protocolo de tratamento, já que o tratamento da lesão ligamentar isolada é conservador (STIELL ET AL., 1992).

A translação anterior do tálus dentro da pinça maleolar é o comprimento de uma linha que parte da borda mais posterior da superfície articular distal da tíbia e incide perpendicularmente no domus talar adjacente na radiografia em perfil com estresse em gaveta anterior. A pequena variabilidade entre os lados faz com que o lado contralateral sirva como comparativo ideal, e não há diferença entre a avaliação radiográfica utilizando estresse manual, comparada à realizada através de aparato de realização de estresse (LAURIN E MATHIEU, 1975).

As medidas realizadas através das radiografias com estresse são consideradas como o padrão ouro no diagnóstico das instabilidades ou frouxidão do tornozelo, neste trabalho com 120 pacientes portadores de instabilidade funcional (KARLSSON ET AL., 1991).

O teste da gaveta anterior tem alta especificidade no diagnóstico da instabilidade lateral do tornozelo nas lesões ligamentares. O valor que estabelece o diagnóstico da lesão ligamentar é uma diferença na translação anterior do tálus maior do que $3 \mathrm{~mm}$, nas radiografias com estresse manual. Os exames baseados na utilização de instrumentos falham em demonstrar reprodutibilidade na determinação da instabilidade da articulação do tornozelo, e por isso a radiografia com estresse manual continua sendo utilizado mais comumente para este fim (PHISITKUL ET AL., 2009).

A variação nos resultados dos valores do estresse em inversão é grande, bem como a variabilidade nos resultados entre lado direito e esquerdo em indivíduos normais. O teste da 
gaveta anterior, ao contrário, é útil na avaliação da estabilidade ligamentar lateral do tornozelo, pois apresenta pequena variabilidade entre os lados (não maior do que três mm), nos tornozelos funcionalmente normais (SELIGSON ET AL., 1980).

A assimetria existente entre os tornozelos do mesmo indivíduo é pequena e o exame comparativo é eficiente. Não há diferença entre a capacidade de detecção da mobilidade da articulação do tornozelo nas radiografias com estresse manual ou realizadas com aparatos comercialmente disponíveis para este tipo de teste, como o Telos (Telos, HungenObbornhofen, Germany) (SAUSER ET AL., 1983).

Os autores consideram necessárias diferenças acima de 5 graus, nas radiografias com estresse em varo do tornozelo, ou maior que $5 \mathrm{~mm}$ nas radiografias com estresse em gaveta anterior, comparativamente ao lado normal, para se estabelecer o diagnóstico de instabilidade articular no tornozelo (CASS ET AL, 1985).

Deslocamentos anteriores, com diferença de até $5 \mathrm{~mm}$ com relação ao lado normal, nas radiografias com estresse em gaveta anterior do tornozelo, e inclinações de até 5 graus acima do lado normal, nas radiografias com estresse em varo comparativas do tornozelo são considerados normais (MARDER, 1994).

As radiografias em estresse manual do tornozelo são utilizadas para determinar a presença de instabilidade desta articulação. As lesões isoladas do LTFA causam instabilidade da mesma forma que as associadas com o LCF (OKUDA ET AL., 1999).

O teste de inclinação talar deve ser considerado positivo quando a diferença entre o lado acometido e o normal é maior do que cinco a 15 graus. Safran et al., em 1999 afirmam também que o controle do edema acelera o processo cicatricial.

Quatro a $5 \%$ dos indivíduos normais apresentam frouxidão ligamentar generalizada, porém este fato não aumenta, segundo este estudo, a chance de ocorrerem episódios de lesao ligamentar do tornozelo (PACEY, 2010). 
A ressonância magnética confirma a lesão ligamentar lateral do tornozelo, porém, não é necessária para o adequado diagnóstico, sendo o exame físico suficiente. A correlação entre a presença de lesão ligamentar grave e exame físico positivo ocorre em 100\% das vezes (DE SIMONI ET AL., 1996).

A ressonância magnética permite a adequada avaliação das estruturas ligamentares do tornozelo e estruturas periarticulares. $\mathrm{O}$ entendimento da anatomia e das alterações associadas aos traumas do tornozelo é importante para a adequada análise das imagens do tornozelo traumatizado (CAMPBELL, 2006).

Landis e Kock (1977) descrevem os cálculos para avaliação da correlação inter e intra-observadores dos dados colhidos nos resultados. 


\subsection{TRATAMENTO}

Um estudo experimental em gatos demonstra que a falha provocada pela lesão ligamentar é preenchida por coágulo, que logo é invadido por proliferação celular do tecido conectivo frouxo da região, que forma um tecido de granulação inicial, com aumento da vascularização dos cotos do ligamento. Após quatro dias da lesão tem início a formação de novas fibras de colágeno que, juntamente com as células que migram dos cotos da lesão, preenchem o defeito. Após duas semanas o tecido de granulação começa a ser substituído por fibras de colágeno imaturo em continuidade com as fibras do ligamento lesado. Após três semanas o número de células e vasos diminui, enquanto as fibras de colágeno aumentam de tamanho e resistência, e são depositadas em feixes. Após seis semanas não há mais diferença na resistência tênsil entre ligamentos suturados e os não suturados. Com sete semanas a aparência geral do ligamento já é a mesma, exceto pelo espessamento do local da lesão. (CLAYTON ET AL., 1968).

A resistência dos tendões lesados retorna a níveis aceitáveis após três semanas da reparação. As fases do processo cicatricial são: fase inicial de exsudação e união fibrosa (rápida diminuição da resistência tênsil, que dura aproximadamente cinco dias), fase de fibroplasia (aumento da resistência até formar um platô próximo do $16^{\circ}$ dia), e fase de maturação e organização diferenciada (aumento gradual e lento da resistência tendínea) (MASON E ALLEN, 1941).

Cks-Little, em 2002 afirmam que as propriedades mecânicas dos ligamentos não retornam ao normal antes da sexta semana após a lesão.

Este estudo in vitro sugere que os fibroblastos rapidamente alteram sua morfologia em resposta ao alongamento regular, melhorando a expressão dos genes relacionados com as vias de transdução mecânica (vimentina e actina), facilitando desta forma o processo cicatricial dos ligamentos lesados (KANEKO ET AL., 2009).

Estudo com residentes de ortopedia e traumatologia e ortopedistas brasileiros, observam que existe dificuldade no diagnóstico e classificação das lesões ligamentares 
laterais agudas do tornozelo, e que não há consenso quanto à melhor opção de tratamento das lesões graves (BELANGERO ET AL., 2010).

Comparação da eficiencia do tratamento com mobilização precoce com a imobilização usando gesso por seis semanas e o tratamento cirúrgico, realizado por Freeman em 1965a com 45 pacientes, mostra que o tratamento conservador com mobilização alcalça o melhor resultado quanto à disfunção precoce, não há maior incidência de instabilidade crônica, e o tratamento cirúrgico tem os piores resultados à longo prazo. Recomenda que o tratamento com mobilização precoce limitado pela dor seja indicado para todos os pacientes com lesão ligamentar aguda isolada do tornozelo, independente da gravidade da lesão.

Os resultados do tratamento cirúrgico de lesões ligamentares agudas do tornozelo através de sutura dos ligamentos lesados (107 pacientes), comparados aos do tratamento conservador através de imobilização com gesso, mostra não haver diferença estatisticamente relevante quanto à tendência de ocorrência de nova lesão, presença de dor, instabilidade do tornozelo, sensação de instabilidade, ou resultado clínico após um ano da lesão. No entanto, no grupo tratado cirurgicamente houve $4 \%$ de infecções pós-operatórias superficiais, $7 \%$ de disestesia ao redor da cicatriz, e $9 \%$ de sensação de choque na cicatriz. Concluem que não há vantagem de tratar cirurgicamente mesmo os atletas (NIEDERMANN ET ALL., 1981).

Cem pacientes com lesão ligamentar do tornozelo, são randomicamente tratados através de imobilização com gesso ou cirurgicamente, por Evans et al., 1984. O tratamento cirúrgico se associou a um número maior de complicações na primeira semana e retardo para o retorno às atividades profissionais. Na reavaliação após dois anos do tratamento não houve evidência de que o tratamento cirúrgico ofereceu melhora nos sintomas ou benefícios funcionais.

Moller-Larsen et al., em 1988 avaliam os resultados do tratamento das lesões ligamentares do tornozelo (LTFA isolado ou associado com o LCF) em 200 pacientes divididos em três grupos: tratamento cirúrgico seguido por imobilização gessada por cinco 
semanas, tratamento conservador através de imobilização gessada por cinco semanas, e tratamento conservador com uso de bandagem inelástica por cinco semanas. Os melhores resultados ocorrem nos pacientes do último grupo (menor incidência de rigidez e menor número de complicações, além de maior chance de retorno às atividades realizadas antes da lesão). O tratamento destas lesões tem excelente resultados, independente da mobilidade realizada, ou do número de ligamentos acometidos.

Três tipos de tratamento para as lesões ligamentares agudas graves do tornozelo são comparados (tratamento cirúrgico e gesso por cinco semanas, gesso por cinco semanas, e bandagem elástica) com resultados equivalentes. O tratamento clínico é considerado suficiente (MUNK ET AL., 1995).

Os pacientes tratados conservadoramente retornam ao trabalho mais rápidamente que os pacientes operados, sem haver diferença quanto à frouxidão articular até dois anos após a lesão. O único grupo para o qual o tratamento cirúrgico pode ser considerado são as bailarinas de alto desempenho, devido à alta demanda de solicitação mecânica de seus tornozelos (POVACZ ET AL., 1998).

Nesta revisão da literatura sobre o tema, 12 trabalhos prospectivos randomizados com seguimento de seis meses a 3,8 anos comparando tratamento cirúrgico precoce com imobilização gessada e mobilização precoce controlada, notam que o retorno ao trabalho ocorreu duas a quatro vezes mais rapidamente no grupo mobilizado precocemente. Não há diferença com relação à dor, edema, sensação de rigidez durante a atividade, ou instabilidade funcional crônica. Mesmo atletas com estas lesões devem ser tratados conservadoramente (KANNUS E RENSTROM, 1991).

Neste estudo prospectivo, Kaikkonen et al. (1996) comparam o tratamento cirúrgico com o tratamento funcional das lesões ligamentares graves do tornozelo em 60 pacientes. A mobilidade dos casos operados permaneceu limitada até o sexto mês de pós-operatório, e os resultados foram excelentes e bons em $87 \%$ dos pacientes tratados funcionalmente, em comparação aos $60 \%$ dos tratados cirurgicamente, mostrando que o tratamento funcional é superior. 
O tratamento inicial das lesões ligamentares do tornozelo deve ser conservador, pois os resultados são satisfatórios em $80 \%$ dos pacientes. Os valores normais para o teste de inclinação talar, na avaliação da integridade do ligamento calcâneo fibular, variam entre cinco e 23 graus e, tendo em vista esta variabilidade entre os indivíduos, deve ser realizado comparativamente ao lado normal (COX, 1985).

As lesões ligamentares Grau III do tornozelo apresentam bons resultados com o tratamento conservador. O diagnóstico radiográfico com estresse não é reprodutível porque existe uma variação de até 25 graus no ângulo de inclinação do tálus, e diferenças de até 19 graus de um lado para o outro na população normal. O tratamento conservador de 24 atletas com lesão ligamentar aguda do tornozelo foi eficiente em 79,5\% dos casos (DREZ ET AL., 1982).

O tratamento das entorses do tornozelo com imobilização gessada se associa a grande morbidade. Há pouca ou nenhuma correlação entre a instabilidade funcional e a instabilidade mecânica da articulação do tornozelo (STAPLES, 1972).

O tecido ligamentar passa a um estado catabólico e degenerativo após período de imobilização. Isso pode ser interpretado como um estímulo ao uso de tratamentos funcionais ao invés das imobilizações rígidas para as lesões ligamentares (GAMBLE ET AL., 1984).

Em estudo randomizado realizado por Klein et al., 1991, o tratamento funcional é comparado à imobilização gessada para as lesões ligamentares agudas do tornozelo. Afirmam que a imobilização promove proteção, diminui o edema, e minimiza a dor, no entanto, carrega consigo a desvantagem de provocar atrofia muscular, diminuir a massa total de colágeno nos ligamentos do tornozelo, alterando suas propriedades estruturais e macânicas.

A fase inicial do tratamento conservador baseado no princípio PRICE (proteção, repouso, gelo) em indivíduos com lesão ligamentar lateral do tornozelo permite que o paciente retorne mais rapidamente às atividades físicas (HOCUTT ET AL., 1982). 
O tratamento precoce não só é crucial para promover a recuperação rápida dos sintomas agudos, como também para limitar os sintomas crônicos da lesão. A incidência de sintomas residuais em dois anos é de $74 \%$. O tratamento apropriado se associa com melhores resultados (ANANDACOOMARASAMY E BARNSLEY, 2005).

A recuperação funcional é rápida após tratamento com gelo, compressão e mobilização precoce, sob orientação e controle fisioterápico (105 pacientes com lesão ligamentar aguda do tornozelo). A estrutura do arco longitudinal medial não se correlaciona com a ocorrência das entorses (JACKSON ET AL., 1974).

O tratamento inicial, através do repouso, gelo, compressão e elevação, permite o controle da hemorragia local, do edema, e do processo inflamatório, facilitando o processo cicatricial (JARVINEN, 1993).

Pacientes com entorse do tornozelo que receberam tratamento fisioterápico com preocupação de restaurar a propriocepção tem chance de reincidência de $25 \%$ comparada a $54 \%$ no grupo controle (WESTER ET AL., 1996).

Em 92 pacientes com entorse do tornozelo, o tratamento convencional sem fisioterapia supervisionada (grupo controle), comparado a grupo de pacientes que receberam treino de equilíbrio, o índice de reincidência foi $29 \%$ e $7 \%$ respectivamente, um ano após a lesão. Houve melhor controle muscular e postural nos pacientes submetidos à reabilitação supervisionada, porém estes parâmetros se igualaram após quatro meses (HOLME ET AL., 1999).

A condução inicial das lesões ligamentares agudas do tornozelo inclui repouso, gelo e elevação do membro afetado. O tratamento funcional permite recuperação e retorno mais rápido às atividades profissionais, sem comprometer a estabilidade lateral do tornozelo. $\mathrm{O}$ tratamento cirúrgico desta lesão é indicado para os pacientes com recorrência da lesão, mesmo após a realização de reabilitação adequada (POPOVIC, 2005). 
Neste trabalho, envolvendo o departamento de emergência de oito hospitais no Reino Unido, 584 pacientes com mais do que 16 anos de idade foram randomizados em quatro grupos de tratamento conservador: bandagem tubular, gesso suro podálico e dois tipos de órtese (Aircast ${ }^{\circledR}$ ou "bota de Bladsoe"). A imobilização gessada foi superior aos demais no controle da dor, porém não houve diferença nos resultados finais. Do ponto de vista financeiro houve superioridade da imobilização gessada e do Aircast ${ }^{\circledR}$ sobre os outros (COOKE ET ALL. 2009).

Os mecanoreceptores tipo II (responsáveis pela percepção do início do movimento articular) e tipo III (responsáveis pela percepção dos extremos da mobilidade articular) são comuns nos ligamentos do tornozelo. Estes achados são a base neuroanatômica para o entendimento da necessidade de exercícios de propriocepção na reabilitação após as lesões ligamentares do tornozelo. (MICHELSON E HUTCHINS, 1995).

Seto e Brewster (1994) descrevem detalhadamente as fases do processo de reabilitação no tratamento conservador funcional para os casos de lesão ligamentar aguda do tornozelo.

A mobilização precoce, associada à proteção de uma órtese gessada (confeccionada pelos autores), alcança resultados funcionais equivalentes aos do tratamento conservador com imobilização rígida, com a vantagem de permitir recuperação mais precoce (HENNING E EGGE, 1977).

As órteses para proteção do tornozelo permitem flexão parcial, enquanto limitam a inversão, e podem ser usadas com calçados esportivos convencionais. As lesões ligamentares do tornozelo são a indicação primária de tratamento com este tipo de imobilizador (STOVER, 1980).

Trabalho com 80 pacientes com entorse grau III do tornozelo, Konradsen et al., 1991, demonstram que a mobilização precoce acelera o retorno da mobilidade normal da articulação, e o retorno às atividades profissionais e esportivas, quando comparada à 
imobilização rígida. Não há diferença na estabilidade do tornozelo após um ano do tratamento.

No tratamento do primeiro episódio de lesão ligamentar aguda do tornozelo de 82 pacientes, a imobilização (gesso por 10 dias), comparada com mobilização precoce (esparadrapagem elástica durante 2 dias seguida por ortese por 8 dias), tem capacidade semelhante de prevenir sintomas residuais e sensação de instabilidade. O grupo submetido à mobilização precoce apresenta melhor mobilidade articular e capacidade para o apoio, e retorno mais rápido ao trabalho, e o grupo submetido à imobilização teve mais dor nas avaliações de três e seis semanas, relacionadas à maior rigidez articular e atrofia muscular. A mobilização precoce, combinada com um programa de reabilitação previne sequelas a longo prazo, e resulta em excelente estabilização mecânica do tornozelo. Sintomas residuais ocorrem em $5 \%$ dos pacientes em um ano, e chance de nova lesão é de $8 \%$ (EIFF ET AL., 1994).

Nesta revisão sistemática da literatura, incluindo 84 estudos, somando 32025 pacientes, Ogilvie-Harris e Gilbart, 1995, observam que, o tratamento funcional com mobilização ativa nas lesões ligamentares agudas do tornozelo (sem referências quanto à gravidade) tem resultados satisfatórios.

Pacientes com entorses grau III são tratados inicialmente com gelo, elevação e compressão, e em seguida, submetidos à imobilização com órtese suropodálica por três semanas, seguida pela mobilização funcional curta por adicionais três semanas. Na terceira semana tem início o processo de reabilitação (SHRIER, 1995).

Em 86 pacientes portadores de lesão ligamentar aguda grave do tornozelo tipo II e III, distribuídos randomicamente em dois grupos de tratamento (pacientes imobilizados com ortese funcional, permitido apoio imediato, e o outro grupo mantendo os pacientes em repouso por uma semana), não ocorre diferença no resultado final, porém o tempo de afastamento das atividades profissionais e físicas é menor no grupo tratado funcionalmente (KARLSSON ET AL., 1996). 
O tratamento funcional da lesão ligamentar grave do tornozelo traz rápida recuperação da mobilidade articular, retorno mais rápido ao trabalho e atividades físicas, sem afetar a estabilidade mecânica. A reparação cirúrgica secundária, mesmo anos após o trauma tem resultados semelhantes à reparação ligamentar aguda. Mesmo atletas profissionais devem ser inicialmente tratados conservadoramente com reabilitação precoce, e, se houver instabilidade mecânica residual, submetidos ao procedimento de reconstrução ligamentar lateral do tornozelo (LYNCH, RENSTROM, 1999).

O tratamento funcional das lesões ligamentares agudas do tornozelo parece ser o mais apropriado e deve ser encorajado (metanálise com 22 trabalhos), pois apresenta melhores resultados quanto a retorno para atividade profissional e esportiva, presença de edema e dor, instabilidade objetiva através de $\mathrm{Rx}$ com estresse, mobilidade articular e satisfação do paciente (KERKHOFFS ET AL., 2001).

O resultado do tratamento da lesão ligamentar grave do tornozelo é estudado em 121 pacientes distribuídos randomicamente em grupos tratados com imobilização gessada ou tratados funcionalmente (com mobilização controlada). Não há diferença na incidência de recidivas em 12 meses, porém o grupo tratado funcionalmente retornou mais precocemente à atividade física, e com menor incidência de frouxidão articular. Para tal avaliação utilizam radiografias em estresse manual (ARDÉVOL ET AL., 2002).

O tratamento funcional precoce parece ser mais favorável do que a imobilização rígida (mais pacientes retornaram às atividades esportivas, e o retorno às atividades profissionais e esportivas é mais rápido, com menor incidência de edema e dor após o tratamento, e maior satisfação com o tratamento), nesta metanálise que inclui 21 trabalhos. Estes resultados não são claros, pela qualidade dos trabalhos incluídos, e pelo pequeno seguimento destes, além do fato de não contemplarem a incidência de recorrência das lesões (KERKHOFFS ET AL., 2002a).

O tratamento conservador funcional das lesões ligamentares agudas do tornozelo é considerado o de escolha por Weber e Maleski, 2002. 
A comparação entre o tratamento das lesões ligamentares grau III através de órteses curtas tipo Aircast ${ }^{\circledR}$ ou imobilização gessada por 10 dias seguida de uso de órtese não mostra diferenças quanto à frequência de novas entorses, mobilidade articular do tornozelo e função. O tratamento funcional promove rápida recuperação da mobilidade, rápido retorno às atividades profissionais e físicas, sem comprometer a estabilidade mecânica da articulação, após completa cicatrização. (BEYNNON ET AL., 2006).

Nesta metanálise, incluindo nove trabalhos, o tratamento conservador funcional precoce das entorses do tornozelo permite retorno mais rápido aos níveis de atividade realizados antes do trauma, não havendo, no entanto, separação destes resultados de acordo com a gravidade da lesão (JONES E AMENDOLA, 2007).

Esta outra metanálise, incluindo 892 pacientes, compara a eficiência das diversas formas de tratamento funcional das lesões ligamentares do tornozelo e mostra que os imobilizadores funcionais são mais eficientes no controle do edema e da dor, e não apresentam complicações como as esparadrapagens (irritação da pele) e bandagens elásticas. A incidência de instabilidade como queixa, também é menor com este tipo de tratamento (KERKHOFFS ET AL., 2002b).

Em metanálise incluindo nove trabalhos e 2184 pacientes, comparam diversas formas de tratamento funcional para as lesões ligamentares graves do tornozelo, havendo superioridade das órteses funcionais, porém sem dados suficientes para se definir condutas (KERKHOFFS ET AL., 2003).

Nesta revisão da literatura, a respeito das diferenças entre as formas de tratamento conservador das entorses do tornozelo, Kemler et al., 2011, avaliam 8 trabalhos e afirmam que apenas poucos estudos evidenciam melhores resultados com o uso de órteses, comparados a outros métodos funcionais (como por exemplo a esparadrapagem), em termos de evolução funcional e do ponto de vista econômico. 
As entorses do tornozelo são tratadas conservadoramente, através de reabilitação funcional, com bons resultados em $80 \%$ a $85 \%$ das vezes, e geralmente o tratamento cirúrgico é reservado para os casos de instabilidade recorrente ou recidiva da lesão (BAUMHAUER E O’BRIEN, 2002).

DiGiovanni et al., 2000 afirmam que nos casos de suspeita de lesões associadas é necessário a avaliação com ressonância magnética. $O$ tratamento conservador com mobilização precoce controlada se relaciona com recuperação mais rápida, retorno precoce às atividades profissionais e esportivas, sem comprometer a estabilidade lateral do tornozelo.

O tratamento das lesões ligamentares agudas do tornozelo é conservador. O tratamento cirúrgico deve ser considerado apenas quando o tratamento conservador (incluindo a reabilitação) estiver terminado, caso o paciente continue a apresentar múltiplos episódios de entorses, e com instabilidade mecânica documentada através de radiografias em estresse (HOCKENBURY E SAMMARCO, 2001).

Em estudo com 84 jogadores de basquete de cinco escolas de Long Beach, California, a incidência de trauma no tornozelo é de $70 \%$. Em $80 \%$ destes ocorrem múltiplas entorses, em $32 \%$ das vezes o atleta perdeu duas ou mais semanas de treinamento, e não houve tratamento adequado, em $55 \%$ dos casos. Metade dos atletas que sofreram entorse tem sintomas por tempo prolongado, e 15\% deles afirmam que os sintomas interferem com o desempenho. Estes atletas não receberam tratamento baseado em programa consistente de reabilitação. O atendimento, com diagnóstico e tratamento adequado, é de suma importância na melhora dos parâmetros encontrados. O tratamento é conservador, e a cirurgia é reservada aos casos de instabilidade crônica, com resultados muito bons (SMITH E REISCHL, 1986).

O tratamento conservador da lesão ligamentar do tornozelo é o de escolha, com falha em aproximadamente $20 \%$ a $40 \%$ dos casos, que continuam a apresentar instabilidade 
ligamentar lateral crônica. Nestes casos está indicada a reparação cirúrgica com reconstrução ligamentar lateral (JACKSON E McGARVEY, 2006).

Metanálise realizada por Handoll et al., 2001, incluindo 14 trabalhos randomizados, identifica que o uso de órteses para estabilização do tornozelo diminui a incidência das entorses tanto nos pacientes com história de entorses prévios como nos pacientes com lesões agudas, sem antecedentes. A utilização de estabilizadores do tornozelo deve ser mantida até o final do processo de reabilitação. 


\subsection{RESULTADOS DO TRATAMENTO}

As lesões do complexo ligamentar lateral do tornozelo correspondem a $23 \%$ de todas as lesões relacionadas à prática esportiva na Academia Militar dos Estados Unidos, sendo distribuídas em: lesões laterais em $85 \%$ dos pacientes, lesões da sindesmose distal (tibiofibular anterior) em 10\%, e lesões mediais em $5 \%$. Gerber et al., 1998 sugerem mecanismo de classificação baseado na gravidade da instabilidade, o que permite a programação do tratamento, e determinar o prognóstico da lesão. Afirmam que 95\% dos pacientes retornaram à sua atividade prévia em seis semanas, porém 55\% ainda apresentavam perda da função normal e dor de moderada intensidade. Após seis meses todos retornaram à atividade prévia, porém, $40 \%$ apresentavam sintomas residuais.

A maioria dos indivíduos vítimas de entorses do tornozelo não desenvolve instabilidade crônica desta articulação. Os pacientes que evoluem com instabilidade podem apresentar instabilidade mecânica, quando apresentam comprovadamente hipermobilidade da articulação tibiotalar. Nestes, a reconstrução ligamentar lateral tem indicação (COLVILLE, 1998).

Neste estudo com 393 jogadores de basquete, o fator preditivo mais importante para as entorses é a história de lesão ligamentar prévia, o que ocorre em $73 \%$ dos pacientes incluídos. $57 \%$ dos jogadores que sofreram entorses não procuraram atenção médica no momento do trauma. A reabilitação é considerada muito importante nos pacientes que praticam esporte recreacional para prevenir novos episódios (McKAY ET AL., 2001).

A incidência de lesão do complexo ligamentar lateral do tornozelo nas entorses é de 75\%. Dez a 30 \% dos pacientes apresentam sintomas crônicos, como rigidez articular, edema, dor, fraqueza muscular, ou sensação de instabilidade (RENSTROM E LYNCH, 1999).

Pacientes com entorse do tornozelo que apresentam alterações posicionais do tornozelo e retropé mostram alterações na cinemática articular com consequente limitação da mobilidade e alteração na função articular, sobrecarga das estruturas 
ligamentares, aumento da chance de recidiva da entorse e maior chance de desenvolver instabilidade articular. Afirmam que, se o paciente retorna à atividade antes da completa cicatrização da estrutura ligamentar, o ligamento pode cicatrizar em uma posição alongada, mantendo mobilidade anormal da articulação (DENEGAR E MILLER, 2002).

A dor, após entorses do tornozelo, é muito frequente, configurando problema desafiador, já que inclui inúmeros diagnósticos diferentes. Cui et al., em 2005, abordam especificamente a capsulite adesiva.

A lesão de estruturas ligamentares e capsulares causam reação inflamatória local e formação de tecido cicatricial, que pode levar à situação de impacto de partes moles, principalmente se o tratamento não é inclui adequada reabilitação (GOLANÒ ET AL., 2006).

A presença de insuficiência ligamentar, e o processo de cicatrização das lesões destas estruturas, não são cuidadosamente examinados ou relatados na maioria dos estudos. A falta de imobilização em metade dos pacientes com lesão ligamentar aguda do tornozelo, e o rápido retorno às atividades, podem interferir no processo cicatricial com consequente maior frouxidão. Maiores pesquisas são necessárias para determinar o tempo adequado de retorno dos atletas (HUBBARD, 2008).

Os achados indicam que $13 \%$ dos casos de artroses pós-traumáticas do tornozelo tem como causa a instabilidade crônica (VALDERRABANO ET ALL., 2006).

A incidência de artrite degenerativa em série de 36 pacientes portadores de instabilidade ligamentar lateral do tornozelo com mais de 10 anos de evolução é de $78 \%$. A reconstrução ligamentar com estabilização da articulação reverte esta tendência (HARRINGTON, 1979). 


\subsection{INSTABILIDADE FUNCIONAL}

A ocorrência de sintomas (dor durante atividade física, edema recorrente, fraqueza e sensação de falseio) e de entorses de repetição, tem sido considerada como instabilidade crônica do tornozelo. Os fatores mecânicos incluem frouxidão patológica, alteração da cinemática do tornozelo, e alterações degenerativas e sinoviais. Os fatores funcionais incluem propriocepção alterada, controle neuromuscular alterado, déficits de força, e controle postural deficiente (HERTEL, 2002).

O mecanismo básico de instabilidade do tornozelo, após entorse, ocorre por lesão dos mecanorreceptores localizados na cápsula articular, e estruturas ligamentares ao redor do tornozelo, teoria conhecida como deaferentação articular. Segundo esta teoria, a estabilidade dinâmica ou functional do tornozelo depende da capacidade dos eversores reagirem rapidamente às perturbações de inverção rápida, no sentido de desenvolver tensão suficiente para prevenir amplitudes que possam provocar lesões. Os indivíduos com instabilidade funcional teriam reflexos de resposta diminuídos e atrasados nos músculos eversores, frente aos estímulos de inversão, relacionados à alteração dos estímulos aferentes capsulares e ligamentares (FREEMAN ET AL., 1965).

Em trabalho com 42 pacientes vítimas de primeiro episódio de lesão ligamentar grave do tornozelo (diagnosticado através do exame clínico e Rx com estresse manual), comparados a 20 pacientes com lesões ligamentares leves (sem instabilidade), Freeman (1965 b) observa incidência de $40 \%$ de sensação de instabilidade no primeiro grupo, e 36 $\%$ no segundo grupo. No grupo de pacientes com lesão grave, apenas $14 \%$ apresentaram instabilidade mecânica. Discute que a possível causa da evolução com instabilidade crônica possa ser a recidiva do trauma relacionada à instabilidade funcional.

O controle dinâmico da estabilidade do tornozelo depende de controle motor realizado pelo sistema nervoso central num mecanismo de antero alimentação (feed forword). $\mathrm{O}$ adequado posicionamento do pé durante a marcha melhora a velocidade de reação dos músculos fibulares ao estresse em inversão (KONRADSEN ET AL., 1997). 
Comparando 24 pacientes com instabilidade funcional do tornozelo com 22 pessoas sem lesões, através de avaliação da cinemática e eletroneuromiografia, observam que indivíduos com instabilidade funcional apresentam posicionamento em inversão do tornozelo durante o final da fase de balanço e início da fase de apoio, menor elevação do pé durante a fase de balanço, além de aumento da atividade dos músculos fibulares no momento das sensações de falseio, relacionado, provavelmente a um mecanismo protetor (DELAHUNT ET AL., 2006).

A propriocepção é a sensação de posição, pressão, movimento e dor, dependendo da cinestesia e sensação de posição articular (LEPHART ET AL., 1998).

A instabilidade funcional do tornozelo, que ocorre após lesões ligamentares agudas, não se relaciona, na maioria das vezes, à instabilidade mecânica da articulação, mas à alteração da função de propriocepção (HINTERMANN, 1999).

Nos indivíduos vítimas de lesão ligamentar do tornozelo graus II e III, 25 a 50\% apresentam instabilidade funcional após seis meses do trauma (MANN ET AL., 2002).

Pacientes com instabilidade funcional do tornozelo apresentam retardo da ativação dos músculos fibulares comparado aos indivíduos normais (KONRADSEN E RAVN, 1990).

Existe correlação entre instabilidade do tornozelo e a diminuição da força de contração concêntrica e excêntrica dos músculos inversores e eversores desta articulação (HARTSELL E SPAULDIN, 1999).

A insuficiência mecânica (frouxidão em inversão e translação anterior) e funcional (força e equilíbrio dinâmico) contribuem de forma significativa como fatores etiológicos da instabilidade crônica do tornozelo após lesão ligamentar aguda. Um adequado programa de reabilitação voltado para a recuperação funcional pode diminuir a chance de recidivas dos pacientes com lesão ligamentar aguda, e de evolução para situação de instabilidade crônica (HUBBARD ET AL., 2007). 
As recidivas após entorses do tornozelo são muito comuns, e se relacionam a instabilidade mecânica, instabilidade funcional, ou combinação de ambas. Nesta situação a identificação da real causa da entorse de repetição permite o tratamento adequado (HERTEL, 2008).

Em 18 pacientes portadores de instabilidade funcional do tornozelo, Hirai et al., em 2009, não observam correlação com a presença de instabilidade mecânica.

Esta metanálise de Munn et al., de 2012, confirma a existência de déficits sensoriomotores para sensação de posição articular em indivíduos com instabilidade funcional do tornozelo. Não há déficit de reação dos fibulares. 
4. CASUÍSTICA E MÉTODOS 


\subsection{CASUÍSTICA}

Foram incluídos neste estudo 186 pacientes portadores de lesão ligamentar aguda grave do tornozelo, atendidos na Unidade de Pronto Atendimento do Hospital Israelita Abert Einstein, ou pacientes atendidos no consultório do autor, no período de março de 2008 a maio de 2012 (amostra de conveniência).

O Comitê de Ética em Pesquisa do Hospital Israelita Albert Einstein aprovou previamente este estudo.

Cada indivíduo selecionado foi adequadamente orientado a respeito do experimento e solicitado a assinar o termo de consentimento informado para participação no estudo. 


\subsubsection{CRITÉRIOS DE INCLUSÃO}

- Idade entre 15 e 65 anos.

- Primeiro episódio de entorse da articulação do tornozelo.

- Sinais clínicos que indicassem lesão ligamentar grave (dor intensa no momento do trauma, incapacidade de apoio, gaveta anterior positiva ao exame físico). 


\subsubsection{CRITÉRIOS DE EXCLUSÃO (Beynnon et al., 2006):}

- Histórico de entorse grave prévio do tornozelo.

- Antecedente de fratura na extremidade afetada.

- Associação com fraturas que exijam tratamento diferenciado.

- Presença de lesões grave da sindesmose, ou outras lesões que exigissem tratamento diferenciado, na ressonância magnética.

- Associação com queimaduras, lacerações, ferimentos perfuro contusos.

- Placa de crescimento aberta ao Rx inicial.

- Pacientes grávidas.

- Portadores de doenças sistêmicas, neurológicas ou vestibulares.

- Pacientes incapazes de seguir o tratamento proposto.

- Pacientes portadores de sinais clínicos de frouxidão ligamentar generalizada (hiperextensão dos polegares, cotovelos e joelhos) (Beinghton, Horan, 1969). 


\subsection{MÉTODOS}

Os pacientes incluídos neste estudo foram atendiddos inicialmente no Serviço de Pronto Atendimento do Hospital Israelita Albert Einstein ou no consultório do autor, e, após orientação adequada, acompanhados no seu consultório privado (Hospital Israelita Albert Einstein, Unidade Morumbi, ou no Hospital do Coração, ambos na cidade de São Paulo). Trata-se, portanto, de amostra de conveniência.

Todos os pacientes foram avaliados em cinco oportunidades (logo após o trauma e com uma, três, seis e 12 semanas). Durante a avaliação inicial o exame físico detalhado foi realizado, e os pacientes incluídos assinaram o termo de consentimento informado. As cópias das fichas de avaliação utilizadas estão dispostas no Anexo A.

O diagnóstico de instabilidade articular foi realizado através da história e exame físico, com a identificação de dor à palpação na topografia das estruturas ligamentares laterais do tornozelo, do teste clínico da gaveta anterior e do estresse em varo.

A postura dos pés observada durante o exame físico em posição ortostática foi levada em consideração na avaliação dos pacientes incluídos no estudo, com o intuito de verificar a presença de relação entre o pé cavo, e retropé varo com a ocorrência de lesões ligamentares, ou maior chance de evolução insatisfatória.

A presença de frouxidão ligamentar generalizada foi pesquisada através da avaliação dos sinais descritos por Beighton e Horan em 1969: extensão passiva dos dedos das mãos além de $90^{\circ}$, aposição do polegar à face flexora do respectivo antebraço, hiperextensão dos cotovelos além de $10^{\circ}$, hiperextensão dos joelhos além de $10^{\circ}$ e flexão do tronco com os joelhos completamente estendidos de modo que as palmas das mãos repousem no solo.

O teste da gaveta anterior foi realizado com o paciente sentado, com o joelho fletido 90 graus e o tornozelo em posição neutra ou flexão plantar de 10 a 15 graus. Uma mão era colodada na tíbia distal e a outra mão no calcanhar. Aplicava-se pressão em direções opostas, sustentando a posição da perna com uma mão e puxando o retropé anteriormente com a outra (Figura 1). O deslocamento anterior do tálus pode ser visualizado, sentido e palpado pelo examinador. A presença de dor, subluxação anterior e o sinal da sucção (depressão da pele na face anterolateral do tornozelo no momento do teste) foram 
considerados como achados positivos. A comparação com o lado contralateral normal facilitou a percepção da mobilidade anormal da articulação afetada.

Figura 1- Teste clínico da gaveta anterior

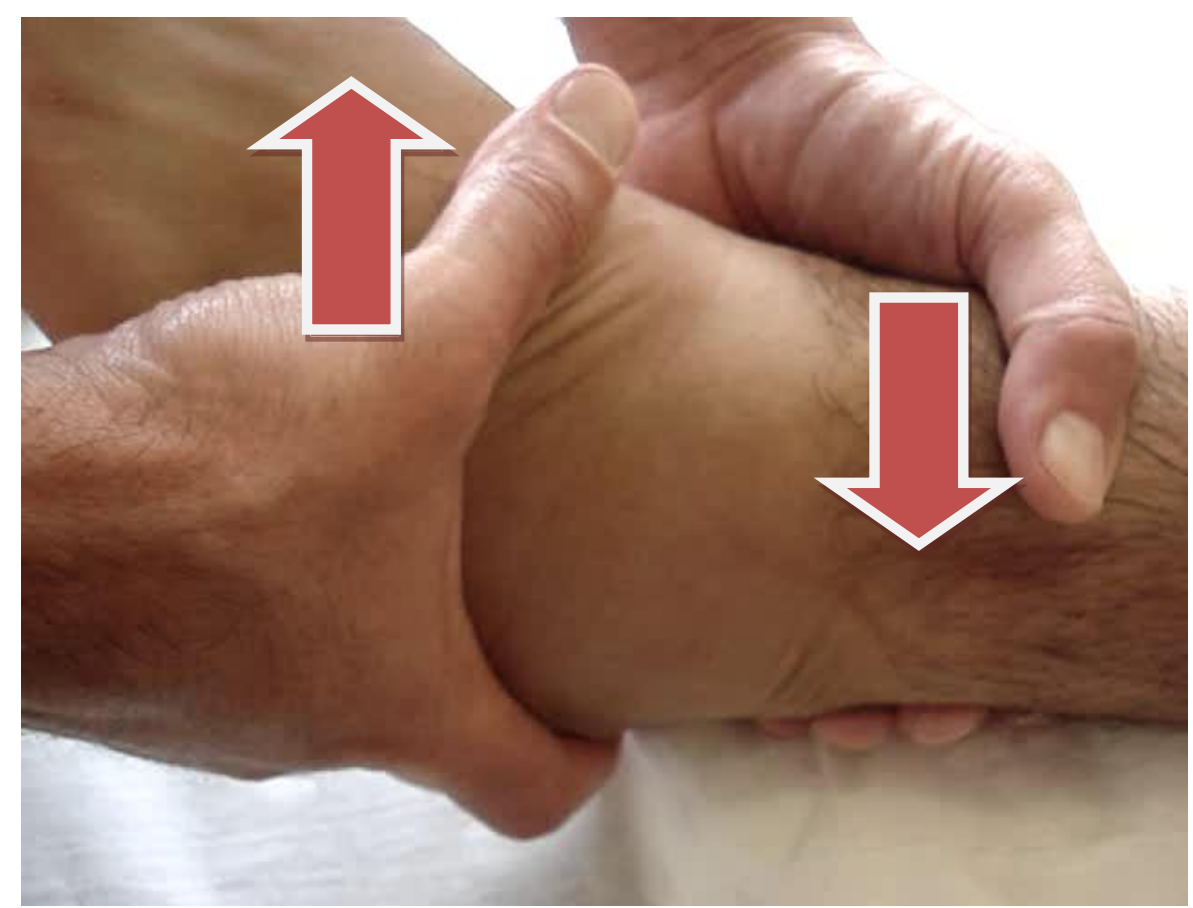

As setas mostram a direção da força realizada pelo examinador.

O teste do estresse em varo foi realizado através do apoio de uma mão na face interna da porção distal da perna, a outra mão na face lateral do retropé, com a realização de varização forçada do tornozelo, observando de assimetria da amplitude total de movimento comparativamente ao lado normal e a presença ou não de final brusco do movimento (Figura 2). 
Figura 2 - Teste de estresse em varo

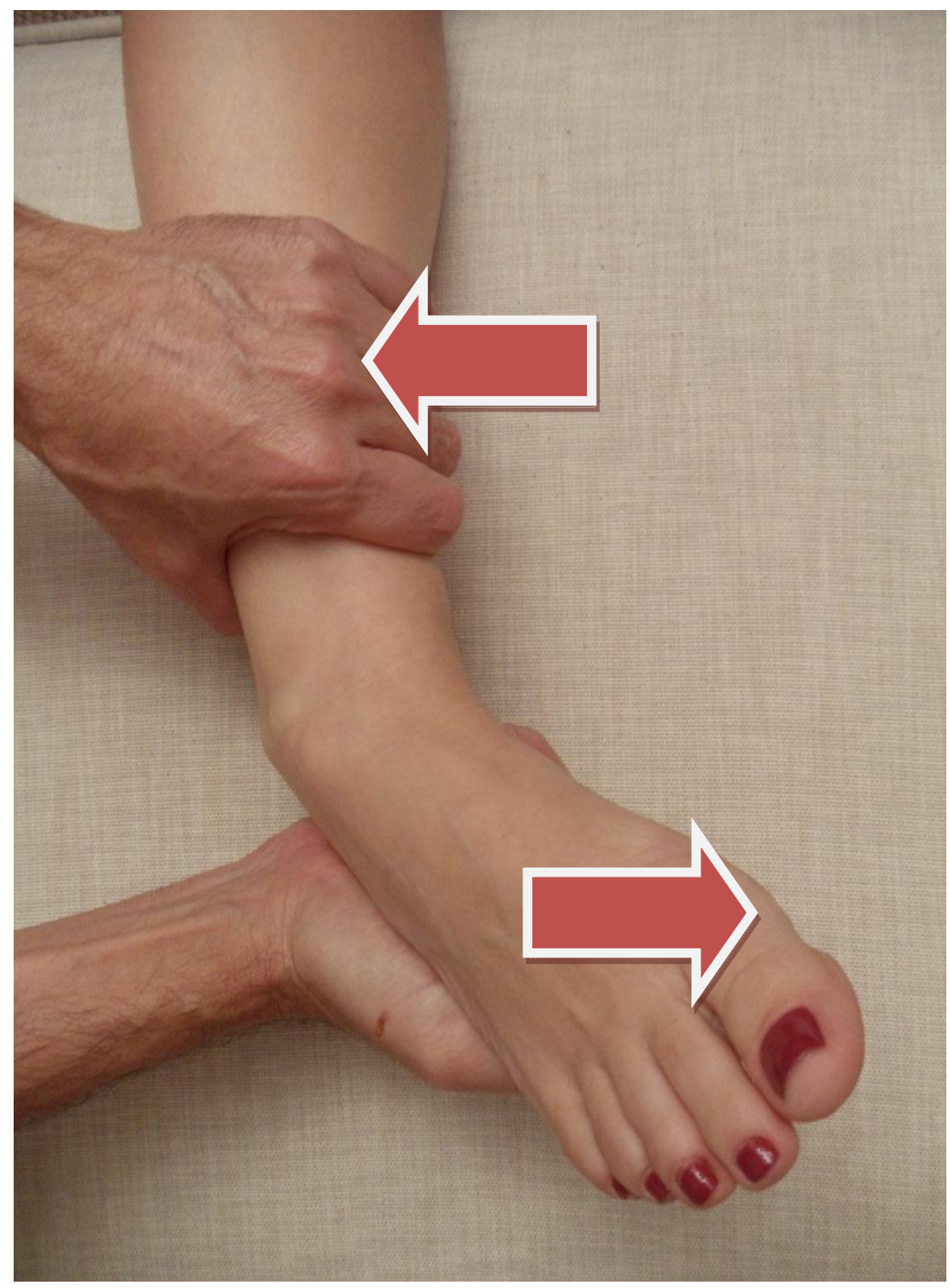

A classificação da gravidade da lesão ligamentar do tornozelo foi realizada de acordo com o quadro 1 . 
Quadro 1 - Sistema de graduação das lesões ligamentares do tornozelo (Mack, 1982 e Gerber et al., 1998)

\begin{tabular}{|l|l|l|l|}
\hline Critério/Graduação & Grau I & Grau II & Grau III \\
\hline Local da dor & LTFA & LTFA e LCF & Todo tornozelo \\
\hline $\begin{array}{l}\text { Reação ao teste de } \\
\text { estresse }\end{array}$ & Desconforto & $\begin{array}{l}\text { Desconforto moderado a } \\
\text { intenso }\end{array}$ & $\begin{array}{l}\text { Nenhuma ou dor } \\
\text { intensa }\end{array}$ \\
\hline Edema e equimose & Leve, localizado & Moderado, localizado & Importante, difuso \\
\hline $\begin{array}{l}\text { Capacidade para o } \\
\text { apoio }\end{array}$ & $\begin{array}{l}\text { Completa } \\
\text { ou parcial }\end{array}$ & $\begin{array}{l}\text { Dificil, sem necessidade } \\
\text { de muletas }\end{array}$ & $\begin{array}{l}\text { Imposível, com dor } \\
\text { importante }\end{array}$ \\
\hline Lesão ligamentar & Estiramento & Lesão parcial & Lesão completa \\
\hline Instabilidade & Não & Não & Instável \\
\hline
\end{tabular}

LTFA: ligamento talofibular anterior.

LCF: ligamento calcâneo fibular.

Todos os pacientes foram submetidos a radiografias do tornozelo em três posições para investigação da presença de fraturas maiores, seguindo os critérios de Otawa.

Foi realizada ressonância magnética com aquisição de imagens em aparelho GE de 1.0T ou 1.5T nos planos ortogonais coronal, sagital e axial, utilizando sequencias de pulso fast spin echo (FSE) ponderada em $\mathrm{T} 1$ e fast recovery fast spin echo (FRFSE) com supressão de gordura (FAT SAT) ponderada em T2, para confirmar e estadiar a lesão, e procurar por variações anatômicas (Tabela 8) e lesões associadas. As imagens foram analisadas por radiologistas especializados em aparelho músculo esquelético.

Fizemos sorteio aleatório computadorizado prévio, com o tipo de intervenção (tratamento) a ser realizado, e as fichas geradas foram mantidas em envelopes fechados numerados sequencialmente. Quando cada paciente era incluído no trabalho retiravamos a ficha correspondente que continha o tipo de tratamento, dividindo os pacientes em dois grupos: grupo A e grupo B.

Os pacientes incluídos no grupo A foram tratados com uso de imobilização suro podálica (Robofoot®) imediata (Figura 3) que foi mantida por três semanas. Após este 
período esta órtese foi substituída por uma órtese curta funcional (Aircast ${ }^{\circledR}$ esportivo), mantida, por sua vez, por adicionais três semanas.

Figura 3 - Órtese suro podálica para imobilização do tornozelo tipo Robofoot®

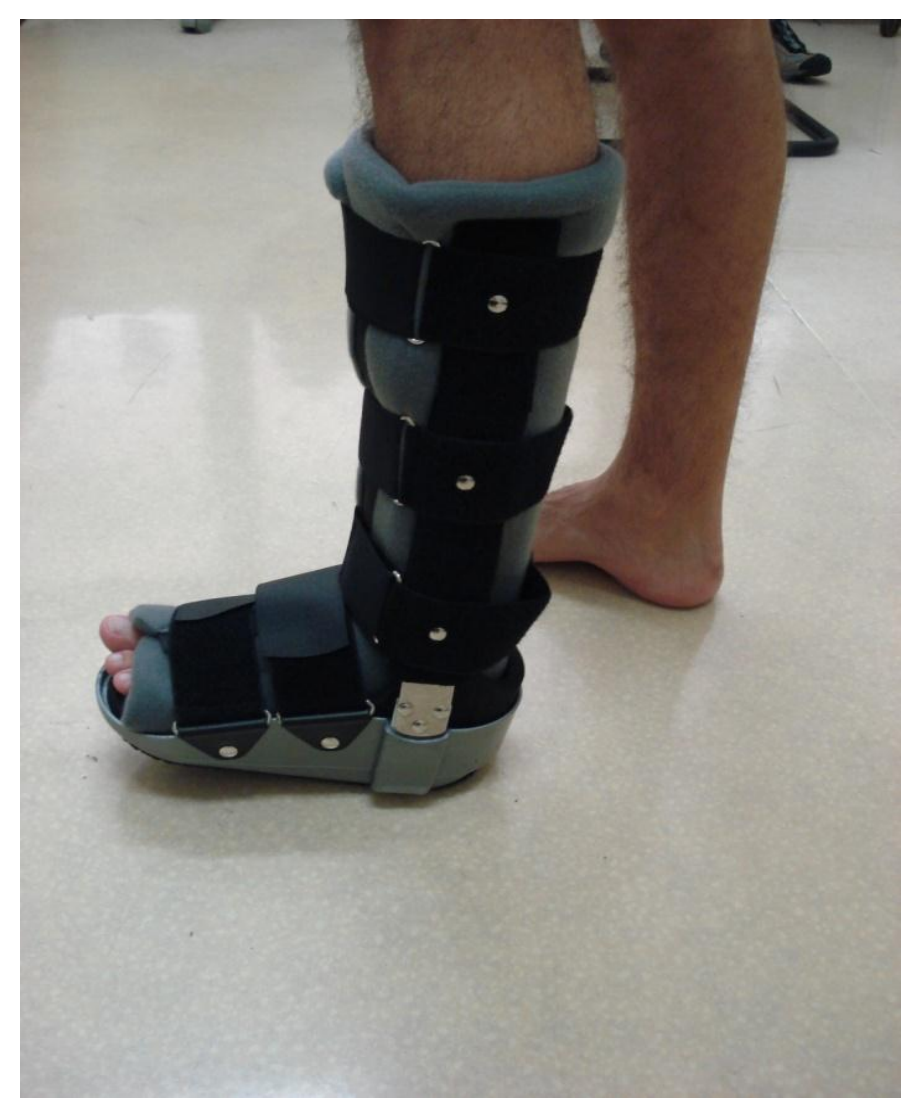

No grupo B, os pacientes foram imobilizados, no momento da inclusão no trabalho, com órtese curta funcional (Aircast ${ }^{\circledR}$ esportivo), mantida por seis semanas (Figura 4).

Os imobilizadores foram adquiridos pelos pacientes, pagos pelas suas fontes pagadoras de serviços médicos, e fornecidos pelos hospitais onde foi realizado o atendimento inicial.

Durante as três semanas iniciais do tratamento (em ambos os grupos) o apoio foi permitido dependendo do conforto, inicialmente com o auxílio de um par de muletas, seguido por apenas uma muleta, e finalmente com o auxílio de uma bengala. 
Figura 4 - Órtese curta funcional tipo Aircast $\AA^{\circledR}$ esportivo

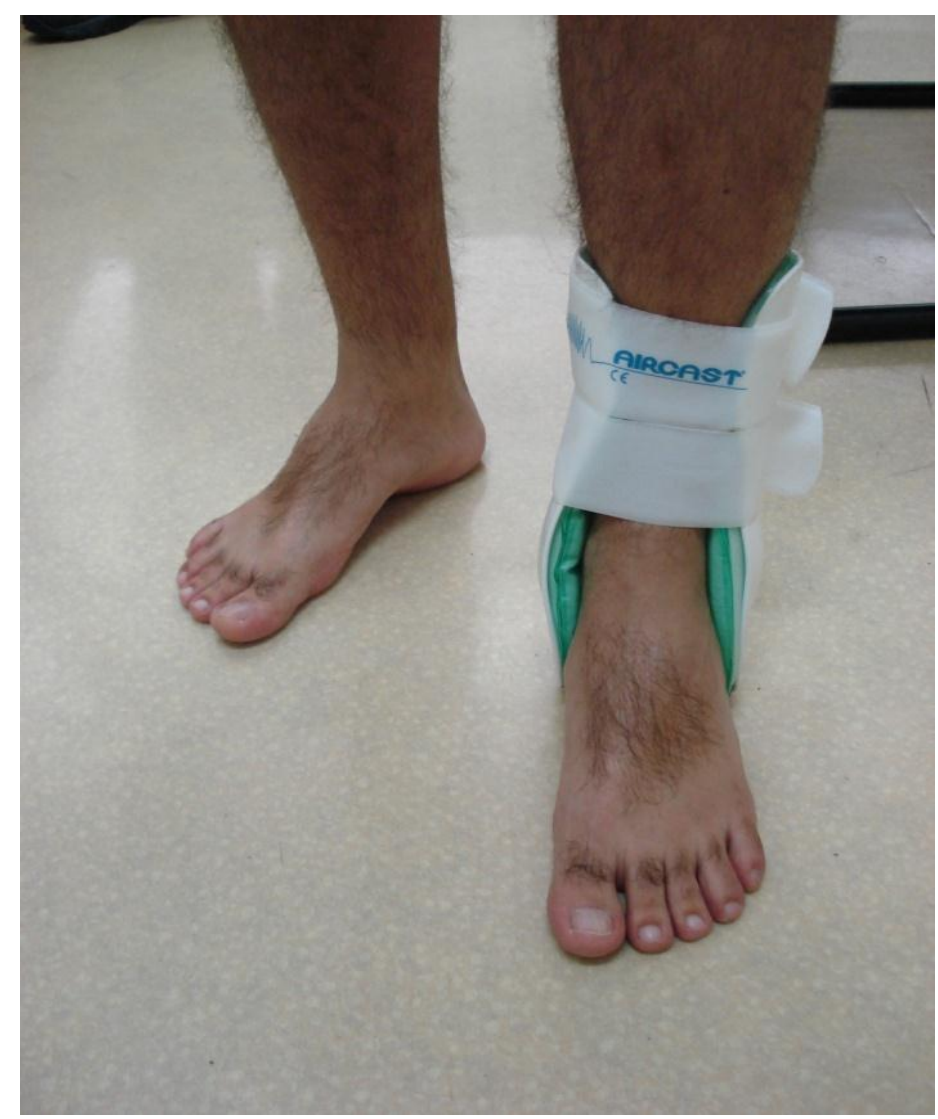

Todos os pacientes incluídos foram submetidos à avaliação da intensidade da dor baseada na escala visual analógica de dor (EVA) na qual a pontuação determinada pelo paciente varia de zero (0), que corresponde ausência de dor, a dez (10), que corresponde à dor mais intensa por ele experimentada, complementada por uma escala de cores, na qual o verde significa nenhuma dor e o vermelho escuro significa a dor mais intensa experimentada pelo pacinte (Price et al., 1983), mostrada na figura 5. 
Figura 5 - Escala visual analógica de dor (EVA)

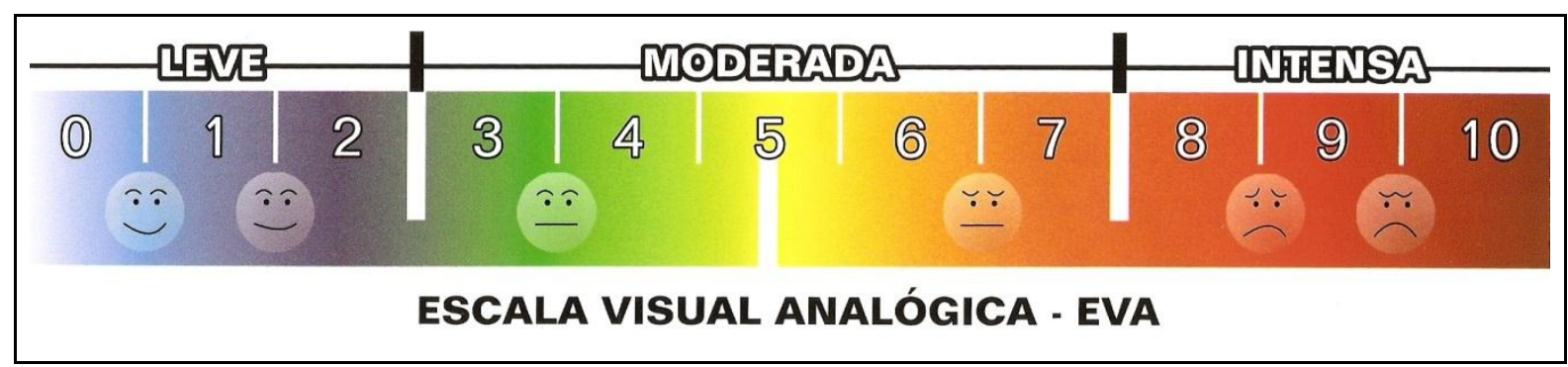

A avaliação da função e intensidade da dor, nas várias fases do tratamento, foi baseada na escala da American Orthopaedic Foot and Ankle Society (AOFAS) para tornozelo e retropé (Kitaoka et al., 1994), que propõe uma pontuação baseada em fatores clínicos e de exame físico, que inclui:

Intensidade da dor (máximo: 40 pontos): ausente (40 pontos); leve, ocasional (30 pontos); moderada, diária (20 pontos); grave, frequente (zero ponto).

Função - limitação da atividade e uso de órteses (máximo: 10 pontos): sem limitações, sem uso de órteses (10 pontos); limitação da atividade esportiva, sem uso de órteses (sete pontos); limitação da atividade diária, uso de bengala (quatro pontos); limitação grave da vida diária, uso de muletas (zero ponto).

Distância de marcha máxima em quarteirões (máximo: cinco pontos): mais de seis (cinco pontos); quatro a seis (quatro pontos); um a três (dois pontos); menos de um (zero ponto).

Marcha em diferentes superfícies (máximo: cinco pontos): sem dificuldade, qualquer superfície (cinco pontos); discreta dificuldade, terrenos irregulares e escadas (três pontos); grande dificuldade, terrenos irregulares e escadas (zero ponto).

Alteração da marcha (máximo: oito pontos): normal (oito pontos); discreta (quatro pontos); grave (zero ponto).

Mobilidade no plano sagital - flexo extensão (máximo: oito pontos): normal ou discreta redução, $>30^{\circ}$ (oito pontos); limitação moderada, 15 a $29^{\circ}$ (quatro pontos); limitação grave, $<15^{\circ}$ (zero ponto).

Mobilidade do retropé - inversão, eversão (máximo: seis pontos): normal a discreta redução 75 a 100 \% (seis pontos); limitação moderada, 25 a $75 \%$ (três pontos); limitação grave, <25\% (zero ponto). 
Estabilidade do tornozelo e retropé (máximo: oito pontos): estável (oito pontos); instável (zero ponto).

Alinhamento (máximo: 10 pontos): bom, pé plantígrado, tornozelo e retropé alinhados (10 pontos); regular, pé plantígrado, discreto mau alinhamento entre tornozelo e retropé, sem sintomas (cinco pontos); mau, pé não plantígrado, mau alinhamento, sintomático (zero ponto).

As fases da reabilitação são descritas por semanas, e foram realizados no local de escolha de cada paciente, e orientado através de prescrição e contato telefônico prévio com o fisioterapeuta reaponsável.

Durante as primeiras três semanas os pacientes foram orientados a realizar compressas de gelo (com bolsas de gelo ou bolsas térmicas de gel), com proteção adequada da pele usando uma toalha fina, quatro a seis vezes ao dia, por período de 20 minutos cada aplicação. Nos momentos da aplicação de gelo e do banho, foram orientados a realizar mobilização do tornozelo afetado de pequena amplitude, limitando a flexão plantar a 15 graus, e sem realizar inversão. $\mathrm{O}$ membro acometido era mantido elevado sempre que possível e o repouso estimulado. O programa de reabilitação, propriamente dito, teve início após a terceira semana do trauma.

Quarta semana após o trauma: analgesia, controle do edema e cinesioterapia leve, com mobilização do tornozelo sem realizar inversão e limitando a flexão plantar a 15 graus, treino de marcha em terreno estável, propriocepção leve para estímulo da sensibilidade, e fortalecimento muscular através de exercícios isométricos (Jahss, 1991).

Quinta e sexta semanas após o trauma: progressão do fortalecimento muscular (isométricos para flexão plantar e inversão, e isotônicos para eversão e doriflexão), exercícios de propriocepção e de marcha, respeitando a limitação da inversão e flexão plantar forçada.

Após as sexta semana do tratamento as órteses foram removidas e os pacientes foram autorizados a retomarem gradativamente às atividades físicas com restrição para as atividades com salto ou mudança de direção, iniciando com as atividades na água, bicicleta e caminhadas.

Setima semama após o trauma: Mobilização do tornozelo em todas as direções, exercícios de fortalecimento e propriocepção com progressão gradual. 
Oitava semana após o trauma: progressão dos exercícios de propriocepção com cama elástica e balancim para treino de equilíbrio. Retomadas as corridas e os saltos.

Nona semana após o trauma: início de exercícios de mudança de direção e interrupção brusca do deslocamento e atividades específicas de cada modalidade esportiva, sem contato. $\mathrm{O}$ fortalecimento é mantido durante todas as fases do processo de reabilitação, bem como a crioterapia após os exercícios.

Décima a $12^{\mathrm{a}}$ semanas após o trauma: retorno às atividades físicas habituais sem restrição, incluindo as atividades com mudança brusca de direção e contato.

Todos os pacientes foram mantidos no programa de reabilitação até desenvolverem força muscular normal (observada através do exame físico da força), e propriocepção normal (avaliado pelo fisioterapeuta, durante os exercícios específicos), comparativamente ao lado contralateral normal.

No terceiro mês os pacientes foram submetidos a exame físico e avaliação radiográfica da estabilidade articular através de Rx com estresse manual em gaveta anterior e em varo, realizados pelo autor ou por técnicos em radiografia supervisionados pelo autor, para comparar a sua eficiência à do exame físico na determinação da presença de instabilidade mecânica articular.

$\mathrm{O} \mathrm{Rx}$ com estresse em varo do tornozelo foi realizado com incidência anteroposterior enquanto se realiza inversão forçada no tornozelo com pequena flexão plantar (5 a 15 graus). O ângulo entre o pilão tibial e a porção proximal do domus talar foi medido (Figura 6).

O Rx com estresse em gaveta anterior foi realizado através da incidência em perfil do tornozelo enquanto se realizava a translação anterior do tálus na pinça maleolar (Johannsen,1978). A medida da perpendicular entre o ponto mais posterior da superfície articular distal da tíbia e o domus talar adjacente corresponde à translação anterior do tálus na pinça maleolar como descrito por Laurin e Mathieu em 1975 (Figura 7). 
Figura 6 - Medida da inclinação talar na radiografia com estresse em varo

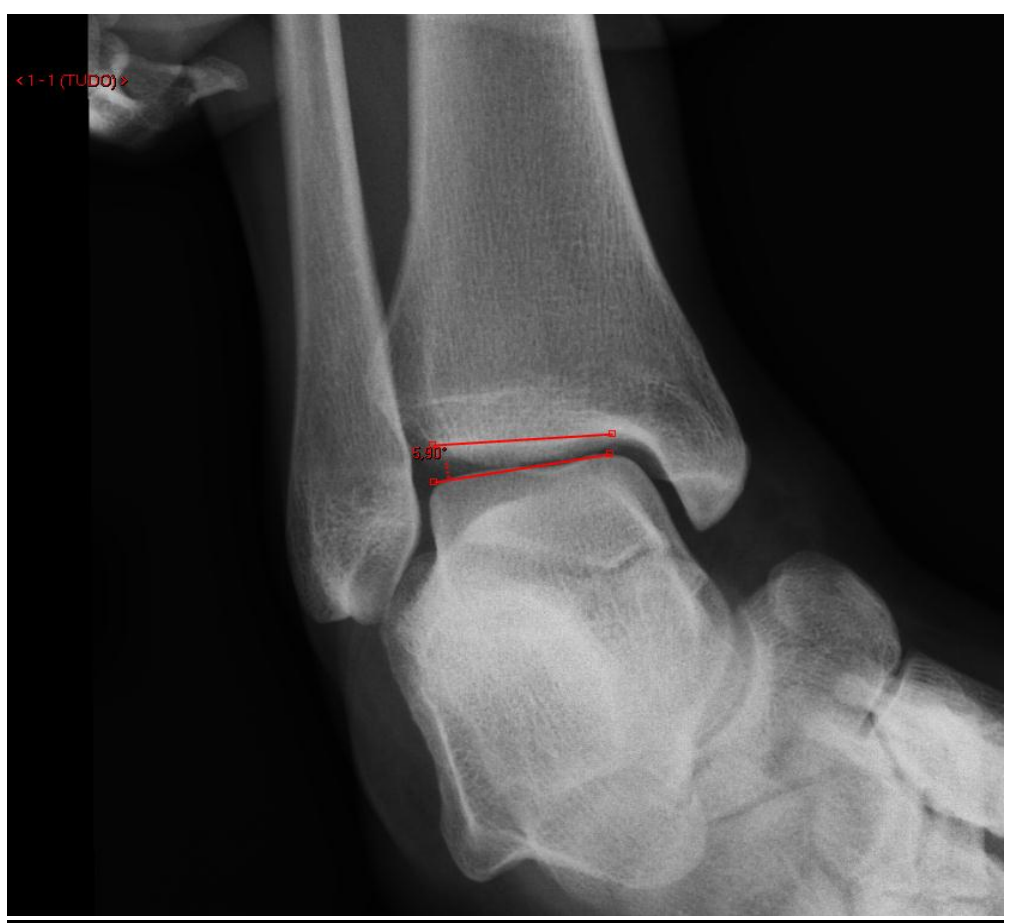

Figura 7 - Medida do deslocamento anterior do tálus na radiografia com estresse em gaveta anterior

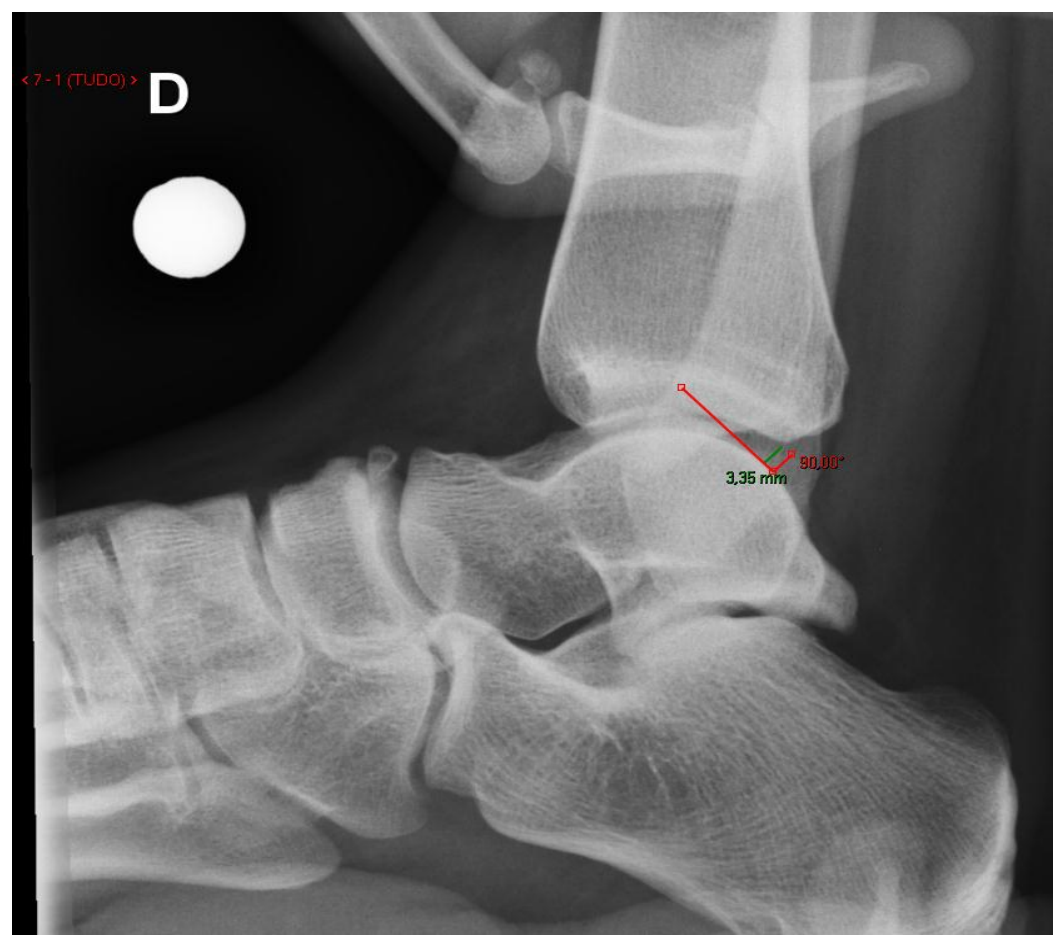


As mensurações foram realizadas por dois médicos ortopedistas com especialização em cirurgia do pé e tornozelo (com experiência nesta especialidade há 17 e 6 anos), em duas oportunidades diferentes, com intervalo de duas semanas entre elas, em formato duplo cego (através da identificação de cada paciente por um número), utilizando programa de imagem digital (Carestrem PACS Versão 11.3 Siemens ou Magic Web Versão VA42C_0306 Siemens).

A variabilidade inter e intraobservador foi analisada através do Coeficiente de Correlação Intra Classe (ICC), cujo valor foi interpretado como: zero a 0,2 indica correlação ruim: 0,3 a 0,4 indica correlação média; 0,5 a 0,6 indica correlação moderada; 0,7 a 0,8 indica correlação forte; e maior do que 0.8 indica correlação quase perfeita (Landis, Koch, 1977).

Houve correlação entre a avaliação clínica e radiográfica da estabilidade articular do tornozelo em 142 pacientes, quando aplicamos o critério de diferença mínima necessária, entre o lado acometido e o lado contralateral, de 5 graus na radiografia com estresse em varo, ou $5 \mathrm{~mm}$ na radiografia em estresse com gaveta anterior. Nesse ponto interrompemos a avaliação radiográfica da estabilidade articular.

Todos os dados colhidos estão disponíveis nas tabelas localizadas no Anexo B.

Os dados obtidos foram comparados estatisticamente com a intenção de se determinar a presença de diferença significativa na intensidade da dor, no tempo de afastamento das atividades profissionais, no desempenho funcional dos pacientes, e na evolução para instabilidade mecânica da articulação do tornozelo, entre as duas modalidades de tratamento realizadas (Grupos A e B).

Não houve verba externa direcionada a este estudo. 


\section{AVALIAÇÃO ESTATíSTICA}

O calculo do tamanho da amostra partiu de uma pressuposição que teríamos $15 \%$ de diferença entre os grupos A e B. Utilizando os valores de erro alfa < 0,05 e poder do estudo $>0,80$, chegando ao resultado de que seriam necessáios 76 pacientes para cada grupo. Imaginando que ocorreria $15 \%$ de perda de pacientes no decorrer do estudo chegamos a um número final de 90 pacientes em cada grupo.

Os dados analisados foram armazenados em uma planilha de Excel e posteriormente importados para o programa SPSS 20 for MAC para análise.

Todos os dados contínuos foram submetidos ao teste de normalidade de Kolmogorov-Smirnov, de forma a respeitar o desenho do estudo de ensaio clínico aleatorizado, portanto sempre dividindo esta análise nos dois grupos estudados.

Para comparação e inferência estatística da comparação entre os grupos, quando os dados apresentavam distribuição normal, os mesmos foram submetidos ao teste-t student, os dados com distribuição não normal foram submetidos ao teste de Rank de Wilcoxon de Mann-Whitney.

Para os dados dicotômicos, o teste do qui-quadrado foi utilizado para análise das associações das frequências entre as variáveis categóricas.

Para verificar a influência das características dos pacientes, como lesão associada e alterações anatômicas, a análise de variância (ANOVA) de um e dois fatores foi utilizada, além de análises de regressão linear múltipla. Quando mais de três variáveis foram comparadas, o post hoc Bonferroni foi utilizado para avaliar entre quais variáveis ocorreu diferença estatística.

Para a avaliação da variabilidade inter e intraobservador na análise das radiografias com estresse foi utilizado o Coeficiente de Correlação Intra Classe (ICC).

O nível de significância estatística utilizado para todos os testes foi de $\mathrm{p} \leq 0,05$ (Rosner, 2010; Triola, 2011). 
6. ANÁLISE DA CASUÍSTICA E RESULTADOS 


\subsection{ANÁLISE DA CASUÍSTICA}

A distribuição dos pacientes de acordo com o gênero pode ser observada na tabela 1.

Tabela 1 - Distribuição dos pacientes segundo o sexo

\begin{tabular}{lcc}
\hline SEXO & NÚMERO DE CASOS & PORCENTAGEM \\
\hline MASCULINO & 106 & 57,0 \\
FEMININO & 80 & 43,0 \\
\hline Total & 186 & 100,0 \\
\hline
\end{tabular}

A média de idade foi de 32,7 anos, com variação entre 15 e 64, e desvio padrão de 12,2 .

A distribuição de todos os pacientes incluídos segundo o lado acometido é mostrada na tabela 2:

Tabela 2 - Distribuição dos pacientes segundo o lado acometido

\begin{tabular}{lcc}
\hline LADO ACOMETIDO & FREQUÊNCIA & PORCENTAGEM \\
\hline DIREITO & 93 & 50,0 \\
ESQUERDO & 93 & 50,0 \\
\hline Total & 186 & 100,0 \\
\hline
\end{tabular}

Observamos a base de dados dos pacientes incluídos neste estudo na tabela 3: 
Tabela 3 - Dados base da casuística, segundo distribuição nos grupos de tratamento

\begin{tabular}{|c|c|c|c|c|}
\hline DADOS BASE DA AVALIAÇÃO & $\begin{array}{c}\text { Grupo } A \\
(n=94)\end{array}$ & $\begin{array}{c}\text { Grupo } B \\
(n=92)\end{array}$ & $p$ & $\begin{array}{l}\text { Teste } \\
\text { estatístico }\end{array}$ \\
\hline Sexo feminino, \% & 42 & 38 & NS & $X^{\wedge} 2$ \\
\hline Lado direito, \% & 51 & 42 & NS & $X^{\wedge} 2$ \\
\hline \multirow[t]{2}{*}{ Idade em anos (media \pm dp) } & $32,6 \pm 12,1$ & $32,8 \pm 21,2$ & NS & Komogorov \\
\hline & & & & Test $\mathbf{t}$ \\
\hline Incapacidade de apoio (n/\%) & $74 / 78,5$ & $57 / 62$ & $\mathbf{0 , 0 1 2}$ & $\mathbf{X}^{\wedge} \mathbf{2}$ \\
\hline Incapacidade de apoio imediato (n/\%) & 93/99 & 92/100 & NS & $\mathrm{X}^{\wedge} \mathbf{2}$ \\
\hline \multirow[t]{2}{*}{ EVA dor (media \pm dp) } & $7,1 \pm 1,3$ & $6,6 \pm 1,4$ & $\mathbf{0 , 0 1 3}$ & Komogorov \\
\hline & & & & Test $\mathbf{t}$ \\
\hline Sem outras dores $(\mathrm{n} / \%)$ & $86 / 92$ & $89 / 97$ & NS & $X^{\wedge} \mathbf{2}$ \\
\hline Teste de gaveta positivo $(\mathrm{n} / \%)$ & $94 / 100$ & $92 / 100$ & NS & $\mathrm{X}^{\wedge} \mathbf{2}$ \\
\hline Sem lesões concomitantes (n/\%) & 91/97 & 91/99 & NS & $X^{\wedge} 2$ \\
\hline Pé plantígrado (n/\%) & 88/94 & $88 / 96$ & NS & $\mathbf{X}^{\wedge} \mathbf{2}$ \\
\hline Mobilidade subtalar normal (n/\%) & 94/100 & $92 / 100$ & NS & $X^{\wedge} 2$ \\
\hline Mobilidade mediotarsal normal (n/\%) & $94 / 100$ & $90 / 98$ & NS & $X^{\wedge} 2$ \\
\hline Sem frouxidao ligamentar (n/\%) & 94/100 & $92 / 100$ & NS & $X^{\wedge} \mathbf{2}$ \\
\hline
\end{tabular}

$\mathrm{X}^{\wedge}$ 2: teste do qui-quadrado.

NS: não estatisticamente significativo (>0.05).

dp: desvio padrão.

Test T: teste T de Student.

n/\%: número absoluto e porcentagem.

Komogorov / Test t: teste de normalidade de Kolmogorov-Smirnov e teste-t student.

EVA: escala visual analógica. 
Os mecanismos de trauma associados à lesão são listados na tabela 4.

Tabela 4 - Mecanismo de trauma relacionados à lesão

\begin{tabular}{lcc}
\hline MECANISMO DE TRAUMA & FREQUÊNCIA & PORCENTAGEM \\
\hline FUTEBOL & 59 & 31.72 \\
TERRENO IRREGULAR & 50 & 26.88 \\
CORRIDA & 15 & 8.06 \\
ESCADA & 13 & 6.99 \\
VOLEIBOL & 10 & 5.38 \\
TÊNIS & 9 & 4.84 \\
QUEDA DE PEQUENA ALTURA & 8 & 4.30 \\
SALTO ALTO & 6 & 3.23 \\
HANDEBOL & 3 & 1.61 \\
BALLET & 2 & 1.07 \\
BASQUETE & 2 & 1.07 \\
SALTOS & 2 & 1.07 \\
AUTOMÓVEL & 2 & 1.07 \\
ATROPELAMENTO & 1 & 0.54 \\
BARCO & 1 & 0.54 \\
BADMINTON & 1 & 0.54 \\
CAVALO & 1 & 0.54 \\
SQUASH & 1 & 0.54 \\
PÉ ADORMECIDO & 1 & 0.54 \\
\hline TOTAL & 186 & 100.0 \\
\hline
\end{tabular}

$\mathrm{Na}$ avaliação do mecanismo de trauma envolvido na lesão, agrupamos as atividades em dois sub grupos: no primeiro foram incluídas as atividades que envolvem saltos e mudança brusca de direção, e no segundo grupo atividades nas quais estes tipos de movimentos não estão presentes (Tabela 5). 
Tabela 5 - Mecanismo de trauma dividido em grupo de atividades sem movimentos de mudança brusca de direção e saltos e grupo com estes movimrntos

\begin{tabular}{lcc}
\hline MECANISMO DE & $\begin{array}{c}\text { GRUPO A } \\
\text { TRAUMA }\end{array}$ & $\begin{array}{c}\text { GRUPO B } \\
(92)\end{array}$ \\
\hline $\begin{array}{l}\text { Sem mudança de direção } \\
\text { e salto (n/\%) }\end{array}$ & $48 / 51$ & $43 / 47$ \\
\hline $\begin{array}{l}\text { Com mudança de direção } \\
\text { e salto (n/\%) }\end{array}$ & $46 / 49$ & $49 / 53$ \\
\hline n/\%: número absoluto e porcentagem. & & \\
\end{tabular}

No que se refere ao alinhamento do retropé e ao tipo de pé, observamos as seguintes distribuições (Tabela 6 e 7):

Tabela 6 - Distribuição do alinhamento do retropé na amostra incluída no trabalho

\begin{tabular}{lcc}
\hline ALINHAMENTO RETROPÉ & FREQUENCIA & PORCENTAGEM \\
\hline NEUTRO & 182 & 97,8 \\
VARO & 3 & 1,6 \\
VALGO & 1 & 0,5 \\
\hline Total & 186 & 100,0 \\
\hline
\end{tabular}


Tabela 7 - Distribuição do tipo de pé na amostra incluída no trabalho

\begin{tabular}{lcc}
\hline TIPO DE PÉ & FREQUÊENCIA & PORCENTAGEM \\
\hline PLANTÍGRADO & 176 & 94,6 \\
PLANO & 1 & 0,5 \\
CAVO & 9 & 4,8 \\
\hline Total & 186 & 100,0 \\
\hline
\end{tabular}

A mobilidade subtalar foi considerada normal em todos os pacientes incluídos, porém a mobilidade do médio pé era parcialmente limitada em dois pacientes $(1,1 \%)$.

As variações anatômicas encontradas na ressonância magnética dos pacientes incluídos estão na tabela 8: 
Tabela 8 - Variação anatômica nos pacientes incluídos no trabalho

\begin{tabular}{lcc}
\hline VARIAÇÃO ANATÔMICA & FREQUÊNCIA & PORCENTAGEM \\
\hline SEM VARIAÇÃO & 142 & 76,3 \\
$\begin{array}{l}\text { TUBEROSIDADE } \\
\text { ANTERIOR DO } \\
\text { CALCÂNEO } \\
\text { PROEMINENTE }\end{array}$ & 33 & 17,7 \\
OS TRIGONUM & & \\
$\begin{array}{l}\text { TUBEROSIDADE } \\
\text { POSTERIOR TÁLUS } \\
\text { PROEMINENTE } \\
\text { BARRA FIBROSA CN }\end{array}$ & 6 & 3,2 \\
BARRA FIBROSA CN + \\
$\begin{array}{l}\text { NAVICULAR } \\
\text { ACESSORIO }\end{array}$ & 3 & 1,6 \\
\hline Total & 1 & \\
\hline CN: calcâneo navicular & & 0,5 \\
\end{tabular}

Observamos as lesões concomitantes à lesão ligamentar nos pacientes incluídos no trabalho na tabela 9: 
Tabela 9 - Lesões concomitantes

\begin{tabular}{lcc}
\hline LESÕES & FREQUÊNCIA & PORCENTAGEM \\
CONCOMITANTES & & \\
\hline SEM LESÕES & 176 & 94,6 \\
AVULSÃO MALÉOLO & 8 & 4.4 \\
LATERAL & & 0,5 \\
FRATURA COTOVELO & 1 & 0,5 \\
SÍNDROME DO TÚNEL & 1 & \\
DO TARSO AGUDA & & 100,0 \\
\hline Total & 186 & \\
\hline
\end{tabular}

As lesões associadas à lesão ligamentar, diagnosticadas através da ressonância magnética, são mostradas na tabela 10: 
Tabela 10 - Lesões associadas às lesões ligamentares do tornozelo

\begin{tabular}{|c|c|c|}
\hline LESÕES ASSOCIADAS & № casos & $\%$ \\
\hline SEM LESÕES ASSOCIADAS & 78 & 41.93 \\
\hline CONTUSÃO TÁLUS & 53 & 28.49 \\
\hline $\begin{array}{l}\text { CONTUSÃO TALUS + } \\
\text { MALÉOLO MEDIAL (MM) }\end{array}$ & 15 & 8.06 \\
\hline LESÃO FIBULAR CURTO & 8 & 4.30 \\
\hline $\begin{array}{l}\text { CONTUSÃO TÁLUS + } \\
\text { LESÃO FIBULAR CURTO }\end{array}$ & 6 & 3.23 \\
\hline AVULSÃO MALÉOLO LATERAL (ML) & 5 & 2.69 \\
\hline $\begin{array}{l}\text { LESÃO DA SINDESMOSE ANTERIOR } \\
\text { (LTFAI) }\end{array}$ & 4 & 2.15 \\
\hline AVULSÃO OS TRIGONUM & 3 & 1.61 \\
\hline $\begin{array}{l}\text { CONTUSÃO TÁLUS + } \\
\text { LESÃO SINDESMOSE ANTERIOR }\end{array}$ & 2 & 1.07 \\
\hline LESÃO FIBULAR LONGO & 1 & 0.54 \\
\hline $\begin{array}{l}\text { AVULSÃO MALÉOLO MEDIAL } \\
\text { AVULSÃO TÁLUS }\end{array}$ & $\begin{array}{l}1 \\
1\end{array}$ & $\begin{array}{l}0.54 \\
0.54\end{array}$ \\
\hline $\begin{array}{l}\text { LESÃO LIG INTERÓSSEO TALO } \\
\text { CALCANEANO }\end{array}$ & 1 & 0.54 \\
\hline $\begin{array}{l}\text { CONTUSÃO TÁLUS + MM + } \\
\text { AVULSÃO ML }\end{array}$ & 1 & 0.54 \\
\hline $\begin{array}{l}\text { CONTUSÃO TÁLUS + AVULSÃO ML } \\
\text { + LESÃO FIBULAR LONGO }\end{array}$ & 1 & 0.54 \\
\hline CONTUSÃO TÁLUS + AVULSÃO ML & 1 & 0.54 \\
\hline $\begin{array}{l}\text { CONTUSÃO TÁLUS + LESÃO } \\
\text { FIBULAR CURTO + AVULSÃO ML }\end{array}$ & 1 & 0.54 \\
\hline $\begin{array}{l}\text { CONTUSÃO TÁLUS + } \\
\text { AVULSÃO TAC }\end{array}$ & 1 & 0.54 \\
\hline $\begin{array}{l}\text { CONTUSÃO TÁLUS + } \\
\text { CONTUSÃO CUBOIDE }\end{array}$ & 1 & 0.54 \\
\hline $\begin{array}{l}\text { CONTUSÃO TÁLUS + } \\
\text { AVULSÃO TÁLUS }\end{array}$ & 1 & 0.54 \\
\hline $\begin{array}{l}\text { SINDESMOSE ANTERIOR (LTFAI) + } \\
\text { FRATURA TÍBIA POSTERIOR }\end{array}$ & 1 & 0.54 \\
\hline TOTAL & 186 & $\mathbf{1 0 0 . 0}$ \\
\hline
\end{tabular}

MM: maléolo medial

ML: maléolo lateral

LTFAI: ligamento tibiofibular antero inferior

TAC: tuberosidade anterior do calcâneo 
Observamos contusão do tálus isoladamente ou associada a outras lesões em 82 pacientes $(44,09 \%)$. 


\subsection{RESULTADOS}

Na avaliação com uma semana da lesão observamos os dados da tabela 11:

Tabela 11 - Comparação entre os dois grupos de tratamento das variáveis avaliadas uma semana após a lesão

\begin{tabular}{lccll}
\hline $\begin{array}{l}\text { AVALIAÇÃO UMA } \\
\text { SEMANA }\end{array}$ & $\begin{array}{c}\text { Grupo A } \\
(n=94)\end{array}$ & $\begin{array}{c}\text { Grupo B } \\
(n=92)\end{array}$ & $p$ & Teste estatístico \\
\hline $\begin{array}{l}\text { Intensidade do edema } \\
(1+/ 2+/ 3+/ 4+\text { em 4) }\end{array}$ & $\mathbf{6 / 5 0 / 3 3 / 5}$ & $10 / 57 / 24 / 1$ & NS & $\mathrm{X}^{\wedge} 2$ \\
$\begin{array}{l}\text { EVA dor (média } \pm \text { dp) } \\
\text { Conforto de deambulação }\end{array}$ & $37,3 \pm 1,5$ & $3 \pm 1,4$ & NS & $\begin{array}{l}\text { Kolmogorv/Teste U } \\
\text { de Mann-Whitney }\end{array}$ \\
$\begin{array}{l}\text { (sim/não/parcial) } \\
\text { Capacidade de apoio }\end{array}$ & $58 / 62$ & $71 / 77$ & NS & $X^{\wedge} 2$ \\
$\begin{array}{l}\text { (sim,\%) } \\
\text { AOFAS (média } \pm \text { dp) }\end{array}$ & $61 \pm 11,2$ & $67 \pm 10,8$ & 0,00003 & $\begin{array}{l}\text { Kolmogorv/Teste U } \\
\text { de Mann-Whitney }\end{array}$ \\
\hline
\end{tabular}

NS: não estatisticamente significativo (>0.05).

$\mathrm{X}^{\wedge} 2$ : teste do qui-quadrado.

EVA: escala visual analógica.

dp: desvio padrão.

Komogorov / Teste U de Mann-Whitney: teste de normalidade de Kolmogorov-Smirnov e teste de Rank de Wilcoxon de Mann-Whitney.

AOFAS: escala da Associação Americana dos Cirurgiões de Pé e Tornozelo

Nesta fase da avaliação notamos haver diferença entre as duas formas de tratamento comparadas somente no que se refere ao conforto à deambulação e à pontuação AOFAS, com maior número de pacientes confortáveis para caminhar e maior pontuação AOFAS no grupo B. 
A distribuição dos ligamentos acometidos é mostrada na tabela 12:

Tabela 12 - Distribuição dos ligamentos lesados nos dois grupos de tratamento

\begin{tabular}{ccc}
\hline LIGAMENTO LESADO & Grupo A $(n=94)$ & Grupo B $(n=92)$ \\
\hline LTFA (n/\%) & $94 / 100$ & $92 / 100$ \\
LCF (n/\%) & $82 / 87,2$ & $76 / 82,5$ \\
LTFP (n/\%) & 0 & 0 \\
LDP (n/\%) & $46 / 49$ & $40 / 43,5$ \\
\hline LDS (n/\%) & 0 & 0 \\
\hline
\end{tabular}

LTFA: ligamento talofibular anterior.

LCF: ligamento calcâneo fibular.

LTFP: ligamento talofibular posterior.

LDP: ligamento deltóide profundo.

LDS: ligamento deltóide superficial.

n/\%: número absoluto e porcentagem

Observamos lesão do LTFA em 100\% dos pacientes, do LCF em 82.5 e $87.2 \%$ dos pacientes e do LDP em 43.5 e 49\%, nos grupos A e B respectivamente. Não houve diferença entre o acometimento dos ligamentos comparando os dois grupos de tratamento.

Procuramos correlacionar a localização da dor na avaliação inicial com os ligamentos acometidos e observamos a seguinte distribuição (Tabela 13): 
Tabela 13 - Comparação entre a localização da dor no primeiro atendimento com os ligamentos acometidos pela lesão

\begin{tabular}{|c|c|c|c|c|c|}
\hline \multirow{2}{*}{$\begin{array}{l}\text { NÚMERO DE } \\
\text { LIGAMENTOS } \\
\text { ACOMETIDOS }\end{array}$} & \multicolumn{5}{|c|}{ Local da Dor } \\
\hline & $\mathbf{A L}$ & AL e SML & AL, SML e PL & AL, SML, PL e MM & Total \\
\hline $1(\mathrm{n} / \%)$ & $6 / 29$ & $8 / 38$ & $3 / 14$ & $4 / 19$ & $\begin{array}{c}21 / 10 \\
0\end{array}$ \\
\hline $2(\mathrm{n} / \%)$ & $5 / 6$ & $23 / 26$ & 29/34 & 29/34 & $\begin{array}{c}86 / 10 \\
0\end{array}$ \\
\hline $3(\mathbf{n} / \%)$ & $3 / 4$ & $11 / 14$ & $15 / 19$ & $50 / 63$ & $\begin{array}{c}79 / 10 \\
0\end{array}$ \\
\hline $\begin{array}{l}\text { PORCENTAGE } \\
\text { M }\end{array}$ & 8,00 & 23,00 & 25,00 & 45,00 & $\begin{array}{c}100,0 \\
0\end{array}$ \\
\hline
\end{tabular}

AL: antero lateral

SML: sob o maléolo lateral

PL: póstero lateral

MM: sob o maléolo medial.

$\mathrm{n} / \%$ : número absoluto e porcentagem

Não pudemos confirmar a presença de correlação entre o ligamento lesado e o local da dor no momento do primeiro atendimento.

$\mathrm{Na}$ avaliação com três semanas, todos os pacientes do trabalho apresentaram estabilidade ao exame físico, demonstrada através do desaparecimento do sinal da gaveta anterior, com exceção do paciente 69 que evoluiu com o tornozelo clinicamente instável.

A tabela 14 mostra os resultados na avaliação com três semanas. 
Tabela 14 - Comparação entre os dois grupos de tratamento das variáveis avaliadas três semana após a lesão

\begin{tabular}{|c|c|c|c|c|}
\hline $\begin{array}{l}\text { AVALIAÇÃO TRÊS } \\
\text { SEMANAS }\end{array}$ & $\begin{array}{c}\text { Grupo } A \\
(n=94)\end{array}$ & $\begin{array}{c}\text { Grupo } B \\
(n=92)\end{array}$ & $p$ & Teste estatístico \\
\hline $\begin{array}{l}\text { Localização da dor/edema } \\
\text { (AL/AL e SML/ AL,SML e } \\
\text { PL/ TODO TORNOZELO) }\end{array}$ & $2 / 65 / 26 / 1$ & $8 / 65 / 19 / 0$ & $\mathbf{N S}$ & $X^{\wedge} 2$ \\
\hline EVA dor (média $\pm d p)$ & $1,7 \pm 1,2$ & $1,4 \pm 1,2$ & $\mathbf{0 , 0 3 4 8}$ & $\begin{array}{l}\text { Kolmogorv/Teste U de } \\
\text { Mann-Whitney }\end{array}$ \\
\hline Capacidade de apoio (sim, \%) & $86 / 92$ & $88 / 96$ & NS & $X^{\wedge} 2$ \\
\hline AOFAS (média $\pm d p)$ & $79,5 \pm 9,2$ & $84,8 \pm 8,8$ & 0,00004 & $\begin{array}{l}\text { Kolmogorv/Teste U de } \\
\text { Mann-Whitney }\end{array}$ \\
\hline $\begin{array}{l}\text { Dias de afastamento do } \\
\text { trabalho (média } \pm d p)\end{array}$ & $7.00 \pm 3,78$ & $3.90 \pm 2.66$ & $<0.01$ & $\begin{array}{l}\text { Kolmogorv/Teste U de } \\
\text { Mann-Whitney }\end{array}$ \\
\hline
\end{tabular}

AL: antero lateral

SML: sob o maléolo lateral

PL: postero lateral

NS: não estatisticamente significativo (>0.05).

$\mathrm{X}^{\wedge}$ 2: teste do qui-quadrado.

EVA: escala visual analógica.

dp: desvio padrão.

Komogorov / Teste U de Mann-Whitney: teste de normalidade de Kolmogorov-Smirnov e teste de Rank de Wilcoxon de Mann-Whitney.

AOFAS: escala da Associação Americana de dos Cirurgiões de Pé e Tornozelo

Nesta avaliação observamos menor média de dor e maior pontuação AOFAS, nos pacientes tratados com órtese funcional.

A avaliação com seis semanas mostra os seguintes resultados (Tabela 15): 
Tabela 15 - Comparação entre os dois grupos de tratamento das variáveis avaliadas seis semanas após a lesão

\begin{tabular}{lcccl}
\hline AVALIAÇÃO SEIS SEMANA & $\begin{array}{c}\text { GrupoA } \\
(n=94)\end{array}$ & $\begin{array}{c}\text { GrupoB } \\
(n=92)\end{array}$ & $p$ & Teste estatístico \\
\hline EVA dor (média \pm dp) & $\mathbf{0 , 7 5 \pm 0 , 9 3}$ & $\mathbf{0 , 5} \pm 0,75$ & NS & $\begin{array}{l}\text { Kolmogorv/Teste U } \\
\text { de Mann-Whitney }\end{array}$ \\
AOFAS (média \pm dp) & $90,5 \pm 10,6$ & $94,3 \pm 6,6$ & 0,027 & $\begin{array}{l}\text { Kolmogorv/Teste U } \\
\text { de Mann-Whitney }\end{array}$ \\
$\begin{array}{l}\text { ADM } \\
\text { (Normal/Limitação Moderada/Grave) }\end{array}$ & $81 / 11 / 2$ & $83 / 7 / 2$ & NS & $X^{\wedge} 2$ \\
$\begin{array}{l}\text { Limitacao AVD's } \\
\text { (Nao/Dirigir/Propriocepcao/Trabalho) }\end{array}$ & $83 / 4 / 6 / 1$ & $87 / 0 / 5 / 0$ & NS & $X^{\wedge} 2$ \\
\hline
\end{tabular}

EVA: escala visual analógica de dor.

dp: desvio padrão.

NS: não estatisticamente significativo (>0.05).

Komogorov / Teste U de Mann-Whitney: teste de normalidade de Kolmogorov-Smirnov e teste de Rank de Wilcoxon de Mann-Whitney.

AOFAS: escala da Associação Americana dos Cirurgiões de Pé e Tornozelo

ADM: amplitude de movimento - limitação

$\mathrm{X}^{\wedge}$ 2: teste do qui-quadrado.

AVD: atividade da vida diária

Observamos pontuação AOFAS maior no grupo tratado com órtese funcional, sem diferença no que se refere à dor, limitação das atividades da vida diária ou mobilidade articular.

A evolução da intensidade da dor dependendo do número de ligamentos acometidos segue o demonstrado na tabela 16 , com diferença significativa da intensidade da dor nos pacientes com lesão de um ou dois ligamentos, em comparação com os que tiveram lesão de três ligamentos, nas avaliações com uma e três semanas. Na sexta semana os pacientes com um ligamento acometido tiveram dor menos intensa comparativamente aos pacientes com dois ou três ligamentos lesados. 
Tabela 16 - Comparação entre o número de ligamentos acometidos e intensidade da dor nas avaliações com uma, três e seis semanas após a lesão

\begin{tabular}{|c|c|c|c|}
\hline NÚMERO DE & \multicolumn{3}{|c|}{$E V A$} \\
\hline LIGAMENTOS & 1 semana & 3 semanas & 6 semanas \\
\hline ACOMETIDOS & & & \\
\hline 1 (média $\pm d p)$ & $2,9 \pm 1,2$ & $1,48 \pm 1,1$ & $0,48 \pm 0,92$ \\
\hline 2 (média $\left.\_d p\right)$ & $2,9 \pm 1,4$ & $1,3 \pm+1$ & $1,8 \pm 1,3$ \\
\hline 3 (média $\left.\_d p\right)$ & $3,5 \pm 1,4$ & $1,8 \pm 1,3$ & $0,85 \pm 0,92$ \\
\hline Anova & $P=0,025$ & $P=0,016$ & $\mathrm{p}=0,006$ \\
\hline post hoc & 3 & $\mathbf{3}$ & 2 e 3 \\
\hline Bonferroni & $\begin{array}{l}\text { LIGAMENTOS } \\
\text { ACOMETIDOS }\end{array}$ & $\begin{array}{l}\text { LIGAMENTOS } \\
\text { ACOMETIDOS }\end{array}$ & $\begin{array}{l}\text { LIGAMENTOS } \\
\text { ACOMETIDOS }\end{array}$ \\
\hline
\end{tabular}

EVA: escala visual analógica de dor.

dp: desvio padrão.

Post hoc Bonferroni: análise post hoc Bonferroni.

A relação entre a pontuação AOFAS e o número de ligamentos acometidos é mostrado na tabela 17. 
Tabela 17 - Comparação entre o número de ligamentos acometidos pela lesão e pontuação da escala AOFAS nas avaliações com uma, três e seis semanas após a lesão

\begin{tabular}{lccc}
\hline \multicolumn{1}{c}{ NÚMERO DE } & \multicolumn{3}{c}{ AOFAS } \\
$\begin{array}{l}\text { LIGAMENTOS } \\
\text { ACOMETIDOS }\end{array}$ & 1 semana & 3 semanas & 6 semanas \\
\hline 1 (média \pm dp) & $67,38 \pm 9,42$ & $96,24 \pm 6,88$ & $98,26 \pm 4,16$ \\
2 (média \pm dp) & $66,06 \pm 9,73$ & $98,77 \pm 3,7$ & $99,55 \pm 2,2$ \\
3 (média \pm dp) & $60,47 \pm 12,76$ & $97,44 \pm 5,47$ & $98,84 \pm 3,18$ \\
Anova & $\mathrm{p}=0,002$ & $\mathrm{NS}$ & $\mathrm{NS}$ \\
\hline $\begin{array}{l}\text { post hoc } \\
\text { Bonferroni }\end{array}$ & 3 ligamentos acometidos é diferente dos indivíduos que tiveram \\
\end{tabular}

AOFAS: escala da Associação Americana dos Cirurgiões de Pé e Tornozelo dp: desvio padrão.

Post hoc Bonferroni: análise post hoc Bonferroni.

NS: não estatisticamente significativo.

Na primeira semana a pontuação foi menor nos pacientes com três ligamentos lesados, comparados aos indivíduos com um ou dois ligamentos acometidos.

Após 12 semanas do trauma não notamos mais diferenças entre os dois grupos. Neste ponto do tratamento a estabilidade articular foi avaliada clínicamente e através da realização de Rx com estresse. Os resultados são descritos na tabela 18. 
Tabela 18 - Comparação entre os dois grupos de tratamento das variáveis avaliadas doze semana após a lesão

\begin{tabular}{|c|c|c|c|c|}
\hline AVALIAÇÃO DOZE SEMANAS & $\begin{array}{c}\text { Grupo A } \\
(n=94)\end{array}$ & $\begin{array}{c}\text { Grupo B } \\
(n=92)\end{array}$ & $p$ & Teste estatístico \\
\hline AOFAS (média $\pm d p)$ & $97,4 \pm 5,5$ & $98,4 \pm 4,4$ & NS & $\begin{array}{l}\text { Kolmogorv/Teste } \\
\text { U de Mann- } \\
\text { Whitney }\end{array}$ \\
\hline $\begin{array}{l}\text { Limitacao AVD's } \\
\text { (Não/Dirigir/Propriocepção/Trabalh } \\
\text { o) }\end{array}$ & $80 / 4 / 9 / 1$ & $87 / 2 / 3 / 0$ & NS & $X^{\wedge} 2$ \\
\hline $\begin{array}{l}\text { Varo contralateral } \\
\text { (graus, média } \pm d p)\end{array}$ & $\underset{0}{3,45 \pm 2,5}$ & $3,05 \pm 2,93$ & NS & $\begin{array}{l}\text { Komogorov/Test } \\
t\end{array}$ \\
\hline $\begin{array}{l}\text { Varo lado acometido } \\
\text { (graus, média } \pm \text { dp) }\end{array}$ & $\frac{3,45 \pm 2,9}{3}$ & $3,3 \pm 2,2$ & NS & $\begin{array}{l}\text { Komogorov/Test } \\
\text { t }\end{array}$ \\
\hline $\begin{array}{l}\text { Gaveta contralateral } \\
(\mathbf{m m}, \text { média } \pm \text { dp })\end{array}$ & $\frac{4,76 \pm 1,4}{6}$ & $4,63 \pm 1,35$ & NS & $\begin{array}{l}\text { Komogorov/Test } \\
\text { t }\end{array}$ \\
\hline $\begin{array}{l}\text { Gaveta lado acometido } \\
(\mathbf{m m}, \text { média } \pm \text { dp) }\end{array}$ & $\underset{6}{4,82 \pm 1,4}$ & $4,74 \pm 1,45$ & NS & $\begin{array}{l}\text { Komogorov/Test } \\
\text { t }\end{array}$ \\
\hline
\end{tabular}

AOFAS: escala da Associação Americana dos Cirurgiões de Pé e Tornozelo.

dp: desvio padrão.

NS: não estatisticamente significativo $(<0.05)$.

Komogorov / Teste U de Mann-Whitney: teste de normalidade de Kolmogorov-Smirnov e teste de Rank de Wilcoxon de Mann-Whitney.

AVD: atividade da vida diária.

$\mathrm{X}^{\wedge}$ 2: teste do qui-quadrado.

Test T: Teste T de Studebt.

A avaliação clínica da estabilidade articular através do teste da gaveta anterior não mostrou diferença entre os grupos, porém, em um caso, no Grupo A, ocorreu evolução para instabilidade articular. Não houve diferença nos valores dos ângulos medidos nas radiografias com estresse nos dois grupos. Vinte pacientes $(10,7 \%)$ queixaram-se de dor leve e ocasional, três $(1,6 \%)$ dor para as atividades da vida diária, e uma $(0,54 \%)$ paciente, 
dor para usar salto alto. Não houve diferença significativa entre os grupos no que se refere à dor.

A tabela 19 compara a gravidade da dor e a escala funcional AOFAS com a presença ou não de lesão associada.

Tabela 19 - Comparação da intensidade da dor através da escala EVA e função através da escala AOFAS com a presença de lesão associada à lesão ligamentar

\begin{tabular}{|c|c|c|c|}
\hline \multirow{2}{*}{$\begin{array}{c}\text { Lesão Asociada X Dor e } \\
\text { AOFAS }\end{array}$} & \multicolumn{2}{|c|}{ Lesãa Associada } & \multirow[b]{2}{*}{ p valor } \\
\hline & Não $(n=78)$ & $\operatorname{Sim}(n=108)$ & \\
\hline EVA 1 semana (média $\pm d p)$ & $2,81 \pm 1,04$ & $3,4 \pm 1,66$ & $\mathbf{0 , 0 3 6}$ \\
\hline \multirow{2}{*}{$\begin{array}{l}\text { AOFAS } 1 \text { semana } \\
\text { (média } \pm d p)\end{array}$} & $66,62 \pm 8,41$ & $63,04 \pm 12,50$ & NS \\
\hline & Não (n=63) & $\operatorname{Sim}(n=91)$ & \\
\hline $\begin{array}{l}\text { EVA } 3 \text { semanas } \\
\text { (média } \pm \text { dp) }\end{array}$ & $\mathbf{1 , 3 8 \pm 1 , 0 9}$ & $1,62 \pm 1,32$ & NS \\
\hline \multirow{2}{*}{$\begin{array}{l}\text { AOFAS } 3 \text { semana } \\
(\text { média } \pm d p)\end{array}$} & $83,87 \pm 7,42$ & $81,7 \pm 9,80$ & NS \\
\hline & Não (n=62) & $\operatorname{Sim}(n=86)$ & \\
\hline $\begin{array}{l}\text { EVA } 6 \text { semanas } \\
\text { (média } \pm d p)\end{array}$ & $0,4 \pm 0,58$ & $0,74 \pm 1,05$ & NS \\
\hline $\begin{array}{l}\text { AOFAS } 6 \text { semanas } \\
\text { (média } \pm d p)\end{array}$ & $95,21 \pm 5,26$ & $90,35 \pm 10,79$ & 0,011 \\
\hline $\begin{array}{l}\text { AOFAS } 12 \text { semanas } \\
(\text { média+dp) }\end{array}$ & $\begin{array}{l}\text { Não }(n=61) \\
98,41 \pm 3,72\end{array}$ & $\begin{array}{c}\operatorname{Sim}(n=80) \\
97,11 \pm 6,38\end{array}$ & NS \\
\hline
\end{tabular}

EVA: Escala visual analógica de dor.

dp: desvio padrão.

AOFAS: Escala functional da Sociedade Americana dos Cirurgiões de Pé e Tornozelo.

NS: não estatisticamente significativo

$\mathrm{Na}$ avaliação com uma semana, a dor foi mais intensa nos pacientes com lesão associada, com diferença média de 1,6. Com seis semanas a escala AOFAS foi maior nos pacientes sem lesão associada. 
Para validar as medidas utilizadas nas radiografias com estresse, realizamos teste de correlação inter-observador (primeira avaliação dos dois observadores) e intraobservados (duas medidas do primeiro observador). Os resultados estão na tabela 20:

Tabela 20 - Testes de correlação inter e intraobservadores para a avaliação radiográfica das radiografias com estresse em varo e gaveta anterior

\begin{tabular}{|c|c|c|c|c|}
\hline $\begin{array}{l}\text { CORRELAÇÃO } \\
\text { INTRACLASSE } \\
\text { (Interobservador) }\end{array}$ & $I C C$ & $\begin{array}{c}\text { IC95\% lower - } \\
\text { upper }\end{array}$ & $\begin{array}{l}p \\
\text { valor }\end{array}$ & Teste estatístico \\
\hline Varo contralateral & 0,695 & $0,567-0,791$ & $<0,01$ & ICC \\
\hline Varo lado acometido & 0,762 & $0,656-0,839$ & $<0,01$ & ICC \\
\hline Gaveta contralateral & $\mathbf{0 , 7 1 7}$ & $0,596-\mathbf{0 , 8 0 7}$ & $<0,01$ & ICC \\
\hline $\begin{array}{l}\text { Gaveta lado } \\
\text { acometido }\end{array}$ & 0,761 & $0,654-0,838$ & $<0,01$ & ICC \\
\hline 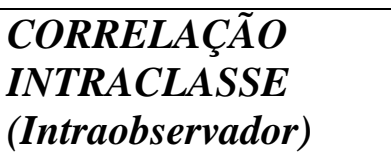 & $I C C$ & $\begin{array}{c}\text { IC95\% lower - } \\
\text { upper }\end{array}$ & $\begin{array}{l}p \\
\text { valor }\end{array}$ & \\
\hline Varo contralateral & 0,722 & $0,603-0,810$ & $<0,01$ & ICC \\
\hline Varo lado acometido & 0,790 & $0,694-0,858$ & $<0,01$ & ICC \\
\hline Gaveta contralateral & 0,764 & $0,659-0,840$ & $<0,01$ & ICC \\
\hline $\begin{array}{l}\text { Gaveta lado } \\
\text { acometido }\end{array}$ & 0,799 & $0,706-0,864$ & $<0,01$ & ICC \\
\hline
\end{tabular}

ICC: coeficiente de correlação intra classe.

Na comparação dos resultados das radiografias em estresse, dependendo do tipo de tratamento realizado, não observamos diferenças entre os grupos (Tabela 21): 
Tabela 21 - Comparação do resultado das radiografias em estresse dependendo do tipo de tratamento

\begin{tabular}{lcccccccc}
\hline $\begin{array}{l}\text { TESTE } \\
\text { REALIZADO }\end{array}$ & \multicolumn{2}{c}{ Grupo A } & & \multicolumn{5}{c}{ Grupo B } \\
& NORMAL & ACOM & p & $\begin{array}{l}\text { Teste } \\
\text { estatístico }\end{array}$ & NORMAL & ACOM & P & $\begin{array}{l}\text { Teste } \\
\text { estatístico }\end{array}$ \\
\hline $\begin{array}{l}\text { Varo em } \\
\text { graus } \\
\text { (média } \pm \text { dp) }\end{array}$ & $3,5 \pm 2,5$ & $3,5 \pm 2,9$ & NS & Test t & $3,1 \pm 3$ & $3,3 \pm 2,2$ & NS & Test t \\
$\begin{array}{l}\text { Gaveta em } \\
\text { mm } \\
\text { (média } \pm \text { dp) }\end{array}$ & $4,8 \pm 1,5$ & $4,8 \pm 1,5$ & NS & Test t & $4,6 \pm 1,4$ & $4,7 \pm 1,5$ & NS & Test t \\
\hline
\end{tabular}

ACOM: acometidos.

dp: desvio padão.

NS: diferença não significativa.

Test t: teste T de Student.

Comparando a presença de instabilidade nas radiografias com estresse, levando em consideração diferença maiores do que 3 e 5 graus na medida do estresse em varo, e 3 e 5 $\mathrm{mm}$ na medida do estresse em gaveta anterior, observamos a seguinte distribuição de acordo com o tratamento (Tebela 22): 
Tabela 22 - Comparação entre as variações maiores do que 3 graus ou $3 \mathrm{~mm}$, e variações maiores do que 5 graus ou $5 \mathrm{~mm}$ nas radiografias com estresse

\begin{tabular}{|c|c|c|c|c|}
\hline $\begin{array}{l}\text { INSTABILIDADE } \\
(>3 \text { graus ou }>3 \mathrm{~mm})\end{array}$ & $\begin{array}{c}\text { Grupo } A \\
(n=81)\end{array}$ & $\begin{array}{c}\text { Grupo B } \\
(n=73)\end{array}$ & p valor & $\begin{array}{l}\text { Teste } \\
\text { estatístico }\end{array}$ \\
\hline $\operatorname{COM}(\mathbf{n} / \%)$ & $73 / 90$ & $68 / 93$ & NS & $X^{\wedge} 2$ \\
\hline $\operatorname{SEM}(\mathbf{n} / \%)$ & $8 / 10$ & $5 / 7$ & & \\
\hline $\begin{array}{l}\text { INSTABILIDADE } \\
(>5 \text { graus ou }>5 \mathrm{~mm})\end{array}$ & $\begin{array}{c}\text { Grupo A } \\
(\mathbf{n}=\mathbf{8 1})\end{array}$ & $\begin{array}{c}\text { Grupo B } \\
(n=73)\end{array}$ & p valor & $\begin{array}{l}\text { Teste } \\
\text { utilizado }\end{array}$ \\
\hline $\operatorname{COM}(\mathbf{n} / \%)$ & $80 / 99$ & 73/100 & NS & $X^{\wedge} 2$ \\
\hline $\operatorname{SEM}(\mathbf{n} / \%)$ & $1 / 1$ & $\mathbf{0}$ & & \\
\hline
\end{tabular}

n/\%: número absoluto e porcentagem.

NS: não estatisticamente significativo.

$\mathrm{X}^{\wedge}$ 2: teste do qui-quadrado.

Não houve diferença significativa entre os grupos. 


\section{DISCUSSÃO}

A avaliação da base de dados dos pacientes incluídos na casuística mostra que não houve variação significativa entre os dois grupos de tratamento, com exceção da capacidade de apoio logo após o trauma e da intensidade da dor.

Com relação à capacidade de apoioa diferença observada não nos pareceu relevante, pois não houve variação na gravidade da lesão, e a diferença na intensidade da dor foi menor do que dois, considerada a mínima disparidade necessária para haver percepção clínica de dor com intensidade diferente (Gatchel et al., 2010).

A distribuição dos casos, segundo os grupos de tratamento foi, portanto, homogênea, indicando que o processo de randomização foi eficiente.

Não houve perda de dados neste trabalho, provavelmente pelo fato de os pacientes terem sido atendidos e acompanhados no consultório privado do autor.

O pé e o tornozelo fazem parte de um sistema complexo, responsável pela flexibilidade e estabilidade do membro inferior. Durante atividades em cadeia cinética fechada (realizadas com o segmento distal do membro inferior fixo), as articulações funcionam de forma a absorver impacto no momento do contato do calcâneo com o solo, prover uma base de sustentação estável para permitir a postura ereta, permitir a adaptação às irregularidades do terreno e agir como uma alavanca rígida durante a fase de desprendimento do calcâneo (Seto, Brewster, 1994). A função normal deste segmento depende da integridade anatômica, da mobilidade articular e da função muscular.

O objeto deste estudo são as estruturas ligamentares laterais da articulação do tornozelo, e a fase de apoio é o período no qual normalmente ocorrem as lesões destes ligamentos, relacionadas aos traumas conhecidos como entorses.

As estruturas ligamentares do tornozelo tem três funções principais. A primeira função é contribuir para a estabilidade mecânica da articulação, prevenindo movimentos excessivos. A mobilidade permitida é a amplitude de movimento normal da articulação (Noyes et al., 1974). A segunda é agirem como guias para a movimentação articular (Safran et al., 1999). A terceira função é fornecerem informações proprioceptivas para regular a função articular.

O mecanismo de trauma mais comum associado às lesões ligamentares do tornozelo é a entorse que ocorre em inversão, flexão plantar e rotação interna. Uma vez que a 
inversão tem início, o tornozelo perde relativamente sua estabilidade óssea (maior lateralmente) e o maléolo medial age como um fulcro, aumentando o momento de inversão (Mack, 1982).

Os ligamentos laterais são as estruturas mais frequentemente acometidas nestes traumas, principalmente os ligamento talo fibular anterior (LTFA) e ligamento calcâneo fibular (LFC) (Ferkel et al., 1991), que tem ação sinérgica (Renstrom et al., 1988), visto que, quando um está relaxado, o outro é tensionado.

A sequência mais comum da lesão ligamentar lateral do tornozelo é o acometimento do LTFA seguida pela cápsula anterior. A progressão do mecanismo de trauma provoca o acometimento do LCF, seguida pelo LTFP (Burks, Morgan, 1994), e pode se associar a lesões do ligamento deltoide profundo (LDP), luxação do tornozelo, fraturas do maléolo lateral, fraturas do maléolo medial, fraturas por compressão medial da tróclea ou face articular medial do tálus e até fraturas do colo do tálus (Cox, 1985).

Nesta casuística, 28 pacientes $(15.05 \%)$ apresentaram lesão isolada do LTFA e 158 (85.4\%) lesão associada deste com o LCF. Oitenta e seis pacientes (46.49\%) apresentaram lesão do LFTA, LFC e LDP. Não ocorreu lesão do LFTP nesta casuística.

Na prática clínica, tanto no consultório como nas unidades de primeiro atendimento, é grande a frequência das entorses no tornozelo, e como consequência, das lesões ligamentares desta articulação. A literatura confirma esta observação. Acomete 27000 indivíduos por dia nos Estados Unidos (Baumhauer et al., 1995), e corresponde a 10\% de todos os atendimentos em serviços de emergência.

A incidência, nesta casuística, foi maior (57\%) no sexo masculino (Tabela 1), sem predomínio com relação ao lado (Tabela 2). A média de idade dos pacientes incluídos foi de 32.6 anos (Tabela 3), mas, na literatura, é, reconhecidamente, um trauma que acomete indivíduos mais jovens. Isto pode se relacionar às características dos pacientes deste estudo, mostrando a tendência desta população.

De acordo com o mecanismo de trauma (Tabela 4) notamos frequência importante (162 pacientes ou 87,1 \%) de entorses associadas com atividades físicas. São as lesões mais comuns associadas aos esportes (Ekstrand, 1983; Kadel, 2006; Mack 1982) e atividades recreativas. Destas lesões, 15\% correspondem a lesões ligamentares graves (Beynnon et al., 2006). 
Dividimos o mecanismo de trauma em dois grupos. Em 95 pacientes (51,35\% dos casos) houve associação com atividades com saltos e mudanças de direção (pois atividades com estas características favorecem a ocorrência da entorse), e o restante relacionado às atividades que não envolvem este tipo de movimento (Tabela 5). Não houve variação entre os grupos de tratamento.

As informações a respeito da relação da estrutura do arco longitudinal medial e a ocorrência de lesões ligamentares do tornozelo são conflitantes, havendo trabalhos que afirmam haver maior incidência nos pacientes com pé cavo varo e arco longitudinal medial elevado (Morrison e Kaminski, em 2007), e outros não (Jackson et al., em 1974).

Não tivemos número importante de pacientes com alterações posturais (Tabelas 6 e 7) do retropé em varo (três pacientes $-1,6 \%$ ) ou pé cavo (nove pacientes $-4,8 \%$ ), diagnosticados pelo exame clínico (Mann, 1992), e, portanto, não conseguimos realizar comparação estatística adequada para verificar a presença de evolução pior nestes pacientes.

O uso de calçados de salto alto aumenta a chance de traumas em inversão do tornozelo (Foster et al., 2012). Em seis pacientes $(3,23 \%)$ o trauma foi relacionado ao uso deste tipo de calçado, considerado instável.

Estas lesões são responsáveis por longos períodos de afastamento das atividades esportivas (Garrick, 1977) e profissionais, provocando grave prejuízo econômico. Belangero et al., 2010, afirmam que na cidade de São Paulo (população de 10 milhões de indivíduos) ocorrem 1000 lesões ligamentares laterais do tornozelo ao dia, acometendo 500 indivíduos economicamente ativos (metade da população entre 20 e 65 anos de idade). Considerando, como consequência, 14 dias sem trabalhar por indivíduo, isso significaria 1750 faltas por dia e 1.277.500 faltas ao trabalho em um ano. Como o salário médio do trabalhador era de $\mathrm{R} \$ 818,00$ ao mês, na ocasião do estudo, isso levou ao cálculo de um custo anual de 34 milhões de reais. Trata-se, portanto, de um sério problema de saúde pública.

Este fato indica a necessidade de adequada padronização da conduta, com base na eficácia, custo e segurança.

A história e o exame físico minuciosos são importantes para o diagnóstico adequado das lesões ligamentares agudas e graves do tornozelo (Trevino et al., 1994). 
Nos pacientes deste estudo, a intensidade da dor (EVA) no momento do diagnóstico (Tabela 3) foi, em média, de 7,1 e 6,6 nos grupos A e B respectivamente, variação significativa estatisticamente, porém menor do que dois. Dentre estes pacientes, $70.04 \%$ não conseguiam apoiar o pé acometido imediatamente após o trauma, com exceção de um em que a incapacidade de apoio ocorreu tardiamente. Consideramos este parâmetro, indicativo de maior gravidade e importante no diagnóstico de lesões ligamentares acompanhadas de instabilidade articular (Stiell et al., 1992), no entanto, pode estar ausente na presença de lesões completas, como ocorreu em 29,96\% dos pacientes.

Um paciente apresentou quadro de dor intensa em toda a planta do pé e sinal de tinel positivo no trajeto retromaleolar medial do tornozelo (síndrome do túnel tarsal aguda) consequente ao trauma (Tabela 9), com resolução apenas com medidas para controle do edema.

Hockenbury e Sammarco, 2001 descrevem a ocorrência de lesões dos nervos periféricos associadas às entorses, o que não ocorreu nestes casos.

$\mathrm{O}$ conhecimento da anatomia permite a pesquisa objetiva das estruturas envolvidas no trauma e os testes de estabilidade articular permitem a identificação das lesões que provocam alteração da mecânica normal do tornozelo (Campbell, 1996).

As figuras 8 e 9 (Anexo C) mostram a localização dos LTFA (Rasmussen, 1985) e LCF (Golano et al., 2006) em dissecções anatômicas.

Não pudemos relacionar o local da dor na primeira avaliação com os ligamentos acometidos na lesão (Tabela 13), pois o grande número de grupos formados e consequente pequeno número de indivíduos em alguns grupos, impediu que se realizasse avaliação da presença de correlação estatística. Acreditamos, no entanto, que a localização inicial da dor é fundamental na identificação dos ligamentos lesados (Funder et al., 1982), da mesma forma que é de extrema importância na suspeição de lesões associadas.

O teste manual utilizado para o diagnóstico da instabilidade lateral do tornozelo foi a gaveta anterior (Clanton, McGarvey, 2007; Trevino et al., 1994), que permite, de forma reprodutível, a identificação clínica da instabilidade articular (Phisitkul et al., 2009; Kerkhoffs et al., 2007; Klenerman, 1998; van Dijk et al., 1996 b; Black et al., 1978).

O exame clínico cuidadoso, feito com o paciente relaxado e devidamente orientado, mesmo logo após o trauma, mostra, comparativamente ao lado normal, a presença de 
translação anterior aumentada na lesão ligamentar aguda completa do LTFA (Klenerman, 1998; Jahss, 2002; Watson, 2007). Van Dijk et al., 1996b afirmam que o exame realizado dentro de 48 hs tem sensibilidade de $71 \%$ e especificidade de $33 \%$, em parte, devido à contração reflexa da musculatura da perna secundária à presença de dor, porém, quando realizado após cinco dias da lesão mostra sensibilidade de $96 \%$ e especificidade de $84 \%$, com boa correlação entre os observadores.

A porcentagem de pacientes portadores de lesão ligamentar grave e que apresentam sinal da gaveta anterior positiva no exame físico pode ser tão alta quanto $100 \%$ (De Simoni et al., 1996), ou tão baixa como 68\% (Raatikainen et al., 1992), e esta variação da sua especificidade pode significar que pacientes com lesão grave podem não ter sido incluídos neste estudo, porém este não foi considerado um problema importante, pois o objetivo deste trabalho foi avaliar a instabilidade residual nos pacientes comprovadamente portadores de instabilidade articular relacionada a lesões ligamentares graves, o que todos apresentaram.

Os pacientes com outros sinais clínicos de lesão ligamentar grave, mesmo com gaveta anterior negativa, devem ser tratados como portadores de lesão grave até o diagnóstico definitivo seja firmado em nova avaliação clínica (exames sequenciais) ou através de exames de imagem complementares.

Este teste clínico é conveniente para os médicos, pois é realizado pelo próprio examinador, e não há a necessidade de aparatos específicos, ou da realização de procedimentos anestésicos, como a infiltração intra-articular, porém apresentam subjetividade relacionada ao nível de experiência do indivíduo que o executa, apresentando variação entre observadores (Fujii et al., 2000).

Frey et al, (1996) encontraram $100 \%$ de correlação entre o exame físico de pacientes com lesão ligamentar aguda grave (grau III, com instabilidade mecânica) e a avaliação através de ressonância magnética. Isto também ocorreu nos pacientes desta casuística, examinados dentro de, no máximo, cinco dias, e todos apresentaram instabilidade perceptível ao teste clínico da gaveta anterior positivo, mesmo quando este foi realizado nas primeiras horas após o trauma. A presença da lesão completa de pelo menos um ligamento lateral foi confirmada através de ressonância magnética. Sendo assim, a presença deste sinal é de suma importância para o diagnóstico de lesões ligamentares agudas associadas à instabilidade da articulação do tornozelo. 
Comparativamente, o teste clínico da gaveta anterior é preditivo da instabilidade do tornozelo, o que não ocorre com o teste da inclinação talar (Baumhauer et al., 1995). Este teste é de difícil realização no primeiro atendimento, por provocar maior desconforto, porém, tardiamente, pode ser útil no diagnóstico da instabilidade articular remanescente. São considerados complementares e não diferenciam as lesões ligamentares isoladas das associadas (Johannsen, 1978).

As radiografias são utilizadas para afastar a presença de lesões ósseas associadas, porém, não são todos os pacientes com entorse do tornozelo que devem ser submetidos a este exame. Os critérios para indicar a necessidade de se realizar o exame radiográfico (radiografias com incidência anteroposterior, anteroposterior com 15 a 20 graus de rotação interna e lateral do tornozelo) estão descritos no protocolo de Ottawa (Stiell et al., 1992). As radiografias com estresse não foram consideradas úteis para o diagnóstico da lesão ligamentar aguda, porque todos os pacientes incluídos tinham alterações objetivas ao exame físico (dor na topografia dos ligamentos laterais do tornozelo e teste da gaveta anterior positivo), que demonstravam a presença da instabilidade articular.

Nestes pacientes, o exame radiográfico mostrou a ocorrência de lesões concomitantes em apenas 4,3\% dos casos, em todos, fraturas avulsão do maléolo lateral.

A ressonância magnética confirmou a presença da lesão ligamentar lateral (Figuras 10 a 12, Anexo C), permitindo a comparação dos resultados com a extensão desta lesão, e auxiliou na identificação das lesões associadas, situação considerada frequente na literatura (van Dijk et al., 1996a). Não é necessária para o diagnóstico da lesão ligamentar, já que o exame físico é suficiente (Tiling et al., 1994).

A graduação das lesões ligamentares do tornozelo, de acordo com sua gravidade, auxilia a escolha da melhor forma de tratamento, a capacidade de prever o tempo de retorno às atividades de vida diária e profissionais e às atividades físicas realizadas previamente à lesão (Gerber et al., 1998), e a antever o prognóstico.

Optamos pela classificação proposta por Mack (1982) e devidamente descrita por Gerber et al., (1998), porque as lesões parciais (tipos I e II) não provocam instabilidade articular, e as lesões ligamentares laterais completas (tipo III), podem evoluir com instabilidade mecânica crônica, sendo, portanto, as lesões que necessitam tratamento 
diferenciado no que se refere ao tempo mais prolongado de proteção, além de adequado programa de reabilitação.

As classificações que levam em consideração quais ligamentos foram acometidos (Hamilton, em 1982) não foram utilizadas, pois a lesão isolada do LTFA, é suficientes para provocar instabilidade articular (Glasgow et al., 1980), fato observado em 15,05\% dos pacientes incluídos neste trabalho, e apresentavam instabilidade ao exame físico. A presença de associação de lesões do LTFA e LCF (84,95 \% dos pacientes) ou a associação destes com a lesão do LDP (Tabela 12) não muda a indicação da forma de tratamento, pois não houve diferença no resultado final do tratamento conservador quanto à estabilidade articular.

A lesão ligamentar medial nos parece relacionada à mobilização do tálus em varo dentro da pinça maleolar no momento do trauma, o que provoca impacto da borda medial do tálus de encontro à face articular do maléolo medial, com lesão por compressão do ligamento ali localizado. Isso fica evidente nos pacientes que apresentaram alteração do sinal do LDP associada à presença de áreas de contusão óssea da borda medial do tálus e do maléolo medial. A presença deste tipo de lesão não provoca maior instabilidade da articulação. Não encontramos, na literatura, afirmações contrárias a esta observação.

A ocorrência de variações anatômicas (Tabela 8) aparentemente não se relacionou com resultados piores, porém a adequada avaliação da presença de tendências estatísticas não pode ser realizada, pelo pequeno número de indivíduos nos grupos.

As lesões traumáticas associadas às entorses do tornozelo, também foram investigadas através da ressonância magnética (De Simoni et al., 1996; Ferkel et al., 1991), fato importante, pois, em alguns casos o tratamento específico pode ser necessário (Judd, Kim,2002; van Dijk et al., 1996a).

A incidência de lesões associadas foi expressiva. As lesões mais comumente observadas foram: contusão isolada do tálus $(28,49 \%)$, contusão do tálus associada à contusão do maléolo medial $(8,06 \%)$, lesões do tendão fibular curto $(7,53 \%)$, como vemos nas figuras 13 a 15 (Anexo C), fratura avulsão da extremidade do maléolo lateral $(4,3 \%$ ) e lesão da sindesmose anterior (ligamento tibiofibular anterior inferior) em 2,15\% (Tabela 10). 
A incidência de lesões osteocondrais associadas foi zero, porém observamos sinais radiográficos de contusão óssea em 44,62 \% dos pacientes. As lesões osteocondrais pequenas, inicialmente visualizadas apenas como áreas de contusão óssea, podem evoluir para lesões maiores e mais graves. No caso de evolução não satisfatória esta possibilidade deve ser avaliada.

Estas observações provocam reflexões a respeito da real necessidade da investigação com ressonância magnética em todos os pacientes com sinais de lesão ligamentar grave. Esta poderia ser indicada nos pacientes com dores em locais não habituais, indicando lesões associadas, e situações de evolução não esperada após o início do tratamento conservador.

Três pacientes foram excluídos, um por apresentar lesão extensa dos ligamentos da sindesmose, um por fratura completa e sem desvio do corpo do tálus, e um por lesão associada do médio pé.

Pacientes com fraturas avulsão relacionadas à lesão ligamentar foram mantidos no protocolo (Figura 16 e 17, Anexo C), com o que concordam Moller-Larsen et al. (1988). A evolução nestes casos não diferiu da observada nos casos sem este tipo de lesão. O fragmento avulsionado consolida no local ou fica estável na posição, através do tecido cicatricial fibroso denso formado, não havendo sintomas residuais após a adequada cicatrização.

As lesões ligamentares agudas graves do tornozelo, no Brasil, são tratadas conservadoramente com imobilização rígida por $63,7 \%$ dos ortopedistas, cirurgicamente por $40,5 \%$, com fisioterapia por $24,3 \%$ e com imobilização funcional por 16,2 \% (Belangero et al., 2010). As porcentagens não perfazem $100 \%$ porque, neste estudo, foi possível escolher mais do que uma forma de tratamento.

Concordamos com a afirmação de Kerkhoffs et al. (2001) de que a variação do modo de tratamento sugerem a falta de evidências quanto às estratégias de condução deste problema tão frequente. As conclusões são limitadas pela grande variedade de formas de tratamento utilizadas, e pela inconsistência dos seguimentos (Kerkhoffs et al., 2002b). Além disso, há incerteza quanto a real incidência de instabilidade residual, pois, nos pacientes com maus resultados, a instabilidade articular funcional não é diferenciada da 
instabilidade mecânica do tornozelo, sendo todos incluídos como portadores de instabilidade crônica do tornozelo.

Analisando a literatura notamos que o prognóstico é excelente ou bom na maioria dos pacientes, a despeito do tratamento realizado (reparação cirúrgica, imobilização gessada, mobilização precoce controlada) (Kannus, Renstrom, 1991). O tratamento conservador é o preferido por Freeman, 1965.

Metanálise incluindo 16 trabalhos, comparando os resultados do tratamento conservador com o tratamento cirúrgico das lesões ligamentares do tornozelo, observa que não há evidências suficientes a respeito da melhor forma de tratamento para estas lesões. A recomendação é levar em consideração as complicações (Niedermann et al., 1981; Evans et al., 1984) e alto custo relacionados ao procedimento cirúrgico, sendo a melhor opção o tratamento conservador com acompanhamento cuidadoso para identificar os pacientes que continuarão com sintomas.

$\mathrm{Na}$ literatura encontramos referências que mostram melhores resultados do tratamento clínico funcional com relação ao tratamento cirúrgico (Henning, Egge, 1977; Munk et al., 1995; Kaikkonen et al., 1996; Kerkhoffs et al., 2007) e ao uso de imobilizações gessadas rígidas (Kerkhoffs et al., 2001; Kerkhoffs et al., 2002a; Kerkhoffs et al., 2002b; Karlsson et al., 1996). O tratamento clínico funcional promove recuperação mais rápida, e retorno mais precoce às atividades profissionais (Jones e Amendola, 2007; Konradsen et al., 1991; Seto, Brewster, 1994 e Lynch, Renstrom, 1999), e, além disso, não se relaciona a aumento da incidência de instabilidade objetiva ou subjetiva, e nem a um maior número de recidivas (Weber, Maleski, 2002). Apesar de não haver estudos controlados sobre o tratamento destas lesões nos atletas não há razão para tratá-los de forma diferente (Evans et al., 1984; Tiling et al., 1994; Ogilvie-Harris, Gilbart, 1995; Shrier, 1995).

Apesar dos resultados convincentes, as órteses raramente são utilizadas nos estágios iniciais do tratamento das lesões ligamentares do tornozelo. Kemler et al., 2011 afirmam que não existe, na literatura, avaliação sistemática da eficiência do uso das órteses funcionais, comparada às outras formas de imobilização, durante o tratamento funcional.

Durante o apoio, as cargas axiais aumentam o contato entre as superfícies articulares do tálus e da tíbia, provendo maior estabilidade rotacional (Cawley, France, 1991) nesta articulação com grande congruência anatômica (Krips, 2006). Esta afirmação serve de 
suporte para permitir a carga precoce aos pacientes com lesão ligamentar grave do tornozelo, na dependência do conforto, sem haver prejuízo no processo de cicatrização e, portanto, do resultado final (Hockenbury, Sammarco, 2001).

Os ligamentos tem pouca ou nenhuma função na estabilização do tornozelo durante movimentos dentro da amplitude fisiológica, sendo apenas solicitados em posições forçadas (Noyes et al., 1974). Esta constatação permite a indicação do tratamento funcional nas lesões ligamentares graves do tornozelo, através do uso de imobilizadores que mantém a mobilidade dentro de limites fisiológicos, limitando apenas os movimentos que provocam solicitação das estruturas lesadas, possibilitando a formação do tecido cicatricial sem que ocorram lesões sucessivas por tensionamento exagerado da cicatriz em formação (Clayton et al., 1968; DiGiovanni et al., 2000). No caso das lesões ligamentares laterais, as mais comuns e motivo deste estudo, os movimentos que devem ser limitados são a flexão plantar e a inversão.

A mobilização precoce melhora a diferenciação dos fibroblastos no tecido cicatricial (Kaneko et al., 2009) e a aplicação de tensão leve neste tecido favorece a formação das fibras colágenas orientadas ao longo das linhas de estresse (Gamble et al., 1984), melhorando a qualidade deste tecido. Além disso, são conhecidos os efeitos nocivos da imobilização rígida (gessada) no processo de cicatrização e maturação tecidual, e na cartilagem articular, no tecido ósseo, nos músculos e nos tendões (Klein et al., 1991).

Um período de três semanas é necessário para que os fibroblastos invadam a área da lesão e iniciem o processo de proliferação celular, para a produção das fibras colágenas no tecido cicatricial, fato confirmado através de experimentos em animais (Mason, Allen, 1941).

Após seis semanas as novas fibras colágenas já toleram a solicitação normal, mas o processo de remodelação permanece em atividade por seis a 12 meses. Até a sexta semana, o uso de alguma forma de proteção é, portanto, necessário (Hubbard e Hicks-Little, 2002), e após este período restringimos seu uso às situações de atividade física, momento de maior solicitação e risco de nova lesão relacionada ao déficit de força e de propriocepção, mantendo a proteção até o final do programa de reabilitação, com a recuperação completa da força e dos reflexos de proteção. Limitamos até a sexta semana a inversão e a flexão plantar, para não solicitar mecanicamente o tecido cicatricial em formação (Jahss, 1991). 
Este cuidado nos parece importante, porque a manipulação vigorosa do tecido cicatricial, antes que este desenvolva resistência adequada, pode permitir que a cicatriz seja alongada além do limite ideal, com consequente instabilidade mecânica do tornozelo.

No grupo A, submetemos os pacientes a período de três semanas de proteção rígida, através do uso de órtese suro podálica, (Shrier, em 1995). Nos pacientes do grupo B, permitimos mobilização compatível com as atividades da vida diária desde a fase inicial do tratamento e este fator não se relacionou a piores resultados de estabilidade articular (Tabela 21).

O imobilizador com coxim de ar tipo Aircast@ (Stover et al., 1980) é ideal para a proteção do tornozelo lesado, pois possibilita o ajuste de acordo com o edema e pode ser usado com calçado convencional, permitindo uma marcha praticamente normal, e o retorno mais rápido às atividades da vida diária e esportivas (Mack, 1982), além de ser vantajoso do ponto de vista econômico (Cooke et al., 2009).

$\mathrm{Na}$ avaliação com uma semana, os pacientes do grupo $\mathrm{B}$, apresentaram maior conforto para a deambulação que os do grupo A (Tabela 11).

$\mathrm{Na}$ terceira semana (Tabela 14) os pacientes do grupo A tiveram mais dor, novamente com diferença menor do que dois pontos, e, portanto, não clinicamente perceptível. Nas avaliações com seis e doze semanas não houve diferença significativa na intensidade da dor entre os grupos.

A ocorrência de dor após trauma no tornozelo é considerada comum (Cui et al., 2005), porém, todos os pacientes, com exceção de um, iniciaram o retorno às atividades prévias após seis semanas do trauma, ainda com o uso de órtese de proteção, com média de dor de 0,75 e 0,5 nos grupos A e B, respectivamente, e observamos dor de pequena intensidade após três meses do trauma (dor leve e ocasional em 20 pacientes e dor apenas para atividades em um, correspondendo a $10 \%$ e 0,54\%). Este resultado se relaciona, provavelmente, ao programa de reabilitação precoce realizado, o que permite a formação de tecido cicatricial de maior resistência e menor volume, o que minora a incidência de dores após entorses, relacionadas, na maioria das vezes, ao atrito entre o tecido cicatricial e as superfícies ósseas articulares.

A presença de maior pontuação AOFAS, no grupo B, nas avaliações com uma, três e seis semanas (Tabela 15) indica que os pacientes tratados com órtese funcional 
apresentam melhores condições clínicas e menor restrição para as atividades da vida diária, comparativamente aos pacientes que usaram órteses mais restritivas e mais pesadas (Eiff et al., 1994). Este fato é esperado, porém, o maior conforto à deambulação e a ausência de diferença na dor relatada contrariam nossa expectativa inicial de que a órtese suropodálica traria maior conforto ao paciente, com menor dor e maior capacidade para o apoio, principalmente nas fases iniciais do tratamento, como afirma Cooke et al., 2009.

As críticas envolvendo a escala de avaliação da AOFAS residem no fato de que a queixa álgica corresponde a uma porcentagem muito grande desta pontuação (40 \%). Como não houve diferença na intensidade da dor, sob o ponto de vista clínico, a melhor função presente nos pacientes do grupo B foi responsável pela diferença observada. Além disso, esta escala é considerada adequada na avaliação das questões relacionadas à qualidade de vida nos pacientes com patologias do pé e tornozelo (Ibrahim et al., 2006).

A diferença no tempo de afastamento das atividades profissionais, comparando as duas formas de tratamento, foi estatisticamente significativa, com média de sete dias para os pacientes do grupo A e quatro dias para os pacientes do grupo B (Tabela 14), como também observam Popovic, 2005; Povacz et al. 1998; e Baumhauer, O`Brien, 2002. Os indivíduos incluídos no estudo são pacientes de dois Hospitais privados da cidade de São Paulo, e apresentam atividades profissionais que muitas vezes podem ser mantidas mesmo com uso de órteses, e, portanto, esta diferença pode ser ainda maior nos trabalhadores que se deslocam utilizando transporte público e apresentam trabalho mais pesado do ponto de vista da exigência física.

A escala de pontuação AOFAS foi pior, também, nos pacientes com três ligamentos acometidos, apenas na avaliação com uma semana (Tabela 17), e a dor foi mais intensa (apesar de estatística, não clinicamente representativa) nas avaliações com uma e três semanas nos pacientes com três ligamentos lesados, comparativamente aos pacientes com um ou dois ligamentos acometidos (Tabela 16). Isso provavelmente se deve à extensão da lesão e ao acometimento da porção medial do tornozelo pelo trauma.

Comparando a dor com a presença ou não de lesões associadas às lesões ligamentares houve dor mais intensa (diferença menor do que dois pontos), nos pacientes com lesão associada. A pontuação AOFAS também foi pior nos pacientes com lesão associada na avaliação com seis semanas, indicando que esta variável interfere na atividade 
do paciente por mais tempo. Os pacientes que apresentam três ligamentos acometidos ou lesões associadas nos exames de imagem apresentam maior desconforto e mais dificuldades para manter a função normal, situação que se mantém por mais tempo, comparativamente aos que não apresentam estas lesões (Tabela 19).

Após doze semanas os grupos não mostraram diferenças em nenhum dos itens avaliados (Tabela 18).

A estabilidade do tornozelo depende da integridade ligamentar desta articulação e da integridade dos mecanismos reflexos. A lesão dos mecanoreceptores presentes nos ligamentos do tornozelo e nas estruturas miotendíneas, alteram a informação recebida pelo sistema nervoso central a respeito da articulação (deaferentação), como observado por Freeman et al., 1965. O mesmo Freeman, em 1965b, foi o primeiro autor a descrever a função de propriocepção, introduzindo o termo instabilidade funcional, que significa sensação de instabilidade sem mobilidade articular além dos limites anatômicos e fisiológicos. A presença dos mecanoreceptores tipo II, responsáveis pela percepção do início do movimento articular, e tipo III, responsáveis pela percepção dos extremos da mobilidade articular nos ligamentos do tornozelo (Michelson, Hutchins, 1995), são a base neuroanatômica para a ocorrência de instabilidade funcional.

A propriocepção é definida como a capacidade de detectar estímulos sensórios como o toque, pressão, dor, movimentos (cinestesia) e o posicionamento articular. A cinestesia é acessada através da velocidade de detecção de movimentos passivos, e a sensação de posição articular través da reprodução de posições ativas e passivas (Lephart et al., 1998; Munn et al., 2010).

A incidência de sensação de instabilidade é praticamente igual nos pacientes que sofreram lesões ligamentares completas e lesões leves (Mann et al., 2002), pois mesmo as lesões parciais podem alterar os reflexos de proteção (Staples, 1972).

A presença de instabilidade funcional não se relaciona à presença de instabilidade mecânica na maioria das vezes (Hintermann, 1999; Hirai et al., 2009). Esta relação ocorre apenas em $42 \%$ dos pacientes (Tropp et al., 1985).

O controle dinâmico da estabilidade articular depende do controle motor realizado pelo sistema nervoso central, do posicionamento do pé durante a marcha e do tempo de reação muscular (Konradsen et al., 1997; Konradsen, Ravn, 1990; Hartsell, Spaulding, 
1999; Hubbard et al., 2007; Hertel, 2002; Delahunt et al., 2006). A presença de alterações da propriocepção após entorse (Hertel, 2008) é considerada como causa da instabilidade funcional do tornozelo.

Apenas 7,53\% dos pacientes desta casuística apresentaram queixas de instabilidade funcional após três meses da lesão. A continuidade do estudo, ainda com resultados preliminares, mostra que esta porcentagem diminui ainda mais, com a continuidade do tratamento fisioterápico e o retorno às atividades físicas habituais.

A preocupação em diferenciar os pacientes com instabilidade funcional e instabilidade mecânica reside no fato de que $13 \%$ dos casos de artrose do tornozelo são consequência da presença de instabilidade mecânica desta articulação (Valderrabano, et al., 2006).

Alterações posicionais (pé cavo; retropé varo) e anatômicas (coalizões tarsais, barras tarsais funcionais) do tornozelo e retropé, podem provocar situações de diminuição da mobilidade do retropé com consequente sobrecarga da articulação do tornozelo e consequente maior chance de desenvolver instabilidade crônica.

Observamos proeminência da tuberosidade anterior do calcâneo em 33 pacientes (17.74\%), porém, sem alterações da mobilidade do retro e médiopé na avaliação clínica. Os 2 pacientes portadores de barra calcâneo navicular fibrosa apresentavam limitação da mobilidade médio tarsal. Não houve pior resultado nestes pacientes.

A estabilidade articular mecânica residual foi avaliada no terceiro mês após o trauma, através do exame clínico e das radiografias com estresse manual, pela maior facilidade deste método, considerado por Karlsson et al.,1991 e Ardévol et al., 2002 como padrão ouro no diagnóstico da instabilidade e frouxidão ligamentar do tornozelo, e pela ausência, na maioria dos serviços, de aparato adequado para a aplicação do estresse controlado (Telos, Hungen-Obbornhofen, Germany). Da mesma forma que outros autores (Black et al., 1978; Okuda et al., 1999; Sauser et al., 1983) consideramos as avaliações com estresse manual equivalentes às realizadas com tais aparelhos, e, portanto, suficientes para a avaliação da presença de instabilidade na articulação do tornozelo.

A medição dos ângulos e distâncias nas radiografias com estresse foi realizada através do uso de software para visualização de radiografias digitais (Carestrem PACS Versão 11.3 Siemens ou Magic Web Versão VA42C_0306 Siemens), o que permitiu ótima 
reprodutibilidade intra e inter observador, avaliada estatisticamente (Tabela 20). Os resultados do ICC mostraram correlação forte entre as medidas, já que ficaram todas iguais ou acima de 0,7 (Tabela 20).

A avaliação em formato duplo cego dos resultados das radiografias em estresse diminui a possibilidade de o conhecedor do método de tratamento poder influenciar no resultado das medidas.

Há dúvida, na literatura se este exame é útil na identificação das lesões ligamentares agudas, devido à presença da dor, e consequente contração muscular involuntária, porém este fato não é limitante nos pacientes submetidos ao exame na fase de identificação de instabilidade residual, como foi realizado neste trabalho.

Os valores normais para o teste de inclinação talar varia entre cinco e 23 graus em indivíduos normais, e existem pessoas com o tornozelos hipermóveis (Pacey et al., 2010), e, portanto, deve ser realizado comparativamente ao lado normal (Cox, 1985). Não observamos maior variabilidade nas radiografias com estresse em varo, com relação às radiografias com estresse em gaveta anterior, como afirmam Seligson et al., em 1980, e consideramos que ambos são úteis na avaliação da estabilidade articular do tornozelo relacionada à insuficiência dos diferentes ligamentos.

Após a observação de 142 pacientes (casuística mínima considerada para este trabalho), notamos que a avaliação clínica e radiográfica da estabilidade articular foram equivalentes, ao considerarmos a diferença acima de 5 graus na radiografia em estresse em varo, ou acima de $5 \mathrm{~mm}$ nas radiografias com estresse em gaveta anterior (Tabela 22), como recomendado por Cass (1985) e Marder (1994). Apenas a avaliação clínica foi realizada a partir desta constatação.

Esta mudança na avaliação da presença de instabilidade articular é aceitável, pois a alteração do método não ocorreu na intervenção (tratamento), e o protocolo não foi modificado. Através de análise interina a continuidade da avaliação radiográfica da estabilidade articular do tornozelo deixou de ser recomendada, decisão justificada pelo fato de haver radiação ionizante associada ao método.

Baseado nas observações e resultados, o diagnóstico da instabilidade do tornozelo deve ser estabelecido através do exame clínico adequado, não sendo necessária a realização de radiografias em estresse. O teste da gaveta anterior é mais fácil de ser realizado 
comparativamente ao teste em varo, porque a inversão envolve a mobilidade da articulação subtalar além da varização pesquisada ao nível do tornozelo. Comparativamente ao lado normal pode se perceber maior inversão do pé do lado portador de instabilidade mecânica.

Não houve maior incidência de instabilidade mecânica residual nos pacientes do grupo B, observados após três meses do trauma, um paciente (pertencente ao grupo A, tratado inicialmente com a órtese rígida) permaneceu com instabilidade mecânica crônica (Figura 18, Anexo C). Além deste, todos os outros pacientes incluídos neste estudo, deixaram de apresentar sinais clínicos de instabilidade articular do tornozelo na avaliação após três semanas do trauma, fato considerado indicativo de evolução para adequada estabilização mecânica da articulação. A incidência de instabilidade mecânica após lesão ligamentar aguda grave do tornozelo foi muito pequena $(0.54 \%)$ nestes pacientes, independente da forma de tratamento conservador realizado, portanto, o tratamento conservador traz excelentes chances de estabilização articular.

$\mathrm{Na}$ literatura observamos que $30 \%$ a $40 \%$ dos pacientes que sofrem lesões ligamentares agudas graves do tornozelo, mantém queixas de entorses de repetição e de sintomas persistentes (Gerber et al., 1998) e $20 \%$ a $40 \%$ desenvolvem instabilidade articular crônica (Jackson, McGarvey, 2006).

Neste trabalho incluímos pacientes que sofreram o primeiro episódio torcional, e, portanto, não podemos avaliar a incidência de instabilidade articular mecânica após lesões ligamentares recorrentes.

A avaliação do resultado do tratamento de acordo com o número de ligamentos acometidos mostra que não houve relação entre maior incidência de instabilidade residual e maior número de ligamentos lesados, apenas dor mais intensa (sem diferença clínica) e menor pontuação funcional AOFAS nos pacientes com lesões mais extensas (Tabelas 16 e 17). A interpretação desta observação revela que as lesões de um ou mais ligamentos do tornozelo tem gravidade semelhante, pois provocam instabilidade articular aguda, e tem evolução comparável, devendo, portanto, ser tratadas da mesma forma. Após 12 semanas não observamos mais diferenças entre estes grupos.

$\mathrm{O}$ que pode explicar a diferença entre a pequena incidência de instabilidade crônica do tornozelo nestes pacientes e a observada na a literatura, é o fato de que a sensação de instabilidade do tornozelo, o sintoma residual mais comum associado às lesões 
ligamentares desta articulação (Karlsson et al., 1991), pode ter duas apresentações distintas: a instabilidade mecânica, quando há, comprovadamente, mobilidade exagerada da articulação tíbio talar (Colville, 1998); e a instabilidade funcional, relacionada à falta de reflexos normais de proteção. A queixa comum a estas duas situações é a sensação de insegurança, de um tornozelo não firme, a ocorrência de falseios e recorrências das entorses. Neste trabalho consideramos como instabilidade crônica apenas a instabilidade mecânica.

A alta taxa de insucesso de alguns trabalhos na literatura pode se relacionar à falta de imobilização adequada, tempo insuficiente de proteção (menor do que seis semanas, tempo necessário para que ocorre adequada formação de tecido cicatricial com resistência equivalente ao tecido original) (Moller-Larsen et al., 1998), alterações proprioceptivas (Mann et al., 2002) e presença de dor residual (impacto antero lateral e as sinovites pós traumáticas), com consequente sensação de falta de estabilidade.

Pacientes com queixas de dor ou instabilidade do tornozelo após trauma devem ser submetidos à adequada avaliação diagnóstica para que se possa decidir pela melhor forma de tratamento. Nos casos com evolução para instabilidade mecânica crônica, situação considerada como potencial causa de artrite degenerativa, a reconstrução cirúrgica tardia tem resultados excelentes, sendo indicada nestas circunstâncias (Harrington, 1979).

A alta reincidência de lesões ligamentares do tornozelo em atletas de basquete recreacional se relaciona, segundo McKay et al., 2001, à falta de reabilitação, já que 57\% dos indivíduos que sofreram esta lesão não procuram atenção médica. Além disso, Denegar e Miller (2002), afirmam que o retorno às atividades antes da cicatrização adequada do ligamento pode provocar alongamento do tecido cicatricial e consequente instabilidade mecânica.

A reabilitação inadequada é um dos fatores determinantes na falha do tratamento conservador. A falta de função protetora (propriocepção) aumenta a incidência de novos episódios de entorse, com consequente maior chance de evolução para instabilidade mecânica crônica (Weber, Maleski, 2002).

A reabilitação funcional é composta por três fases distintas (Smith, Reischl, 1986; Seto, Brewster, 1994). 
A primeira fase consiste em proteção, repouso, gelo e compressão do membro afetado. Tem o objetivo de limitar a progressão da lesão, controlar a dor, o edema e o hematoma relacionados ao trauma (Jarvinen, 1993). A aplicação do gelo provoca constrição das arteríolas locais, diminuição da hemorragia, minorando o espasmo muscular e a velocidade de condução nervosa, diminui o metabolismo celular local, com menor liberação de mediadores inflamatórios, com consequente menor sensibilidade dolorosa (Hocutt et al., 1982). O controle do edema acelera o processo cicatricial (Safran et al., 1999), diminui a dor e facilita a reabilitação (Anandacoomarasamy, Barnsley, 2005), o que proporciona um retorno mais precoce do paciente às atividades da vida diária e às atividades profissionais (Jackson et al., 1974; Hocut et al., 1982). Esta fase do tratamento termina quando o paciente conseguir apoiar confortavelmente o pé acometido, e quando há controle do edema.

A segunda fase tem o objetivo de restaurar a força muscular (através de exercícios isométricos) e a mobilidade articular normal.

A terceira fase envolve o restabelecimento da coordenação motora, através de exercícios de propriocepção, condicionamento e treino de resistência (Trevino et al., 1994), o que diminui substancialmente a chance de reincidência (de $29 \%$ nos pacientes não reabilitados para 7\%) desta lesão (Wester et al., 1996; Holme et al., 1999). O treino de marcha com ênfase nas atividades de maior demanda (saltos com deslocamento e treino de agilidade) são importantes nos estágios finais do processo de recuperação funcional (Delahunt et al., 2006).

Durante as fases de reabilitação recomendamos o uso de órteses protetoras no tornozelo, mesmo após o retorno às atividades físicas habituais, principalmente durante as realizadas em terrenos irregulares, ou que envolvam saltos e mudanças bruscas de direção, até aproximadamente o terceiro mês após o trauma (Drez et al., 1982), quando o paciente volta a apresentar força muscular normal nos membros inferiores (exame físico comparativo e sensação de normalização da força) e propriocepção normal (retorno da sensação normal de estabilidade, equilíbrio e dos reflexos de proteção), como afirmam Handoll et al., em 2001.

Uma limitação deste trabalho é o fato de não ser possível fazer avaliação duplo cego dos pacientes nas fases iniciais do trabalho, já que os tipos de imobilizador utilizados como 
tratamento são evidentemente diferentes (Beynnon et al., 2006). A avaliação da estabilidade articular através das radiografias com estresse foi em formato duplo cego, como descrito no capítulo métodos.

A avaliação radiográfica da instabilidade articular foi feita com radiografias em estresse manual, pois não dispúnhamos de aparato mecânico de realização de estresse com controle da força exercida.

Consideramos como valores indicativos da presença de instabilidade articular, na radiografia com estresse em gaveta anterior e em varo, $5 \mathrm{~mm}$ e 5 graus, porque houve correlação destes com a presença de instabilidade no exame físico, apesar de outros autores usarem os valores de $3 \mathrm{~mm}$ ou 3 graus. A real importância desta diferença será adequadamente avaliada nas fases subsequentes deste trabalho, quando observarmos a incidência de sintomas residuais e de recidivas da lesão, comparando esta variável.

$\mathrm{Na}$ nossa opinião, o tratamento precoce com proteção adequada, por tempo suficiente, e a reabilitação apropriada da função articular (força muscular, propriocepção e treino de marcha) são de fundamental importância para que os bons resultados observados neste trabalho possam ser reproduzidos.

A instabilidade funcional que ocorre após a lesão ligamentar raramente se associa com quadro de instabilidade mecânica do tornozelo (Freeman, 1965 A), mas, provavelmente, aumenta a possibilidade de ocorrerem entorses subsequentes, com consequente instabilidade mecânica secundária.

A utilização de imobilizador funcional, durante todo o tratamento da lesão ligamentar aguda grave do tornozelo, se relacionou a dor de menor intensidade (estatisticamente significativo, porém sem diferença clínica), maior pontuação AOFAS, até a sexta semanaindicando melhor manutenção das funções, além de menor tempo de afastamento das atividades laborais, sem prejuízo dos resultados de estabilidade articular. Não houve diferença entre os grupos de tratamento após três meses do trauma. Trata-se, portanto, da melhor forma de tratamento para esta lesão.

Esta investigação clínica vem preencher uma lacuna no estudo das lesões ligamentares do tornozelo e procura tornar mais objetivas as formas de diagnóstico, e determinar uma forma de tratamento que possa ser reproduzida através da utilização de órteses facilmente encontradas no mercado, bem como esclarecer a importância da 
adequada e completa reabilitação, tornando possível futuros estudos envolvendo maior número de pacientes e realizados de forma multicêntrica.

Nossos próximos passos serão a avaliação a médio e longo prazo dos resultados funcionais, a presença de sintomas residuais e a incidência de recidivas das lesões. 


\section{CONCLUSÃO}

1. O tratamento clínico da lesão ligamentar aguda grave e primária do tornozelo com o imobilizador funcional (Aircast ${ }^{\circledR}$ ) mostrou melhores resultados funcionais e menor tempo de afastamento das atividades profissionais, comparativemente aos tratados com órtese suropodálica rígida (Robofoot $\left.{ }^{\circledR}\right)$, sem haver diferença no resultado da estabilidade articular. 
9. ANEXO A: Fichas de avaliação 


\section{AVALIAÇÃO INICIAL}

IDENT. (ETIQUETA)

DATA

TELEFONES:

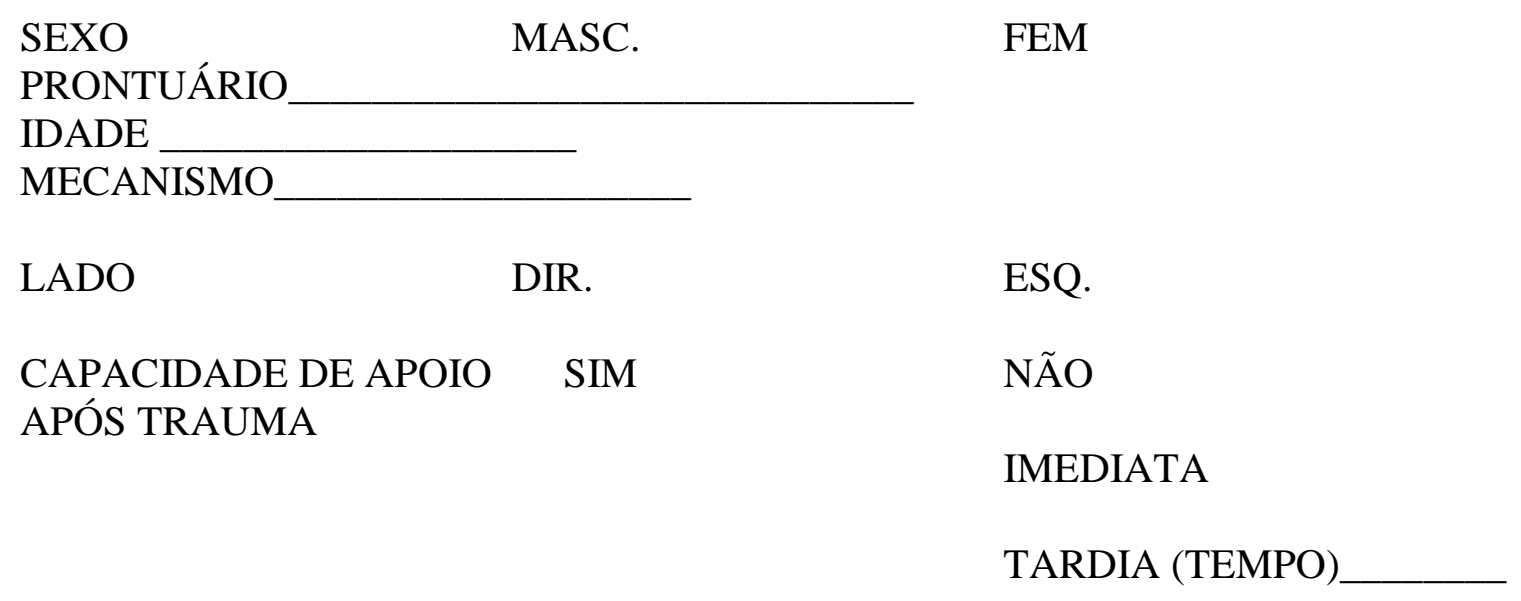

QUADRO CLÍNICO:

ESCALA ANALÓGICA DE DOR:

DOR:

ANTERO LATERAL SOBMALÉOLO LATERAL

POSTERO LATERAL SOB MALÉOLO MEDIAL

GAVETA ANTERIOR: POSITIVA NEGATIVA

LOCALIZAÇÃO DE OUTRAS DORES:

LESÕES ASSOCIADAS:

ALINHAMENTO RETRO PÉ: $\quad$ NEUTRO VALGO VARO

TIPO PÉ: $\quad$ PLANTÍGRADO PLANO CAVO

MOBILIDADE SUBTALAR: NORMAL LIMITADA

MOBILIDADE MEDIOTARSAL: NORMAL LIMITADA

FROUXIDÃO LIGAMENTAR GENERALIZADA: SIM NÃO

TESTES: HIPEREXTENSÃO JOELHO COTOVELO POLEGAR 


\begin{abstract}
AVALIAÇÃO 1 SEMANA
QUADRO CLÍNICO:

LOCALIZAÇÃO EDEMA E EQUIMOSE:

GRAVIDADE DA DOR (ESCALA ANALÓGICA):

CONFORTO À DEAMBULAÇÃO:

CAPACIDADE DE APOIO:

AOFAS:
\end{abstract}

RESSONÂNCIA MAGNÉTICA:

LESÕES LIGAMENTARES TTA FC FTP

DELTÓIDE PROFUNDO DELTÓIDE SUPERFICIAL

LESÕES ASSOCIADAS:

ALTERAÇÕES ANATÔMICAS: 


\section{AVALIAÇÃO 3 SEMANAS}

QUADRO CLÍNICO:

EDEMA:

ESCALA ANALÓGICA DE DOR:

CAPACIDADE DE APOIO:

AOFAS:

LIMITAÇÃO ATIVIDADE VIDA DIÁRIA:

TEMPO DE AFASTAMENTO DO TRABALHO: 


\section{AVALIAÇÃO 6 SEMANAS}

QUADRO CLÍNICO:

ESCALA ANALÓGICA DE DOR:

AOFAS:

LIMITAÇÃO ATIVIDADE VIDA DIÁRIA:

AMPLITDE DE MOVIMENTO:

INVERSÃO

EVERSÃO

FLEXÃO PLANTAR

DORSILEXÃO 


\section{AVALIAÇÃO 3 MESES}

QUADRO CLÍNICO:

AOFAS:

LIMITAÇÃO ATIVIDADE FÍSICA:

RX COM ESTRESSE:

COM INSTABILIDADE

SEM INSTABILIDADE 


\section{MEDIDAS OBSERVADOR 1}

PRONTUÁRIO:

MEDIDA 1A

\begin{tabular}{|l|l|l|l|l|}
\hline MEDIDA/INCIDENCIA & $\begin{array}{l}\text { AP } \\
\text { ACOMETIDO } \\
\text { (graus) }\end{array}$ & $\begin{array}{l}\text { AP } \\
\text { NORMAL } \\
\text { (graus) }\end{array}$ & $\begin{array}{l}\text { P } \\
\text { ACOMETIDO } \\
(\mathrm{mm})\end{array}$ & $\begin{array}{l}\text { P } \\
\text { NORMAL } \\
(\mathrm{mm})\end{array}$ \\
\hline & & & & \\
MEDIDA & & & & \\
\hline
\end{tabular}

MEDIDA 1B

\begin{tabular}{|l|l|l|l|l|}
\hline MEDIDA/INCIDENCIA & $\begin{array}{l}\text { AP } \\
\text { ACOMETIDO } \\
\text { (graus) }\end{array}$ & $\begin{array}{l}\text { AP } \\
\text { NORMAL } \\
\text { (graus) }\end{array}$ & $\begin{array}{l}\text { P } \\
\text { ACOMETIDO } \\
\text { (mm) }\end{array}$ & $\begin{array}{l}\text { P } \\
\text { NORMAL } \\
(\mathrm{mm})\end{array}$ \\
\hline & & & & \\
MEDIDA & & & & \\
\hline
\end{tabular}


MEDIDAS OBSERVADOR 2

PRONTUÁRIO:

MEDIDA 2A

\begin{tabular}{|l|l|l|l|l|}
\hline MEDIDA/INCIDENCIA & $\begin{array}{l}\text { AP } \\
\text { ACOMETIDO } \\
\text { (graus) }\end{array}$ & $\begin{array}{l}\text { AP } \\
\text { NORMAL } \\
\text { (graus) }\end{array}$ & $\begin{array}{l}\text { P } \\
\text { ACOMETIDO } \\
(\mathrm{mm})\end{array}$ & $\begin{array}{l}\text { P } \\
\text { NORMAL } \\
(\mathrm{mm})\end{array}$ \\
\hline & & & & \\
MEDIDA & & & \\
\hline
\end{tabular}

MEDIDA 2B

\begin{tabular}{|l|l|l|l|l|}
\hline MEDIDA/INCIDENCIA & $\begin{array}{l}\text { AP } \\
\text { ACOMETIDO } \\
\text { (graus) }\end{array}$ & $\begin{array}{l}\text { AP } \\
\text { NORMAL } \\
\text { (graus) }\end{array}$ & $\begin{array}{l}\text { P } \\
\text { ACOMETIDO } \\
(\mathrm{mm})\end{array}$ & $\begin{array}{l}\text { P } \\
\text { NORMAL } \\
(\mathrm{mm})\end{array}$ \\
\hline & & & & \\
MEDIDA & & & \\
\hline
\end{tabular}


10. ANEXO B: Quadros dos dados colhidos durante a execução do trabalho 


\subsection{Quadro com dados do primeiro atendimento, pacientes do Grupo A}

\begin{tabular}{|c|c|c|c|c|c|c|c|c|c|c|c|c|c|c|c|c|c|}
\hline $\mathrm{N}$ & ID & Grupo & Data & Sexo & Idade & Lado & $\mathrm{CA}$ & Imed & $\begin{array}{l}\text { Local } \\
\text { Dor }\end{array}$ & EVA & Gaveta & 0 & Lco & Al & Pé & Sub & Med \\
\hline 93 & AMP 931083 & A & 22308 & Masc & 44 & Esq & Não & Sim & 4 & 6 & Posit & 0 & 0 & $\mathrm{Neu}$ & $\mathrm{NI}$ & $\mathrm{NI}$ & $\mathrm{NI}$ \\
\hline 94 & ASS 81462 & $\mathrm{~A}$ & 310707 & Masc & 39 & Dir & Não & Sim & 4 & 8 & Posit & 0 & 0 & $\mathrm{Vg}$ & $\mathrm{PL}$ & $\mathrm{NI}$ & $\mathrm{NI}$ \\
\hline 95 & AU 1273378 & A & 30509 & Masc & 54 & Esq & Sim & Sim & 2 & 5 & Posit & 0 & 0 & $\mathrm{Neu}$ & $\mathrm{NI}$ & $\mathrm{NI}$ & $\mathrm{NI}$ \\
\hline 96 & BCGM 4145615 & A & 241008 & Fem & 16 & Dir & Não & Sim & 4 & 9 & Posit & 0 & 0 & $\mathrm{Neu}$ & $\mathrm{NI}$ & $\mathrm{NI}$ & $\mathrm{NI}$ \\
\hline 97 & CBMC 3200051 & $\mathrm{~A}$ & 191009 & Fem & 52 & Dir & Não & Sim & 4 & 8 & Posit & 0 & 0 & $\mathrm{Neu}$ & $\mathrm{NI}$ & $\mathrm{NI}$ & $\mathrm{NI}$ \\
\hline 98 & CPC 542163 & $\mathrm{~A}$ & 230808 & Fem & 42 & Esq & Sim & Sim & 3 & 6 & Posit & 1 & 1 & $\mathrm{Neu}$ & $\mathrm{NI}$ & $\mathrm{NI}$ & $\mathrm{NI}$ \\
\hline 99 & ESNP 3360890 & $\mathrm{~A}$ & 100909 & Masc & 16 & Dir & Não & Sim & 4 & 9 & Posit & 0 & 0 & $\mathrm{Neu}$ & $\mathrm{NI}$ & $\mathrm{NI}$ & $\mathrm{NI}$ \\
\hline 100 & EPGM 325169 & $\mathrm{~A}$ & 50708 & Fem & 55 & Dir & Não & Sim & 4 & 8 & Posit & 1 & 0 & $\mathrm{Neu}$ & $\mathrm{NI}$ & $\mathrm{NI}$ & $\mathrm{NI}$ \\
\hline 101 & GAA 4467426 & $\mathrm{~A}$ & 30609 & Fem & 33 & Dir & Não & Sim & 3 & 8 & Posit & 0 & 0 & $\mathrm{Neu}$ & $\mathrm{NI}$ & $\mathrm{NI}$ & $\mathrm{NI}$ \\
\hline 102 & GSPL 368627 & $\mathrm{~A}$ & 110708 & Masc & 22 & Esq & Não & Sim & 2 & 8 & Posit & 0 & 0 & $\mathrm{Neu}$ & $\mathrm{NI}$ & $\mathrm{NI}$ & $\mathrm{NI}$ \\
\hline 103 & JV 2010526 & A & 200508 & Masc & 40 & Dir & Não & Sim & 4 & 8 & Posit & 0 & 0 & $\mathrm{Neu}$ & $\mathrm{NI}$ & $\mathrm{NI}$ & $\mathrm{NI}$ \\
\hline 104 & LPRN 4206339 & $\mathrm{~A}$ & 100609 & Masc & 31 & Dir & Não & Sim & 4 & 8 & Posit & 0 & 0 & $\mathrm{Neu}$ & $\mathrm{NI}$ & $\mathrm{NI}$ & $\mathrm{NI}$ \\
\hline 105 & MRMA 3090434 & $\mathrm{~A}$ & 181009 & Masc & 24 & Dir & Sim & Sim & 4 & 5 & Posit & 0 & 0 & $\mathrm{Neu}$ & $\mathrm{CV}$ & $\mathrm{NI}$ & $\mathrm{NI}$ \\
\hline 106 & PE 2690543 & A & 280509 & Fem & 29 & Esq & Sim & Sim & 4 & 8 & Posit & 0 & 0 & $\mathrm{Neu}$ & $\mathrm{NI}$ & $\mathrm{NI}$ & $\mathrm{NI}$ \\
\hline 107 & RME 792282 & A & 260209 & Fem & 16 & Dir & Não & Sim & 2 & 5 & Posit & 0 & 0 & $\mathrm{Neu}$ & $\mathrm{NI}$ & $\mathrm{NI}$ & $\mathrm{NI}$ \\
\hline 108 & RKM 3379930 & $\mathrm{~A}$ & 250809 & Masc & 15 & Esq & Não & Sim & 4 & 7 & Posit & 0 & 0 & $\mathrm{Neu}$ & $\mathrm{NI}$ & $\mathrm{NI}$ & $\mathrm{NI}$ \\
\hline 109 & SJB 3805379 & $\mathrm{~A}$ & 240308 & Masc & 37 & Esq & Não & Sim & 1 & 6 & Posit & 0 & 0 & $\mathrm{Neu}$ & $\mathrm{NI}$ & $\mathrm{NI}$ & $\mathrm{NI}$ \\
\hline 110 & TGPA 2752522 & $\mathrm{~A}$ & 100508 & Masc & 23 & Esq & Sim & Sim & 1 & 8 & Posit & 0 & 0 & $\mathrm{Vr}$ & $\mathrm{CV}$ & $\mathrm{NI}$ & $\mathrm{NI}$ \\
\hline 111 & TF 4240073 & $\mathrm{~A}$ & 160109 & Masc & 26 & Esq & Não & Sim & 4 & 8 & Posit & 0 & 0 & $\mathrm{Neu}$ & $\mathrm{NI}$ & $\mathrm{NI}$ & $\mathrm{NI}$ \\
\hline 112 & SADN 1214285 & A & 101008 & Fem & 50 & Dir & Não & Sim & 3 & 7 & Posit & 0 & 0 & $\mathrm{Neu}$ & $\mathrm{NI}$ & $\mathrm{NI}$ & $\mathrm{NI}$ \\
\hline 113 & RMK 1160641 & $\mathrm{~A}$ & 30098 & Fem & 56 & Esq & $\operatorname{Sim}$ & Sim & 1 & 7 & Posit & 0 & 0 & $\mathrm{Neu}$ & $\mathrm{NI}$ & $\mathrm{NI}$ & $\mathrm{NI}$ \\
\hline 114 & PRPM 1208993 & $\mathrm{~A}$ & 90804 & Fem & 30 & Dir & Não & Sim & 4 & 8 & Posit & 0 & 0 & $\mathrm{Neu}$ & $\mathrm{NI}$ & $\mathrm{NI}$ & $\mathrm{NI}$ \\
\hline 115 & MEB 4048075 & $\mathrm{~A}$ & 40808 & Masc & 37 & Dir & Não & Sim & 3 & 8 & Posit & 0 & 0 & $\mathrm{Neu}$ & $\mathrm{NI}$ & $\mathrm{NI}$ & $\mathrm{NI}$ \\
\hline 116 & JMCB 914712 & $\mathrm{~A}$ & 21008 & Fem & 26 & Dir & Sim & Sim & 2 & 7 & Posit & 0 & 0 & $\mathrm{Neu}$ & $\mathrm{CV}$ & $\mathrm{NI}$ & $\mathrm{NI}$ \\
\hline 117 & HLSJ 4056388 & $\mathrm{~A}$ & 110808 & Masc & 31 & Dir & Sim & Sim & 4 & 6 & Posit & 0 & 0 & $\mathrm{Neu}$ & $\mathrm{NI}$ & $\mathrm{NI}$ & $\mathrm{NI}$ \\
\hline 118 & GNF 1248171 & A & 101008 & Masc & 27 & Dir & Não & Sim & 4 & 8 & Posit & 0 & 0 & $\mathrm{Neu}$ & $\mathrm{NI}$ & $\mathrm{NI}$ & $\mathrm{NI}$ \\
\hline 119 & GGP 1245752 & $\mathrm{~A}$ & 311008 & Fem & 37 & Esq & Não & Sim & 4 & 8 & Posit & 0 & 0 & $\mathrm{Neu}$ & $\mathrm{NI}$ & $\mathrm{NI}$ & $\mathrm{NI}$ \\
\hline 120 & FBRM 1180401 & $\mathrm{~A}$ & 220109 & Masc & 25 & Dir & Sim & Sim & 4 & 6 & Posit & 0 & 0 & $\mathrm{Neu}$ & $\mathrm{NI}$ & $\mathrm{NI}$ & $\mathrm{NI}$ \\
\hline 121 & ARF 835237 & A & 31108 & Masc & 39 & Esq & Sim & Sim & 3 & 8 & Posit & 0 & 0 & $\mathrm{Neu}$ & $\mathrm{NI}$ & $\mathrm{NI}$ & $\mathrm{NI}$ \\
\hline 122 & BM 571926 & $\mathrm{~A}$ & 101109 & Masc & 31 & Dir & Sim & Sim & 3 & 5 & Posit & 2 & 0 & $\mathrm{Neu}$ & $\mathrm{NI}$ & $\mathrm{NI}$ & $\mathrm{NI}$ \\
\hline 123 & EDS 544720 & $\mathrm{~A}$ & 161009 & Masc & 37 & Esq & Não & Sim & 4 & 4 & Posit & 0 & 0 & $\mathrm{Neu}$ & $\mathrm{NI}$ & $\mathrm{NI}$ & $\mathrm{NI}$ \\
\hline 124 & FLO 304126 & $\mathrm{~A}$ & 100110 & Masc & 23 & Esq & Não & Sim & 4 & 8 & Posit & 0 & 0 & $\mathrm{Neu}$ & $\mathrm{NI}$ & $\mathrm{NI}$ & $\mathrm{NI}$ \\
\hline 125 & FQT 927616 & $\mathrm{~A}$ & 310110 & Masc & 37 & Esq & Sim & Sim & 4 & 5 & Posit & 0 & 0 & $\mathrm{Neu}$ & $\mathrm{NI}$ & $\mathrm{NI}$ & $\mathrm{NI}$ \\
\hline 126 & GHPA 4688899 & $\mathrm{~A}$ & 200110 & Masc & 20 & Esq & Não & Sim & 3 & 7 & Posit & 0 & 0 & $\mathrm{Neu}$ & $\mathrm{NI}$ & $\mathrm{NI}$ & $\mathrm{NI}$ \\
\hline 127 & RHM 2081067 & A & 10507 & Masc & 18 & Esq & Não & Sim & 3 & 7 & Posit & 0 & 0 & $\mathrm{Neu}$ & $\mathrm{NI}$ & $\mathrm{NI}$ & $\mathrm{NI}$ \\
\hline 128 & RHM 2081067 & A & 201107 & Fem & 18 & Dir & Não & Sim & 3 & 6 & Posit & 0 & 0 & $\mathrm{Neu}$ & $\mathrm{NI}$ & $\mathrm{NI}$ & $\mathrm{NI}$ \\
\hline 129 & DGM 4767918 & $\mathrm{~A}$ & 120210 & Masc & 27 & Dir & Não & Sim & 3 & 8 & Posit & 0 & 0 & $\mathrm{Neu}$ & $\mathrm{NI}$ & $\mathrm{NI}$ & $\mathrm{NI}$ \\
\hline 130 & DF 3778754 & $\mathrm{~A}$ & 200907 & Fem & 33 & Esq & Não & Sim & 4 & 8 & Posit & 0 & 0 & $\mathrm{Neu}$ & $\mathrm{NI}$ & $\mathrm{NI}$ & $\mathrm{NI}$ \\
\hline 131 & EAM 2444526 & $\mathrm{~A}$ & 10210 & Fem & 40 & Dir & Sim & Sim & 4 & 5 & Posit & 0 & 0 & $\mathrm{Neu}$ & $\mathrm{NI}$ & $\mathrm{NI}$ & $\mathrm{NI}$ \\
\hline 132 & BMSB 5705692 & A & 50210 & Fem & 27 & Esq & Não & Sim & 3 & 10 & Posit & 0 & 0 & $\mathrm{Neu}$ & $\mathrm{NI}$ & $\mathrm{NI}$ & $\mathrm{NI}$ \\
\hline 133 & AKD 1333949 & $\mathrm{~A}$ & 180310 & Fem & 39 & Dir & Não & Sim & 2 & 7 & Posit & 0 & 0 & $\mathrm{Neu}$ & $\mathrm{NI}$ & $\mathrm{NI}$ & $\mathrm{NI}$ \\
\hline 134 & KMSC 4837800 & $\mathrm{~A}$ & 10410 & Fem & 47 & Dir & Não & Sim & 4 & 8 & Posit & 0 & 0 & $\mathrm{Neu}$ & $\mathrm{NI}$ & $\mathrm{NI}$ & $\mathrm{NI}$ \\
\hline 135 & LKNF 2801302 & $\mathrm{~A}$ & 50310 & Fem & 43 & Esq & Não & Sim & 4 & 10 & Posit & 0 & 0 & $\mathrm{Neu}$ & $\mathrm{NI}$ & $\mathrm{NI}$ & $\mathrm{NI}$ \\
\hline 136 & GDMBGZ 1050761 & $\mathrm{~A}$ & 110310 & Fem & 45 & Esq & Não & Sim & 2 & 6 & Posit & 0 & 0 & $\mathrm{Neu}$ & $\mathrm{NI}$ & $\mathrm{NI}$ & $\mathrm{NI}$ \\
\hline 137 & GCS 4842421 & $\mathrm{~A}$ & 10410 & Masc & 24 & Esq & Não & Sim & 1 & 6 & Posit & 0 & 0 & $\mathrm{Neu}$ & $\mathrm{NI}$ & $\mathrm{NI}$ & $\mathrm{NI}$ \\
\hline 138 & FRCS 1339525 & $\mathrm{~A}$ & 10410 & Masc & 18 & Esq & Não & Sim & 4 & 8 & Posit & 0 & 0 & $\mathrm{Neu}$ & $\mathrm{NI}$ & $\mathrm{NI}$ & $\mathrm{NI}$ \\
\hline 139 & TPTB 4867130 & A & 100410 & Masc & 15 & Dir & Não & Sim & 4 & 8 & Posit & 0 & 0 & $\mathrm{Neu}$ & $\mathrm{NI}$ & $\mathrm{NI}$ & $\mathrm{NI}$ \\
\hline 140 & RGSC 1340670 & $\mathrm{~A}$ & 20310 & Fem & 45 & Dir & Não & Sim & 4 & 7 & Posit & 0 & 0 & $\mathrm{Neu}$ & $\mathrm{NI}$ & $\mathrm{NI}$ & $\mathrm{NI}$ \\
\hline 141 & RAAV 1032448 & $\mathrm{~A}$ & 260310 & Masc & 28 & Dir & Não & Sim & 4 & 5 & Posit & 0 & 0 & $\mathrm{Neu}$ & $\mathrm{NI}$ & $\mathrm{NI}$ & $\mathrm{NI}$ \\
\hline 142 & RSF 430963 & A & 160510 & Masc & 17 & Esq & Não & Sim & 2 & 7 & Posit & 0 & 0 & $\mathrm{Neu}$ & $\mathrm{NI}$ & $\mathrm{NI}$ & $\mathrm{NI}$ \\
\hline 143 & JRM 4915771 & A & 310510 & Masc & 37 & Dir & Não & Sim & 3 & 9 & Posit & 0 & 0 & $\mathrm{Neu}$ & $\mathrm{NI}$ & $\mathrm{NI}$ & $\mathrm{NI}$ \\
\hline 144 & DAW 564899 & A & 311008 & Masc & 21 & Dir & Sim & Sim & 2 & 9 & Posit & 0 & 0 & $\mathrm{Neu}$ & $\mathrm{NI}$ & $\mathrm{NI}$ & $\mathrm{NI}$ \\
\hline
\end{tabular}




\subsection{Quadro com dados do primeiro atendimento, pacientes do Grupo A (conclusão)}

\begin{tabular}{|c|c|c|c|c|c|c|c|c|c|c|c|c|c|c|c|c|c|}
\hline $\mathrm{N}$ & ID & Grupo & Data & Sexo & Idade & Lado & $\mathrm{CA}$ & Imed & $\begin{array}{c}\text { Local } \\
\text { Dor }\end{array}$ & EVA & Gaveta & 0 & Lco & $\mathrm{Al}$ & Pé & Sub & Med \\
\hline 145 & TRO 2997584 & $\mathrm{~A}$ & 90710 & Masc & 26 & Dir & Não & Sim & 3 & 8 & Posit & 0 & 0 & $\mathrm{Neu}$ & $\mathrm{NI}$ & $\mathrm{NI}$ & $\mathrm{NI}$ \\
\hline 146 & MTS 4695631 & $\mathrm{~A}$ & 200810 & Masc & 29 & Esq & Não & Sim & 4 & 8 & Posit & 0 & 0 & $\mathrm{Vr}$ & $\mathrm{CV}$ & $\mathrm{NI}$ & $\mathrm{NI}$ \\
\hline 147 & FGSLCO 1333151 & $\mathrm{~A}$ & 81110 & Masc & 32 & Dir & Não & Sim & 4 & 8 & Posit & 0 & 0 & $\mathrm{Neu}$ & $\mathrm{NI}$ & $\mathrm{NI}$ & $\mathrm{NI}$ \\
\hline 148 & FJSW 959219 & A & 81010 & Masc & 63 & Esq & Não & Sim & 4 & 7 & Posit & 0 & 3 & $\mathrm{Neu}$ & $\mathrm{NI}$ & $\mathrm{NI}$ & $\mathrm{NI}$ \\
\hline 149 & AAM 1342844 & $\mathrm{~A}$ & 300410 & Masc & 45 & Esq & Sim & Sim & 4 & 6 & Posit & 0 & 0 & $\mathrm{Neu}$ & $\mathrm{NI}$ & $\mathrm{NI}$ & $\mathrm{NI}$ \\
\hline 150 & TD 1405676 & $\mathrm{~A}$ & 160211 & Fem & 13 & Dir & Não & Sim & 4 & 6 & Posit & 0 & 0 & $\mathrm{Neu}$ & $\mathrm{NI}$ & $\mathrm{NI}$ & $\mathrm{NI}$ \\
\hline 151 & CMC 1422120 & $\mathrm{~A}$ & 210411 & Fem & 35 & Esq & Não & Sim & 4 & 8 & Posit & 0 & 0 & $\mathrm{Neu}$ & $\mathrm{NI}$ & $\mathrm{NI}$ & $\mathrm{NI}$ \\
\hline 152 & TNF 5366887 & $\mathrm{~A}$ & 100511 & Masc & 17 & Dir & Não & Sim & 4 & 6 & Posit & 0 & 0 & $\mathrm{Neu}$ & $\mathrm{NI}$ & $\mathrm{NI}$ & $\mathrm{NI}$ \\
\hline 153 & FFX 1845814 & $\mathrm{~A}$ & 260311 & Fem & 29 & Esq & Não & Sim & 4 & 8 & Posit & 0 & 0 & $\mathrm{Neu}$ & $\mathrm{NI}$ & $\mathrm{NI}$ & $\mathrm{NI}$ \\
\hline 154 & SEM 2025736 & $\mathrm{~A}$ & 110711 & Fem & 45 & Esq & Não & Sim & 3 & 9 & Posit & 0 & 0 & $\mathrm{Neu}$ & $\mathrm{NI}$ & $\mathrm{NI}$ & $\mathrm{NI}$ \\
\hline 155 & SHPGJS 31293844 & $\mathrm{~A}$ & 120811 & Fem & 22 & Esq & Não & Sim & 4 & 8 & Posit & 0 & 0 & $\mathrm{Neu}$ & $\mathrm{NI}$ & $\mathrm{NI}$ & $\mathrm{NI}$ \\
\hline 156 & AOSS 859449 & $\mathrm{~A}$ & 50811 & Fem & 37 & Dir & Sim & Sim & 4 & 7 & Posit & 0 & 0 & $\mathrm{Neu}$ & $\mathrm{NI}$ & $\mathrm{NI}$ & $\mathrm{NI}$ \\
\hline 157 & MDM 1399953 & $\mathrm{~A}$ & 260811 & Fem & 18 & Esq & Sim & Sim & 2 & 6 & Posit & 0 & 0 & $\mathrm{Neu}$ & $\mathrm{NI}$ & $\mathrm{NI}$ & $\mathrm{NI}$ \\
\hline 158 & JMFB 517732 & $\mathrm{~A}$ & 40811 & Masc & 35 & Dir & Não & Sim & 3 & 5 & Posit & 0 & 0 & $\mathrm{Vr}$ & $\mathrm{CV}$ & $\mathrm{NI}$ & $\mathrm{NI}$ \\
\hline 159 & LFB 5490782 & $\mathrm{~A}$ & 10811 & Fem & 30 & Dir & Não & Sim & 3 & 7 & Posit & 0 & 0 & $\mathrm{Neu}$ & $\mathrm{NI}$ & $\mathrm{NI}$ & $\mathrm{NI}$ \\
\hline 160 & AP 5314844 & A & 120911 & Masc & 34 & Esq & Não & Sim & 3 & 8 & Posit & 2 & 4 & $\mathrm{Neu}$ & $\mathrm{NI}$ & $\mathrm{NI}$ & $\mathrm{NI}$ \\
\hline 161 & LAA 760659 & $\mathrm{~A}$ & 70911 & Fem & 15 & Dir & Não & Sim & 2 & 7 & Posit & 0 & 0 & $\mathrm{Neu}$ & $\mathrm{NI}$ & $\mathrm{NI}$ & $\mathrm{NI}$ \\
\hline 162 & RCVA 1165044 & $\mathrm{~A}$ & 260511 & Masc & 29 & Dir & Sim & Sim & 2 & 5 & Posit & 0 & 0 & $\mathrm{Neu}$ & $\mathrm{NI}$ & $\mathrm{NI}$ & $\mathrm{NI}$ \\
\hline 163 & JESSP 1353608 & $\mathrm{~A}$ & 180911 & Fem & 52 & Esq & Sim & Sim & 3 & 5 & Posit & 0 & 0 & $\mathrm{Neu}$ & $\mathrm{NI}$ & $\mathrm{NI}$ & $\mathrm{NI}$ \\
\hline 164 & LM 30978942 & A & 190311 & Fem & 24 & Esq & Não & Sim & 3 & 7 & Posit & 0 & 0 & $\mathrm{Neu}$ & $\mathrm{NI}$ & $\mathrm{NI}$ & $\mathrm{NI}$ \\
\hline 165 & DCA 917275 & $\mathrm{~A}$ & 281011 & Fem & 39 & Dir & Não & Sim & 4 & 8 & Posit & 0 & 0 & $\mathrm{Neu}$ & $\mathrm{NI}$ & $\mathrm{NI}$ & $\mathrm{NI}$ \\
\hline 166 & AMF 5592461 & A & 251011 & Fem & 43 & Dir & Não & Sim & 2 & 5 & Posit & 0 & 0 & $\mathrm{Neu}$ & $\mathrm{NI}$ & $\mathrm{NI}$ & $\mathrm{NI}$ \\
\hline 167 & DMK 2469359 & $\mathrm{~A}$ & 211211 & Fem & 56 & Esq & Não & Sim & 4 & 7 & Posit & 0 & 0 & $\mathrm{Neu}$ & $\mathrm{NI}$ & $\mathrm{NI}$ & $\mathrm{NI}$ \\
\hline 168 & FAC 1219039 & $\mathrm{~A}$ & 61211 & Masc & 15 & Esq & Não & Sim & 3 & 6 & Posit & 0 & 0 & $\mathrm{Neu}$ & $\mathrm{NI}$ & $\mathrm{NI}$ & $\mathrm{NI}$ \\
\hline 169 & MBC 490459 & $\mathrm{~A}$ & 301110 & Masc & 64 & Esq & Não & Sim & 4 & 7 & Posit & 0 & 0 & $\mathrm{Neu}$ & $\mathrm{NI}$ & $\mathrm{NI}$ & $\mathrm{NI}$ \\
\hline 170 & AGB 1160326 & $\mathrm{~A}$ & 170212 & Fem & 41 & Dir & Não & Sim & 2 & 7 & Posit & 0 & 0 & $\mathrm{Neu}$ & $\mathrm{NI}$ & $\mathrm{NI}$ & $\mathrm{NI}$ \\
\hline 171 & FLM 366648 & $\mathrm{~A}$ & 101111 & Fem & 22 & Esq & Não & Sim & 3 & 7 & Posit & 4 & 0 & $\mathrm{Neu}$ & $\mathrm{NI}$ & $\mathrm{NI}$ & $\mathrm{NI}$ \\
\hline 172 & MM 1217648 & $\mathrm{~A}$ & 150212 & Masc & 38 & Esq & Não & Sim & 4 & 8 & Posit & 0 & 0 & $\mathrm{Neu}$ & $\mathrm{NI}$ & $\mathrm{NI}$ & $\mathrm{NI}$ \\
\hline 173 & GDP 536106 & $\mathrm{~A}$ & 200312 & Fem & 15 & Dir & Não & Sim & 4 & 5 & Posit & 0 & 0 & $\mathrm{Neu}$ & $\mathrm{NI}$ & $\mathrm{NI}$ & $\mathrm{NI}$ \\
\hline 174 & HCSP 1297162 & $\mathrm{~A}$ & 80412 & Masc & 42 & Dir & Não & Sim & 4 & 8 & Posit & 3 & 0 & $\mathrm{Neu}$ & $\mathrm{NI}$ & $\mathrm{NI}$ & $\mathrm{NI}$ \\
\hline 175 & AGPLF 5124727 & $\mathrm{~A}$ & 170412 & Masc & 30 & Dir & Sim & Sim & 4 & 6 & Posit & 0 & 0 & $\mathrm{Neu}$ & $\mathrm{NI}$ & $\mathrm{NI}$ & $\mathrm{NI}$ \\
\hline 176 & AB 4795881 & $\mathrm{~A}$ & 140310 & Masc & 30 & Dir & Não & 2 & 2 & 7 & Posit & 0 & 0 & $\mathrm{Neu}$ & $\mathrm{NI}$ & $\mathrm{NI}$ & $\mathrm{NI}$ \\
\hline 177 & ACSM 1000609 & $\mathrm{~A}$ & 100111 & Fem & 46 & Dir & Não & Sim & 4 & 8 & Posit & 0 & 0 & $\mathrm{Neu}$ & $\mathrm{NI}$ & $\mathrm{NI}$ & $\mathrm{NI}$ \\
\hline 178 & CAASB 4544765 & $\mathrm{~A}$ & 80809 & Fem & 31 & Dir & Não & Sim & 2 & 5 & Posit & 0 & 0 & $\mathrm{Neu}$ & $\mathrm{NI}$ & $\mathrm{NI}$ & $\mathrm{NI}$ \\
\hline 179 & GRDT 5249422 & $\mathrm{~A}$ & 200211 & Fem & 49 & Esq & Não & Sim & 3 & 7 & Posit & 0 & 0 & $\mathrm{Neu}$ & $\mathrm{NI}$ & $\mathrm{NI}$ & $\mathrm{NI}$ \\
\hline 180 & JPAS 5063698 & $\mathrm{~A}$ & 200910 & Masc & 28 & Dir & Não & Sim & 4 & 8 & Posit & 0 & 0 & $\mathrm{Neu}$ & $\mathrm{NI}$ & $\mathrm{NI}$ & $\mathrm{NI}$ \\
\hline 181 & KDRN 4695224 & $\mathrm{~A}$ & 70111 & Masc & 28 & Dir & Não & Sim & 4 & 9 & Posit & 0 & 0 & $\mathrm{Neu}$ & $\mathrm{NI}$ & $\mathrm{NI}$ & $\mathrm{NI}$ \\
\hline 182 & OMJ 1023336 & $\mathrm{~A}$ & 110311 & Masc & 55 & Dir & Não & Sim & 3 & 6 & Posit & 4 & 0 & $\mathrm{Neu}$ & $\mathrm{NI}$ & $\mathrm{NI}$ & $\mathrm{NI}$ \\
\hline 183 & VRBM 1343261 & $\mathrm{~A}$ & 281210 & Masc & 29 & Dir & Não & Sim & 1 & 5 & Posit & 0 & 0 & $\mathrm{Neu}$ & $\mathrm{NI}$ & $\mathrm{NI}$ & $\mathrm{NI}$ \\
\hline 184 & GMR 1091314 & $\mathrm{~A}$ & 70512 & Masc & 17 & Dir & Não & Sim & 4 & 8 & Posit & 36 & 0 & $\mathrm{Neu}$ & $\mathrm{NI}$ & $\mathrm{NI}$ & $\mathrm{NI}$ \\
\hline 185 & DLS 462565 & $\mathrm{~A}$ & 110412 & Fem & 24 & Esq & Não & Sim & 4 & 8 & Posit & 0 & 0 & $\mathrm{Neu}$ & $\mathrm{NI}$ & $\mathrm{NI}$ & $\mathrm{NI}$ \\
\hline 186 & AZF 1045060 & $\mathrm{~A}$ & 130212 & Masc & 28 & Esq & Não & Sim & 4 & 7 & Posit & 0 & 0 & $\mathrm{Neu}$ & $\mathrm{NI}$ & $\mathrm{NI}$ & $\mathrm{NI}$ \\
\hline
\end{tabular}




\subsection{Quadro com dados do primeiro atendimento, pacientes do Grupo B}

\begin{tabular}{|c|c|c|c|c|c|c|c|c|c|c|c|c|c|c|c|c|c|}
\hline $\mathrm{N}$ & ID & Grupo & Data & Sexo & Idade & Lado & $\mathrm{CA}$ & Imed & $\begin{array}{l}\text { Local } \\
\text { Dor }\end{array}$ & EVA & Gaveta & $\mathrm{O}$ & Lco & $\mathrm{Al}$ & Pé & Sub & Med \\
\hline 1 & $\begin{array}{l}\text { AMFLC } \\
585762 \\
\end{array}$ & $\mathrm{~B}$ & 60809 & Fem & 49 & Esq & Sim & Sim & 4 & 3 & Posit & 0 & 0 & $\mathrm{Neu}$ & $\mathrm{NI}$ & $\mathrm{NI}$ & $\mathrm{NI}$ \\
\hline 2 & AAC 4569890 & B & 280809 & Fem & 37 & Dir & Não & Sim & 3 & 5 & Posit & 0 & 0 & $\mathrm{Neu}$ & $\mathrm{NI}$ & $\mathrm{NI}$ & $\mathrm{NI}$ \\
\hline 3 & ESE 4000188 & B & 160708 & Masc & 18 & Esq & Não & Sim & 1 & 6 & Posit & 0 & 0 & $\mathrm{Neu}$ & $\mathrm{NI}$ & $\mathrm{NI}$ & $\mathrm{NI}$ \\
\hline 4 & FHB 3046915 & B & 71108 & Masc & 16 & Esq & Não & Sim & 2 & 8 & Posit & 0 & 0 & $\mathrm{Neu}$ & $\mathrm{Cv}$ & $\mathrm{NI}$ & $\mathrm{NI}$ \\
\hline 5 & GSM 470052 & B & 180308 & Masc & 16 & Esq & Sim & Sim & 1 & 4 & Posit & 0 & 0 & $\mathrm{Neu}$ & $\mathrm{NI}$ & $\mathrm{NI}$ & $\mathrm{NI}$ \\
\hline 6 & MGS 4573781 & B & 50909 & Fem & 23 & Esq & Sim & Sim & 2 & 5 & Posit & 2 & 0 & $\mathrm{Neu}$ & $\mathrm{NI}$ & $\mathrm{NI}$ & $\mathrm{NI}$ \\
\hline 7 & MCB 4339290 & B & 280309 & Masc & 20 & Dir & Sim & Sim & 2 & 5 & Posit & 0 & 0 & $\mathrm{Neu}$ & $\mathrm{NI}$ & $\mathrm{NI}$ & $\mathrm{NI}$ \\
\hline 8 & MCB 4339290 & B & 40409 & Masc & 20 & Esq & Sim & Sim & 1 & 4 & Posit & 0 & 0 & $\mathrm{Neu}$ & $\mathrm{NI}$ & $\mathrm{NI}$ & $\mathrm{NI}$ \\
\hline 9 & MCB 705827 & B & 11107 & Masc & 41 & Esq & Não & Sim & 3 & 8 & Posit & 0 & 0 & $\mathrm{Neu}$ & $\mathrm{NI}$ & $\mathrm{NI}$ & $\mathrm{NI}$ \\
\hline 10 & $\begin{array}{l}\text { MERB } \\
1225042 \\
\end{array}$ & $\mathrm{~B}$ & 280708 & Fem & 35 & Dir & Sim & Sim & 2 & 6 & Posit & 0 & 0 & $\mathrm{Neu}$ & $\mathrm{NI}$ & $\mathrm{NI}$ & $\mathrm{NI}$ \\
\hline 11 & MJP 4259416 & $\mathrm{~B}$ & 300109 & Masc & 18 & Esq & Não & Sim & 3 & 7 & Posit & 3 & 0 & $\mathrm{Neu}$ & $\mathrm{NI}$ & $\mathrm{NI}$ & $\mathrm{NI}$ \\
\hline 12 & NR 923575 & B & 40709 & Masc & 35 & Dir & Sim & Sim & 2 & 7 & Posit & 0 & 0 & $\mathrm{Neu}$ & $\mathrm{NI}$ & $\mathrm{NI}$ & $\mathrm{NI}$ \\
\hline 13 & OMJ 1023336 & B & 250708 & Masc & 53 & Esq & Sim & Sim & 2 & 7 & Posit & 0 & 0 & $\mathrm{Neu}$ & $\mathrm{NI}$ & $\mathrm{NI}$ & $\mathrm{NI}$ \\
\hline 14 & PK 436322 & B & 120908 & Fem & 27 & Dir & Não & Sim & 3 & 8 & Posit & 0 & 0 & $\mathrm{Neu}$ & $\mathrm{NI}$ & $\mathrm{NI}$ & $\mathrm{NI}$ \\
\hline 15 & RYN 3828689 & $\mathrm{~B}$ & 271009 & Masc & 24 & Esq & Não & Sim & 3 & 7 & Posit & 0 & 0 & $\mathrm{Neu}$ & $\mathrm{Nl}$ & $\mathrm{NI}$ & $\mathrm{NI}$ \\
\hline 16 & RPC 840912 & B & 230309 & Fem & 46 & Dir & Sim & Sim & 3 & 7 & Posit & 0 & 0 & $\mathrm{Neu}$ & $\mathrm{NI}$ & $\mathrm{NI}$ & $\mathrm{NI}$ \\
\hline 17 & $\begin{array}{l}\text { SFGM } \\
3523322 \\
\end{array}$ & B & 121208 & Fem & 41 & Dir & Não & Sim & 3 & 5 & Posit & 0 & 0 & $\mathrm{Neu}$ & $\mathrm{NI}$ & $\mathrm{NI}$ & $\mathrm{Nl}$ \\
\hline 18 & TPM 548217 & B & 250209 & Fem & 52 & Esq & Não & Sim & 4 & 9 & Posit & 0 & 0 & $\mathrm{Neu}$ & $\mathrm{NI}$ & $\mathrm{NI}$ & $\mathrm{NI}$ \\
\hline 19 & VCB 810093 & B & 51208 & Fem & 36 & Dir & Sim & Sim & 2 & 8 & Posit & 0 & 0 & $\mathrm{Neu}$ & $\mathrm{NI}$ & $\mathrm{NI}$ & $\mathrm{NI}$ \\
\hline 20 & WFA 1228700 & B & 11208 & Masc & 29 & Esq & Sim & Sim & 4 & 7 & Posit & 0 & 0 & $\mathrm{Neu}$ & $\mathrm{Cv}$ & $\mathrm{NI}$ & $\mathrm{NI}$ \\
\hline 21 & PPN 4007409 & $\mathrm{~B}$ & 11108 & Masc & 19 & Dir & Não & Sim & 4 & 8 & Posit & 0 & 0 & $\mathrm{Neu}$ & $\mathrm{NI}$ & $\mathrm{Nl}$ & $\mathrm{NI}$ \\
\hline 22 & RJL 1177389 & B & 181108 & Fem & 46 & Esq & Não & Sim & 3 & 7 & Posit & 0 & 0 & $\mathrm{Neu}$ & $\mathrm{NI}$ & $\mathrm{NI}$ & $\mathrm{NI}$ \\
\hline 23 & LOL 904561 & B & 130508 & Fem & 34 & Dir & Não & Sim & 4 & 8 & Posit & 0 & 0 & $\mathrm{Neu}$ & $\mathrm{NI}$ & $\mathrm{NI}$ & $\mathrm{NI}$ \\
\hline 24 & $\begin{array}{l}\text { MPBG } \\
1209635 \\
\end{array}$ & B & 100508 & Masc & 33 & Esq & Não & Sim & 4 & 5 & Posit & 0 & 0 & $\mathrm{Neu}$ & $\mathrm{NI}$ & $\mathrm{NI}$ & $\mathrm{NI}$ \\
\hline 25 & MPM 407763 & $\mathrm{~B}$ & 251108 & Fem & 40 & Esq & Não & Sim & 3 & 7 & Posit & 0 & 0 & $\mathrm{Neu}$ & $\mathrm{NI}$ & $\mathrm{Nl}$ & $\mathrm{NI}$ \\
\hline 26 & LMR 405954 & B & 90908 & Masc & 18 & Esq & Sim & Sim & 1 & 6 & Posit & 0 & 0 & $\mathrm{Neu}$ & $\mathrm{NI}$ & $\mathrm{NI}$ & $\mathrm{PL}$ \\
\hline 27 & $\begin{array}{l}\text { HMVB } \\
3679861\end{array}$ & $\mathrm{~B}$ & 40409 & Masc & 41 & Esq & Sim & Sim & 3 & 6 & Posit & 0 & 0 & $\mathrm{Neu}$ & $\mathrm{NI}$ & $\mathrm{NI}$ & $\mathrm{NI}$ \\
\hline 28 & GBT 1213450 & B & 120508 & Masc & 21 & Dir & Sim & $\operatorname{Sim}$ & 4 & 9 & Posit & 0 & 0 & $\mathrm{Neu}$ & $\mathrm{NI}$ & $\mathrm{NI}$ & $\mathrm{NI}$ \\
\hline 29 & $\begin{array}{l}\text { AAAT } \\
2498251\end{array}$ & B & 220109 & Fem & 27 & Dir & Não & Sim & 2 & 6 & Posit & 0 & 0 & $\mathrm{Neu}$ & $\mathrm{NI}$ & $\mathrm{NI}$ & $\mathrm{NI}$ \\
\hline 30 & $\begin{array}{l}\text { CGDR } \\
2016419\end{array}$ & $\mathrm{~B}$ & 101008 & Masc & 20 & Esq & Sim & Sim & 1 & 6 & Posit & 0 & 0 & $\mathrm{Neu}$ & $\mathrm{Cv}$ & $\mathrm{Nl}$ & $\mathrm{NI}$ \\
\hline 31 & ABM 4531353 & B & 310709 & Masc & 47 & Esq & Sim & Sim & 1 & 7 & Posit & 0 & 0 & $\mathrm{Neu}$ & $\mathrm{NI}$ & $\mathrm{NI}$ & $\mathrm{NI}$ \\
\hline 32 & $\begin{array}{l}\text { APFLC } \\
3939677\end{array}$ & B & 90110 & Fem & 38 & Dir & Não & Sim & 2 & 7 & Posit & 0 & 0 & $\mathrm{Neu}$ & $\mathrm{NI}$ & $\mathrm{NI}$ & $\mathrm{NI}$ \\
\hline 33 & $\begin{array}{l}\text { AQCA } \\
2461161\end{array}$ & B & 61009 & Fem & 27 & Dir & Sim & Sim & 1 & 6 & Posit & 0 & 0 & $\mathrm{Neu}$ & $\mathrm{NI}$ & $\mathrm{NI}$ & $\mathrm{NI}$ \\
\hline 34 & CBU 4070866 & B & 11209 & Fem & 18 & Esq & Não & Sim & 4 & 8 & Posit & 0 & 0 & $\mathrm{Neu}$ & $\mathrm{NI}$ & $\mathrm{Nl}$ & $\mathrm{NI}$ \\
\hline 35 & CNT 1306303 & B & 231009 & Fem & 36 & Esq & Sim & Sim & 2 & 5 & Posit & 0 & 0 & $\mathrm{Neu}$ & $\mathrm{NI}$ & $\mathrm{NI}$ & $\mathrm{NI}$ \\
\hline 36 & FMB 824049 & B & 130508 & Masc & 19 & Esq & Não & Sim & 2 & 7 & Posit & 0 & 0 & $\mathrm{Neu}$ & $\mathrm{NI}$ & $\mathrm{NI}$ & $\mathrm{NI}$ \\
\hline 37 & JFS 4624009 & B & 300909 & Fem & 26 & Dir & Não & Sim & 4 & 8 & Posit & 0 & 0 & $\mathrm{Neu}$ & $\mathrm{NI}$ & $\mathrm{NI}$ & $\mathrm{NI}$ \\
\hline 38 & $\begin{array}{l}\text { MVG } \\
38860043\end{array}$ & B & 81109 & Masc & 42 & Esq & Sim & Sim & 4 & 4 & Posit & 0 & 0 & $\mathrm{Neu}$ & $\mathrm{NI}$ & $\mathrm{NI}$ & $\mathrm{NI}$ \\
\hline 39 & NK 463621 & B & 261009 & Fem & 15 & Esq & Sim & Sim & 2 & 5 & Posit & 0 & 0 & $\mathrm{Neu}$ & $\mathrm{NI}$ & $\mathrm{NI}$ & $\mathrm{NI}$ \\
\hline 40 & RKM 3379930 & B & 261109 & Masc & 15 & Dir & Sim & Sim & 2 & 6 & Posit & 0 & 0 & $\mathrm{Neu}$ & $\mathrm{NI}$ & $\mathrm{NI}$ & $\mathrm{NI}$ \\
\hline 41 & $\begin{array}{l}\text { THOB } \\
4043979 \\
\end{array}$ & $\mathrm{~B}$ & 230110 & Masc & 23 & Esq & Sim & Sim & 4 & 7 & Posit & 0 & 0 & $\mathrm{Neu}$ & $\mathrm{NI}$ & $\mathrm{NI}$ & $\mathrm{PL}$ \\
\hline 42 & $\mathrm{RH} 4150961$ & B & 51008 & Masc & 23 & Dir & Sim & Sim & 3 & 6 & Posit & 0 & 0 & $\mathrm{Neu}$ & $\mathrm{NI}$ & $\mathrm{NI}$ & $\mathrm{NI}$ \\
\hline 43 & RCR 3879879 & B & 280110 & Masc & 18 & Esq & Sim & Sim & 1 & 5 & Posit & 0 & 0 & $\mathrm{Neu}$ & $\mathrm{NI}$ & $\mathrm{NI}$ & $\mathrm{NI}$ \\
\hline 44 & TC 4766415 & B & 300110 & Fem & 16 & Esq & Sim & Sim & 2 & 6 & Posit & 0 & 0 & $\mathrm{Neu}$ & $\mathrm{NI}$ & $\mathrm{NI}$ & $\mathrm{NI}$ \\
\hline 45 & EAM 2444526 & $\mathrm{~B}$ & 230208 & Fem & 38 & Esq & Não & Sim & 2 & 6 & Posit & 0 & 0 & $\mathrm{Neu}$ & $\mathrm{NI}$ & $\mathrm{Nl}$ & $\mathrm{NI}$ \\
\hline 46 & NCE 545273 & B & 150510 & Fem & 19 & Esq & Não & Sim & 3 & 8 & Posit & 0 & 0 & $\mathrm{Neu}$ & $\mathrm{NI}$ & $\mathrm{NI}$ & $\mathrm{NI}$ \\
\hline 47 & CFC 4923103 & $\mathrm{~B}$ & 60610 & Masc & 26 & Esq & Não & Sim & 4 & 6 & Posit & 0 & 0 & $\mathrm{Neu}$ & $\mathrm{NI}$ & $\mathrm{NI}$ & $\mathrm{NI}$ \\
\hline 48 & JHO 1175985 & $\mathrm{~B}$ & 130410 & Masc & 39 & Dir & Não & Sim & 4 & 8 & Posit & 0 & 0 & $\mathrm{Neu}$ & $\mathrm{NI}$ & $\mathrm{Nl}$ & $\mathrm{NI}$ \\
\hline 49 & TA 4698088 & $\mathrm{~B}$ & 20710 & Fem & 32 & Dir & Não & Sim & 4 & 7 & Posit & 0 & 0 & $\mathrm{Neu}$ & $\mathrm{NI}$ & $\mathrm{NI}$ & $\mathrm{NI}$ \\
\hline
\end{tabular}




\subsection{Quadro com dados do primeiro atendimento, pacientes do Grupo B (conclusão)}

\begin{tabular}{|c|c|c|c|c|c|c|c|c|c|c|c|c|c|c|c|c|c|}
\hline $\mathrm{N}$ & ID & Grupo & Data & Sexo & Idade & Lado & $\mathrm{CA}$ & Imed & $\begin{array}{c}\text { Local } \\
\text { Dor }\end{array}$ & EVA & Gaveta & 0 & Lco & $\mathrm{Al}$ & Pé & Sub & Med \\
\hline 50 & \begin{tabular}{|l|} 
CCD \\
38582446 \\
\end{tabular} & $\mathrm{~B}$ & 300510 & Fem & 28 & Esq & Não & Sim & 3 & 7 & Posit & 0 & 0 & $\mathrm{Neu}$ & $\mathrm{NI}$ & $\mathrm{NI}$ & $\mathrm{NI}$ \\
\hline 51 & CEF 1020577 & B & 90810 & Masc & 39 & Esq & Sim & Sim & 2 & 6 & Posit & 0 & 0 & $\mathrm{Neu}$ & $\mathrm{NI}$ & $\mathrm{NI}$ & $\mathrm{NI}$ \\
\hline 52 & RFR 491620 & B & 80710 & Masc & 17 & Esq & Não & Sim & 4 & 8 & Posit & 0 & 0 & $\mathrm{Neu}$ & $\mathrm{NI}$ & $\mathrm{NI}$ & $\mathrm{NI}$ \\
\hline 53 & PHBS 764796 & B & 180710 & Masc & 39 & Esq & $\operatorname{Sim}$ & Sim & 4 & 6 & Posit & 0 & 0 & $\mathrm{Neu}$ & $\mathrm{NI}$ & $\mathrm{NI}$ & $\mathrm{NI}$ \\
\hline 54 & MJ 5059046 & $B$ & 100810 & Masc & 43 & Dir & Não & Sim & 3 & 6 & Posit & 0 & 0 & $\mathrm{Neu}$ & $\mathrm{NI}$ & $\mathrm{NI}$ & $\mathrm{NI}$ \\
\hline 55 & MCF 1140955 & B & 100910 & Masc & 41 & Dir & Não & Sim & 4 & 7 & Posit & 0 & 0 & $\mathrm{Neu}$ & $\mathrm{NI}$ & $\mathrm{NI}$ & $\mathrm{NI}$ \\
\hline 56 & $\begin{array}{l}\text { MGGR } \\
803642 \\
\end{array}$ & $B$ & 100610 & Fem & 57 & Esq & Não & Sim & 3 & 7 & Posit & 0 & 0 & $\mathrm{Neu}$ & $\mathrm{NI}$ & $\mathrm{NI}$ & $\mathrm{NI}$ \\
\hline 57 & VLS 5135613 & B & 11110 & Masc & 23 & Dir & Não & Sim & 4 & 8 & Posit & 0 & 0 & $\mathrm{Neu}$ & $\mathrm{NI}$ & $\mathrm{NI}$ & $\mathrm{NI}$ \\
\hline 58 & CC 3567168 & B & 100910 & Masc & 45 & Dir & Não & Sim & 4 & 7 & Posit & 0 & 0 & $\mathrm{Neu}$ & $\mathrm{NI}$ & $\mathrm{NI}$ & $\mathrm{NI}$ \\
\hline 59 & Zl 1191525 & B & 131010 & $\mathrm{Fem}$ & 46 & Esq & Não & $\mathrm{Sim}$ & 3 & 8 & Posit & 0 & 0 & $\mathrm{Neu}$ & $\mathrm{NI}$ & $\mathrm{NI}$ & $\mathrm{NI}$ \\
\hline 60 & $\begin{array}{l}\text { FCDOS } \\
577500 \\
\end{array}$ & B & 180211 & Fem & 13 & Esq & Sim & Sim & 3 & 7 & Posit & 0 & 0 & $\mathrm{Neu}$ & $\mathrm{NI}$ & $\mathrm{NI}$ & $\mathrm{NI}$ \\
\hline 61 & $\begin{array}{l}\text { JECQ } \\
1171530 \\
\end{array}$ & B & 300111 & Masc & 40 & Dir & Não & Sim & 2 & 7 & Posit & 0 & 0 & $\mathrm{Neu}$ & $\mathrm{NI}$ & $\mathrm{NI}$ & $\mathrm{NI}$ \\
\hline 62 & FKC 5416248 & B & 230611 & Masc & 17 & Esq & Não & Sim & 2 & 9 & Posit & 0 & 0 & $\mathrm{Neu}$ & $\mathrm{NI}$ & $\mathrm{NI}$ & $\mathrm{NI}$ \\
\hline 63 & AWB 5477280 & $B$ & 240811 & Masc & 45 & Esq & Não & Sim & 4 & 8 & Posit & 0 & 0 & $\mathrm{Neu}$ & $\mathrm{NI}$ & $\mathrm{NI}$ & $\mathrm{NI}$ \\
\hline 64 & PPN 1008095 & $\mathrm{~B}$ & 60911 & Fem & 29 & Esq & Não & Sim & 3 & 8 & Posit & 0 & 0 & $\mathrm{Neu}$ & $\mathrm{NI}$ & $\mathrm{NI}$ & $\mathrm{NI}$ \\
\hline 65 & AP 38625494 & B & 280611 & Masc & 41 & Esq & Sim & Sim & 4 & 6 & Posit & 0 & 0 & $\mathrm{Neu}$ & $\mathrm{NI}$ & $\mathrm{NI}$ & $\mathrm{NI}$ \\
\hline 66 & \begin{tabular}{|l|l|} 
ACBSJ \\
1088698 \\
\end{tabular} & $B$ & 250811 & Masc & 49 & Dir & Sim & Sim & 3 & 4 & Posit & 0 & 0 & $\mathrm{Neu}$ & $\mathrm{NI}$ & $\mathrm{NI}$ & $\mathrm{NI}$ \\
\hline 67 & FOCB 379160 & B & 151111 & Masc & 44 & Dir & Sim & Sim & 3 & 6 & Posit & 0 & 0 & $\mathrm{Neu}$ & $\mathrm{NI}$ & $\mathrm{NI}$ & $\mathrm{NI}$ \\
\hline 68 & ASGR 945808 & B & 101211 & Masc & 42 & Dir & Não & Sim & 4 & 8 & Posit & 0 & 0 & $\mathrm{Neu}$ & $\mathrm{NI}$ & $\mathrm{NI}$ & $\mathrm{NI}$ \\
\hline 69 & ZF 1333682 & B & 111111 & $\mathrm{Fem}$ & 60 & Dir & Não & Sim & 3 & 5 & Posit & 0 & 0 & $\mathrm{Neu}$ & $\mathrm{NI}$ & $\mathrm{NI}$ & $\mathrm{NI}$ \\
\hline 70 & MSA 859888 & B & 270112 & Fem & 38 & Dir & Não & Sim & 4 & 7 & Posit & 0 & 0 & $\mathrm{Neu}$ & $\mathrm{NI}$ & $\mathrm{NI}$ & $\mathrm{NI}$ \\
\hline 71 & $\begin{array}{l}\text { FMAMSMO } \\
580627 \\
\end{array}$ & B & 250112 & Fem & 45 & Esq & Não & Sim & 4 & 8 & Posit & 0 & 0 & $\mathrm{Neu}$ & $\mathrm{NI}$ & $\mathrm{NI}$ & $\mathrm{NI}$ \\
\hline 72 & \begin{tabular}{|l|} 
GRJS \\
5758203 \\
\end{tabular} & B & 200212 & Masc & 24 & Dir & Não & Sim & 3 & 6 & Posit & 0 & 0 & $\mathrm{Neu}$ & $\mathrm{NI}$ & $\mathrm{NI}$ & $\mathrm{NI}$ \\
\hline 73 & LMO 470263 & B & 200312 & Masc & 17 & Esq & Não & Sim & 2 & 5 & Posit & 0 & 0 & $\mathrm{Neu}$ & $\mathrm{NI}$ & $\mathrm{NI}$ & $\mathrm{NI}$ \\
\hline 74 & OP 577884 & $\mathrm{~B}$ & 110510 & Masc & 47 & Dir & Não & Sim & 3 & 8 & Posit & 0 & 0 & $\mathrm{Neu}$ & $\mathrm{NI}$ & $\mathrm{NI}$ & $\mathrm{NI}$ \\
\hline 75 & RBN & B & 141009 & Masc & 19 & Esq & Não & Sim & 4 & 10 & Posit & 5 & 2 & $\mathrm{Neu}$ & $\mathrm{NI}$ & $\mathrm{NI}$ & $\mathrm{NI}$ \\
\hline 76 & RKM 3379930 & $\mathrm{~B}$ & 261109 & Masc & 16 & Dir & $\mathrm{Sim}$ & Sim & 2 & 6 & Posit & 0 & 0 & $\mathrm{Neu}$ & $\mathrm{NI}$ & $\mathrm{NI}$ & $\mathrm{NI}$ \\
\hline 77 & MFS 5948762 & B & 100412 & Fem & 58 & Esq & Sim & Sim & 2 & 4 & Posit & 0 & 0 & $\mathrm{Neu}$ & $\mathrm{NI}$ & $\mathrm{NI}$ & $\mathrm{NI}$ \\
\hline 78 & ABN 905123 & $\mathrm{~B}$ & 41110 & Masc & 41 & Esq & Não & Sim & 2 & 8 & Posit & 0 & 0 & $\mathrm{Neu}$ & $\mathrm{NI}$ & $\mathrm{NI}$ & $\mathrm{NI}$ \\
\hline 79 & AFM 1399051 & B & 240111 & Masc & 53 & Esq & Não & Sim & 1 & 4 & Posit & 0 & 0 & $\mathrm{Neu}$ & $\mathrm{NI}$ & $\mathrm{NI}$ & $\mathrm{NI}$ \\
\hline 80 & AHS 4043588 & $\mathrm{~B}$ & 91010 & Masc & 35 & Esq & Sim & Sim & 2 & 6 & Posit & 0 & 0 & $\mathrm{Neu}$ & $\mathrm{NI}$ & $\mathrm{NI}$ & $\mathrm{NI}$ \\
\hline 81 & DHC 4871090 & B & 160410 & Masc & 24 & Dir & Sim & Sim & 4 & 6 & Posit & 0 & 0 & $\mathrm{Neu}$ & $\mathrm{NI}$ & $\mathrm{NI}$ & $\mathrm{NI}$ \\
\hline 82 & $\begin{array}{l}\text { JGGM } \\
1141773\end{array}$ & B & 291110 & Fem & 31 & Dir & Não & Sim & 4 & 7 & Posit & 0 & 0 & $\mathrm{Neu}$ & $\mathrm{NI}$ & $\mathrm{NI}$ & $\mathrm{NI}$ \\
\hline 83 & $\begin{array}{l}\text { LFMSS } \\
1336544 \\
\end{array}$ & B & 230310 & Masc & 16 & Dir & Não & Sim & 2 & 7 & Posit & 0 & 0 & $\mathrm{Neu}$ & $\mathrm{NI}$ & $\mathrm{NI}$ & $\mathrm{NI}$ \\
\hline 84 & $\begin{array}{l}\text { LGCG } \\
1408003\end{array}$ & B & 100211 & Masc & 27 & Dir & Não & Sim & 4 & 6 & Posit & 0 & 0 & $\mathrm{Neu}$ & $\mathrm{NI}$ & $\mathrm{NI}$ & $\mathrm{NI}$ \\
\hline 85 & $\begin{array}{l}\text { MGTM } \\
1098293 \\
\end{array}$ & B & 100111 & Fem & 51 & Dir & Não & Sim & 2 & 6 & Posit & 0 & 0 & $\mathrm{Neu}$ & $\mathrm{NI}$ & $\mathrm{NI}$ & $\mathrm{NI}$ \\
\hline 86 & $\begin{array}{l}\text { RCVA } \\
1165044 \\
\end{array}$ & B & 121110 & Masc & 29 & Esq & Não & Sim & 2 & 5 & Posit & 0 & 0 & $\mathrm{Neu}$ & $\mathrm{NI}$ & $\mathrm{NI}$ & $\mathrm{NI}$ \\
\hline 87 & RBD 1158348 & B & 180310 & Masc & 38 & Dir & Não & Sim & 4 & 8 & Posit & 0 & 0 & $\mathrm{Neu}$ & $\mathrm{Cv}$ & $\mathrm{NI}$ & $\mathrm{NI}$ \\
\hline 88 & RFC 3059642 & B & 100311 & Masc & 34 & Dir & Não & Sim & 2 & 5 & Posit & 0 & 0 & $\mathrm{Neu}$ & $\mathrm{NI}$ & $\mathrm{NI}$ & $\mathrm{NI}$ \\
\hline 89 & SVS 1329081 & B & 60910 & Fem & 39 & Dir & Não & Sim & 4 & 7 & Posit & 0 & 0 & $\mathrm{Neu}$ & $\mathrm{NI}$ & $\mathrm{NI}$ & $\mathrm{NI}$ \\
\hline 90 & $\begin{array}{l}\text { MTNA } \\
1471041 \\
\end{array}$ & $B$ & 10512 & Fem & 45 & Dir & Não & Sim & 4 & 7 & Posit & 0 & 0 & $\mathrm{Neu}$ & $\mathrm{NI}$ & $\mathrm{NI}$ & $\mathrm{NI}$ \\
\hline 91 & FSC 448882 & B & 20512 & Fem & 28 & Esq & Não & Sim & 3 & 8 & Posit & 0 & 0 & $\mathrm{Neu}$ & $\mathrm{NI}$ & $\mathrm{NI}$ & $\mathrm{NI}$ \\
\hline 92 & KS 440027 & B & 180512 & Fem & 48 & Dir & Não & Sim & 4 & 8 & Posit & 0 & 0 & $\mathrm{Neu}$ & $\mathrm{NI}$ & $\mathrm{NI}$ & $\mathrm{NI}$ \\
\hline
\end{tabular}


Abreviaturas dos quadros 10.1 e 10.2:

$\mathbf{N}$ : número do paciente

ID: Identificação (Iniciais e registro)

Grupo: Grupo de tratamento realizado (A ou B)

Sexo: Masc - masculino; Fem - feminino

Idade: em anos

Lado: Dir - direito; Esq - esquerdo)

CA: Capacidade de apoio

Imed: Incapacidade de apoio imediata

Local da dor: 1 - antero lateral; 2 - antero lateral e sob o maléolo lateral; 3 - antero lateral, sob o maléolo lateral e póstero lateral; 4 - antero lateral, sob o maléolo lateral, póstero lateral e sob o maléolo medial

EVA: Escala visual analógida de dor

GA: Gaveta anterior (Posit - positiva)

O: Outras dores (1 - maléolo lateral; 2 - medio pé; 3- sindesmose anterior; 4 - base quinto metatarsal; 5 - dorso pé; 6 - fibulares)

LCo: Lesões concomitantes ( 1 - avulsão do maléolo lateral; 2 - síndrome do túnel tarsal aguda; 3 - fratura cotovelo; 4 - fratura base quinto metatarsal)

Al: Alinhamento do retro pé (Neu - neutro; Val - valgo; Var - varo)

Pé: Tipo de pé (Nl - plantígrado; Pl - plano; Cv - cavo)

Sub: Mobilidade subtalar (Nl - normal; PL - parcialmente limitada; L - limitada)

Med: Mobilidade do médio pé (Não - normal; PL - parcialmente limitada; L - limitada) 
10.3 Quadro com dados da avaliação com uma semana, pacientes do Grupo A

\begin{tabular}{|c|c|c|c|c|c|c|c|c|c|c|c|c|c|}
\hline $\mathrm{N}$ & Dor & Edema & EVA & CD & Ap & AOFAS & LFTA & LFC & LFTP & LDP & LDS & Lac & $A A$ \\
\hline 93 & 4 & 2 & 4 & Parcial & Sim & 67 & $\operatorname{Sim}$ & Sim & Não & Não & Não & Não & Não \\
\hline 94 & 4 & 3 & 2 & Sim & Sim & 69 & Sim & Sim & Não & Sim & Não & 2 & Não \\
\hline 95 & 2 & 2 & 3 & Sim & Sim & 69 & Sim & Sim & Não & Sim & Não & 1 & Não \\
\hline 96 & 3 & 1 & 2 & Sim & Sim & 72 & Sim & Sim & Não & Não & Não & 2 & Não \\
\hline 97 & 3 & 3 & 6 & Não & Não & 44 & Sim & Sim & Não & Não & Não & 3 & 1 \\
\hline 98 & 2 & 2 & 5 & Parcial & Parcial & 57 & Sim & Sim & Não & Sim & Não & 4 & Não \\
\hline 99 & 4 & 2 & 5 & Parcial & Parcial & 52 & Sim & Sim & Não & Sim & Não & 2 & Não \\
\hline 100 & 4 & 3 & 5 & Não & Não & 48 & Sim & Sim & Não & Sim & Não & 24 & 1 \\
\hline 101 & 3 & 3 & 5 & Parcial & Parcial & 57 & Sim & Não & Não & Não & Não & 2 & 1 \\
\hline 102 & 2 & 3 & 4 & Sim & Sim & 70 & Sim & Sim & Não & Não & Não & Não & 1 \\
\hline 103 & 4 & 2 & 5 & Parcial & Não & 30 & Sim & Sim & Não & Sim & Não & 1 & Não \\
\hline 104 & 4 & 3 & 5 & Não & Parcial & 49 & Sim & Sim & Não & Sim & Não & Não & Não \\
\hline 105 & 3 & 3 & 4 & Não & Parcial & 47 & Sim & Sim & Não & Sim & Não & Não & Não \\
\hline 106 & 3 & 2 & 4 & Sim & $\mathrm{Sim}$ & 67 & Sim & Sim & Não & Sim & Não & 13 & Não \\
\hline 107 & 2 & 1 & 3 & Sim & Sim & 67 & Sim & Sim & Não & Sim & Não & 1 & Não \\
\hline 108 & 4 & 2 & 2 & Não & Parcial & 60 & Sim & Sim & Não & Sim & Não & 1 & Não \\
\hline 109 & 1 & 2 & 3 & Parcial & Sim & 60 & Sim & Sim & Não & Sim & Não & 146 & Não \\
\hline 110 & 1 & 2 & 4 & Não & Parcial & 71 & Sim & Sim & Não & Não & Não & Não & Não \\
\hline 111 & 4 & 2 & 5 & Não & Parcial & 72 & Sim & Sim & Não & Sim & Não & 1 & Não \\
\hline 112 & 2 & 2 & 8 & Não & Parcial & 43 & Sim & Sim & Não & Não & Não & 1 & 1 \\
\hline 113 & 1 & 2 & 3 & Sim & $\mathrm{Sim}$ & 60 & Sim & Não & Não & Não & Não & 4 & 1 \\
\hline 114 & 4 & 4 & 6 & Não & Não & 24 & Sim & Sim & Não & Sim & Não & 2 & Não \\
\hline 115 & 4 & 3 & 6 & Parcial & Sim & 66 & Sim & Sim & Não & Sim & Não & 15 & 2 \\
\hline 116 & 3 & 2 & 2 & Sim & Sim & 71 & $\mathrm{Sim}$ & Sim & Não & Não & Não & 5 & Não \\
\hline 117 & 4 & 3 & 3 & Sim & Sim & 66 & Sim & Sim & Não & Sim & Não & Não & Não \\
\hline 118 & 4 & 3 & 4 & Parcial & Sim & 67 & Sim & Sim & Não & Não & Não & Não & Não \\
\hline 119 & 4 & 3 & 6 & & Parcial & 52 & & Sim & Não & Sim & Não & 1 & 1 \\
\hline 120 & 4 & 3 & 3 & Não & Parcial & 60 & Sim & Sim & Não & Sim & Não & Não & Não \\
\hline 121 & 3 & 2 & 2 & Sim & Sim & 70 & Sim & Sim & Não & Não & Não & Não & Não \\
\hline 122 & 3 & 2 & 2 & Sim & Sim & 89 & Sim & Sim & Não & Sim & Não & 1Não & 1 \\
\hline 123 & 4 & 2 & 4 & Parcial & Sim & 60 & Sim & Sim & Não & Sim & Não & 15 & 3 \\
\hline 124 & 4 & 2 & 5 & Não & Sim & 62 & Sim & Sim & Não & Não & Não & 1 & Não \\
\hline 125 & 4 & 2 & 1 & Sim & Sim & 73 & Sim & Sim & Não & Não & Não & 1 & Não \\
\hline 126 & 3 & 2 & 3 & Sim & Sim & 67 & Sim & Sim & Não & Não & Não & 1 & Não \\
\hline 127 & 3 & 2 & 3 & Sim & Sim & 70 & Sim & Sim & Não & Não & Não & Não & Não \\
\hline 128 & 3 & 2 & 3 & Parcial & Sim & 66 & Sim & Sim & Não & Não & Não & Não & 1 \\
\hline 129 & 3 & 3 & 2 & Sim & Sim & 66 & Sim & Sim & Não & Não & Não & Não & Não \\
\hline 130 & 4 & 3 & 3 & Parcial & Parcial & 67 & Sim & Não & Não & Não & Não & 13 & Não \\
\hline 131 & 4 & 2 & 2 & Sim & Sim & 69 & Sim & Sim & Não & Sim & Não & Não & Não \\
\hline 132 & 3 & 2 & 6 & Não & Não & 44 & Sim & Não & Não & Não & Não & 1 & 1 \\
\hline 133 & 2 & 2 & 3 & $\mathrm{Sim}$ & $\mathrm{Sim}$ & 67 & Sim & Sim & Não & Sim & Não & 3 & Não \\
\hline 134 & 4 & 3 & 7 & Não & Não & 44 & Sim & Sim & Não & Não & Não & 1 & Não \\
\hline 135 & 4 & 2 & 5 & Não & Não & 48 & Sim & Sim & Não & Sim & Não & 1 & Não \\
\hline 136 & 3 & 2 & 4 & Parcial & Parcial & 57 & Sim & Sim & Não & Não & Não & 4 & Não \\
\hline 137 & 3 & 3 & 4 & Não & Parcial & 67 & Sim & Não & Não & Não & Não & 2 & Não \\
\hline 138 & 3 & 4 & 4 & Não & Não & 52 & Sim & Sim & Não & Sim & Não & 2 & Não \\
\hline 139 & 4 & 3 & 4 & Não & Parcial & 63 & Sim & Sim & Não & Sim & Não & Não & Não \\
\hline 140 & 4 & 2 & 4 & Parcial & Sim & 67 & Sim & Não & Não & Sim & Não & 1 & Não \\
\hline 141 & 4 & 2 & 2 & $\mathrm{Sim}$ & Sim & 67 & Sim & Sim & Não & Sim & Não & Não & 2 \\
\hline 142 & 2 & 3 & 3 & Parcial & Sim & 67 & Sim & Não & Não & Não & Não & Não & Não \\
\hline 143 & 3 & 3 & 3 & Parcial & Sim & 67 & Sim & Sim & Não & Não & Não & Não & 1 \\
\hline 144 & 2 & 4 & 2 & Sim & Sim & 69 & Sim & Sim & Não & Não & Não & Não & Não \\
\hline
\end{tabular}




\subsection{Quadro com dados da avaliação com uma semana, pacientes do Grupo A (conclusão)}

\begin{tabular}{|c|c|c|c|c|c|c|c|c|c|c|c|c|c|}
\hline $\mathrm{N}$ & Dor & Edema & EVA & $C D$ & Ap & AOFAS & LFTA & LFC & LFTP & LDP & LDS & Lac & $\mathrm{AA}$ \\
\hline 145 & 3 & 4 & 5 & Não & Parcial & 53 & Sim & Sim & Não & Sim & Não & 134 & Não \\
\hline 146 & 4 & 3 & 4 & Parcial & Parcial & 50 & Sim & Sim & Não & Sim & Não & Não & Não \\
\hline 147 & 4 & 2 & 3 & Parcial & Parcial & 50 & Sim & Sim & Não & Sim & Não & 2 & 1 \\
\hline 148 & 4 & 4 & 3 & Parcial & Sim & 63 & Sim & Sim & Não & Sim & Não & 13 & 1 \\
\hline 149 & 3 & 3 & 3 & Parcial & Sim & 66 & Sim & Não & Não & Não & Não & Não & Não \\
\hline 150 & 3 & 1 & 1 & Sim & Sim & 75 & Sim & Não & Não & Não & Não & 4 & Não \\
\hline 151 & 4 & 3 & 5 & Parcial & Parcial & 64 & Sim & Sim & Não & Não & Não & 1 & Não \\
\hline 152 & 4 & 2 & 3 & Sim & Parcial & 53 & Sim & Sim & Não & Não & Não & 1Não & 1 \\
\hline 153 & 4 & 3 & 2 & Parcial & Parcial & 65 & Sim & Sim & Não & Não & Não & Não & Não \\
\hline 154 & 2 & 2 & 2 & Parcial & Sim & 54 & Sim & Sim & Não & Não & Não & Não & Não \\
\hline 155 & 4 & 3 & 4 & Não & Não & 37 & Sim & Sim & Não & Sim & Não & 1 & Não \\
\hline 156 & 4 & 2 & 3 & Parcial & Sim & 57 & Sim & Sim & Não & Sim & Não & Não & Não \\
\hline 157 & 2 & 2 & 1 & Sim & Sim & 63 & Sim & Sim & Não & Não & Não & 14 & 1 \\
\hline 158 & 3 & 2 & 1 & Sim & Sim & 73 & Sim & Sim & Não & Não & Não & Não & Não \\
\hline 159 & 3 & 2 & 2 & Parcial & Sim & 62 & Sim & Sim & Não & Não & Não & 1 & Não \\
\hline 160 & 3 & 2 & 3 & Não & Parcial & 50 & Sim & Sim & Não & Não & Não & Não & Não \\
\hline 161 & 2 & 2 & 3 & Sim & Sim & 68 & Sim & Sim & Não & Sim & Não & Não & 1 \\
\hline 162 & 2 & 2 & 2 & Sim & Sim & 77 & Sim & Não & Não & Não & Não & Não & 1 \\
\hline 163 & 2 & 2 & 2 & Sim & Sim & 72 & Sim & Sim & Não & Sim & Não & 1 & Não \\
\hline 164 & 3 & 2 & 2 & Sim & Sim & 66 & Sim & Sim & Não & Não & Não & Não & Não \\
\hline 165 & 4 & 3 & 3 & Parcial & Sim & 46 & Sim & Sim & Não & Sim & Não & 1 & Não \\
\hline 166 & 2 & 1 & 2 & Sim & Sim & 67 & Sim & Não & Não & Não & Não & Não & Não \\
\hline 167 & 4 & 2 & 2 & Parcial & Sim & 64 & Sim & Sim & Não & Sim & Não & 18 & Não \\
\hline 168 & 4 & 2 & 1 & Sim & Sim & 71 & Sim & Sim & Não & Não & Não & Não & Não \\
\hline 169 & 4 & 3 & 2 & Sim & Sim & 71 & Sim & Sim & Não & Não & Não & Não & Não \\
\hline 170 & 2 & 2 & 2 & Sim & Sim & 67 & Sim & Sim & Não & Não & Não & 13 & 45 \\
\hline 171 & 2 & 2 & 1 & Sim & Sim & 60 & Sim & Sim & Não & Não & Não & 12 & Não \\
\hline 172 & 4 & 3 & 3 & Não & Parcial & 49 & Sim & Não & Não & Não & Não & 113 & 16 \\
\hline 173 & 4 & 2 & 2 & Sim & Sim & 64 & Sim & Sim & Não & Sim & Não & Não & Não \\
\hline 174 & 4 & 3 & 2 & Parcial & Sim & 50 & Sim & Sim & Não & Não & Não & 514 & Não \\
\hline 175 & 3 & 2 & 2 & Não & Parcial & 67 & Sim & Sim & Não & Sim & Não & 1 & 3 \\
\hline 176 & 3 & 1 & 3 & Sim & Sim & 76 & Sim & Sim & Não & Não & Não & Não & Não \\
\hline 177 & 3 & 2 & 3 & Parcial & Sim & 67 & Sim & Sim & Não & Sim & Não & 1 & 1 \\
\hline 178 & 3 & 2 & 3 & Sim & Sim & 67 & Sim & Sim & Não & Sim & Não & Não & 1 \\
\hline 179 & 2 & 2 & 2 & Sim & Sim & 60 & Sim & Sim & Não & Não & Não & Não & Não \\
\hline 180 & 4 & 3 & 4 & Não & Parcial & 46 & Sim & Sim & Não & Sim & Não & 1 & Não \\
\hline 181 & 4 & 3 & 4 & Não & Não & 40 & Sim & Sim & Não & Sim & Não & 1 & Não \\
\hline 182 & 4 & 3 & 4 & Não & Não & 43 & Sim & Sim & Não & Não & Não & 12 & Não \\
\hline 183 & 3 & 3 & 3 & Parcial & Sim & 67 & Sim & Sim & Não & Não & Não & Não & Não \\
\hline 184 & 4 & 3 & 6 & Parcial & Sim & 44 & Sim & Sim & Não & Sim & Não & 1 & Não \\
\hline 185 & 4 & 2 & 3 & $\mathrm{Sim}$ & Sim & 50 & Sim & Sim & Não & Sim & Não & 1 & Não \\
\hline 186 & 4 & 1 & 2 & Parcial & Sim & 77 & Sim & Sim & Não & Sim & Não & 1 & 3 \\
\hline
\end{tabular}


10.4 Quadro com dados da avaliação com uma semana, pacientes do Grupo B

\begin{tabular}{|c|c|c|c|c|c|c|c|c|c|c|c|c|c|}
\hline $\mathrm{N}$ & Dor & Edema & EVA & $C D$ & Ap & AOFAS & LFTA & LFC & LFTP & LDP & LDS & Lac & $\mathrm{AA}$ \\
\hline 1 & 4 & 2 & 2 & Sim & Sim & 80 & Sim & Sim & Não & Não & Não & Não & Não \\
\hline 2 & 3 & 2 & 2 & Parcial & Sim & 69 & Sim & Sim & Não & Não & Não & 3 & Não \\
\hline 3 & 1 & 1 & 2 & Parcial & Sim & 75 & Sim & Sim & Não & Não & Não & Não & Não \\
\hline 4 & 2 & 2 & 2 & Sim & Sim & 54 & Sim & Sim & Não & Não & Não & 1 & 1 \\
\hline 5 & 1 & 0 & 1 & Sim & Sim & 70 & Sim & Não & Não & Não & Não & 3 & Não \\
\hline 6 & 2 & 2 & 1 & Sim & Sim & 77 & Sim & Sim & Não & Não & Não & Não & Não \\
\hline 7 & 2 & 2 & 3 & Sim & Sim & 72 & Sim & Sim & Não & Não & Não & Não & Não \\
\hline 8 & 1 & 1 & 3 & Sim & Sim & 85 & Sim & Sim & Não & Não & Não & Não & Não \\
\hline 9 & 4 & 3 & 3 & Sim & Sim & 77 & Sim & Sim & Não & Sim & Não & 4 & Não \\
\hline 10 & 2 & 1 & 2 & Sim & $\mathrm{Sim}$ & 78 & Sim & Sim & Não & Não & Não & Não & Não \\
\hline 11 & 4 & 3 & 3 & Não & Parcial & 50 & Sim & Sim & Não & Sim & Não & 5 & 1 \\
\hline 12 & 2 & 2 & 4 & Parcial & Sim & 77 & Sim & Sim & Não & Não & Não & Não & Não \\
\hline 13 & 2 & 2 & 2 & Sim & Sim & 74 & Sim & Sim & Não & Não & Não & 6 & Não \\
\hline 14 & 4 & 2 & 2 & Parcial & Sim & 72 & Sim & Sim & Não & Sim & Não & Não & Não \\
\hline 15 & 2 & 2 & 3 & Parcial & Parcial & 63 & Sim & Sim & Não & Não & Não & Não & Não \\
\hline 16 & 2 & 1 & 2 & Sim & Sim & 90 & Sim & Sim & Não & Não & Não & 1 & Não \\
\hline 17 & 3 & 2 & 6 & Não & $\mathrm{Sim}$ & 67 & Sim & Não & Não & Sim & Não & 7 & Não \\
\hline 18 & 2 & 2 & 5 & Não & Parcial & 54 & Sim & Sim & Não & Sim & Não & 13 & Não \\
\hline 19 & 4 & 3 & 4 & Parcial & Sim & 76 & Sim & Sim & Não & Sim & Não & 1 & 1 \\
\hline 20 & 2 & 1 & 0 & Sim & Sim & 90 & Sim & Sim & Não & Sim & Não & 1 & Não \\
\hline 21 & 4 & 2 & 4 & Não & Não & 50 & Sim & Sim & Não & Não & Não & 2 & Não \\
\hline 22 & 4 & 2 & 3 & Sim & Sim & 70 & Sim & Sim & Não & Sim & Não & 2 & Não \\
\hline 23 & 2 & 2 & 3 & Parcial & Sim & 70 & Sim & Sim & Não & Não & Não & 2 & Não \\
\hline 24 & 2 & 3 & 4 & Parcial & Sim & 67 & Sim & Sim & Não & Não & Não & 2 & Não \\
\hline 25 & 2 & 2 & 3 & Sim & Sim & 70 & Sim & Não & Não & Não & Não & Não & Não \\
\hline 26 & 2 & 2 & 3 & Sim & Sim & 76 & Sim & Não & Não & Não & Não & 1 & 1 \\
\hline 27 & 4 & 2 & 4 & Sim & Sim & 62 & Sim & Sim & Não & Não & Não & 1 & Não \\
\hline 28 & 4 & 3 & 2 & Parcial & Sim & 62 & Sim & Sim & Não & Sim & Não & 5 & Não \\
\hline 29 & 2 & 3 & 4 & Parcial & Sim & 58 & Sim & Sim & Não & Não & Não & Não & Não \\
\hline 30 & 4 & 2 & 4 & Parcial & Sim & 64 & Sim & Sim & Não & Sim & Não & 1 & Não \\
\hline 31 & 2 & 2 & 5 & Parcial & Sim & 64 & Sim & Sim & Não & Não & Não & 9 & Não \\
\hline 32 & 3 & 3 & 4 & Parcial & Sim & 67 & Sim & Não & Não & Sim & Não & Não & 3 \\
\hline 33 & 3 & 2 & 3 & Sim & Sim & 74 & Sim & Sim & Não & Sim & Não & 1 & 1 \\
\hline 34 & 3 & 2 & 3 & Sim & Sim & 69 & Sim & Sim & Não & Sim & Não & Não & Não \\
\hline 35 & 3 & 2 & 3 & Sim & Sim & 77 & Sim & Não & Não & Não & Não & 2 & 1 \\
\hline 36 & 3 & 2 & 2 & Não & Não & 77 & Sim & Sim & Não & Não & Não & 1 & Não \\
\hline 37 & 2 & 2 & 4 & Sim & Sim & 71 & Sim & Sim & Não & Não & Não & 1 & Não \\
\hline 38 & 3 & 2 & 3 & Sim & Sim & 77 & Sim & Sim & Não & Não & Não & 1Não & 3 \\
\hline 39 & 2 & 2 & 2 & Sim & Sim & 79 & Sim & Não & Não & Não & Não & 1 & Não \\
\hline 40 & 2 & 2 & 2 & Sim & Sim & 79 & Sim & Não & Não & Sim & Não & 1 & Não \\
\hline 41 & 3 & 1 & 2 & Sim & Sim & 70 & Sim & Sim & Não & Não & Não & 5 & 1 \\
\hline 42 & 3 & 2 & 1 & Sim & Sim & 77 & Sim & Sim & Não & Não & Não & 1 & Não \\
\hline 43 & 1 & 2 & 3 & Sim & Sim & 73 & Sim & Não & Não & Não & Não & Não & Não \\
\hline 44 & 2 & 2 & 2 & Sim & Sim & 79 & Sim & Sim & Não & Não & Não & Não & Não \\
\hline 45 & 2 & 2 & 3 & Sim & Sim & 69 & Sim & Sim & Não & Não & Não & Não & Não \\
\hline 46 & 2 & 2 & 7 & Não & Parcial & 57 & Sim & Sim & Não & Sim & Não & 1 & 2 \\
\hline 47 & 3 & 3 & 3 & Parcial & Parcial & 56 & Sim & Sim & Não & Não & Não & Não & Não \\
\hline 48 & 3 & 3 & 4 & Parcial & Sim & 60 & Sim & Sim & Não & Sim & Não & Não & Não \\
\hline 49 & 4 & 3 & 7 & Não & Parcial & 53 & Sim & Sim & Não & Não & Não & 13 & 1 \\
\hline 50 & 4 & 3 & 3 & \begin{tabular}{|l|} 
Parcial \\
\end{tabular} & Parcial & 67 & Sim & Sim & Não & Sim & Não & Não & Não \\
\hline 51 & 1 & 1 & 1 & \begin{tabular}{|l|} 
Sim \\
\end{tabular} & Sim & 79 & Sim & Não & Não & Não & Não & 1 & Não \\
\hline 52 & 4 & 3 & 5 & Não & Não & 37 & Sim & Sim & Não & Sim & Não & 111 & 1 \\
\hline
\end{tabular}




\subsection{Quadro com dados da avaliação com uma semana, pacientes do Grupo B (conclusão)}

\begin{tabular}{|c|c|c|c|c|c|c|c|c|c|c|c|c|c|}
\hline $\mathrm{N}$ & Dor & Edema & EVA & $C D$ & Apoio & AOFAS & LFTA & LFC & LFTP & LDP & LDS & Lac & $\mathrm{AA}$ \\
\hline 53 & 3 & 2 & 2 & Sim & Sim & 67 & Sim & Sim & Não & Não & Não & Não & Não \\
\hline 54 & 3 & 2 & 3 & Sim & Sim & 68 & Sim & Sim & Não & Não & Não & 1 & Não \\
\hline 55 & 4 & 3 & 5 & Parcial & Parcial & 57 & Sim & Sim & Não & Sim & Não & Não & Não \\
\hline 56 & 3 & 2 & 3 & Parcial & Parcial & 67 & Sim & Sim & Não & Não & Não & Não & Não \\
\hline 57 & 4 & 3 & 5 & Sim & Sim & 44 & Sim & Sim & Não & Sim & Não & 19 & Não \\
\hline 58 & 4 & 4 & 3 & Sim & Parcial & 52 & Sim & Sim & Não & Não & Não & Não & Não \\
\hline 59 & 2 & 3 & 2 & Sim & $\operatorname{Sim}$ & 69 & Sim & Sim & Não & Não & Não & Não & Não \\
\hline 60 & 3 & 2 & 2 & Sim & Sim & 70 & Sim & Sim & Não & Não & Não & 2 & Não \\
\hline 61 & 3 & 2 & 1 & Sim & Sim & 66 & Sim & Sim & Não & Não & Não & 1 & Não \\
\hline 62 & 2 & 2 & 5 & Não & Parcial & 56 & Sim & Sim & Não & Sim & Não & 3 & 4 \\
\hline 63 & 4 & 2 & 3 & Sim & Sim & 73 & Sim & Sim & Não & Não & Não & 2 & 1 \\
\hline 64 & 3 & 1 & 2 & Sim & Sim & 72 & Sim & Sim & Não & Não & Não & Não & Não \\
\hline 65 & 4 & 2 & 2 & Parcial & Sim & 75 & Sim & Sim & Não & Sim & Não & Não & Não \\
\hline 66 & 2 & 2 & 1 & Sim & Sim & 73 & Sim & Sim & Não & Não & Não & Não & Não \\
\hline 67 & 2 & 3 & 2 & Sim & $\operatorname{Sim}$ & 69 & Sim & Sim & Não & Sim & Não & 1 & Não \\
\hline 68 & 4 & 3 & 4 & Parcial & Parcial & 67 & Sim & Não & Não & Sim & Não & Não & Não \\
\hline 69 & 3 & 2 & 1 & Sim & Sim & 70 & Sim & Sim & Não & Sim & Não & 1 & Não \\
\hline 70 & 4 & 2 & 3 & Parcial & Sim & 54 & Sim & Sim & Não & Sim & Não & Não & Não \\
\hline 71 & 4 & 2 & 6 & Não & Parcial & 48 & Sim & Sim & Não & Sim & Não & Não & Não \\
\hline 72 & 3 & 2 & 2 & Sim & Sim & 72 & Sim & Sim & Não & Sim & Não & 1 & Não \\
\hline 73 & 2 & 1 & 1 & Sim & Sim & 79 & Sim & Sim & Não & Sim & Não & Não & Não \\
\hline 74 & 4 & 3 & 4 & Parcial & Sim & 67 & Sim & Sim & Não & Sim & Não & 1 & Não \\
\hline 75 & 4 & 3 & 5 & Não & Não & 34 & Sim & Sim & Não & Sim & Não & Não & 1 \\
\hline 76 & 3 & 2 & 1 & Sim & Sim & 79 & Sim & Não & Não & Sim & Não & 1 & Não \\
\hline 77 & 3 & 2 & 2 & Sim & Sim & 61 & Sim & Sim & Não & Sim & Não & 3 & Não \\
\hline 78 & 4 & 2 & 3 & Sim & Sim & 67 & Sim & Não & Não & Não & Não & Não & Não \\
\hline 79 & 3 & 2 & 2 & Sim & Sim & 70 & Sim & Não & Não & Não & Não & Não & 1 \\
\hline 80 & 3 & 2 & 3 & Sim & Sim & 62 & Sim & Sim & Não & Não & Não & Não & Não \\
\hline 81 & 2 & 2 & 2 & Sim & Sim & 73 & Sim & Não & Não & Sim & Não & Não & Não \\
\hline 82 & 4 & 2 & 2 & Sim & Sim & 73 & Sim & Sim & Não & Sim & Não & 1 & Não \\
\hline 83 & 4 & 3 & 4 & Parcial & Parcial & 46 & Sim & Sim & Não & Não & Não & Não & Não \\
\hline 84 & 4 & 2 & 3 & Sim & Sim & 59 & Sim & Sim & Não & Sim & Não & 1 & Não \\
\hline 85 & 3 & 2 & 5 & Não & Não & 58 & Sim & Não & Não & Não & Não & Não & Não \\
\hline 86 & 2 & 3 & 2 & Sim & Sim & 77 & Sim & Sim & Não & Sim & Não & 3 & Não \\
\hline 87 & 4 & 3 & 6 & Não & Não & 48 & Sim & Sim & Não & Não & Não & 1 & Não \\
\hline 88 & 3 & 2 & 2 & $\mathrm{Sim}$ & Sim & 63 & Sim & Sim & Não & Não & Não & Não & Não \\
\hline 89 & 3 & 3 & 4 & Parcial & Sim & 63 & Sim & Sim & Não & Sim & Não & 1 & 1 \\
\hline 90 & 4 & 2 & 2 & $\mathrm{Sim}$ & Sim & 78 & Sim & Sim & Não & Sim & Não & 1 & 3 \\
\hline 91 & 3 & 2 & 3 & Parcial & Sim & 57 & Sim & Sim & Não & Não & Não & Não & Não \\
\hline 92 & 4 & 3 & 4 & Não & Parcial & 54 & Sim & Sim & Não & Sim & Não & 3 & Não \\
\hline
\end{tabular}


Abreviatura quadros 10.3 e 10.4:

Dor: Local da dor (1 - Antero lateral; 2 - Antero lateral e sob o maléolo lateral; 3_ao redor de todo o maléolo lateral; 4 - em todo o tornozelo)

Edema: Intensidade do edema ( 1 a 4 , em cruzes)

EVA: Escala visual analógica de dor

CD: Conforto para deambulação

Apoio: Capacidade de apoio

AOFAS: Escala de pontuação da Sociedade Americana de Cirurgia do Pé e Tornozelo (varia de 0 a 100)

LFTA: Lesão do ligamento talo fibular anterior (Sim - acometido; Não - não acometido)

LFC: Lesão do ligamento calcâneo fibular (Sim - acometido; Não - não acometido)

LTFP: Ligamento talofibular posterior (Sim - acometido; Não - não acometido)

LDP: Ligamento deltóide profundo (Sim - acometido; Não - não acometido)

LDS: Ligamento deltóide superficial (Sim - acometido; Não - não acometido)

Lac: Lesões associadas (1 - contusão tálus; 2 - contusão tálus e do maléolo medial; 3 lesão tendão fibular curto; 4 - avulsão do maléolo lateral; 5 - lesão sindesmose anterior; 6 lesão tendão fibular longo; 7 - avulsão maléolo medial; 8 - fratura do colo do quinto metatarsal; 9 - avulsão tálus; 10 - avulsão os trigonum; 11 - fratura da tuberosidade anterior do calcâneo; 12 - fratura base quinto metatarsal; 13 - contusão cubóide; 14 - fratura tibia posterior)

AA: Alterações anatômicas (1 - Tuberosidade anterior do calcâneo proeminente; 2 tuberosidade posterior do tálus proeminente; 3 - os trigonum; 4 - barra fibrosa calcâneo navidular; 5 - navicular acessório; 6 - osteocondroma da tíbia distal) 
10.5 Quadro com dados da avaliação com três, seis e doze semanas, pacientes do Grupo A

\begin{tabular}{|c|c|c|c|c|c|c|c|c|c|c|c|c|c|c|c|c|}
\hline $\mathrm{N}$ & $3 \mathrm{Sem}$ & Edema & EVA & Apoio & AFOAS & AVD & Dias & $6 \mathrm{Sem}$ & EVA & AOFAS & AVD & Adm & $12 \mathrm{Sem}$ & QC & AOFAS & LF \\
\hline 93 & & 1 & 3 & Sim & 80 & Dirigir & 7 & & 1 & 90 & Não & Não & & $\mathrm{NI}$ & 100 & $\mathrm{NI}$ \\
\hline 94 & & 2 & 0 & Sim & 87 & Não & 6 & & 0 & 100 & Não & Não & & $\mathrm{NI}$ & 100 & $\mathrm{NI}$ \\
\hline 95 & & 2 & 2 & Sim & 81 & Dirigir & 3 & & 1 & 85 & Não & Não & & $\mathrm{NI}$ & 100 & $\mathrm{NI}$ \\
\hline 96 & & 1 & 2 & $\mathrm{Sim}$ & 85 & Dirigir & 9 & & 0 & 100 & Não & Não & & $\mathrm{NI}$ & 100 & $\mathrm{NI}$ \\
\hline 97 & & 2 & 4 & Parcial & 62 & Dirigir & 18 & & 1 & 100 & Não & Não & & $\mathrm{NI}$ & 100 & $\mathrm{NI}$ \\
\hline 98 & & 2 & 2 & Sim & 80 & Dirigir & 15 & & 0 & 85 & Não & Não & & $\mathrm{NI}$ & 100 & $\mathrm{NI}$ \\
\hline 99 & & 1 & 2 & Sim & 71 & Propr & 16 & & 2 & 90 & Não & Não & & $\mathrm{NI}$ & 100 & $\mathrm{NI}$ \\
\hline 100 & & 2 & 2 & Parcial & 63 & Propr & 19 & & 1 & 85 & Propr & Não & & $\mathrm{NI}$ & 100 & $\mathrm{NI}$ \\
\hline 101 & & 1 & 3 & Sim & 80 & Dirigir & 12 & & 1 & 80 & Dirigir & Não & & 2 & 90 & $\mathrm{NI}$ \\
\hline 102 & & 1 & 0 & Sim & 80 & Dirigir & 10 & & 2 & 90 & Não & Não & & $\mathrm{NI}$ & 100 & $\mathrm{NI}$ \\
\hline 103 & & 2 & 3 & Sim & 68 & Propr & 17 & & 2 & 63 & Propr & LM & & 2 & 90 & 2 \\
\hline 104 & & 1 & 4 & Sim & 78 & Dirigir & 9 & & 2 & 87 & Não & Não & & 2 & 90 & $\mathrm{NI}$ \\
\hline 105 & & 1 & 1 & Sim & 90 & Dirigir & 7 & & 0 & 100 & Não & Não & & $\mathrm{NI}$ & 100 & $\mathrm{NI}$ \\
\hline 106 & & 1 & 2 & Sim & 80 & Dirigir & 11 & & 2 & 80 & Não & Não & & $\mathrm{NI}$ & 100 & $\mathrm{NI}$ \\
\hline 107 & & 0 & 0 & Sim & 90 & Propr & 7 & & 1 & 90 & Não & Não & & $\mathrm{NI}$ & 100 & $\mathrm{NI}$ \\
\hline 108 & & 1 & 0 & Sim & 81 & Dirigir & 9 & & 0 & 100 & Não & Não & & $\mathrm{NI}$ & 100 & $\mathrm{NI}$ \\
\hline 109 & & 1 & 1 & Sim & 90 & Dirigir & 7 & & 0 & 100 & Não & Não & & $\mathrm{NI}$ & 100 & $\mathrm{NI}$ \\
\hline 110 & & 1 & 2 & Sim & 71 & Dirigir & 8 & & 0 & 100 & Não & Não & & $\mathrm{NI}$ & 100 & $\mathrm{NI}$ \\
\hline 111 & & 1 & 2 & Sim & 80 & Não & 7 & & 1 & 90 & Não & Não & & $\mathrm{NI}$ & 90 & $\mathrm{NI}$ \\
\hline 112 & & 1 & 0 & Sim & 81 & Dirigir & 13 & & 0 & 100 & Não & Não & & $\mathrm{NI}$ & 100 & $\mathrm{NI}$ \\
\hline 113 & & 1 & 2 & Sim & 80 & Dirigir & 6 & & 0 & 80 & Não & Não & & 2 & 90 & $\mathrm{NI}$ \\
\hline 114 & & 3 & 5 & Sim & 56 & Dirigir & 10 & & 3 & 63 & Não & LM & & $\mathrm{NI}$ & 100 & $\mathrm{NI}$ \\
\hline 115 & & 2 & 3 & Sim & 81 & Dirigir & 7 & & 0 & 100 & Não & Não & & $\mathrm{NI}$ & 100 & $\mathrm{NI}$ \\
\hline 116 & & 1 & 0 & Sim & 82 & Dirigir & 4 & & 0 & 100 & Não & Não & & $\mathrm{NI}$ & 100 & $\mathrm{NI}$ \\
\hline 117 & & 2 & 2 & Sim & 86 & Dirigir & 4 & & 0 & 100 & Não & Não & & $\mathrm{NI}$ & 100 & $\mathrm{NI}$ \\
\hline 118 & & 1 & 1 & Sim & 81 & Dirigir & 6 & & 0 & 100 & Não & Não & & $\mathrm{NI}$ & 100 & $\mathrm{NI}$ \\
\hline 119 & & 1 & 3 & Parcial & 75 & Trab & 9 & & 5 & 51 & Propr & LM & & 2 & 90 & 2 \\
\hline 120 & & 2 & 3 & Parcial & 75 & Propr & 6 & & 2 & 90 & Não & Não & & $\mathrm{NI}$ & 100 & $\mathrm{NI}$ \\
\hline 121 & & 1 & 1 & Sim & 85 & Dirigir & 8 & & 0 & 100 & Não & Não & & $\mathrm{NI}$ & 100 & $\mathrm{NI}$ \\
\hline 122 & & 1 & 1 & Sim & 90 & Dirigir & 4 & & 1 & 100 & Não & Não & & $\mathrm{NI}$ & 100 & $\mathrm{NI}$ \\
\hline 123 & & 2 & 6 & Sim & 71 & Propr & 5 & & 1 & 90 & Propr & Não & & $\mathrm{NI}$ & 100 & $\mathrm{NI}$ \\
\hline 124 & & 1 & 2 & Sim & 72 & Dirigir & 8 & & 1 & 72 & Instável & Não & & 4 & 78 & 3 \\
\hline 125 & & 1 & 1 & Sim & 87 & Dirigir & 3 & & 0 & 100 & Não & Não & & $\mathrm{NI}$ & 100 & $\mathrm{NI}$ \\
\hline 126 & & 1 & 2 & Sim & 75 & Propr & 6 & & 1 & 90 & Não & Não & & $\mathrm{NI}$ & 100 & $\mathrm{NI}$ \\
\hline 127 & & 1 & 2 & Sim & 80 & Propr & 7 & & 0 & 100 & Não & Não & & $\mathrm{NI}$ & 100 & $\mathrm{NI}$ \\
\hline 128 & & 1 & 1 & Sim & 90 & Não & 8 & & 0 & 100 & Não & Não & & $\mathrm{NI}$ & 100 & $\mathrm{NI}$ \\
\hline 129 & & 0 & 1 & Sim & 90 & Propr & 5 & & 0 & 100 & Não & Não & & $\mathrm{NI}$ & 100 & $\mathrm{NI}$ \\
\hline 130 & & 1 & 2 & Sim & 79 & Propr & 9 & & 1 & 87 & Não & Não & & $\mathrm{Nl}$ & 100 & $\mathrm{NI}$ \\
\hline 131 & & 1 & 2 & Sim & 90 & Dirigir & 6 & & 0 & 90 & Não & Não & & $\mathrm{NI}$ & 100 & $\mathrm{NI}$ \\
\hline 132 & & 2 & 5 & Parcial & 58 & Dirigir & 16 & & 4 & 67 & Dirigir & LM & & 3 & 74 & 1 \\
\hline 133 & & 1 & 2 & Sim & 75 & Propr & 6 & & 1 & 90 & Não & Não & & $\mathrm{NI}$ & 100 & $\mathrm{NI}$ \\
\hline 134 & & 1 & 4 & Sim & 65 & Propr & 15 & & 3 & 69 & Não & Não & & 1 & 90 & $\mathrm{NI}$ \\
\hline 135 & & 2 & 2 & Sim & 73 & Propr & 11 & & 0 & 91 & Não & Não & & 1 & 100 & $\mathrm{NI}$ \\
\hline 136 & & 1 & 0 & Sim & 90 & Propr & 5 & & 0 & 100 & Não & Não & & $\mathrm{NI}$ & 100 & $\mathrm{NI}$ \\
\hline 137 & & 1 & 2 & Sim & 75 & Propr & 12 & & 0 & 100 & Não & Não & & $\mathrm{NI}$ & 100 & $\mathrm{NI}$ \\
\hline 138 & & 2 & 3 & Não & 60 & Trab & 16 & & 2 & 70 & Dirigir & LM & & $\mathrm{NI}$ & 90 & $\mathrm{NI}$ \\
\hline 139 & & 2 & 2 & Sim & 75 & Dirigir & 8 & & 0 & 97 & Não & Não & & $\mathrm{NI}$ & 100 & $\mathrm{NI}$ \\
\hline 140 & & 2 & 1 & Sim & 78 & Dirigir & 7 & & 1 & 77 & Propr & LM & & 2 & 90 & $\mathrm{NI}$ \\
\hline 141 & & 2 & 1 & Sim & 85 & Dirigir & 5 & & 0 & 100 & Não & LM & & $\mathrm{NI}$ & 100 & $\mathrm{NI}$ \\
\hline 142 & & 1 & 0 & Sim & 81 & Dirigir & 5 & & 0 & 100 & Não & LM & & $\mathrm{NI}$ & 100 & $\mathrm{NI}$ \\
\hline 143 & & 1 & 0 & Sim & 94 & Propr & 5 & & 0 & 100 & Não & Não & & $\mathrm{NI}$ & 100 & $\mathrm{NI}$ \\
\hline 144 & & 1 & 2 & Sim & 86 & Dirigir & 5 & & 0 & 96 & Não & Não & & $\mathrm{Nl}$ & 100 & $\mathrm{NI}$ \\
\hline
\end{tabular}


10.5 Quadro com dados da avaliação com três, seis e doze semanas, pacientes do Grupo A (conclusão)

\begin{tabular}{|c|c|c|c|c|c|c|c|c|c|c|c|c|c|c|c|c|}
\hline $\mathrm{N}$ & 3 Sem & Edema & EVA & Apoio & AFOAS & AVD & Dias & $6 \mathrm{Sem}$ & EVA & AOFAS & AVD & Adm & 12 Sem & $\mathrm{QC}$ & AOFAS & LF \\
\hline 145 & & 1 & 4 & Sim & 78 & Dirigir & 9 & & 1 & 90 & Não & $\mathrm{LG}$ & & 3 & 77 & $\mathrm{NI}$ \\
\hline 146 & & 2 & 2 & Sim & 80 & Dirigir & 7 & & 1 & 90 & Não & Não & & $\mathrm{NI}$ & 90 & $\mathrm{NI}$ \\
\hline 147 & & 2 & 1 & Sim & 86 & Dirigir & 6 & & 1 & 90 & Não & Não & & 2 & 100 & $\mathrm{NI}$ \\
\hline 148 & & 2 & 1 & Sim & 90 & Dirigir & 6 & & 1 & 90 & Não & Não & & $\mathrm{NI}$ & 100 & 2 \\
\hline 149 & & 1 & 1 & Sim & 80 & Dirigir & 3 & & 0 & 90 & Não & Não & & $\mathrm{NI}$ & 90 & $\mathrm{NI}$ \\
\hline 150 & & 1 & 1 & Sim & 90 & Não & 1 & & 0 & 100 & Não & Não & & $\mathrm{NI}$ & 100 & $\mathrm{NI}$ \\
\hline 151 & & 1 & 2 & Sim & 75 & Propr & 6 & & 1 & 90 & Não & Não & & $\mathrm{NI}$ & 100 & $\mathrm{NI}$ \\
\hline 152 & & 1 & 1 & Sim & 87 & Propr & 7 & & 0 & 100 & Não & Não & & $\mathrm{NI}$ & 100 & $\mathrm{NI}$ \\
\hline 153 & & 2 & 1 & Sim & 76 & Propr & 6 & & 1 & 90 & Não & Não & & $\mathrm{NI}$ & 100 & $\mathrm{NI}$ \\
\hline 154 & & 1 & 2 & Sim & 88 & Não & 7 & & 0 & 100 & Não & Não & & $\mathrm{NI}$ & 100 & $\mathrm{NI}$ \\
\hline 155 & & 2 & 2 & Sim & 61 & Dirigir & 12 & & 1 & 72 & Não & LG & & $\mathrm{NI}$ & 90 & $\mathrm{NI}$ \\
\hline 156 & & 1 & 1 & Sim & 78 & Propr & 6 & & 0 & 90 & Não & Não & & $\mathrm{NI}$ & 100 & 2 \\
\hline 157 & & 1 & 1 & Sim & 87 & Propr & 3 & & 0 & 90 & Não & Não & & 1 & 90 & 2 \\
\hline 158 & & 1 & 1 & Sim & 97 & Propr & 4 & & 0 & 100 & Não & Não & & $\mathrm{NI}$ & 100 & 2 \\
\hline 159 & & 1 & 1 & Sim & 81 & Propr & 5 & & 0 & 100 & Não & Não & & $\mathrm{NI}$ & 100 & $\mathrm{NI}$ \\
\hline 160 & & 1 & 1 & Sim & 72 & Propr & 6 & & 0 & 90 & Não & Não & & $\mathrm{NI}$ & 100 & 2 \\
\hline 161 & & 1 & 1 & Sim & 90 & Dirigir & 4 & & 0 & 100 & Não & Não & & $\mathrm{NI}$ & 100 & $\mathrm{NI}$ \\
\hline 162 & & 1 & 1 & Sim & 80 & Propr & 3 & & 0 & 90 & Não & Não & & 2 & 87 & 2 \\
\hline 163 & & 1 & 1 & Sim & 87 & Propr & 5 & & 1 & 90 & Não & Não & & 2 & 90 & 2 \\
\hline 164 & & 1 & 1 & Sim & 87 & Propr & 5 & & 1 & 90 & Não & Não & & $\mathrm{NI}$ & 100 & $\mathrm{NI}$ \\
\hline 165 & & 1 & 1 & Sim & 83 & Propr & 4 & & 1 & 90 & Não & Não & & $\mathrm{NI}$ & 100 & $\mathrm{NI}$ \\
\hline 166 & & 1 & 1 & Sim & 75 & Propr & 3 & & 1 & 90 & Não & Não & & $\mathrm{NI}$ & 100 & $\mathrm{NI}$ \\
\hline 167 & & 1 & 1 & Sim & 90 & Propr & 5 & & 0 & 100 & Não & Não & & $\mathrm{NI}$ & 100 & $\mathrm{NI}$ \\
\hline 168 & & 1 & 0 & Sim & 97 & Propr & 4 & & 0 & 100 & Não & Não & & $\mathrm{NI}$ & 100 & $\mathrm{NI}$ \\
\hline 169 & & 2 & 2 & Sim & 71 & Dirigir & 3 & & 1 & 90 & Não & Não & & $\mathrm{NI}$ & 100 & $\mathrm{NI}$ \\
\hline 170 & & 1 & 1 & Sim & 77 & Propr & 3 & & 0 & 90 & Não & Não & & $\mathrm{NI}$ & 100 & $\mathrm{NI}$ \\
\hline 171 & & 1 & 1 & Sim & 87 & Propr & 3 & & 0 & 97 & Não & Não & & $\mathrm{NI}$ & 100 & $\mathrm{NI}$ \\
\hline 172 & & 1 & 1 & Sim & 80 & Propr & 3 & & 0 & 100 & Não & Não & & $\mathrm{NI}$ & 100 & $\mathrm{NI}$ \\
\hline 173 & & 1 & 1 & Sim & 79 & Dirigir & 4 & & 0 & 100 & Não & Não & & $\mathrm{NI}$ & 100 & $\mathrm{NI}$ \\
\hline 174 & & 1 & 1 & Sim & 78 & Propr & 4 & & 1 & 87 & Não & Não & & 2 & 90 & 1 \\
\hline 175 & & 1 & 2 & Parcial & 62 & Dirigir & 5 & & 2 & 62 & Propr & Não & & 1 & 97 & 1 \\
\hline 176 & & 1 & 1 & Sim & 90 & Dirigir & 3 & & 1 & 90 & Não & Não & & $\mathrm{NI}$ & 100 & $\mathrm{NI}$ \\
\hline 177 & & 2 & 1 & Sim & 81 & Propr & 6 & & 1 & 90 & Não & LM & & 1 & 98 & $\mathrm{NI}$ \\
\hline 178 & & 1 & 2 & Sim & 81 & Propr & 4 & & 1 & 90 & Não & Não & & 2 & 100 & $\mathrm{NI}$ \\
\hline 179 & & 1 & 2 & Sim & 64 & Propr & 4 & & 0 & 100 & Não & Não & & $\mathrm{NI}$ & 100 & $\mathrm{NI}$ \\
\hline 180 & & 2 & 3 & Sim & 81 & Propr & 8 & & 2 & 90 & Não & Não & & $\mathrm{NI}$ & 100 & $\mathrm{NI}$ \\
\hline 181 & & 2 & 2 & Sim & 68 & Propr & 10 & & 1 & 72 & Dirigir & LM & & 1 & 100 & $\mathrm{NI}$ \\
\hline 182 & & 2 & 2 & Parcial & 51 & Dirigir & 8 & & 1 & 80 & Não & LM & & $\mathrm{NI}$ & 100 & $\mathrm{NI}$ \\
\hline 183 & & 1 & 2 & Sim & 80 & Propr & 5 & & 1 & 85 & Não & Não & & $\mathrm{NI}$ & 100 & $\mathrm{NI}$ \\
\hline 184 & & 1 & 1 & Sim & 87 & Propr & 10 & & 1 & 90 & Não & Não & & $\mathrm{NI}$ & 100 & $\mathrm{NI}$ \\
\hline 185 & & 1 & 1 & Sim & 79 & Propr & 7 & & 1 & 90 & Não & Não & & $\mathrm{NI}$ & 100 & $\mathrm{NI}$ \\
\hline 186 & & 1 & 1 & Sim & 87 & Propr & 4 & & 1 & 97 & Não & Não & & 1 & 98 & $\mathrm{NI}$ \\
\hline
\end{tabular}


10.6 Quadro com dados da avaliação com três, seis e doze semanas, pacientes do Grupo B

\begin{tabular}{|c|c|c|c|c|c|c|c|c|c|c|c|c|c|c|c|c|}
\hline $\mathrm{N}$ & $3 \mathrm{Sem}$ & Edema & EVA & Apoio & AFOAS & AVD & Dias & 6 Sem & EVA & AOFAS & AVD & Adm & 12 Sem & QC & AOFAS & LF \\
\hline 1 & & 0 & 1 & Sim & 90 & Não & 2 & & 0 & 100 & $\mathrm{NI}$ & $\mathrm{NI}$ & & $\mathrm{NI}$ & 100 & $\mathrm{NI}$ \\
\hline 2 & & 1 & 1 & Sim & 85 & Dirigir & 4 & & 0 & 90 & $\mathrm{NI}$ & $\mathrm{NI}$ & & $\mathrm{NI}$ & 100 & $\mathrm{NI}$ \\
\hline 3 & & 2 & 3 & Sim & 75 & Não & 3 & & 0 & 92 & $\mathrm{NI}$ & $\mathrm{NI}$ & & 1 & 100 & $\mathrm{NI}$ \\
\hline 4 & & 2 & 1 & Sim & 78 & Não & 6 & & 0 & 90 & $\mathrm{NI}$ & $\mathrm{NI}$ & & $\mathrm{NI}$ & 100 & $\mathrm{NI}$ \\
\hline 5 & & 0 & 0 & Sim & 100 & Não & 5 & & 0 & 100 & $\mathrm{NI}$ & $\mathrm{NI}$ & & $\mathrm{NI}$ & 100 & $\mathrm{NI}$ \\
\hline 6 & & 1 & 0 & Sim & 97 & Não & 3 & & 0 & 100 & $\mathrm{NI}$ & $\mathrm{NI}$ & & $\mathrm{NI}$ & 100 & $\mathrm{NI}$ \\
\hline 7 & & 1 & 0 & Sim & 88 & Não & 2 & & 0 & 100 & $\mathrm{NI}$ & $\mathrm{NI}$ & & $\mathrm{NI}$ & 100 & $\mathrm{NI}$ \\
\hline 8 & & 0 & 0 & Sim & 95 & Não & 3 & & 0 & 100 & $\mathrm{NI}$ & $\mathrm{NI}$ & & $\mathrm{Nl}$ & 100 & $\mathrm{NI}$ \\
\hline 9 & & 2 & 2 & Sim & 87 & Não & 6 & & 1 & 97 & $\mathrm{NI}$ & $\mathrm{NI}$ & & $\mathrm{NI}$ & 100 & $\mathrm{NI}$ \\
\hline 10 & & 1 & 0 & Sim & 90 & Não & 5 & & 0 & 100 & $\mathrm{NI}$ & $\mathrm{NI}$ & & $\mathrm{NI}$ & 100 & $\mathrm{NI}$ \\
\hline 11 & & 1 & 1 & Sim & 90 & Não & 6 & & 1 & 90 & $\mathrm{NI}$ & $\mathrm{NI}$ & & $\mathrm{NI}$ & 100 & $\mathrm{NI}$ \\
\hline 12 & & 1 & 1 & Sim & 87 & Não & 4 & & 1 & 90 & $\mathrm{NI}$ & $\mathrm{NI}$ & & $\mathrm{NI}$ & 100 & $\mathrm{NI}$ \\
\hline 13 & & 1 & 1 & Sim & 90 & Não & 3 & & 0 & 100 & Propr & $\mathrm{NI}$ & & 2 & 100 & $\mathrm{NI}$ \\
\hline 14 & & 2 & 0 & Sim & 90 & Não & 6 & & 0 & 100 & $\mathrm{NI}$ & $\mathrm{NI}$ & & $\mathrm{NI}$ & 100 & $\mathrm{NI}$ \\
\hline 15 & & 0 & 1 & Sim & 90 & Não & 5 & & 0 & 100 & $\mathrm{NI}$ & $\mathrm{NI}$ & & $\mathrm{NI}$ & 100 & $\mathrm{NI}$ \\
\hline 16 & & 1 & 0 & Sim & 100 & Não & 4 & & 0 & 100 & $\mathrm{NI}$ & $\mathrm{NI}$ & & $\mathrm{NI}$ & 100 & $\mathrm{NI}$ \\
\hline 17 & & 1 & 2 & Sim & 81 & Não & 5 & & 1 & 90 & $\mathrm{NI}$ & $\mathrm{NI}$ & & $\mathrm{NI}$ & 100 & $\mathrm{NI}$ \\
\hline 18 & & 1 & 3 & Sim & 77 & Propr & 9 & & 3 & 77 & Propr & $\mathrm{NI}$ & & $\mathrm{NI}$ & 100 & $\mathrm{NI}$ \\
\hline 19 & & 2 & 2 & Sim & 85 & Não & 9 & & 0 & 95 & $\mathrm{NI}$ & $\mathrm{NI}$ & & $\mathrm{NI}$ & 100 & $\mathrm{NI}$ \\
\hline 20 & & 2 & 0 & Sim & 92 & Não & 3 & & 0 & 94 & $\mathrm{NI}$ & $\mathrm{NI}$ & & $\mathrm{NI}$ & 100 & $\mathrm{NI}$ \\
\hline 21 & & 1 & 0 & Sim & 87 & Não & 5 & & 0 & 90 & $\mathrm{NI}$ & $\mathrm{NI}$ & & $\mathrm{NI}$ & 100 & $\mathrm{NI}$ \\
\hline 22 & & 1 & 1 & Sim & 84 & Não & 3 & & 0 & 95 & Propr & $\mathrm{NI}$ & & 1 & 100 & $\mathrm{NI}$ \\
\hline 23 & & 2 & 1 & Sim & 92 & Não & 4 & & 0 & 100 & $\mathrm{NI}$ & $\mathrm{NI}$ & & $\mathrm{NI}$ & 100 & $\mathrm{NI}$ \\
\hline 24 & & 1 & 1 & Sim & 90 & Não & 3 & & 2 & 90 & $\mathrm{NI}$ & $\mathrm{NI}$ & & $\mathrm{NI}$ & 100 & $\mathrm{NI}$ \\
\hline 25 & & 1 & 2 & Sim & 90 & Não & 4 & & 1 & 90 & $\mathrm{NI}$ & $\mathrm{NI}$ & & $\mathrm{NI}$ & 100 & $\mathrm{NI}$ \\
\hline 26 & & 1 & 1 & Sim & 90 & Não & 2 & & 0 & 100 & $\mathrm{NI}$ & $\mathrm{NI}$ & & $\mathrm{NI}$ & 100 & $\mathrm{NI}$ \\
\hline 27 & & 2 & 3 & Sim & 85 & Não & 3 & & 1 & 90 & $\mathrm{NI}$ & $\mathrm{NI}$ & & $\mathrm{NI}$ & 100 & $\mathrm{NI}$ \\
\hline 28 & & 1 & 0 & Sim & 94 & Não & 2 & & 0 & 100 & $\mathrm{NI}$ & $\mathrm{NI}$ & & $\mathrm{NI}$ & 100 & $\mathrm{NI}$ \\
\hline 29 & & 2 & 6 & Sim & 64 & Dirigir & 5 & & 2 & 100 & $\mathrm{NI}$ & $\mathrm{NI}$ & & $\mathrm{NI}$ & 100 & $\mathrm{NI}$ \\
\hline 30 & & 1 & 0 & Sim & 95 & Não & 3 & & 0 & 100 & $\mathrm{NI}$ & LM & & $\mathrm{NI}$ & 100 & $\mathrm{NI}$ \\
\hline 31 & & 1 & 2 & Sim & 87 & Não & 2 & & 0 & 100 & $\mathrm{NI}$ & $\mathrm{NI}$ & & $\mathrm{NI}$ & 100 & $\mathrm{NI}$ \\
\hline 32 & & 2 & 1 & Sim & 85 & Não & 3 & & 1 & 100 & $\mathrm{NI}$ & $\mathrm{NI}$ & & $\mathrm{NI}$ & 100 & $\mathrm{NI}$ \\
\hline 33 & & 0 & 2 & Sim & 87 & Não & 2 & & 1 & 90 & $\mathrm{NI}$ & $\mathrm{NI}$ & & $\mathrm{NI}$ & 100 & $\mathrm{NI}$ \\
\hline 34 & & 1 & 1 & Sim & 90 & Não & 6 & & 1 & 90 & $\mathrm{NI}$ & $\mathrm{NI}$ & & $\mathrm{NI}$ & 100 & $\mathrm{NI}$ \\
\hline 35 & & 1 & 2 & Sim & 85 & Não & 4 & & 0 & 100 & $\mathrm{NI}$ & $\mathrm{NI}$ & & $\mathrm{NI}$ & 100 & $\mathrm{NI}$ \\
\hline 36 & & 1 & 3 & Sim & 87 & Não & 3 & & 0 & 90 & $\mathrm{NI}$ & $\mathrm{NI}$ & & $\mathrm{NI}$ & 100 & $\mathrm{NI}$ \\
\hline 37 & & 1 & 1 & Sim & 87 & Não & 6 & & 0 & 100 & $\mathrm{NI}$ & $\mathrm{NI}$ & & $\mathrm{NI}$ & 100 & $\mathrm{NI}$ \\
\hline 38 & & 1 & 0 & Sim & 87 & Não & 3 & & 0 & 100 & $\mathrm{NI}$ & $\mathrm{NI}$ & & $\mathrm{NI}$ & 100 & $\mathrm{NI}$ \\
\hline 39 & & 1 & 1 & Sim & 90 & Não & 1 & & 0 & 100 & $\mathrm{NI}$ & $\mathrm{NI}$ & & $\mathrm{NI}$ & 100 & $\mathrm{NI}$ \\
\hline 40 & & 1 & 1 & Sim & 90 & Não & 3 & & 1 & 90 & $\mathrm{NI}$ & $\mathrm{NI}$ & & $\mathrm{NI}$ & 100 & $\mathrm{NI}$ \\
\hline 41 & & 1 & 1 & Sim & 84 & Não & 3 & & 1 & 90 & $\mathrm{NI}$ & $\mathrm{NI}$ & & $\mathrm{NI}$ & 100 & $\mathrm{NI}$ \\
\hline 42 & & 1 & 1 & Sim & 87 & Não & 2 & & 0 & 100 & $\mathrm{NI}$ & $\mathrm{NI}$ & & $\mathrm{NI}$ & 100 & $\mathrm{NI}$ \\
\hline 43 & & 1 & 2 & Sim & 90 & Não & 2 & & 1 & 90 & $\mathrm{NI}$ & $\mathrm{NI}$ & & 1 & 90 & $\mathrm{NI}$ \\
\hline 44 & & 1 & 1 & Sim & 90 & Não & 2 & & 0 & 100 & $\mathrm{NI}$ & $\mathrm{NI}$ & & $\mathrm{NI}$ & 100 & $\mathrm{NI}$ \\
\hline 45 & & 1 & 1 & Sim & 77 & Não & 2 & & 0 & 100 & $\mathrm{NI}$ & $\mathrm{NI}$ & & $\mathrm{NI}$ & 100 & $\mathrm{NI}$ \\
\hline 46 & & 1 & 2 & Sim & 77 & Não & 7 & & 1 & 90 & $\mathrm{NI}$ & $\mathrm{NI}$ & & 2 & 90 & $\mathrm{NI}$ \\
\hline 47 & & 1 & 1 & Sim & 77 & Não & 8 & & 0 & 100 & $\mathrm{NI}$ & $\mathrm{NI}$ & & $\mathrm{NI}$ & 100 & $\mathrm{NI}$ \\
\hline 48 & & 1 & 1 & Sim & 78 & Não & 5 & & 1 & 81 & $\mathrm{NI}$ & LM & & $\mathrm{NI}$ & 100 & $\mathrm{NI}$ \\
\hline 49 & & 2 & 5 & Sim & 67 & Propr & 7 & & 4 & 70 & $\mathrm{NI}$ & LM & & 12 & 90 & $\mathrm{NI}$ \\
\hline 50 & & 1 & 2 & Sim & 90 & Não & 5 & & 0 & 100 & $\mathrm{NI}$ & $\mathrm{NI}$ & & $\mathrm{NI}$ & 100 & $\mathrm{NI}$ \\
\hline 51 & & 0 & 0 & Sim & 100 & Não & 2 & & 0 & 100 & $\mathrm{NI}$ & $\mathrm{NI}$ & & $\mathrm{NI}$ & 100 & $\mathrm{NI}$ \\
\hline 52 & & 2 & 5 & Parcial & 58 & Dirigir & 8 & & 3 & 70 & Propr & LM & & 12 & 70 & 1 \\
\hline
\end{tabular}


10.6 Quadro com dados da avaliação com três, seis e doze semanas, pacientes do Grupo B (conclusão)

\begin{tabular}{|c|c|c|c|c|c|c|c|c|c|c|c|c|c|c|c|c|}
\hline $\mathrm{N}$ & 3 Sem & Edema & EVA & Apoio & AFOAS & AVD & Dias & 6 Sem & EVA & AOFAS & AVD & Adm & 12 Sem & QC & AOFAS & LF \\
\hline 53 & & 1 & 1 & Sim & 87 & Não & 3 & & 0 & 90 & $\mathrm{NI}$ & $\mathrm{NI}$ & & $\mathrm{NI}$ & 100 & $\mathrm{NI}$ \\
\hline 54 & & 1 & 1 & Sim & 90 & Não & 2 & & 0 & 100 & $\mathrm{NI}$ & $\mathrm{NI}$ & & $\mathrm{NI}$ & 100 & $\mathrm{NI}$ \\
\hline 55 & & 2 & 4 & Sim & 80 & Não & 4 & & 1 & 90 & $\mathrm{NI}$ & LM & & $\mathrm{NI}$ & 100 & $\mathrm{NI}$ \\
\hline 56 & & 2 & 2 & Sim & 76 & Não & 5 & & 1 & 90 & $\mathrm{NI}$ & $\mathrm{NI}$ & & $\mathrm{NI}$ & 90 & $\mathrm{NI}$ \\
\hline 57 & & 2 & 2 & Parcial & 64 & Dirigir & 5 & & 0 & 81 & $\mathrm{NI}$ & LG & & $\mathrm{NI}$ & 100 & $\mathrm{NI}$ \\
\hline 58 & & 1 & 1 & Sim & 88 & Não & 5 & & 1 & 90 & $\mathrm{NI}$ & $\mathrm{NI}$ & & $\mathrm{NI}$ & 90 & $\mathrm{NI}$ \\
\hline 59 & & 1 & 2 & Sim & 80 & Não & 4 & & 1 & 90 & $\mathrm{NI}$ & $\mathrm{NI}$ & & $\mathrm{NI}$ & 100 & $\mathrm{NI}$ \\
\hline 60 & & 1 & 1 & Sim & 90 & Não & 2 & & 0 & 100 & $\mathrm{NI}$ & $\mathrm{NI}$ & & $\mathrm{NI}$ & 100 & $\mathrm{NI}$ \\
\hline 61 & & 1 & 1 & Sim & 81 & Não & 1 & & 1 & 90 & $\mathrm{NI}$ & $\mathrm{NI}$ & & $\mathrm{NI}$ & 100 & $\mathrm{NI}$ \\
\hline 62 & & 1 & 3 & Parcial & 65 & Propr & 7 & & 1 & 90 & $\mathrm{NI}$ & $\mathrm{NI}$ & & $\mathrm{NI}$ & 100 & $\mathrm{NI}$ \\
\hline 63 & & 1 & 1 & Sim & 87 & Não & 3 & & 0 & 97 & $\mathrm{NI}$ & LG & & $\mathrm{NI}$ & 100 & $\mathrm{NI}$ \\
\hline 64 & & 1 & 1 & Sim & 90 & Não & 4 & & 0 & 96 & $\mathrm{NI}$ & $\mathrm{NI}$ & & $\mathrm{NI}$ & 96 & $\mathrm{NI}$ \\
\hline 65 & & 1 & 1 & Sim & 84 & Não & 2 & & 0 & 97 & Propr & $\mathrm{NI}$ & & 2 & 90 & 2 \\
\hline 66 & & 1 & 0 & Sim & 97 & Não & 1 & & 0 & 100 & $\mathrm{NI}$ & $\mathrm{NI}$ & & $\mathrm{NI}$ & 100 & 2 \\
\hline 67 & & 1 & 1 & Sim & 87 & Não & 2 & & 0 & 100 & $\mathrm{NI}$ & $\mathrm{NI}$ & & $\mathrm{NI}$ & 100 & $\mathrm{NI}$ \\
\hline 68 & & 1 & 1 & Sim & 80 & Não & 5 & & 1 & 90 & $\mathrm{NI}$ & $\mathrm{NI}$ & & $\mathrm{NI}$ & 100 & $\mathrm{NI}$ \\
\hline 69 & & 1 & 0 & Sim & 90 & Não & 1 & & 0 & 100 & $\mathrm{NI}$ & $\mathrm{NI}$ & & 1 & 100 & $\mathrm{NI}$ \\
\hline 70 & & 1 & 2 & Sim & 77 & Propr & 4 & & 1 & 90 & $\mathrm{NI}$ & $\mathrm{NI}$ & & 5 & 90 & $\mathrm{NI}$ \\
\hline 71 & & 1 & 3 & Sim & 75 & Não & 7 & & 1 & 87 & $\mathrm{NI}$ & $\mathrm{NI}$ & & $\mathrm{NI}$ & 100 & $\mathrm{NI}$ \\
\hline 72 & & 1 & 1 & Sim & 87 & Não & 2 & & 1 & 90 & $\mathrm{NI}$ & $\mathrm{NI}$ & & 2 & 90 & 2 \\
\hline 73 & & 1 & 1 & Sim & 90 & Não & 1 & & 0 & 100 & $\mathrm{NI}$ & $\mathrm{NI}$ & & $\mathrm{NI}$ & 100 & $\mathrm{NI}$ \\
\hline 74 & & 1 & 0 & Sim & 86 & Não & 3 & & 0 & 100 & $\mathrm{NI}$ & $\mathrm{NI}$ & & $\mathrm{NI}$ & 100 & $\mathrm{NI}$ \\
\hline 75 & & 2 & 2 & Sim & 89 & $\begin{array}{l}\text { Dirigir } \\
\text { Propr }\end{array}$ & 3 & & 1 & 90 & $\mathrm{NI}$ & LM & & $\mathrm{NI}$ & 100 & $\mathrm{NI}$ \\
\hline 76 & & 1 & 1 & Sim & 90 & Não & 1 & & 1 & 90 & $\mathrm{NI}$ & $\mathrm{NI}$ & & $\mathrm{NI}$ & 100 & $\mathrm{NI}$ \\
\hline 77 & & 1 & 1 & Sim & 87 & Não & 1 & & 0 & 97 & $\mathrm{NI}$ & $\mathrm{NI}$ & & $\mathrm{NI}$ & 100 & $\mathrm{NI}$ \\
\hline 78 & & 1 & 1 & Sim & 73 & Não & 4 & & 0 & 100 & $\mathrm{NI}$ & $\mathrm{NI}$ & & $\mathrm{NI}$ & 100 & $\mathrm{NI}$ \\
\hline 79 & & 1 & 1 & Sim & 86 & Não & 4 & & 0 & 100 & $\mathrm{NI}$ & $\mathrm{NI}$ & & $\mathrm{NI}$ & 100 & $\mathrm{NI}$ \\
\hline 80 & & 1 & 2 & Sim & 80 & Não & 3 & & 1 & 90 & $\mathrm{NI}$ & $\mathrm{NI}$ & & $\mathrm{NI}$ & 100 & $\mathrm{NI}$ \\
\hline 81 & & 2 & 1 & Sim & 85 & Não & 3 & & 0 & 100 & $\mathrm{NI}$ & $\mathrm{NI}$ & & $\mathrm{NI}$ & 90 & $\mathrm{NI}$ \\
\hline 82 & & 1 & 2 & Sim & 75 & Não & 2 & & 1 & 87 & $\mathrm{NI}$ & LM & & 13 & 90 & 1 \\
\hline 83 & & 2 & 1 & Sim & 79 & Não & 6 & & 0 & 100 & $\mathrm{NI}$ & $\mathrm{NI}$ & & $\mathrm{NI}$ & 100 & $\mathrm{NI}$ \\
\hline 84 & & 0 & 1 & Sim & 90 & Não & 2 & & 0 & 100 & $\mathrm{NI}$ & $\mathrm{NI}$ & & $\mathrm{NI}$ & 100 & $\mathrm{NI}$ \\
\hline 85 & & 1 & 2 & Sim & 81 & Não & 6 & & 1 & 100 & $\mathrm{NI}$ & $\mathrm{NI}$ & & 1 & 100 & $\mathrm{Nl}$ \\
\hline 86 & & 1 & 0 & Sim & 90 & Não & 2 & & 0 & 97 & $\mathrm{NI}$ & $\mathrm{NI}$ & & $\mathrm{NI}$ & 100 & $\mathrm{NI}$ \\
\hline 87 & & 2 & 5 & Não & 58 & Dirigir & 8 & & 0 & 100 & $\mathrm{NI}$ & $\mathrm{NI}$ & & $\mathrm{NI}$ & 100 & $\mathrm{NI}$ \\
\hline 88 & & 1 & 0 & Sim & 97 & Não & 1 & & 0 & 100 & $\mathrm{NI}$ & $\mathrm{NI}$ & & $\mathrm{NI}$ & 100 & $\mathrm{NI}$ \\
\hline 89 & & 0 & 1 & Sim & 90 & Não & 3 & & 0 & 90 & $\mathrm{NI}$ & $\mathrm{NI}$ & & 2 & 90 & $\mathrm{NI}$ \\
\hline 90 & & 1 & 1 & Sim & 87 & Não & 2 & & 1 & 90 & $\mathrm{NI}$ & $\mathrm{NI}$ & & $\mathrm{NI}$ & 100 & $\mathrm{NI}$ \\
\hline 91 & & 1 & 1 & Sim & 81 & Não & 1 & & 1 & 90 & $\mathrm{NI}$ & $\mathrm{NI}$ & & $\mathrm{NI}$ & 100 & $\mathrm{NI}$ \\
\hline 92 & & 1 & 3 & Sim & 60 & Dirigir & 21 & & 1 & 87 & $\mathrm{NI}$ & $\mathrm{NI}$ & & 2 & 98 & $\mathrm{NI}$ \\
\hline
\end{tabular}


Abreviaturas dos quadros 10.5 e 10.6:

3 Sem: Avaliação com três semanas

Edema: Intensidade do edema (1 a 4, em cruzes)

EVA: Escala visual analógica de dor

CD: Conforto para deambulação

Apoio: Capacidade de apoio

AOFAS: Escala de pontuação da Sociedade Americana de Cirurgia do Pé e Tornozelo (varia de 0 a 100)

AVD: Limitação para atividades da vida diaria

Dias: Dias de afastamento do trabalho

6 Sem: Avaliação com seis semanas

ADM: Amplitude de movimento (N1 - normal; LM - limitação moderada; LG - limitação grave)

12 Sem: Avaliação com doze semanas

QC: Quadro clínico (1 - alteração da propriocepção; 2 - dor leve e ocasional; 3 - dor para atividade habitual; 4 - instável; 5 - dor para usar salto alto)

LF: Limitação física (1 - dirigir; 2 - propriocepção; 3 - tornozelo instável) 
10.7 Quadro com dados da avaliação com Rx com estresse, pacientes do Grupo A

\begin{tabular}{|c|c|c|c|c|c|c|c|c|c|c|c|c|c|c|c|c|c|c|c|c|}
\hline $\mathrm{N}$ & RxE11 & VN & VA & GN & GA & RxE12 & VN & VA & GN & GA & RxE21 & VN & VA & GN & GA & RxE22 & VN & VA & GN & GA \\
\hline 93 & & 1.3 & 1.4 & 3.2 & 3.4 & & 4.58 & 5.67 & 3.74 & 4.35 & & 5.03 & 6.37 & 3.15 & 4.52 & & 5.25 & 5.41 & 2.99 & 4.27 \\
\hline 94 & & 4.0 & 3.0 & 6.8 & 7.2 & & & & & & & & & & & & & & & \\
\hline 95 & & 2.0 & 1.0 & 5.47 & 5.20 & & & & & & & & & & & & & & & \\
\hline 96 & & .0 & 2.0 & 6.65 & \begin{tabular}{|l|}
6.69 \\
\end{tabular} & & 0.0 & 2.0 & 6.99 & 7.57 & & 1.0 & 1.0 & 6.96 & 6.88 & & 0.0 & 1.0 & 6.08 & 7.25 \\
\hline 97 & & .0 & .0 & 3.81 & 3.87 & & 2.0 & 2.0 & 4.01 & 4.17 & & 0.0 & 0.0 & 3.58 & 3.31 & & 1.0 & 1.0 & 3.66 & 3.35 \\
\hline 98 & & 5.0 & 5.0 & 3.9 & 4.2 & & 5.34 & 5.44 & 4.16 & 4.05 & & 5.01 & 4.30 & 3.89 & 3.73 & & 5.06 & 4.64 & 3.59 & 3.84 \\
\hline 99 & & 2.0 & 3.0 & 2.59 & 3.70 & & 3.0 & 3.0 & 4.60 & 4.96 & & 0.0 & 2.0 & 3.76 & 4.88 & & 0.0 & 1.0 & 4.45 & 4.79 \\
\hline 100 & & 2.0 & 1.0 & 2.4 & 3.4 & & 2.15 & 0.30 & 6.00 & 4.90 & & 3.07 & 1.80 & 5.55 & 5.50 & & 2.94 & 0.6 & 5.58 & 5.62 \\
\hline 101 & & 3.0 & 1.0 & 5.20 & 5.23 & & 2.0 & 1.0 & 5.31 & 5.24 & & 0.0 & 1.0 & 5.27 & 5.22 & & 1.0 & 1.0 & 5.13 & 4.61 \\
\hline 102 & & 3.0 & 4.0 & 2.5 & 3.0 & & & & & & & & & & & & & & & \\
\hline 103 & & 2.0 & 3.0 & 4.5 & 4.3 & & 0.0 & 3.0 & 5.45 & 4.54 & & 0.0 & 0.0 & 7.46 & 4.38 & & 0.0 & 0.0 & 6.32 & 5.44 \\
\hline 104 & & 1.0 & 0.0 & 4.19 & 4.20 & & 2.0 & 1.0 & 5.44 & 4.61 & & 1.0 & 1.0 & 5.29 & 4.42 & & 0.0 & 1.0 & 5.34 & 4.31 \\
\hline 105 & & 1.0 & 1.0 & 5.09 & 5.13 & & 6.0 & 5.0 & 7.37 & 7.47 & & 6.0 & 5.0 & 8.25 & 6.63 & & 4.0 & 3.0 & 8.60 & 7.04 \\
\hline 106 & & 6.0 & 3.0 & 5.0 & 7.3 & & 10.0 & 2.0 & 7.97 & 5.47 & & 10.0 & 1.0 & 7.34 & 5.78 & & 10.0 & 0.0 & 7.95 & 6.26 \\
\hline 107 & & 3.0 & 2.0 & 3.1 & 3.3 & & 3.70 & 3.60 & 3.94 & 4.75 & & 3.62 & 3.18 & 3.52 & 4.20 & & 3.14 & 3.23 & 3.64 & 3.87 \\
\hline 108 & & 1.0 & 1.0 & 4.43 & 3.29 & & 5.0 & 3.0 & 4.04 & 4.63 & & 5.0 & 3.0 & 3.58 & 4.25 & & 6.0 & 2.0 & 3.73 & 4.34 \\
\hline 109 & & 9.0 & 10.0 & 5.7 & 6.3 & & 10.0 & 8.0 & 5.85 & 6.60 & & 8.0 & 7.0 & 5.11 & 6.51 & & 8.0 & 6.0 & 4.89 & 6.44 \\
\hline 110 & & 6.0 & 4.0 & 6.43 & \begin{tabular}{|l|}
6.71 \\
\end{tabular} & & 1.0 & 3.0 & 5.60 & 6.46 & & 1.0 & 2.0 & 6.16 & 6.44 & & 0.0 & 1.0 & 6.38 & 6.59 \\
\hline 111 & & 3.0 & 1.0 & 7.09 & 6.70 & & 1.0 & 3.0 & 6.90 & 6.00 & & 0.0 & 0.0 & 7.77 & 6.02 & & 1.0 & 1.0 & 7.83 & 7.26 \\
\hline \multicolumn{21}{|l|}{112} \\
\hline 113 & & 2.0 & 2.0 & 2.41 & 3.15 & & & & & & & & & & & & & & & \\
\hline 114 & & 3.0 & 2.0 & 3.25 & \begin{tabular}{|l|}
3.43 \\
\end{tabular} & & & & & & & & & & & & & & & \\
\hline \multicolumn{21}{|l|}{115} \\
\hline \multicolumn{21}{|l|}{116} \\
\hline \multicolumn{21}{|l|}{117} \\
\hline 118 & & 3 & 3 & 4.18 & 3.77 & & & & & & & & & & & & & & & \\
\hline \multicolumn{21}{|l|}{119} \\
\hline \multicolumn{21}{|l|}{120} \\
\hline \multicolumn{21}{|l|}{121} \\
\hline \multicolumn{21}{|l|}{122} \\
\hline 123 & & 0.3 & 0.3 & 4.27 & \begin{tabular}{|l|l|} 
\\
\end{tabular} .98 & & 0.3 & 0.3 & 4.98 & 4.27 & & 0.3 & 0.3 & 4.98 & 4.27 & & 0.3 & 0.3 & 4.98 & 4.27 \\
\hline 124 & & 4 & 14 & 5.5 & \begin{tabular}{|l|}
9.3 \\
\end{tabular} & & 7.47 & 13.23 & \begin{tabular}{|l|}
1.54 \\
\end{tabular} & 4.98 & & 6.25 & 10.76 & 5.06 & \begin{tabular}{|l|l}
10.09 \\
\end{tabular} & & 6.25 & 7.74 & 5.10 & 10.80 \\
\hline \multicolumn{21}{|l|}{125} \\
\hline \multicolumn{21}{|l|}{126} \\
\hline 127 & & 3 & 6 & 5.78 & 4.97 & & 6.0 & 6.0 & 5.72 & 4.90 & & 3.0 & 4.0 & 5.38 & 4.95 & & 3.0 & 3.0 & 5.56 & 4.41 \\
\hline 128 & & 6 & 3 & 4.97 & 5.78 & & 6.0 & 6.0 & 4.90 & 5.72 & & 4.0 & 3.0 & 4.95 & 5.38 & & 3.0 & 3.0 & 4.41 & 5.56 \\
\hline 129 & & 6 & 1 & 6.82 & \begin{tabular}{|l|l|} 
\\
\end{tabular} & & 8.0 & 4.0 & 4.08 & 4.03 & & 7.0 & 4.0 & 4.08 & 3.80 & & 7.0 & 4.0 & 3.80 & 3.80 \\
\hline 130 & & 2 & 1 & 6.64 & 5.97 & & & & & & & & & & & & & & & \\
\hline 131 & & 6 & 4 & 5.97 & \begin{tabular}{|l|l|} 
\\
\end{tabular} & & & & & & & & & & & & & & & \\
\hline 132 & & 3 & 1 & 3.35 & \begin{tabular}{|l}
3.23 \\
\end{tabular} & & & & & & & & & & & & & & & \\
\hline 133 & & 9 & 1 & 4.0 & 6.3 & & 10.25 & 2.21 & 5.20 & 4.11 & & 10.57 & 2.57 & 5.77 & 4.04 & & 10.44 & 2.46 & 5.34 & 4.11 \\
\hline 134 & & 1 & 0 & 3.28 & 2.87 & & 1.0 & 1.0 & 4.46 & 3.04 & & 1.0 & 2.0 & 4.14 & 3.05 & & 0.0 & 2.0 & 3.84 & 3.22 \\
\hline 135 & & 5 & 5 & 6.35 & 7.49 & & 4.0 & 5.0 & 6.43 & 7.45 & & 5.0 & 4.0 & 6.71 & 7.41 & & 5.0 & 5.0 & 6.37 & 7.09 \\
\hline 136 & & 1 & 1 & 4.5 & \begin{tabular}{|l|}
3.8 \\
\end{tabular} & & 1.89 & 1.13 & \begin{tabular}{|l|l|}
4.92 \\
\end{tabular} & 6.29 & & 2.13 & 2.24 & 4.32 & 5.49 & & 1.85 & 1.78 & 4.24 & 5.15 \\
\hline 137 & & 2 & 3 & 4.76 & \begin{tabular}{|l|}
6.31 \\
\end{tabular} & & & & & & & & & & & & & & & \\
\hline 138 & & 5 & 8 & 5.0 & 5.3 & & 8.13 & 6.12 & 6.57 & 6.31 & & 9.45 & 6.42 & 5.91 & 6.27 & & 8.88 & 6.22 & 6.14 & 6.22 \\
\hline 139 & & 4 & 6 & 5.03 & 6.43 & & & & & & & & & & & & & & & \\
\hline 140 & & 2 & 1 & 3.2 & 3.0 & & & & & & & & & & & & & & & \\
\hline 141 & & 1 & 1 & 4.1 & 4.5 & & 1.97 & 1.32 & 4.63 & 4.49 & & 1.96 & 2.61 & 4.50 & 4.38 & & 2.12 & 2.39 & 4.63 & 4.18 \\
\hline 142 & & 3.2 & 4.1 & 6.05 & 7.0 & & 3.99 & 3.22 & 6.64 & 7.94 & & 4.23 & 4.38 & 6.86 & 7.69 & & 4.29 & 4.18 & 6.18 & 7.31 \\
\hline 143 & & 2 & 6 & 4.06 & 3.80 & & 2.0 & 4.0 & 3.74 & 3.25 & & 2.0 & 6.0 & 3.54 & 3.80 & & 2.0 & 5.0 & 3.72 & 3.61 \\
\hline 144 & & 4 & 5 & 5 & 5 & & 8.32 & 5.38 & 5.81 & 5.71 & & 6.05 & 4.70 & 5.42 & 5.71 & & 6.37 & 4.84 & 5.32 & 5.77 \\
\hline
\end{tabular}


10.7 Quadro com dados da avaliação com Rx com estresse, pacientes do Grupo A (conclusão)

\begin{tabular}{|c|c|c|c|c|c|c|c|c|c|c|c|c|c|c|c|c|c|c|c|c|}
\hline $\mathrm{N}$ & RxE11 & VN & VA & GN & GA & RxE12 & VN & VA & GN & GA & RxE21 & VN & VA & GN & GA & RxE22 & VN & VA & GN & GA \\
\hline 145 & & 7 & 1 & 2.88 & 3.97 & & 7.0 & 3.0 & 3.65 & 3.24 & & 5.0 & 4.0 & 4.28 & 3.31 & & 3.0 & 5.0 & 3.55 & 3.07 \\
\hline 146 & & 5 & 9 & 7.78 & 6.83 & & 9.0 & 4.0 & 6.96 & 8.48 & & 4.0 & 8.0 & 8.19 & 8.94 & & 5.0 & 8.0 & 8.03 & 8.38 \\
\hline 147 & & 1.6 & 1.6 & 5.35 & 5.24 & & 1.47 & 1.29 & 4.92 & 5.54 & & 0.68 & 1.05 & 5.16 & 5.82 & & 0.96 & 0.86 & 5.16 & 5.24 \\
\hline 148 & & 2 & 0 & 5.55 & 4.43 & & 1.0 & 0.0 & 6.04 & 4.99 & & 0.0 & 0.0 & 6.19 & 4.81 & & 1.0 & 0.0 & 6.32 & 4.91 \\
\hline 149 & & 2 & 3 & 6.37 & 6.8 & & 2.0 & 3.0 & 6.97 & 6.92 & & 3.0 & 3.0 & 7.00 & 6.92 & & 4.0 & 3.0 & 7.13 & 7.16 \\
\hline 150 & & 4.56 & 4.20 & 8.15 & 4.58 & & 5.33 & 2.46 & 8.53 & 4.97 & & 4.81 & 2.38 & 8.00 & 4.89 & & 3.38 & 2.74 & 7.68 & 4.57 \\
\hline 151 & & 3.10 & 4.25 & 4.56 & 4.26 & & 2.59 & 2.79 & 4.62 & \begin{tabular}{|l|}
4.04 \\
\end{tabular} & & 2.18 & 2.83 & 4.73 & 4.30 & & 2.92 & 3.24 & 4.51 & 4.06 \\
\hline 152 & & 1.0 & 7.0 & 6.02 & 8.33 & & & & & & & & & & & & & & & \\
\hline 153 & & 4.08 & 5.64 & 4.02 & 4.02 & & 3.41 & 5.85 & 4.02 & \begin{tabular}{|l|} 
\\
\end{tabular} & & & & & & & & & & \\
\hline 154 & & 0.0 & 0.0 & 4.93 & 2.99 & & & & & & & & & & & & & & & \\
\hline 155 & & 5.0 & 2.0 & 3.37 & 3.19 & & 6.0 & 2.0 & 3.93 & 3.76 & & 0.0 & 0.0 & 3.80 & 3.06 & & 0.0 & 0.0 & 3.88 & 3.50 \\
\hline 156 & & 5.67 & 1.77 & 2.83 & 2.84 & & 5.96 & 1.97 & 3.05 & 3.00 & & 5.79 & 2.47 & 3.00 & 3.55 & & 4.76 & 2.67 & 2.90 & 3.43 \\
\hline 157 & & 3.40 & 2.42 & 0.78 & 1.88 & & 3.20 & 2.33 & 1.03 & 2.55 & & 0.04 & 2.30 & 3.27 & 2.81 & & 1.08 & 1.95 & 3.50 & 2.92 \\
\hline 158 & & 3.27 & 6.37 & 5.55 & 4.76 & & 3.92 & 6.35 & 5.54 & 4.63 & & 2.05 & 5.83 & 5.59 & 5.07 & & 3.18 & 5.25 & 5.21 & 4.69 \\
\hline 159 & & 1.0 & 4.0 & 4.69 & 5.96 & & 2.0 & 4.0 & 4.53 & 5.39 & & & & & & & & & & \\
\hline 160 & & 6.0 & 5.0 & 6.57 & 7.46 & & 6.0 & 3.0 & 5.75 & \begin{tabular}{|l|}
6.55 \\
\end{tabular} & & & & & & & & & & \\
\hline 161 & & 12.08 & 15.95 & 4.69 & 5.40 & & 10.79 & 13.38 & 4.84 & \begin{tabular}{|l|}
5.63 \\
\end{tabular} & & 15.30 & 11.73 & 7.85 & 5.63 & & 13.86 & 12.51 & 7.65 & 5.85 \\
\hline 162 & & 2.55 & 2.19 & 5.42 & 5.01 & & 2.09 & 0.95 & 5.48 & \begin{tabular}{|l|}
4.54 \\
\end{tabular} & & 1.80 & 2.24 & 5.27 & 5.74 & & 2.39 & 2.46 & 4.74 & 5.12 \\
\hline 163 & & 5.95 & 4.17 & 4.0 & 3.0 & & 5.81 & 4.80 & 4.0 & 3.0 & & & & & & & & & & \\
\hline 164 & & 3.26 & 7.70 & 3.41 & 2.94 & & 3.04 & 7.38 & 3.15 & 2.69 & & & & & & & & & & \\
\hline 165 & & 2.98 & 3.05 & 4.75 & 6.08 & & 2.90 & 1.94 & 4.75 & \begin{tabular}{|l|}
5.99 \\
\end{tabular} & & 4.20 & 3.15 & 5.38 & 4.77 & & 4.09 & 3.01 & 5.65 & 4.59 \\
\hline 166 & & 5.0 & 7.0 & 3.67 & 3.68 & & 4.0 & 7.0 & 3.80 & 3.70 & & & & & & & & & & \\
\hline 167 & & 13.0 & 6.0 & 4.96 & 5.13 & & 13.0 & 7.0 & 5.03 & 5.18 & & & & & & & & & & \\
\hline 168 & & 4.27 & 4.40 & 6.15 & 5.78 & & 5.21 & 5.05 & 6.01 & 5.70 & & 4.98 & 5.01 & 5.34 & 5.74 & & 5.13 & 5.15 & 5.55 & 5.58 \\
\hline 169 & & 0.87 & 0.72 & 3.34 & 3.44 & & 0.22 & 1.95 & 3.29 & 3.42 & & 0.15 & 0.35 & 3.37 & 3.54 & & 0.32 & 0.39 & 3.87 & 3.36 \\
\hline 170 & & 5.03 & 3.39 & 4.84 & 4.55 & & 4.19 & 3.49 & 4.84 & 4.79 & & 4.48 & 3.19 & 4.82 & 4.05 & & 4.59 & 3.29 & 4.17 & 4.12 \\
\hline 171 & & 3.37 & 3.90 & 5.86 & 6.56 & & 3.97 & 4.38 & 6.11 & 6.67 & & 4.49 & 3.71 & 6.02 & 5.88 & & 4.25 & 3.30 & 5.88 & 5.32 \\
\hline 172 & & 3.69 & 3.82 & 4.44 & 5.04 & & 3.92 & 3.82 & 3.11 & 5.71 & & 3.67 & 6.21 & 4.65 & 4.02 & & 2.76 & 6.42 & 4.60 & 4.15 \\
\hline 173 & & 5.70 & 3.86 & 9.39 & 7.33 & & 5.86 & 3.86 & 9.47 & 7.12 & & 6.20 & 3.44 & 9.44 & 9.33 & & 6.12 & 3.41 & 10.09 & 9.35 \\
\hline 174 & & 1.37 & 0.95 & 3.93 & 3.99 & & 1.23 & 1.45 & 3.99 & 4.04 & & 0.93 & 1.21 & 3.97 & 3.80 & & 0.61 & 1.06 & 3.98 & 3.75 \\
\hline 175 & & 4.0 & 2.0 & 4.93 & 4.74 & & 4.0 & 2.0 & 4.63 & 4.64 & & 5.0 & 2.0 & 4.97 & 4.55 & & 5.0 & 3.0 & 4.93 & 4.62 \\
\hline 176 & & 2.0 & 2.0 & 3.88 & 3.0 & & & & & & & & & & & & & & & \\
\hline 177 & & & & & & & & & & & & & & & & & & & & \\
\hline 178 & & & & & & & & & & & & & & & & & & & & \\
\hline 179 & & & & & & & & & & & & & & & & & & & & \\
\hline 180 & & & & & & & & & & & & & & & & & & & & \\
\hline 181 & & & & & & & & & & & & & & & & & & & & \\
\hline 182 & & & & & & & & & & & & & & & & & & & & \\
\hline 183 & & & & & & & & & & & & & & & & & & & & \\
\hline 184 & & 1.18 & 4.35 & 4.76 & 3.98 & & 1.49 & 3.74 & 4.52 & 3.46 & & 1.96 & 3.84 & 4.71 & 3.55 & & 1.77 & 4.12 & 4.55 & 3.58 \\
\hline 185 & & & & & & & & & & & & & & & & & & & & \\
\hline 186 & & 1 & 2 & 3,8 & 3,8 & & & & & & & & & & & & & & & \\
\hline
\end{tabular}


10.8 Quadro com dados da avaliação com Rx com estresse, pacientes do Grupo B

\begin{tabular}{|c|c|c|c|c|c|c|c|c|c|c|c|c|c|c|c|c|c|c|c|c|}
\hline $\mathrm{N}$ & RxE11 & VN & VA & GN & $\mathrm{GA}$ & RxE12 & VN & VA & GN & GA & RxE21 & VN & VA & GN & GA & RxE22 & VN & VA & GN & GA \\
\hline 1 & & 2.0 & 1.0 & 2.30 & 2.50 & & & & & & & & & & & & & & & \\
\hline 2 & & 2.0 & .0 & 3.41 & 2.93 & & 2.0 & 3.0 & 3.49 & 3.08 & & 0.0 & 1.0 & 3.17 & 4.04 & & 1.0 & 0 & 3.23 & 3.47 \\
\hline 3 & & 0.0 & 2.0 & 6.34 & 4.73 & & 0.0 & 0.0 & 6.72 & 5.42 & & 0.0 & 1.0 & 6.32 & 5.33 & & 0.0 & 1.0 & 6.02 & 4.52 \\
\hline 4 & & 2.0 & 4.0 & 3.71 & 6.4 & & & & & & & & & & & & & & & \\
\hline 5 & & 2.0 & 1.0 & 2.0 & 2.1 & & 2.66 & 1.26 & 3.37 & 3.25 & & 2.64 & 1.55 & 3.40 & 3.28 & & 2.18 & 1.77 & 3.38 & 3.15 \\
\hline 6 & & .0 & 3.0 & 2.60 & 3.21 & & 1.0 & 4.0 & 3.36 & 3.26 & & 2.0 & 4.0 & 3.58 & 3.73 & & 2.0 & 4.0 & 3.82 & 3.95 \\
\hline 7 & & 1.0 & 2.0 & 5.78 & 5.16 & & & & & & & & & & & & & & & \\
\hline 8 & & 2.0 & 1.0 & 5.16 & 5.78 & & & & & & & & & & & & & & & \\
\hline 9 & & 1.0 & 2.0 & 2.0 & 2.0 & & 2.15 & 1.52 & 2.54 & 2.66 & & 1.86 & 0.87 & 2.44 & 2.15 & & 2.50 & 0.78 & 2.56 & 2.43 \\
\hline 10 & & 1.0 & 4.0 & 3.19 & 4.62 & & & & & & & & & & & & & & & \\
\hline 11 & & 7.0 & 4.0 & 5.17 & 4.73 & & 7.0 & 3.0 & 6.0 & 5.83 & & 8.0 & 1.0 & 5.70 & 5.04 & & 8.0 & 1.0 & 6.65 & 4.82 \\
\hline 12 & & .0 & 3.0 & 3.87 & 5.15 & & 0.0 & 3.0 & 4.50 & 5.47 & & 0.0 & 0.0 & 4.45 & 5.32 & & 1.0 & 1.0 & 4.59 & 5.08 \\
\hline 13 & & 3.0 & 7.0 & 3.5 & 4.2 & & 6.68 & 0.0 & 9.64 & 5.17 & & 6.43 & 1.13 & 9.33 & 4.76 & & 5.58 & 1.48 & 9.52 & 5.27 \\
\hline 14 & & 4.0 & 3.0 & 7.5 & 7.1 & & 3.62 & 3.47 & 7.49 & 7.69 & & 2.95 & 3.70 & 7.46 & 7.00 & & 1.94 & 3.66 & 7.12 & 7.48 \\
\hline 15 & & 3.0 & 1.0 & 5.14 & 4.76 & & 5.0 & 0.0 & 6.57 & 5.29 & & 6.0 & 1.0 & 5.70 & 4.85 & & 6.0 & 0.0 & 5.42 & 4.76 \\
\hline 16 & & 6.0 & 6.0 & 6.2 & 5.36 & & 6.0 & 7.0 & 6.30 & 5.87 & & 4.0 & 7.0 & 6.16 & 4.72 & & 3.0 & 7.0 & 6.18 & 5.81 \\
\hline 17 & & 0.0 & 2.0 & 5.94 & 5.43 & & 3.0 & 4.0 & 5.81 & 6.36 & & 2.0 & 3.0 & 6.03 & 6.57 & & 4.0 & 2.0 & 5.91 & 6.85 \\
\hline 18 & & 2.0 & 1.0 & 2.5 & 2.9 & & 2.0 & 1.0 & 2.5 & 2.9 & & 2.0 & 1.0 & 2.5 & 2.9 & & 2.0 & 1.0 & 2.5 & 2.9 \\
\hline 19 & & & & & & & & & & & & & & & & & & & & \\
\hline 20 & & & & & & & & & & & & & & & & & & & & \\
\hline 21 & & & & & & & & & & & & & & & & & & & & \\
\hline 22 & & & & & & & & & & & & & & & & & & & & \\
\hline 23 & & & & & & & & & & & & & & & & & & & & \\
\hline 24 & & & & & & & & & & & & & & & & & & & & \\
\hline 25 & & 3.0 & 3.0 & 2.56 & 2.55 & & & & & & & & & & & & & & & \\
\hline 26 & & & & & & & & & & & & & & & & & & & & \\
\hline 27 & & 5 & 2 & 5.68 & 4.91 & & 3.0 & 1.0 & 6.42 & 5.39 & & 4.0 & 1.0 & 5.17 & 5.17 & & 4.0 & 1.0 & 5.53 & 4.42 \\
\hline 28 & & 4 & 6 & 4.36 & 5.36 & & & & & & & & & & & & & & & \\
\hline 29 & & & & & & & & & & & & & & & & & & & & \\
\hline 30 & & 0 & 0 & 4.59 & 5.86 & & 0.0 & 0.0 & 4.64 & 5.43 & & 0.0 & 0.0 & 4.14 & 5.18 & & 1.0 & 2.0 & 4.26 & 5.30 \\
\hline 31 & & 1 & 5 & 5.35 & 4.78 & & 6.0 & 1.0 & 5.68 & 5.09 & & 4.0 & 1.0 & 4.93 & 5.22 & & 4.0 & 2.0 & 5.00 & 4.97 \\
\hline 32 & & 17 & 4 & 6.29 & 6.56 & & 18.0 & 4.0 & 6.53 & 7.26 & & 20.0 & 2.0 & 6.32 & 7.70 & & 23.0 & 2.0 & 6.36 & 7.88 \\
\hline 33 & & & & & & & & & & & & & & & & & & & & \\
\hline 34 & & 12 & 6 & 4.66 & 4.27 & & 10.4 & 4.9 & 0.43 & 0.39 & & 11.42 & 5.19 & 0.41 & 0.41 & & 10.33 & 4.44 & 0.41 & 0.43 \\
\hline 35 & & & & & & & & & & & & & & & & & & & & \\
\hline 36 & & & & & & & & & & & & & & & & & & & & \\
\hline 37 & & 0 & 2 & 6.31 & 3.75 & & 0.0 & 5.0 & 5.67 & 3.56 & & 1.0 & 5.0 & 6.44 & 3.49 & & 2.0 & 2.0 & 6.24 & 3.43 \\
\hline 38 & & 1 & 3 & 4.90 & 4.20 & & 2.0 & 2.0 & 6.26 & 5.30 & & 2.0 & 2.0 & 5.62 & 5.24 & & 2.0 & 3.0 & 5.62 & 5.23 \\
\hline 39 & & 3 & 4 & 3.9 & 4.0 & & 4.15 & 6.33 & 3.87 & 4.17 & & 2.75 & 4.42 & 3.86 & 3.70 & & 2.93 & 4.22 & 3.77 & 3.81 \\
\hline 40 & & 3 & 6 & 4.34 & 4.21 & & & & & & & & & & & & & & & \\
\hline 41 & & 4 & 3 & 3.87 & 4.04 & & 3.0 & 3.0 & 4.30 & 4.90 & & 3.0 & 1.0 & 3.89 & 4.03 & & 3.0 & 1.0 & 3.38 & 4.31 \\
\hline 42 & & 2 & 1 & 5.36 & 4.02 & & 1.0 & 3.0 & 5.44 & 4.31 & & 1.0 & 0.0 & 4.71 & 4.96 & & 1.0 & 0.0 & 4.17 & 5.29 \\
\hline 43 & & 4 & 3 & 3.55 & 3.23 & & 4.0 & 5.0 & 4.01 & 4.26 & & 3.0 & 3.0 & 4.55 & 4.46 & & 4.0 & 4.0 & 4.38 & 4.32 \\
\hline 44 & & 2 & 1 & 3.81 & 3.45 & & & & & & & & & & & & & & & \\
\hline 45 & & 4 & 6 & 4.06 & 5.97 & & & & & & & & & & & & & & & \\
\hline 46 & & 1.6 & 1.5 & 5.71 & 5.47 & & 0.52 & 0.30 & 6.91 & 6.13 & & 1.2 & 1.13 & 6.82 & 6.16 & & 1.02 & 0.60 & 6.91 & 6.02 \\
\hline 47 & & 5 & 4 & 5.87 & 5.03 & & 4.0 & 5.0 & 5.85 & 5.25 & & 5.0 & 5.0 & 5.35 & 5.20 & & 5.0 & 5.0 & 5.74 & 5.20 \\
\hline 48 & & 3.13 & 4.24 & 4.93 & 7.01 & & 1.67 & 3.79 & 4.53 & 7.78 & & 2.24 & 4.03 & 4.38 & 7.65 & & 1.93 & 2.74 & 4.66 & \begin{tabular}{|l}
7.52 \\
\end{tabular} \\
\hline 49 & & 4 & 5 & 4.21 & 4.0 & & 4.0 & \begin{tabular}{|l|} 
\\
\end{tabular} & 4.04 & 4.30 & & 4.0 & 6.0 & 4.30 & 4.30 & & 4.0 & 5.0 & 4.48 & 4.74 \\
\hline 50 & & 1 & 2 & 3.5 & 4.5 & & 1.0 & 1.0 & 3.0 & 3.5 & & 1.5 & 1.0 & 3.5 & 4.0 & & 1.0 & 1.0 & 3.0 & 4.5 \\
\hline 51 & & 2.01 & 2.54 & 3.44 & 4.10 & & 2.09 & 2.43 & 4.02 & 4.20 & & 2.54 & 3.01 & 3.26 & 3.90 & & 2.84 & 2.12 & 3.81 & \begin{tabular}{|l}
4.42 \\
\end{tabular} \\
\hline 52 & & 1.5 & 2 & 4.5 & 6.0 & & & & & & & & & & & & & & & \\
\hline
\end{tabular}


10.8 Quadro com dados da avaliação com Rx com estresse, pacientes do Grupo B (conclusão)

\begin{tabular}{|c|c|c|c|c|c|c|c|c|c|c|c|c|c|c|c|c|c|c|c|c|}
\hline $\mathrm{N}$ & RxE11 & VN & VA & GN & $\mathrm{GA}$ & $\mathrm{RxE} 12$ & VN & VA & GN & $\mathrm{GA}$ & RxE21 & VN & VA & GN & $\mathrm{GA}$ & RxE22 & $\mathrm{VN}$ & VA & GN & $\mathrm{GA}$ \\
\hline 53 & & 4.20 & 3.43 & 4.08 & 2.53 & & 6.39 & 3.83 & 4.46 & 0.33 & & 6.22 & 3.65 & 3.12 & 2.94 & & 6.19 & 3.42 & 3.28 & 2.35 \\
\hline 54 & & 3 & 0 & 3.74 & 5.29 & & 2.0 & 1.0 & \begin{tabular}{|l|}
4.75 \\
\end{tabular} & 5.81 & & 2.0 & 2.0 & 4.90 & 5.03 & & 2.0 & 1.0 & 4.55 & 4.92 \\
\hline 55 & & 3.5 & 4.5 & 4.67 & 4.90 & & 2.27 & 4.66 & 5.00 & 5.88 & & 2.77 & 2.33 & 5.21 & 5.88 & & 1.32 & 1.90 & 5.25 & 5.78 \\
\hline 56 & & 2 & 6 & 7.1 & 5.5 & & & & & & & & & & & & & & & \\
\hline 57 & & 0 & 1 & 7.23 & 6.46 & & 1.0 & 2.0 & 6.85 & 7.19 & & 0.0 & 3.0 & 7.07 & 7.39 & & 0.0 & 2.0 & 7.37 & 7.67 \\
\hline 58 & & 4 & 6 & 6.59 & 6.41 & & 2.0 & 6.0 & 7.49 & 6.63 & & 0.0 & 3.0 & 7.28 & 6.86 & & 2.0 & 4.0 & 6.91 & 6.76 \\
\hline 59 & & 4.26 & 4.39 & 3.30 & 3.50 & & 3.15 & 3.33 & 6.67 & 6.92 & & 2.89 & 2.99 & 6.82 & 6.69 & & 2.84 & 3.40 & 6.49 & 6.86 \\
\hline 60 & & 3.64 & 8.45 & 7.05 & 8.73 & & 8.11 & 3.98 & 8.48 & 7.23 & & 7.50 & 4.77 & 9.10 & 7.32 & & 7.48 & 4.41 & 7.11 & 9.21 \\
\hline 61 & & 0.0 & 2.0 & 6.93 & 6.70 & & 1.0 & 2.0 & 7.74 & 6.59 & & 0.0 & 2.0 & 6.96 & 7.52 & & 0.0 & 2.0 & 8.00 & 7.87 \\
\hline 62 & & 3.0 & 2.0 & 4.40 & 3.74 & & 3.0 & 3.0 & 3.85 & 3.85 & & 2.0 & 2.0 & 6.46 & 6.12 & & 3.0 & 2.0 & 6.78 & 6.16 \\
\hline 63 & & 2.0 & 0.0 & 7.14 & 6.62 & & 3.0 & 3.0 & 6.89 & 6.16 & & & & & & & & & & \\
\hline 64 & & 3.81 & 5.57 & 3.74 & 4.60 & & 3.81 & 4.91 & 4.67 & 4.15 & & 3.68 & 4.46 & 3.56 & 4.98 & & 4.10 & 4.60 & 3.86 & 5.10 \\
\hline 65 & & 1.70 & 2.02 & 3.93 & 4.42 & & 0.78 & 3.40 & 3.85 & 4.30 & & & & & & & & & & \\
\hline 66 & & 4.98 & 4.17 & 3.58 & 2.01 & & 4.88 & \begin{tabular}{|l|}
4.09 \\
\end{tabular} & 3.67 & 2.22 & & 3.30 & 2.29 & 5.55 & 5.58 & & 2.62 & 2.23 & 5.45 & 5.13 \\
\hline 67 & & 0.48 & 1.14 & 4.01 & 3.39 & & 0.92 & 0.98 & \begin{tabular}{|l|}
4.07 \\
\end{tabular} & 3.52 & & 1.02 & 1.97 & 4.77 & 4.15 & & 0.70 & 1.24 & 5.06 & 4.35 \\
\hline 68 & & 1.84 & 1.94 & 5.52 & 6.14 & & 1.68 & 1.34 & 5.66 & 6.01 & & 0.75 & 1.97 & 6.15 & 6.10 & & 1.33 & 0.98 & 6.08 & 6.05 \\
\hline 69 & & 8.75 & 4.30 & 3.30 & 2.90 & & 8.91 & 3.22 & 3.33 & 3.05 & & 7.49 & 4.57 & 3.36 & 3.18 & & 7.50 & 3.59 & 3.35 & 3.20 \\
\hline 70 & & 10.36 & 7.01 & 4.17 & 4.61 & & 9.49 & 6.69 & 4.71 & 4.53 & & 10.57 & 5.66 & 4.68 & 4.65 & & 5.15 & 8.41 & 4.80 & 4.63 \\
\hline 71 & & 5.20 & 4.53 & 5.16 & 4.92 & & 4.66 & 4.57 & 4.76 & 4.61 & & 6.02 & 4.49 & 6.47 & 4.72 & & 5.09 & 5.13 & 6.61 & 5.35 \\
\hline 72 & & 0.0 & 1.0 & 5.34 & 5.27 & & 1.0 & 1.0 & 5.30 & 5.42 & & 0.0 & 3.0 & 5.45 & 5.17 & & 1.0 & 2.0 & 5.00 & 5.50 \\
\hline 73 & & 4.46 & 8.40 & 5.20 & 6.02 & & 5.48 & 8.41 & 5.51 & 6.31 & & 4.78 & 8.29 & 5.51 & 6.08 & & 7.17 & 5.16 & 6.01 & 6.07 \\
\hline 74 & & 00. & 0.0 & 3.33 & 3.53 & & 0.0 & 1.0 & 3.08 & 2.95 & & 1.0 & 1.0 & 3.98 & 3.54 & & 1.0 & 0.5 & 40.2 & 3.96 \\
\hline 75 & & & & & & & & & & & & & & & & & & & & \\
\hline 76 & & 3.0 & 6.0 & 4.34 & 4.21 & & 3.0 & 5.0 & 4.63 & 4.04 & & 4.0 & 6.0 & 4.25 & 3.58 & & 3.0 & 6.0 & 4.34 & 3.73 \\
\hline 77 & & 4.0 & 7.0 & 5.16 & 8.69 & & 4.0 & 7.0 & 4.98 & 8.66 & & 4.0 & 6.0 & 4.88 & 8.75 & & 4.0 & 7.0 & 5.22 & 8.66 \\
\hline 78 & & & & & & & & & & & & & & & & & & & & \\
\hline 79 & & & & & & & & & & & & & & & & & & & & \\
\hline 80 & & & & & & & & & & & & & & & & & & & & \\
\hline 81 & & & & & & & & & & & & & & & & & & & & \\
\hline 82 & & & & & & & & & & & & & & & & & & & & \\
\hline 83 & & & & & & & & & & & & & & & & & & & & \\
\hline 84 & & & & & & & & & & & & & & & & & & & & \\
\hline 85 & & & & & & & & & & & & & & & & & & & & \\
\hline 86 & & 2.19 & 2.55 & 5.01 & 5.42 & & 0.95 & 2.09 & 4.54 & 5.48 & & 2.24 & 1.80 & 5.74 & 5.27 & & 2.46 & 2.39 & 5.12 & 4.74 \\
\hline 87 & & & & & & & & & & & & & & & & & & & & \\
\hline 88 & & & & & & & & & & & & & & & & & & & & \\
\hline 89 & & & & & & & & & & & & & & & & & & & & \\
\hline 90 & & & & & & & & & & & & & & & & & & & & \\
\hline 91 & & & & & & & & & & & & & & & & & & & & \\
\hline 92 & & & & & & & & & & & & & & & & & & & & \\
\hline
\end{tabular}


Abreviaturas dos quadros 10.7 e 10.8:

RxE11: Radiografia com estresse observador 1, primeira medida VN: Varo lado normal (em graus)

VA: Varo lado acometido (em graus)

GN: Gaveta anterior lado normal (em milímetros)

GA: Gaveta anterior lado acometido (em milímetros)

RxE12: Radiografia com estresse observador 1, segunda medida

RXE21: Radiografia com estresse observador 2, primeira medida

RXE22: Radiografia com estresse observador 2, segunda medida 
ANEXO C: Figuras citadas na discussão 
Figura 8 - Imagem de peça anatômica, mostrando a localização do ligamento talofibular anterior (LTFA), indicado pela seta

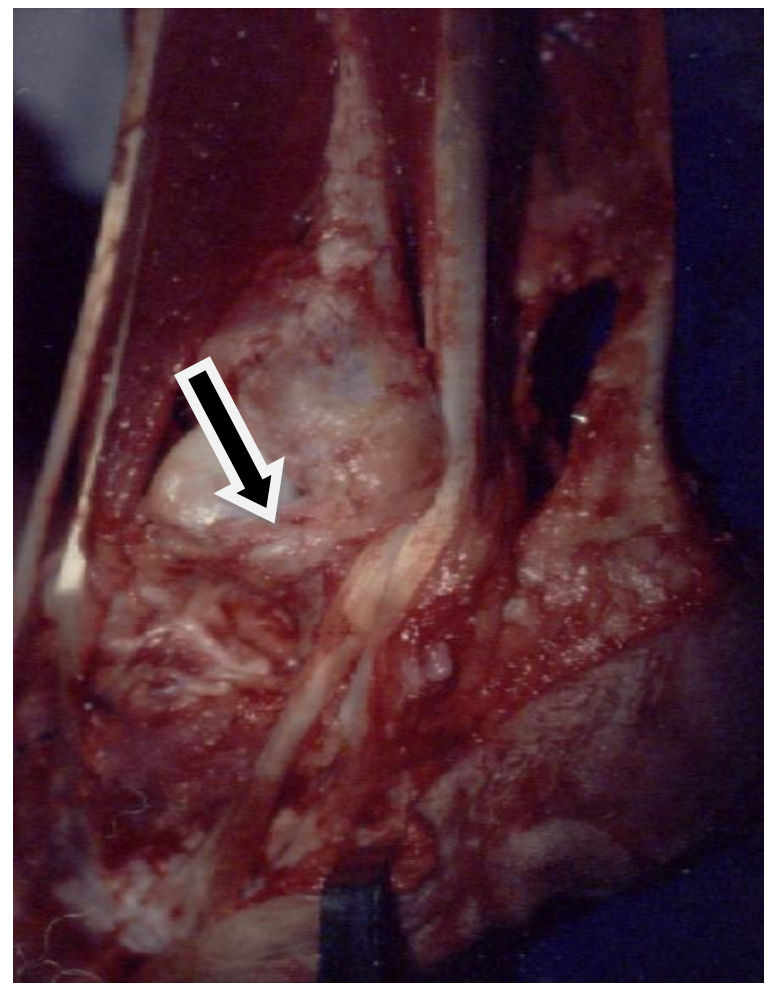

Figura 9 - Imagem de peça anatômica, mostrando a localização do ligamento calcâneo fibular (LCF), indicado pela seta

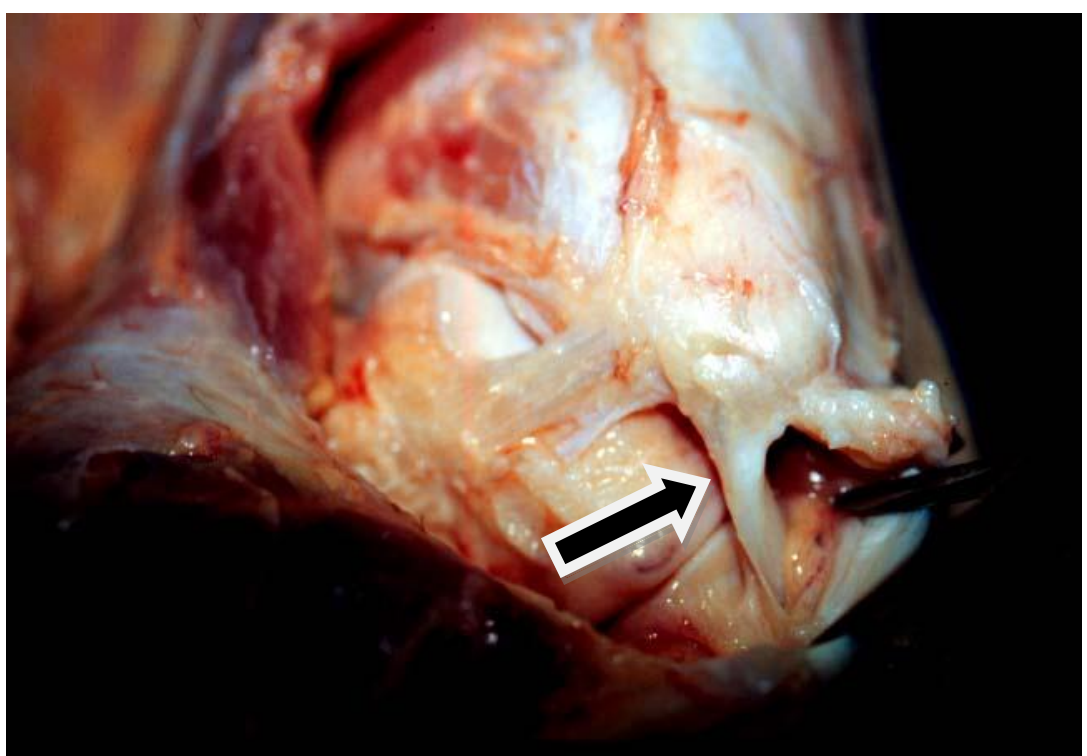


Figura 10 - Imagem de corte axial de ressonância magnética ponderada em T1, mostrando a ausência do ligamento talofibular anterior (LTFA)

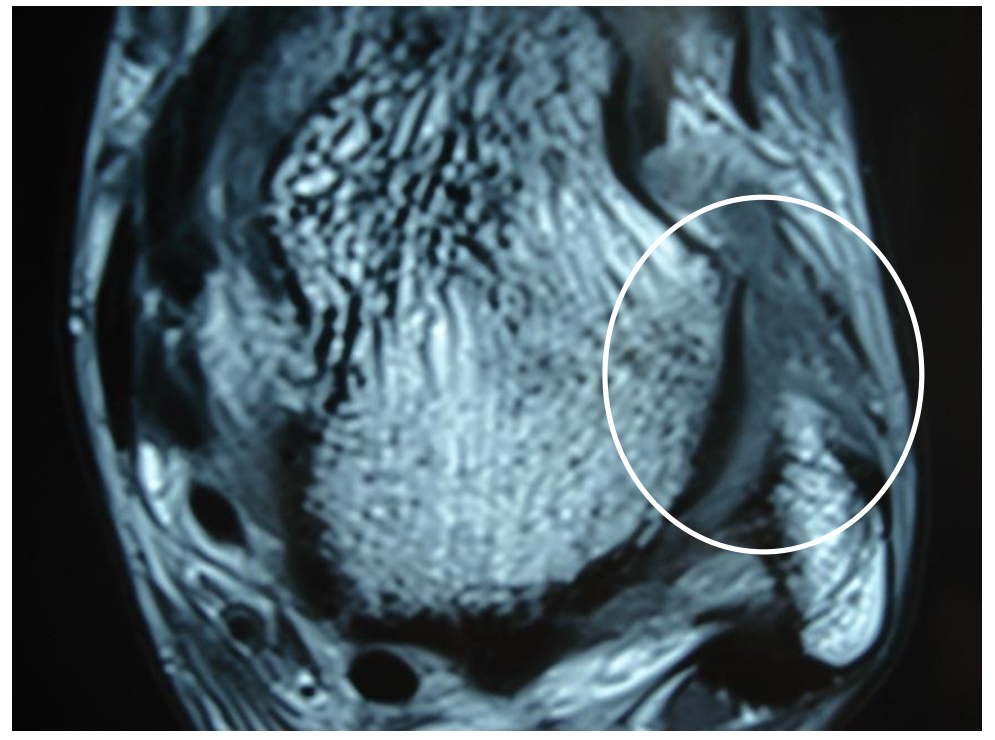

Figura 11 - Imagem de corte coronal de ressonância magnética ponderada em T2, mostrando a ausência do ligamento calcâneo fibular (LCF)

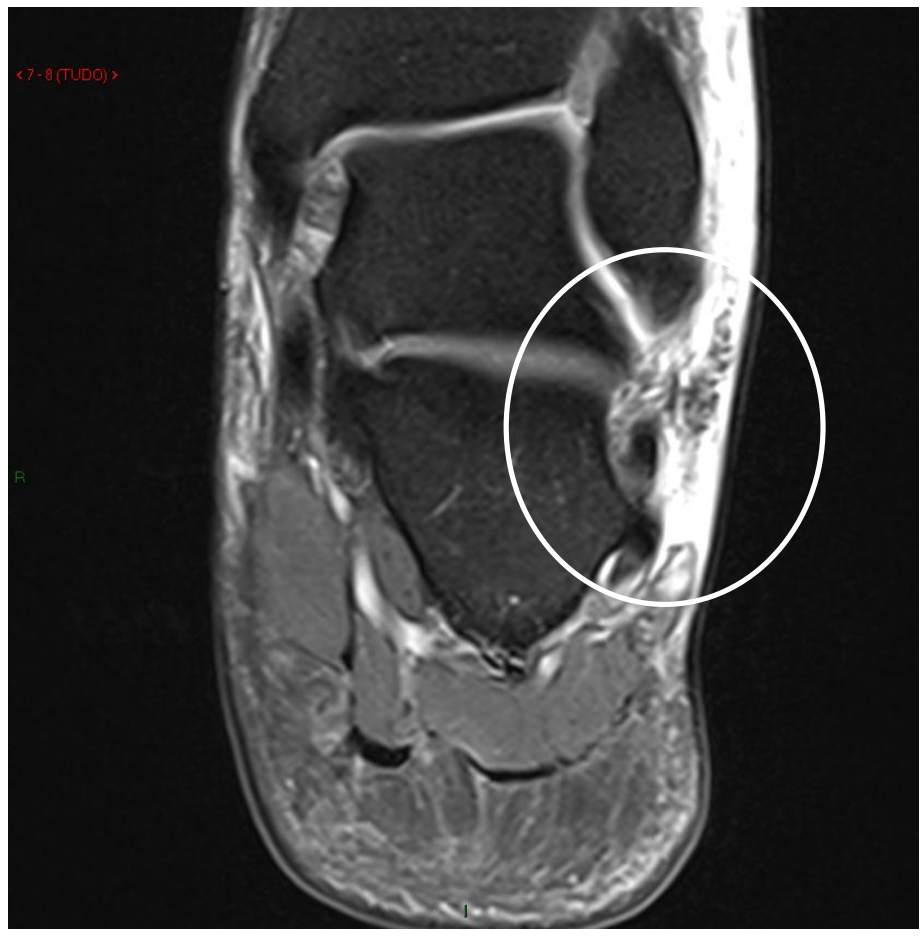


Figura 12 - Imagem de corte coronal de ressonância magnética ponderada em T2, mostrando alteração do sinal e da característica habitual do ligamento deltóide profundo (LDP)

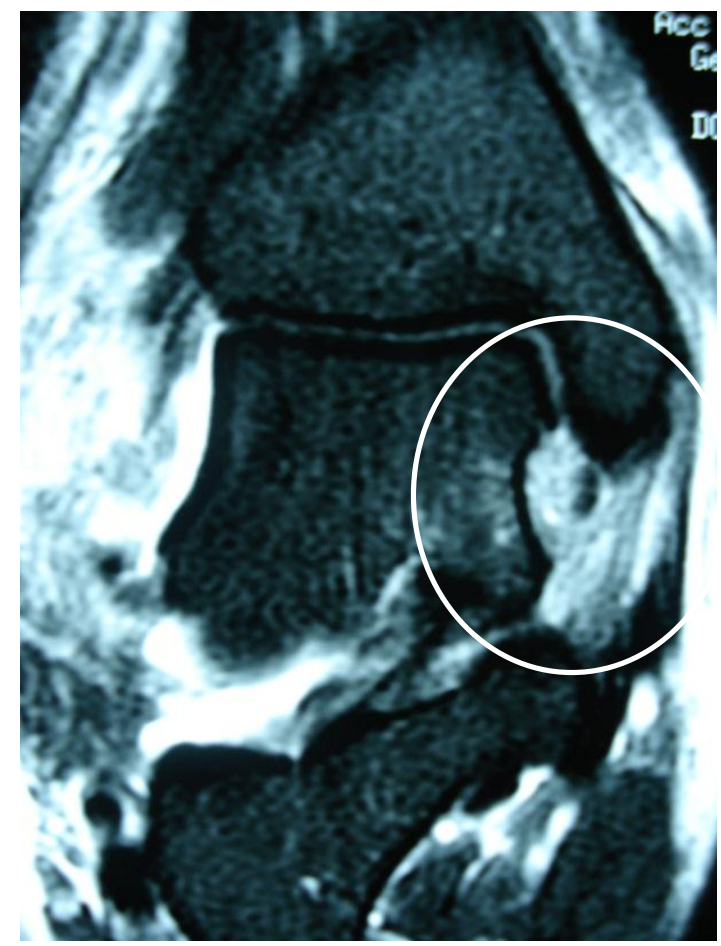

Figura 13 - Imagem de corte sagital de ressonância magnética ponderada em T2, mostrando alteração do sinal do colo do tálus (contusão óssea)

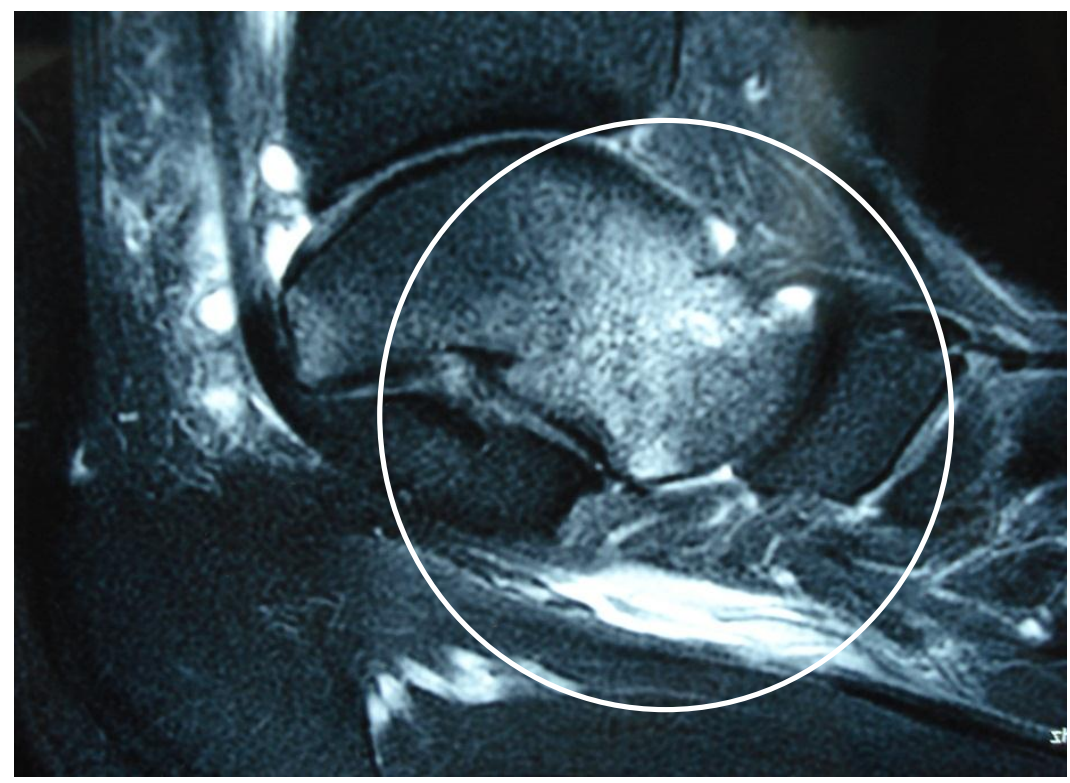


Figura 14 - Imagem de corte coronal de ressonância magnética ponderada em T2, mostrando alteração do sinal do maléolo medial

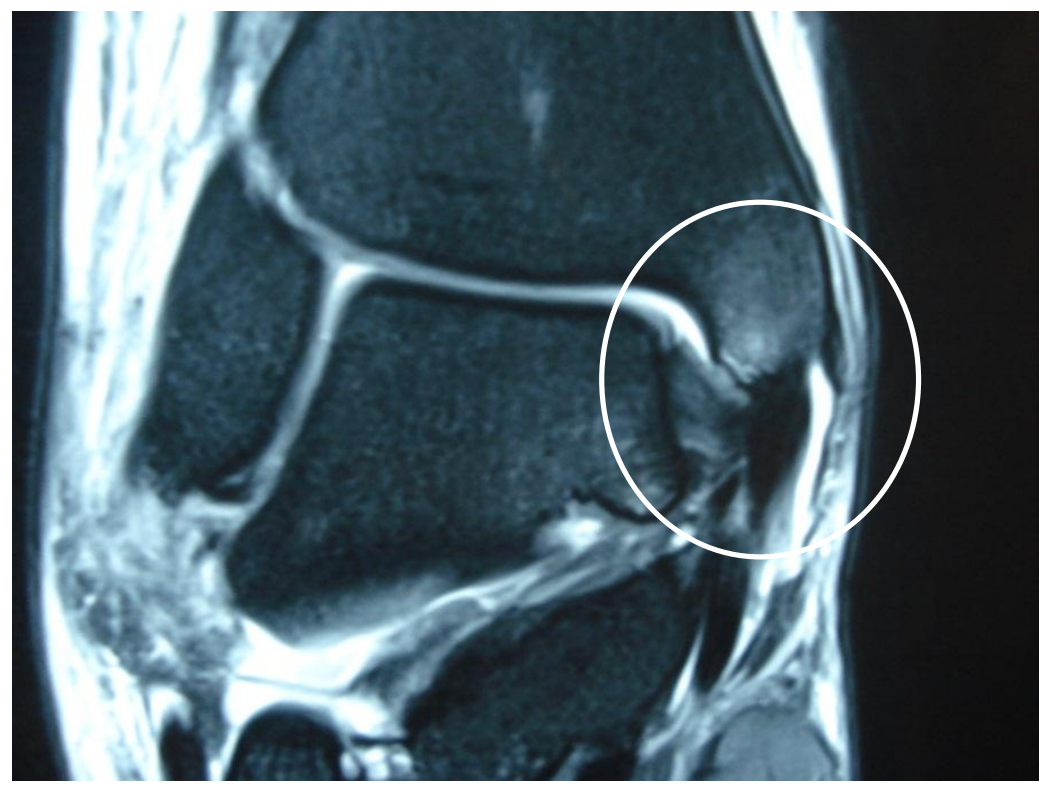

Figura 15 - Imagem de corte coronal de ressonância magnética ponderada em T2, mostrando alteração do sinal dos tendões fibulares

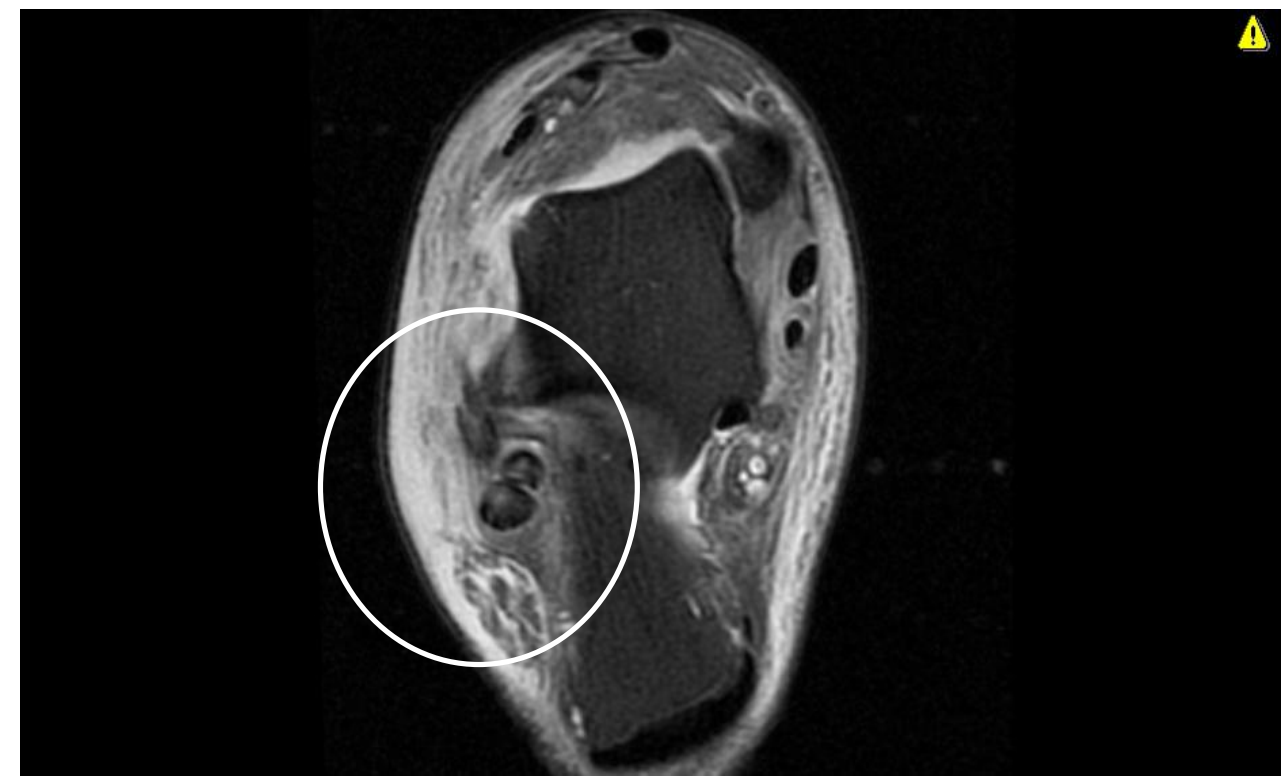


Figura 16 - Imagem de corte coronal de ressonância magnética ponderada em T2, mostrando fratura avulsão da extremidade do maléolo lateral

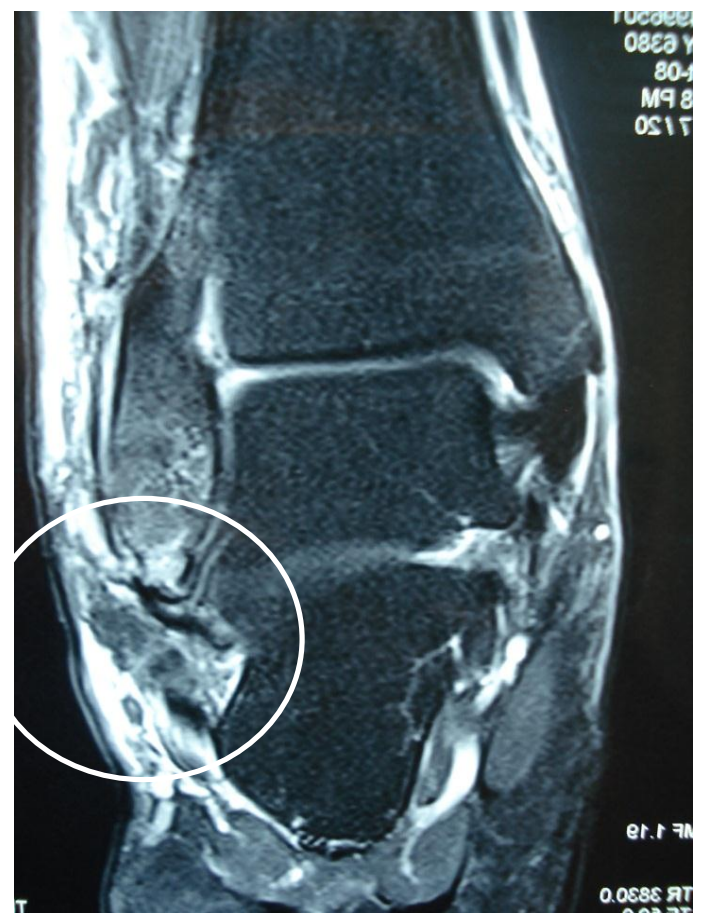

Figura 17 - Imagem de corte sagital de ressonância magnética ponderada em T2, mostrando fratura da borda posterior da tíbia distal, sem desvio

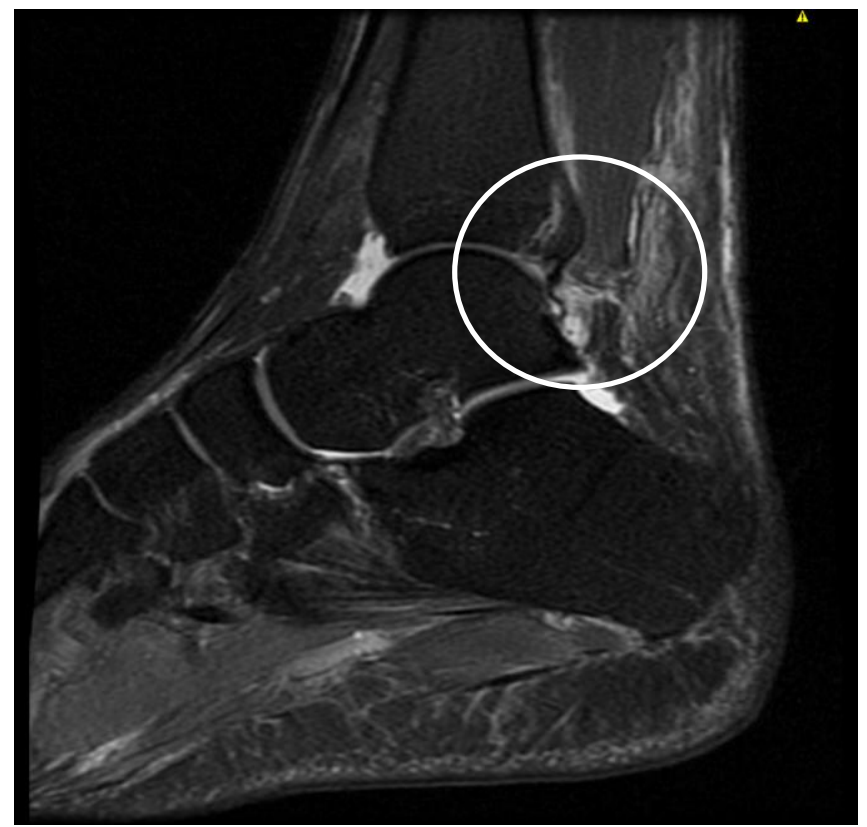


Figura 18 - Rx com estresse em varo comparativo mostrando assimetria entre o tornozelo afetado (esquerdo) e o normal, evidenciando instabilidade

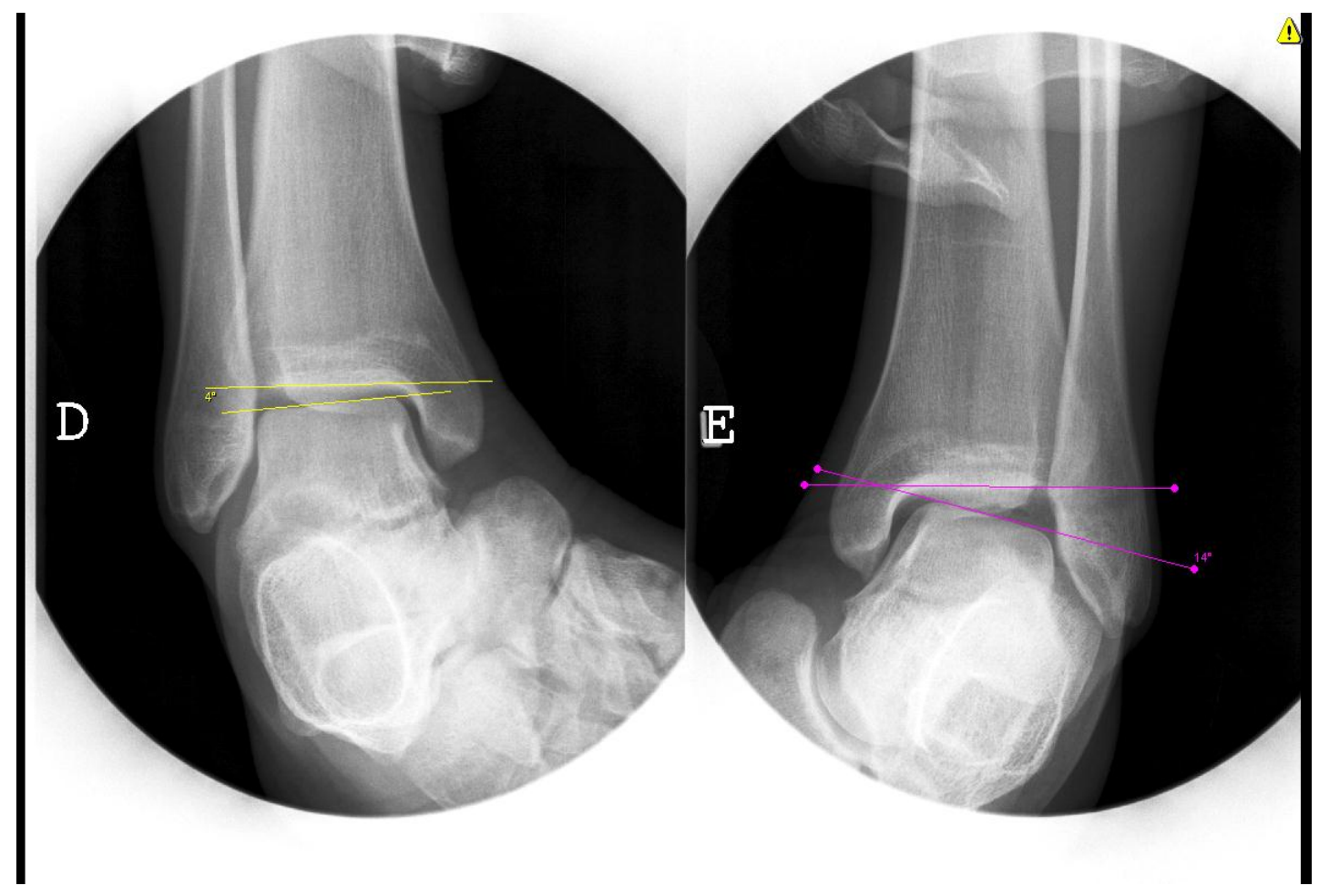




\section{REFERÊNCIAS BIBLIOGRÁFICAS}

Anandacoomarasamy A, Barnsley L. Long term outcomes of inversion ankle injuries. $\mathrm{Br} J$ Sports Med.2005; 39(3):e14; discussion e14.

Ardèvol J, Bolíbar I, Belda V, Argilaga S. Treatment of complete rupture of the lateral ligament of the ankle: a randomized clinical trial comparing cast immobilization with functional treatment.Knee Surg Sports Trumatol Arthrosc. 2002; 10(6): 371-7.

Baumhauer JF, Alosa DM, Renstrom AF, Trevino S, Beynnon B. A prospective study of ankle injurie risk factor.Am J Sports Med. 1995; 23(5): 564-70.

Baumhauer JF, O'Brien T. Surgical considerations in the treatment of ankle instability. $J$ Athl Train. 2002; 37(4):458-62.

Beinghton P, Horan F. Orthopaedis aspects of Ehlers-Danlos syndrome. J Bone Joint Surg [Br]. 1969; 51(3): 444-53.

Belangero OS, Tamaoki MJS, Nakama GY, Shoiti MV, Gomes RVF, Belloti JC. Como o ortopedista brasileiro trata entorse lateral agudo do tornozelo? Rev. Bras. Ortop. 2010; 45(5): 468-73.

Beynnon BD, Renström PA, Haugh,L, Uh,BS, Barker,H. A Prospective, randomized clinical investigation of the treatment of first-time ankle sprains.Am. J. Sports Med. 2006; 34(9): 1401-12.

Black HM, Brand RL, Eichelberger MR. An improved technique for the evaluation of ligamentous injury in severe ankle sprains. Am. J. Sports Med. 1978; 6(6): 276-82.

Burks RT, Morgan J. Anatomy of the lateral ankle ligaments. Am. J. Sport Med. 1994; 22(1): 72-7.

Campbell SE. MRI of Sports Injuries of the Ankle.Clin. Sports Med. 2006; 25(4): 727-62.

Cass LR, Morrey BF, Katoh Y, Chao EYS. Ankle instability: comparision of primary repair and delayed reconstruction after long term follow up study. Clin Orthop Rel Res.1985; 198: 110-117.

Cawley PW, France EP. Biomechanics of the lateral ligaments of the nkle: an evaluation of the effects of axial load and single plane motions on ligament strain patterns. Foot Ankle. 1991; 12(2): 92-9. 
Clanton TO, McGarvey W: Athletic injuries to the soft tissues of the foot and ankle. In: Coughlin, M; Mann, R; Saltzman, C. Surgery of the Foot and Ankle, 8 ed. Philadelphia: Mosby Elsevier, 2007;1425-564.

Clayton ML, Miles JS, Abdulla M. Experimental investigation of ligamentous healling. Clin Orthop Rel Res. 1968; 61:146-53.

Colville M. Surgical treatment of the unstable ankle. J. Am. Acad. Orthop. Surg. 1998; 6(6): $368-77$.

Cooke MW, March JL, Clark M, Nakash R, Jarvis, RM, Hutton JL et al.; CAST trial group. Treatment of severe ankle sprain: a pragmatic randomized controlled trial comparing the clinical effectiveness and cost effectiveness of three types of mechanical ankle support with tubular bandage. Health Technol. 2009; Assess.13 (13): 1-121.

Cox JS. Surgical and nonsurgical treatment of acute ankle sprains. Clin Orthop Relat Res. 1985; 188:118-26.

Cui Q, Milbrandt T, Millington S, Anderson M, Hurwitz S. Treatnent of posttraumatic adhesive capsulitis of the ankle: a case series. Foot Ankle Int.2005; 26(8): 602-6.

Delahunt E, Monaghan K, Caulfield B. Altered neuromuscular control nd ankle joint kinematics during walking in subjects with functional instability of the ankle joint.Am. J. Sports Med. 2006; 34(12): 1970-6.

Denegar CR, Miller SJ3 ${ }^{\text {rd }}$. Can chronic ankle intability be prevented? Rethinkng management of lateral ankle sprains. J. Athl. Train. 2002; 37(4): 430-5.

De Simoni C, Welz HH, Zanetti M, Hodler J, Jacob H, Zollinger H: Clinical examination and magnetic resonance imaging in the assessment of ankle sprains treated with an orthosis. Foot Ankle Int. 1996; 17 (3): 177-82.

DiGiovanni BF, Fraga CJ, Cohen BE, Shereff MJ. Associated injuries found in chronic lateral ankle instability. Foot Ankle Int. 2000; 21(10): 809-15.

Drez JRD, Young JC, Waldman D, Shackleton R, Parker W. Nonoperative treatment of double lateral ligament tears of the ankle. Am. J. Sports Med. 1982; 10(4): 197- 200.

Eiff PM, Smith AT, Smith GE. Early mobilization versus immobilization in the treatment of lateral ankle sprains. Am. J. Sports Med.1994; 22(1): 83 - 8.

Ekstrand J. Soccer injuries and their mechanisms: a prospective study. Med Sci Sports Exc.1983; 15(3): 267-70. 
Evans GA, Hardcastle P, Frenyo AD. Acute rupture of the lateral ligament of the ankle To suture or not to suture? J. Bone Joint Surg [Br]. 1984; 66(2): 209-12.

Ferkel RD, Flannigan BD, Elkins BS. Magnetic resonance imaging of the foot and ankle: correlation of normal anatomy with pathologic conditions. Foot Ankle, 1991; 11(5): 289305.

Foster A, Blanchette MG, Chou YC, Powers CM. The influence of heel height on frontal plane ankle biomechanics: implications for lateral ankle sprains. Foot Ankle Int. 2012; 33(1): 64-9.

Freeman MA. Treatment of the ruptures of the lateral ligaments of the ankle. J. Bone Joint Surg. [Br]. 1965a; 47(4): 661- 8.

Freeman MA. Instability of the ankle after injuries of the lateral ligaments of the ankle. $J$. Bone Joint Surg. [Br]. 1965b; 47(4): 669-77.

Freeman MA, Dean MR, Hanham IW. The etiology and prevention of functional instability of the foot. J Bone Joint Surg [Br]. 1965; 47(4): 678-85.

Frey C, Bell J, Teresi L, Kerr R, Feder K. A comparision of MRI and clinical examination of acute lateral ankle sprains. Foot Ankle. 1996; 17(9): 533-7.

Funder V, Jorgensen JP, Andersen A, Andersen SB, Lindholmer E, Niedermann B et al. Ruptures of the lateral ligaments of the ankle. Clinical diagnosis. Acta Orthop Scand 1982; 53(6): 997-1000.

Fujii T, Lou ZP, Kitaoka HB, An KN. The manual stress test may not be sufficient to differentiate ankle ligament injuries. Clin Biomech. 2000; 15(8): 619-23.

Gamble JG, Edwards CC; Max SR. Enzymatic adaptation in ligaments during immobilization. Am. J. Sports Med. 1984; 12(3): 221-8.

Garrick JG. The frequency of injury, mechanism of injury, and epidemiology of ankle sprains. Am. J. Sports Med.1977; 5(6): 241-2.

Gatchel RJ, Lurie JD, Mayer TG. Minimal clinically important difference. Spine, [editorial]. 2010; 35(19):1739-43.

Gerber JP, Williams GN, Scoville CR, Arciero RA, Taylor DC. Persistent disability associated with ankle sprains: a prospective examination of an athletic population. Foot Ankle Int. 1998; 19 (10): 653-60. 
Glasgow M, Jackson A, Jamieson AM. Instability of the ankle after injury to the lateral ligament. J. Bone Joint Surg.[Br]. 1980; 62(2): 196-200.

Golanó AP, Vega J, Parez-Carro L, Gotzens V. Ankle anatomy for the arthroscopist. Part II: Role of the ankle ligaments in soft tissue impingement.Foot Ankle Clin. 2006; 11 (2): 275-96.

Hamilton WG. Sprained ankles in ballet dancers. Foot Ankle. 1982; 3(2): 99-102.

Handoll HH, Rowe BH, Quinn KM, Bie R. Interventions for preventing ankle ligament injuries. Cochrane Database Sist Rev. 2001;(3):CD000018.

Harrington KD. Degenerative arthritis of the ankle secondary to long-standing lateral ligament instability. J Bone Joint Surg Am. 1979; 61(3): 354-61.

Hartsell HD, Spauldin SJ. Eccentric/concentric ratios at selected velocities for the invertor and evertor muscles of the chronically unstable ankle. Br. J. Sports Med. 1999; 33(4): 2558.

Henning CE, Egge LN, Cast brace treatment after acute unstable lateral ankle sprain: a preliminary report. Am. J. Sports Med. 1977; 5(6): 252-5.

Hertel J. Functional anatomy, pathomechanics, and pathophysiology of lateral ankle instability. J. Athl. Train. 2002; 37(4): 364-75.

Hertel J. Sensorimotor deficits with ankle sprains and chronic ankle instability. Clin Sports Med. 2008;.27(3):353-70.

Hintermann,B: Biomechanics of the untable ankle joint and clinical implication. Med. Sci. Sports Exerc. 1999; 31[7 Suppl]: S459-S69.

Hirai D, Docherty CL, Schrader J. Severity of functional and mechanical ankle instability in an active population. Foot Ankle Int. 2009; 30(11): 1071-7.

Hockenbury RT, Sammarco GJ. Evaluation and treatment of ankle sprains: clinical recommendations for a positive outcome. Phys Sportsmed. 2001; 29(2): 57-64.

Hocutt JEJr, Jaffe R, Rylander CR, Beebe JK. Cryotherapy in ankle prains. Am J. Sports Med. 1982; 10(5): 316-9.

Holme E, Magnuson SP, Becker K, Bieler T, Aagaard P, Kjaer M. The effect of supervised rehabilitation on strength, postural sway, position sense, and re-injurie risk fter acute ankle ligament sprain. Scnd. J. Med. Sci. Sports. 1999; 9(2): 104-9. 
Hubbard TJ. Ligament laxity following inversion injury with and without chronic ankle instability. Foot Ankle Int. 2008; 29(3): 305-11.

Hubbard, TJ,Hicks-Little,CA. Ankle ligament healing after an acute ankle sprain: An evidence-based approach. L Athl. Train. 2002; 43(5): 523-9.

Hubbard TJ, Kramer LC, Denegar CR, Hertel J. Contributing factors to chronic ankle instability. Foot Ankle Int. 2007; 28(3): 343-54.

Ibrahim T, Beiri A, Azzabi M, Best AJ, Taylor,GJ, Menon DK. Reliability and validity of the subjective component of the American Orthopaedic Foot and Ankle Society clinical rating scales. J Foot Ankle Surg. 2007; 46(2): 65-74.

Jackson DW, Ashley RL, Powell JW. Ankle sprain in young athlete. Relation to severity and disability. Clin Orthop. Rel. Res. 1974; 101: 201-15.

Jackson W, McGarvey W. Update on the treatment of chronic ankle instability and syndesmotic injurie. Curr. Opin. Orthop. 2006; 17(2): 97-102.

Jahss MH. Acute Ankle Sprain. In: Jahss MH. Disordrs of the foot and ankle. Philadelphia: Saunders company, $2^{\text {nd }}$ ed. 1991, 2404-13.

Jarvinen MJ; Letho M. The effects of mobilization and immobilization on thr healing process following muscle injuries. Sports Med. 1993; 15(2): 78-89.

Johannsen A. Radiological diagnosis of lateral ligament lesion of the ankle. Acta Orthop Scand. 1978; 49(3): 295-301.

Jones $\mathrm{MH}$, Amendola AS. Acute treatment of inversion ankle sprains: Immobilization versus functional treatment. Clin. Orthop. Rel. Res. 2007; 455: 169-72.

Judd DB, Kim DH. Foot fractures frequently misdiagnosed as ankle sprains. Am. Fam. Physician. 2002; 66(5): 785-94.

Kadel N.J. Foot and ankle injuries in dance. Phys Med Rehabil Clin N Am. 2006; 17(4): 813-26.

Kaikkonen A, Kannus P, Järvinen M. Surgery versus functional treatment in ankle ligament tears. A prospective study. Clin. Orthop. Rel. Res. 1996; 326: 194-202.

Kaneko D, Sasazaki Y, Kikuchi T, Ono T, Nemoto K, Matsumoto H, et al. Temporal effect of cyclic stretching on distribution and gene expression of integrin and cytoskeleton by ligament fibroblasts in vitro. Connect Tiss Res. 2009;50(4): 263-9. 
Kannus P, Renstrom P. Treatment for acute tears of the lateral ligaments of the ankle: operation, cast or early controled mobilisation. J. Bone Joint Surg [Am]. 1991; 73(2): 30512.

Karlsson J, Bergsten T, Petersen L, Zachrisson E. Radiographic evaluation of ankle joint stability. Clin. J. Sports Med. 1991; 1(3): 166-75.

Karlsson J, Eriksson BI, Sward L. Early functional treatment for acute ligament injuries of the ankle joint. Scand J Med Sci Sports 1996; 6(6): 341-5.

Kemler E, van de Port I, Backx F, van Dijk CN. A systematic review on the treatment of acute ankle sprain: brace versus other functional treatment types. Sports Med. 2011;41(3): 185-97.

Kerkhoffs GM, Rowe BH, Assendelft, WJ, Kelly K, Struijs PA, Van Dijk CN. Immobilisation for acute ankle sprain. A systematic review. Arch. Orthop. Trauma Surg. 2001; 121(8): 462-71.

Kerkhoffs GM, Rowe BH, Assendelft WJ, Kelly K, Struijs PA, van Dijk CN. Immobilisation and functional treatment for acute lateral ankle ligament injuries in adults. Cochrane Database Syst. Rerv. 2002a; 3: CD03762. DOI: 10.1002/14651858.CD003762.pub3.

Kerkhoffs GM, Struijs PA, Marti RK, Assendelft WJ, Bankevoort L, van Dijk CN. Diferent functional treatment strategies for acute lateral ankle ligament injuries in adults. Cochrane Database Syst. Rerv. 2002b; 3: CD02938. DOI: 10.1002/14651858.CD002938.pub3.

Kerkhoffs GM, Handoll HH, de Bie R., Rowe BH, Struijs PA. Surgical versus conservative treatment for acute injuries of the lateral ligament complex of the ankle in adults. Cochrane Database Syst Rev.2007, 18(2): CD000380. DOI: 0.1002/14651858.CD000380.pub2.

Kerkhoffs GM, Struijs PA, Marti RK, Bankevoort L, Assendelft WJ, van Dijk CN. Functional treatments for acute ruptures of the ateral nkle ligament: a systematic review. Acta Orthop. Scand. 2003; 74(1): 69-77.

Kerkhoffs G, Blankevoort L, Kingma I, van Dijk N. Three dimensional bone kinematics in an anterior laxity test of the ankle joint. Knee Surg Sports Traumatol Arthrosc. 2007; 15 (6): 817-24. 
Kitaoka HB, Alexander IJ, Adelaar RS, Nunley JA, Myerson MS, Sanders M. Clinical rating systems for the ankle-hindfoot, midfoot, hallux, and lesser toes. Foot Ankle Int. 1994; 15 (7): 349-53.

Klein J, Rixen D, Albring T, Tiling T. Functional versus plaster cast treatment for acute rupture of the fibular ligament of the upper ankle joint: randomized clinical study. Unfallchirurg. 1991; 94(2): 99-104.

Klenerman L. The management of sprained ankle. J. Bone Joint Surg. [Br]. 1998; 80(1): 11-2.

Konradsen L, Holmer P, Sondergaard L. Early mobilizing treatment for grade III ankle ligament injury. Foot Ankle. 1991; 12(2): 69-73.

Konradsen L Ravn JB. Ankle instability caused by prolonged peroneal reaction time. Acta Orthop. Scand. 1990; 61 (5): 388-90.

Konradsen L, Voigt M, Hojsgaard C. Ankle inversion injuries: the role of the dynamic defense mechanism. Am J. Sports Med. 1997; 25(1): 54-8.

Krips R, de Vries J, van Dijk CN. Ankle instability. Foot Ankle Clin, 2006; 11 (2): 311-29.

Landis JR, Koch GG. The measurement of observer agreement for categorical data. Biometrics. 1977; 33(1): 159-74.

Laurin C, Mathieu J. Sagital mobility of the normal ankle. Clin. Orthop. Rel. Res. 1975; 108: 99-104.

Lephart SM, Pincivero DM, Rozzi SL. Prorpioception of the ankle and knee. Sports Med. 1998; 25(3): 149-55.

Lynch SA, Renstrom PA. Treatment of acute lateral ankle ligament ruptures in the athlete. Conservative versus surgical treatment. Sports Med. 1999; 27(1): 61-71.

Mack RP. Ankle injuries in athletics. Clin. Sports Med. 1982; 1(1): 71-84.

Mann RA. Pes cavus. In:Coughlin MJ. Surgery of the foot and ankle. 6th Ed. St Louis, MOSBY. 1992; 785-90.

Mann G, Nyska M, Finsterbush A, Konstantini N, Lowe J. Chronic ankle instability, mechanical and functional. In: Nyska,M, Mann, G. The unstable Ankle. Champaign,IL: Human Kinetics. 2002; 102-8.

Marder RA. Current methods for the evaluation of ankle ligament injuries. Instr Course Lect. J. Bone Joint Surg [Am]. 1994; 76(7):1103-11. 
Mason ML, Allen HS. Rate of healing of tendons: experimental study of tensile strength. Ann.Surg. 1841; 113(3): 424-59.

McKay GD, Goldie PA, Payne WR, Okes BW. Ankle injuries in basketball: injury rates and risk factors. Br. J. Sporrts Med. 2001; 35(2): 103-8.

Michelson JD, Hutchins C. Mechanoreceptors in human ankle ligaments. J. Bone Joint Surg. [Br]. 1995; 77(2): 219-24.

Moller-Larsen F, Wethelund JO, Jurik AG, de Carvalho A, Lucht U. Comparision of three different treatments for ruptured lateral ankle ligaments. Acta Orthop. Scand. 1988; 59(5): 564-6.

Morrison KE, Kaminki TW. Foot characteristics in association with inversion ankle injury. J. Athl. Train. 2007; 42(1): 135-42.

Munk B, Holm-Christensen K, Lind T. Long-term outcome after ruptured lateral ankle ligaments. A prospective study of three different treatments in 79 patients with 11-year follow-up. Acta Orthop Scand. 1995; 66(5): 452-4.

Munn J, Sullivan SJ, Schneiders AG. Evidence of sensorimotor deficits in functional ankle instability: a systematic review with meta-analysis. J Sci Med Sport 2010; 13 (1): 2-12.

Niedermann B, Andersen A, Andersen SB, Funder V, Jorgensen JP, Lindholmer E, Vuust M. Ruptures of the lateral ligaments of the ankle-Operation or plaster cast? A prospective study. Acta Orthop. Scand.,1981; 52(5): 579-87.

Noyes FR, Torvik PJ, Hyde WB, DeLucas JL. Biomechanics of ligament failure: II. An analysis of immobilization, exercise and reconditioning effects in primates. J. Bone Joint Surg [Am]. 1974; 56(7):1406-18.

Ogilvie-Harris DJ, Gilbart M. Treatment modalities for soft tissue injuries of the ankle: A critical review. Clin. J. Sports Med. 1995; 5(3): 175-86.

Okuda R, Kinoshita M, Morikawa J, Jotoku T, Abe M. Reconstruction for chronic lateral ankle instability using the palmaris longus tendon: is reconstruction of the calcâneo fibular ligament necessary? Foot Ankle Int. 1999; 20(11): 714-20.

Pacey V, Nicholson LL, Adams RD, Munn J, Munns CF. Generalized joint hypermobility and risk of lower limb joint injurie during sport: a systematic review with metaanalysis.Am. J. Sports Med. 2010; 38(7): 1487-97. 
Phisitkul P, Chaichankul C, Sripongsai R, Prasitdamrong I, Tengtrakulcharoen P, Suarchawaratana S. Accuracy of anterolateral drawer test in lateral ankle instability: a cadaveric study. Foot Ankle Int. 2009; 30(7): 690-5.

Popovic N, Gillet P. Ankle sprain. Management of recent lesions and prevention of secondary instability. Rev Med Liege. 2005; 60 (10): 783-8.

Povacz P, Unger SF, Miller WK, Tockner R, Resch H. A randomized prospective study of operative and non-operative treatment of injuries of the fibular collateral ligaments of the ankle. J Bone Joint Surg [Am]. 1998; 80(3): 345-51.

Price DD, McGrath PA, Rafii A, Buckingham B. The validation of visual analogue scales as ratio scale measures for chronic and experimental pain. Pain. 1983;17:45-56.

Raatikainen T, Putkonen M, Puranen J. Arthrography, clinical examination, and stress radiograph in the diagnosis of acute injury to the lateral ligaments of the ankle. Am. J. Sports Med., 1992; 20(1): 2-6.

Rasmussen O. Stability of the ankle joint. Analysis of the function and traumatology of the ankle ligaments. Acta Orthop Scand. (Suppl). 1985; 211, 56: 1-75.

Renstrom P, Wertz M, Incavo S, Pope M, Ostgaard HC, Arms S, et al. Strain in the lateral ligaments of the ankle. Foot Ankle, 1988; 9(2): 59-63.

Rosner B. Fundamentals of Biostatistics. $7^{\circ}$ ed. Duxbury Press, 2010.

Safran MR, Benedetti RS, Bartolozzi AR III Mandelbaum BR. Lateral ankle sprains: a comprehensive review. Part 1: etiology, pathoanatomy, histopathogenesis, and diagnosis. Med Sci Sports Exerc. 1999; 31(7 suppl):S429-37.

Sauser DD, Nelson RC, Lavine MH, Wu CW. Acute injuries of the lateral ligaments of the ankle:comparision of stress radiography and arthrography. Radiology. 1983; 148(3): 653-7.

Seligson D, Gassman J, Pope M. Ankle instability: evaluation of the lateral ligaments. Am. J. Sports Med. 1980; 89(1): 39-42.

Seto JL, Brewster CE. Treatment approaches following foot and ankle injury. Clin. Sports Med. 1994; 13(4): 695-718.

Shrier I. Treatment of lateral collateral ligament sprains of the ankle: a critical appraisal of the literature. Clin J Sport Med. 1995; 5(3): 187-95.

Smith RW, Reischl SF. Treatment of ankle sprains in young athletes. Am. J. Sports Med. 1986; 14(6): 465-71. 
Staples OS. Result study of rupture of lateral ligaments of the ankle. Clin. Orthop. Rel. Res. 1972; 85: 50-8.

Stiell IG, Greenberg GH, McKnight RD, Nair RC, McDowell I, Worthington JR. A study to develop clinical rules for the use of radiography in acute ankle injuries. Ann. Emerg. Med. 1992; 21(4): 384-90.

Stover CN. Air stirrup management of ankle injuries in the athlete. Am. J. Sports Med. 1980; 8(5): 360-5.

Tiling T, Bonk A, Hoher J, Klein J. Acute injury to the lateral ligament of the ankle joint in the athlete. Chirurg. 1994; 65(11): 920-33.

Trevino SG, Davis P, Hecht PJ. Management of acute and chronic lateral ligament injuries of the ankle. Orthop. Clin. North. Am. 1994; 25(1): 1-16.

Triola MF. Elementary Statistics Technology Update. $11^{\circ}$ ed. Pearson, 2011.

Tropp HP, Odenrich P, Gillquist J. Stabilometry recordings in functional and mechanical instability of the ankle joint. Iint. J. Sports Med. 1985; 6(3): 180-2.

Valderrabano V, Hintermann B, Horisberger M, Fung TS. Ligamentous posttraumatic ankle osteoarthritis. Am. J. Sports Med. 2006; 34(4): 612-20.

Van Dijk CN, Bossuyt PMM, Marti RK. Medial ankle pain after lateral ligament rupture. J. Bone Joint Surg. [Br]. 1996a; 78(4): 562-7.

Van Dijk CN; Lim LS, Bossuyt PM, Marti RK. Physical examination is sufficient for the diagnosis of sprained ankles. J Bone Joint Surg [Br]. 1996b; 78 (6): 958-62.

Watson AD. Ankle instability and impingement. Foot Ankle Clin. 2007; 12 (1): 177-95.

Weber JM, Maleski RM. Conservative treatment of acute lateral ankle sprains. Clin. Podiatr. Med. Surg. 2002; 19(2): 309-18.

Wester JU, Jesperson SM Nielsen KD, Neumann L. Wobble board training after partial sprains of the lateral ligament of the ankle: a prospective randomized study. J. Orthop. Sports Phys. Ther. 1996; 23(5): 332-6. 